\title{
Perceptions of children's rights in three early childhood settings
}

\author{
by \\ Sarah Jane Mulheron Te One
}

A thesis submitted to the Victoria University of Wellington in fulfilment of the requirements for the degree of Doctor of Philosophy in Education

Victoria University of Wellington

2008 



\section{Abstract}

The purpose of this thesis was to investigate perceptions of young children's rights in early childhood settings and contribute to the expanding discourse about children's rights. The research focus canvassed teachers', parents', and young children's perceptions of their rights in early childhood settings: How did they understand children's rights, and what did these perceptions mean for them in the early childhood settings they participated in?

A qualitative, interpretive approach to the research generated data through interviews with young children, teachers, and adults, focus groups with the adult participants, and observations of day-to-day life in the three case study centres. The early childhood centres selected represented three mainstream services and included a teacher-led crèche for under-two-year-olds, a sessional state, teacher-led kindergarten for three- and four-year-olds, and a parent-led playcentre for mixed ages from birth to six years old. NVIVO, a qualitative data classifying computer program, was used initially to sort and categorise the data alongside more conventional methods for coding categories and identifying emerging themes.

The research found that perceptions of children's rights were interwoven, interrelated, and interdependent. Provision rights, protections rights, and participation rights are recognised categories of children's rights. These categories were used to foreground participants' perceptions of rights in particular early childhood settings. Findings suggest that more in-depth awareness of children's rights in early childhood settings would support the development of a children's rights-based pedagogy.

This thesis potentially contributes to a growing body of international research about children's rights with a particular focus on the early childhood sector in New Zealand Aotearoa. The contribution that this thesis makes is both theoretical and sociological. It combines sociocultural constructs and ecological perspective with an international human rights convention to understand more clearly what children's rights mean in an early childhood sector. The study of childhood sociology is relatively new and challenges universal definitions of childhood and child. This thesis highlights how different conceptual theoretical ideas intersect with diverse sociological constructs. The broad conclusion drawn by this thesis is that for children to participate fully in their early education, the ethos of the community of practice/learners must explicate what that participation entails in a particular context. 


\section{Acknowledgements}

This study would not have been possible without two periods of research and study leave from Victoria University of Wellington. In addition, I was awarded a $\mathrm{PhD}$ scholarship which funded interview transcriptions. There are many people to thank. Without their interest and support, particularly in the final phase, this journey would have been much harder. I am grateful to friends and family who supported me when I struggled to make sense of the issues. Without their constant and unwavering support, I could not have managed this project. Particular thanks must go to the following people:

- Professor Helen May, Associate Professor Val Podmore, and Dr Rob Strathdee who supervised the thesis at various stages;

- Linda Hunt, Andrea Godfree, Susan Kaiser, Shelley Carlyle, and Megan Hart for transcribing, copy editing, and formatting.

- Rozel Pharazyn for the illustration.

- To the children, families, and teachers who welcomed me into their early childhood lives.

- To Soni Mulheron, my mother.

- To my husband Mark for his understanding, and for creating the space for me to complete this thesis and to our children, Mohi, Annie, and Miriama.

Thank you for tolerating my obsession, and for believing in me. We all celebrated as each chapter was completed, but for different reasons. In response to my saying "I'll be glad when I finish this thesis," Annie commented: "We'll be glad when you finish your thesis."

Finally, this thesis is dedicated to my father John Joseph (Jack) Mulheron, a committed teacher and activist, who was passionate about children, education, and rights. 


\title{
Table of Contents
}

\author{
Abstract i
}

Acknowledgements

Chapter 1: Setting the scene.................................................................................................... 1

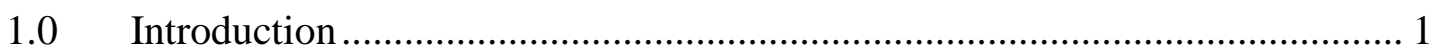

1.1 Rights, children, and childhood are difficult to define................................ 3

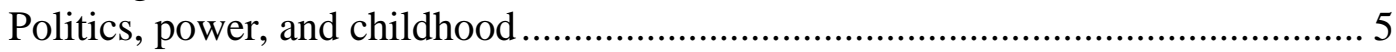

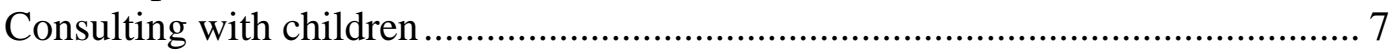

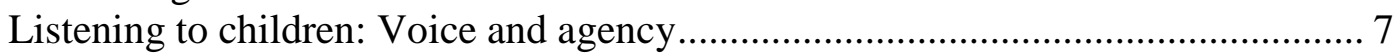

Tensions between children's needs and children's rights ................................. 8

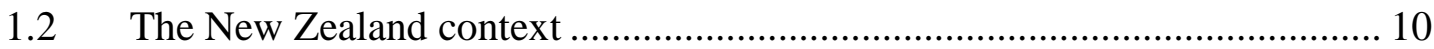

1.3 Theories and interpretations used in the thesis ......................................... 13

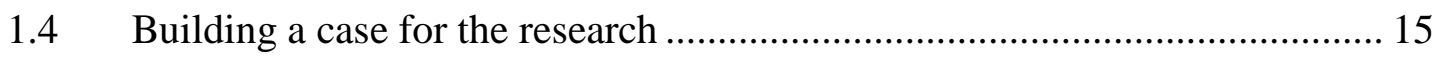

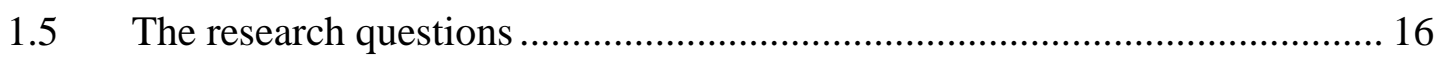

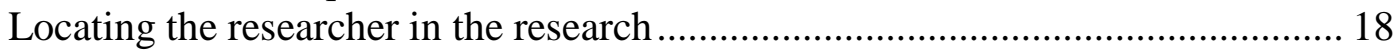

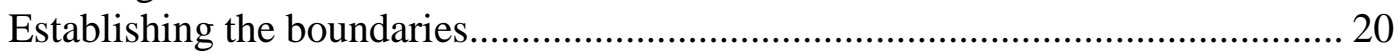

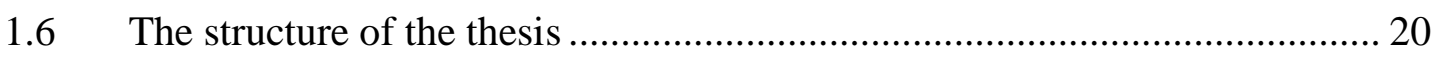

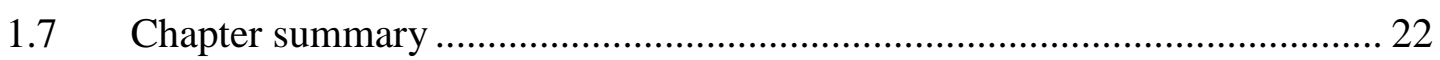

Chapter 2: The United Nations Convention on the Rights of the Child ............. 23

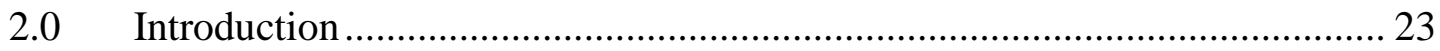

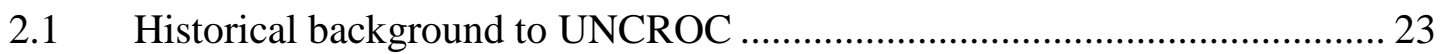

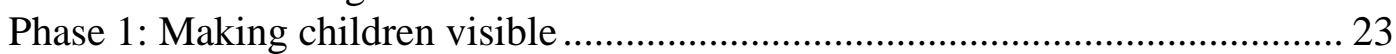

Phase 2: Human rights are children's rights .................................................... 24

Phase 3: The child's rights movement (1978-1989)............................................ 25

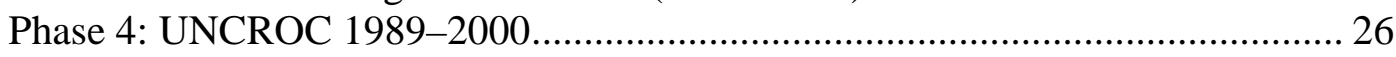

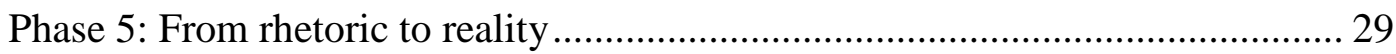

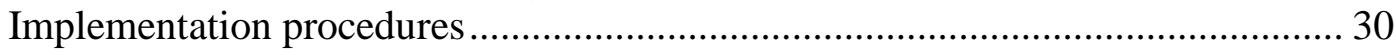

General Comments to guide implementation.................................................... 30

2.2 Implementing UNCROC in New Zealand ............................................... 32

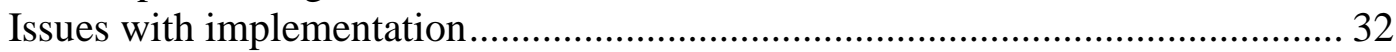

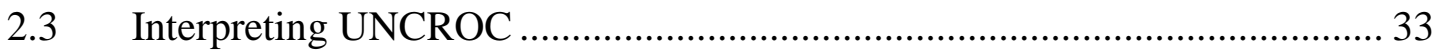

Participation rights: The child's autonomy to express views and make decisions ....... 36

Protection rights: The family's responsibility to nurture and bring up children ........... 37

Provision rights: The state's responsibility to provide services which protect and

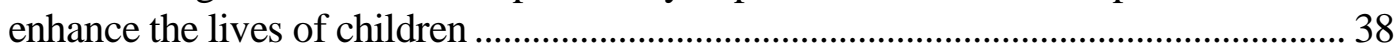


2.4 New Zealand early childhood education policies and UNCROC .................. 40

Te Whäriki - the New Zealand early childhood curriculum .............................. 40

Ngā Huarahi Arataki: The Strategic Plan for Early Childhood Education............ 42

Kei Tua o te Pae: Assessing young children's learning ...................................... 44

Provision measures to promote participation, protect children, and protect

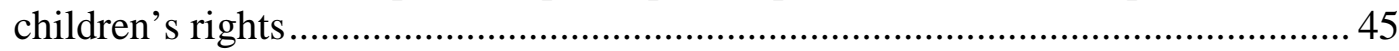

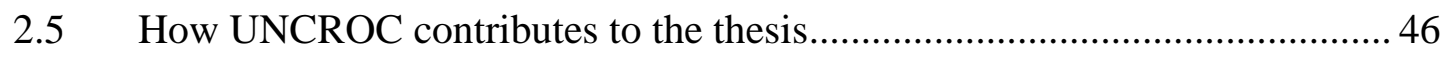

Chapter 3: Interpreting and implementing UNCROC............................................. 49

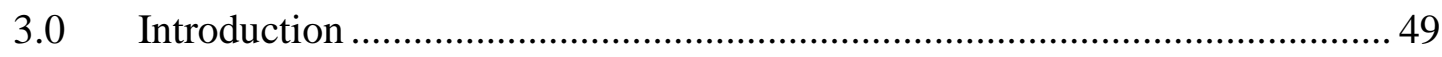

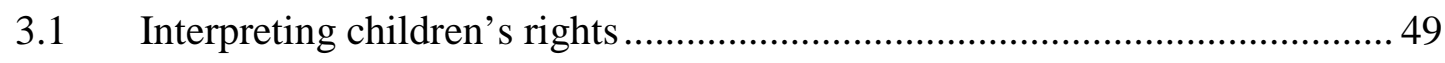

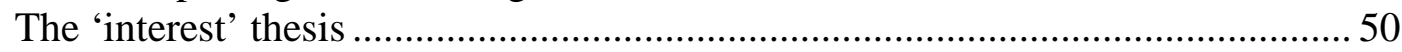

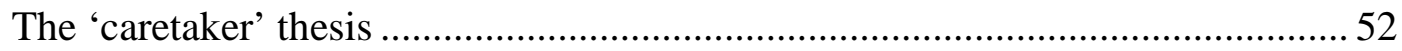

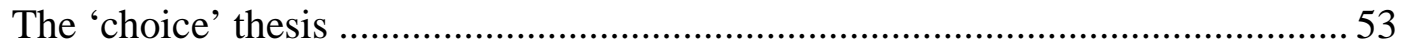

Models to evaluate children's participation rights ...............................................56

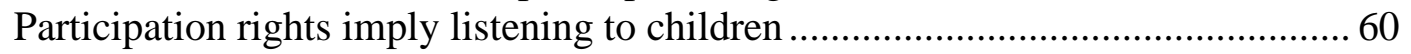

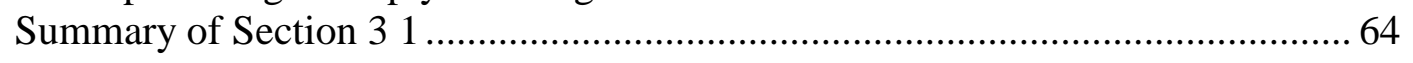

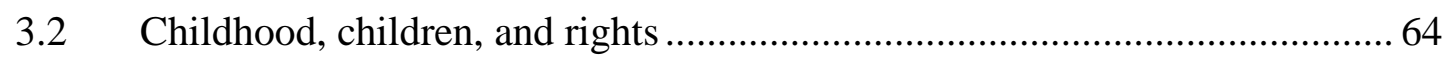

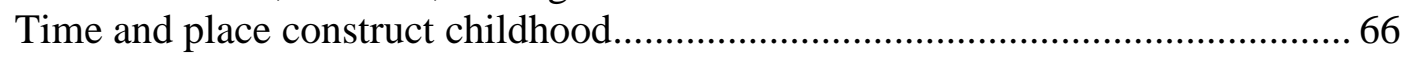

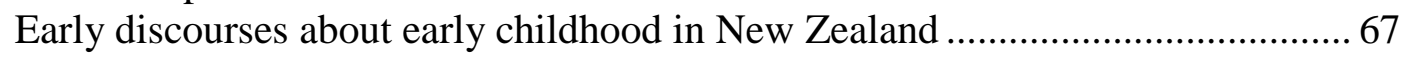

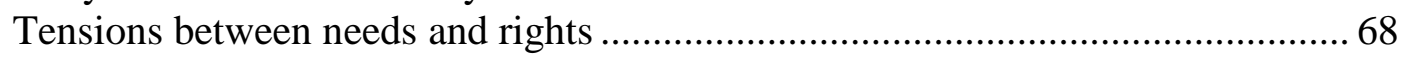

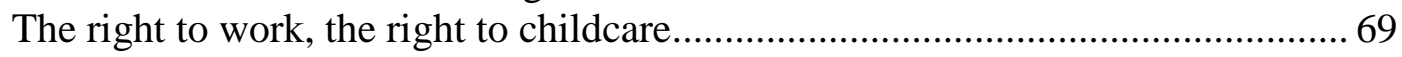

Advocates for quality early childhood education: A rights-based argument ......... 70

Theories of development: Needs-based or rights-based? .................................. 70

New and alternative discourses of childhood.................................................... 72

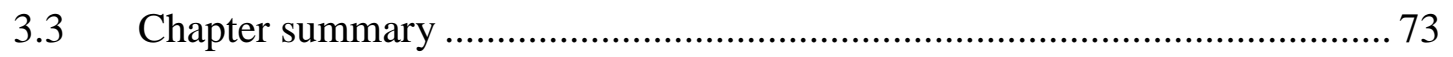

\section{Chapter 4: Children's rights, and sociocultural and ecological theories of} human development .......................................................................... 75

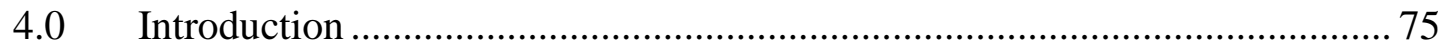

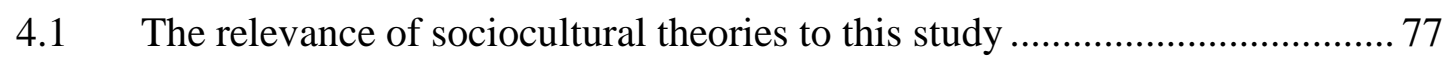

4.2 Vygotsky's sociocultural theory and children's rights.................................. 78

4.3 Sociocultural constructs of community and children's rights ...................... 83

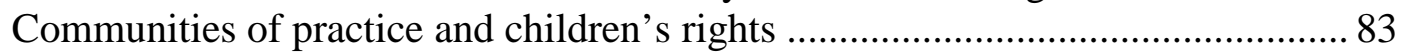

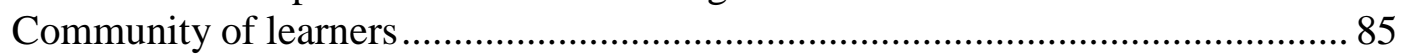

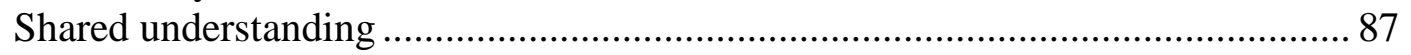

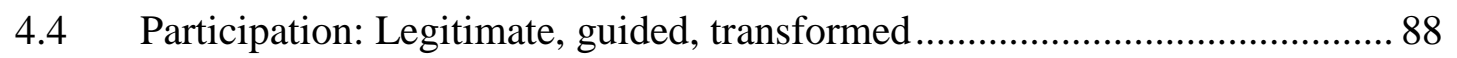

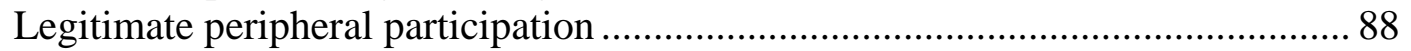

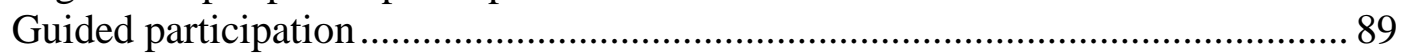

Transformation of participation through shared understanding ........................... 90

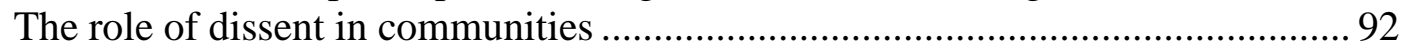

Cross-disciplinary interpretations of participation ........................................... 92 


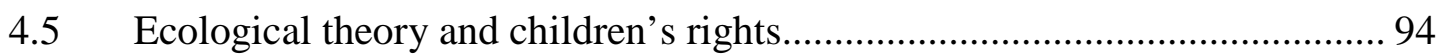

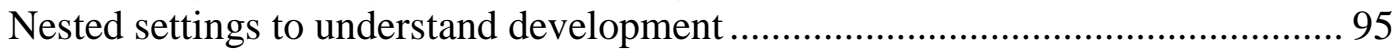

Process, person, context, time, and proximal processes ....................................... 97

Policy and research - a necessary collaborative partnership ................................ 99

4.6 A proposed integrated theoretical framework ........................................... 100

Making new sense of existing theories and interpretations .............................. 100

Common themes to conclude the chapter ......................................................... 102

Chapter 5: Methodology and methods............................................................. 105

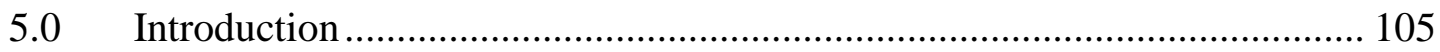

5.1 Rationale for the research methodology and method................................ 106

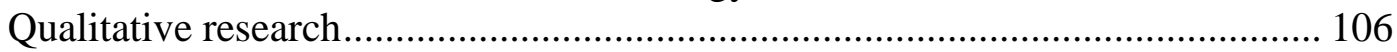

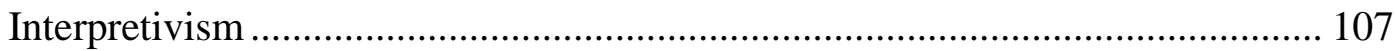

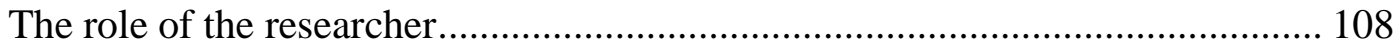

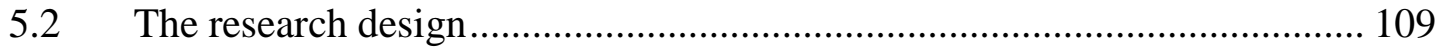

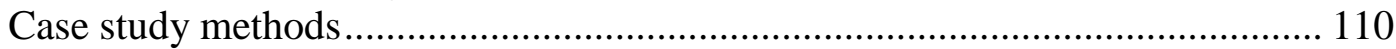

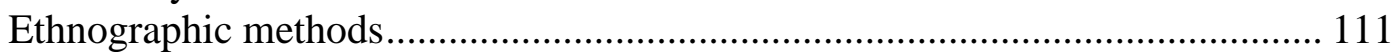

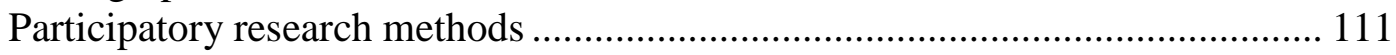

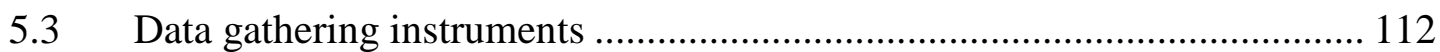

Field notes, photographs, researcher journal, and document analysis ............... 113

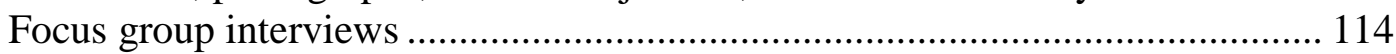

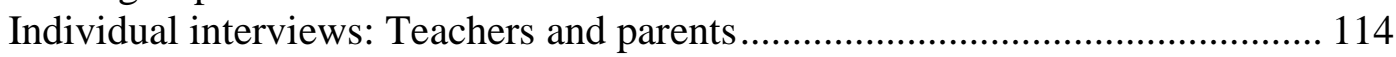

Interviewing children: Semi-structured conversations..................................... 114

Strategies to stimulate discussion about children's rights ................................. 115

5.4 Data generation processes and procedures............................................ 116

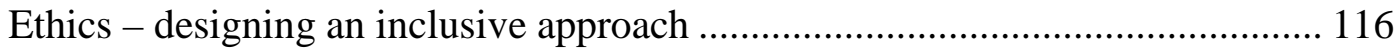

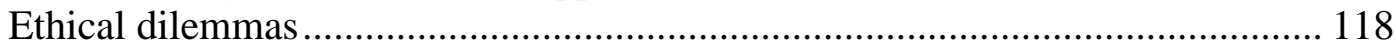

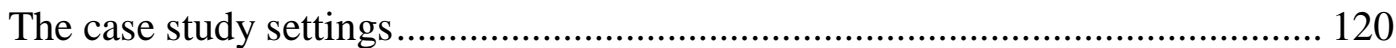

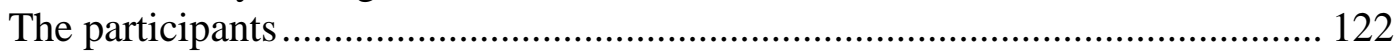

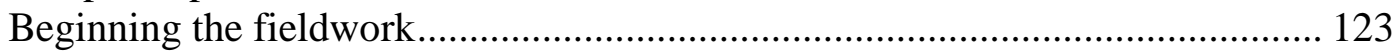

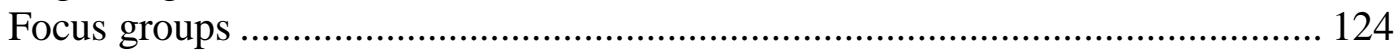

Observations in the field .......................................................................... 124

Interviews with teachers and Playcentre parents .......................................... 127

Conversational interviews with children...................................................... 128

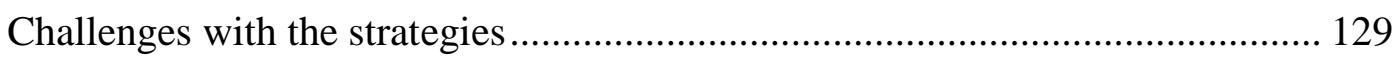

5.5 Data management and analysis procedures ........................................... 130

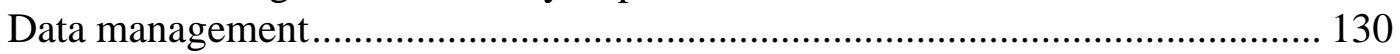

Analysis processes: From field notes to conceptual junctures........................... 131 
5.7 Reflections on the limitations of the methodology and method

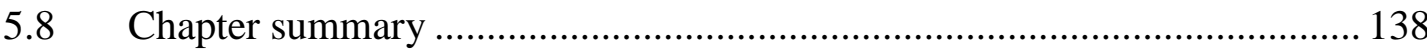

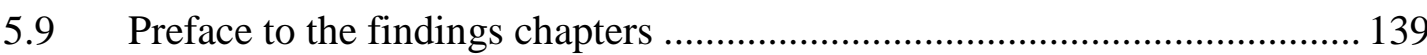

Chapter 6: The Crèche: advocates for infants..................................................... 141

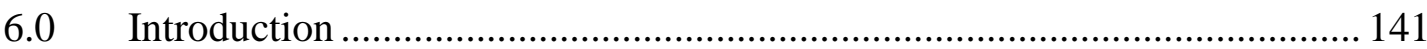

6.1 Protecting children's rights, protecting children ........................................ 142

The right to work, the right to early childhood education................................... 144

The impact of increased participation on 'quality' early education.................... 147

6.2 Teachers' advocacy to support children's rights....................................... 148

Health advocates-a conflict of interest ........................................................ 150

Advocating for choice: Opportunities and considerations ................................ 152

Advocates for listening to the child: Protecting children's rights to participate.. 154

Advocates for the Crèche philosophy: A provision right................................... 156

Advocating to a range of audiences; using a range of strategies ....................... 157

Summing up Sections 61 and 6.2 .................................................................. 159

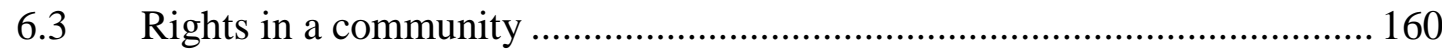

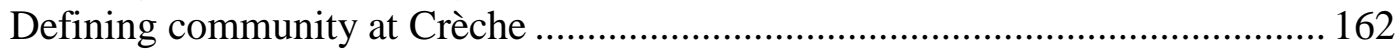

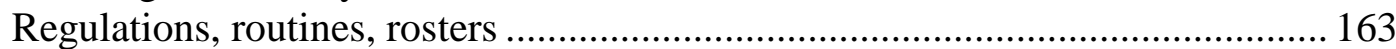

A community of learners in a gated community ........................................... 171

6.4 Conclusions: Who's right, whose rights? ............................................... 173

Chapter 7: Providing for free play at Playcentre .................................................... 177

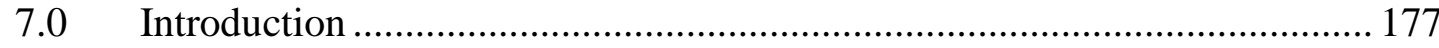

The Playcentre case study - providing for families and children ..................... 179

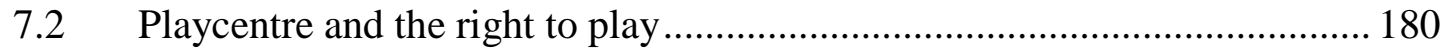

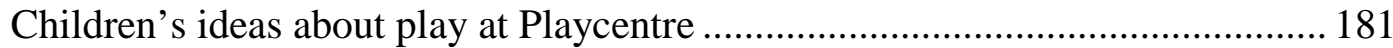

Parents' perceptions about play, choices, and rights......................................... 182

The right to belong, as a child, as children, as a family ...................................... 185

Children's rights to express emotions - a participation right.............................. 188

7.3 The Playcentre: A community within a wider community ........................ 189

Playcentre's effect on perceptions of children's rights ....................................... 190

Morning tea time: The politics of children's rights............................................ 194

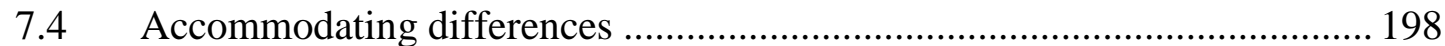

Tidying up: Rights and responsibilities at home and at Playcentre .................... 200

Free play at Playcentre meets structure at school ............................................ 202

7.5 Conclusions: Provision rights: protecting children's rights to participate ... 204 
Chapter 8: "It's the culture of the place": Promoting participation in a community of learners ......................................................................... 207

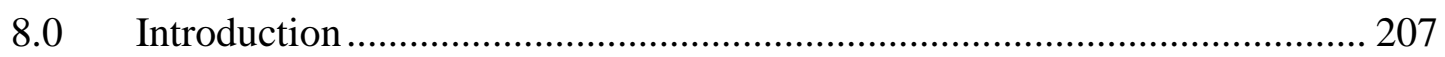

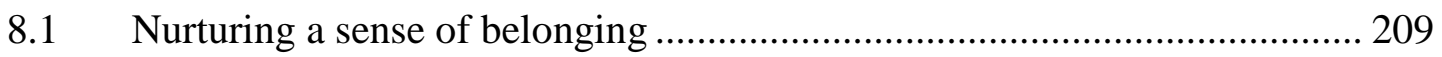

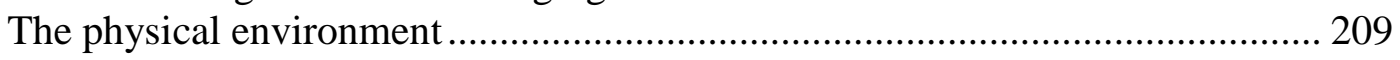

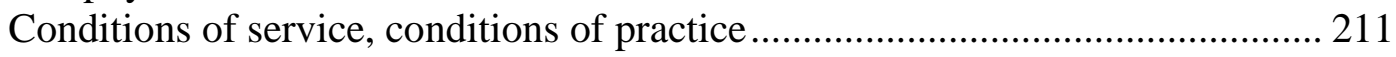

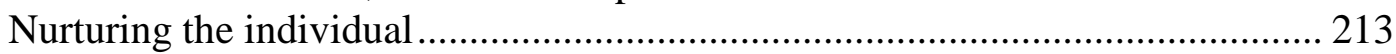

Being a good friend - nurturing relationships.............................................. 214

A sense of belonging enhances participation .................................................. 217

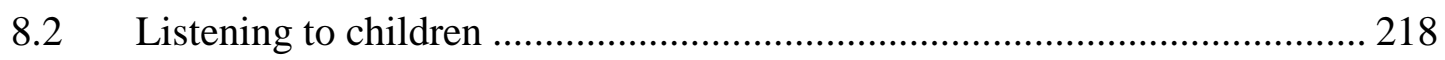

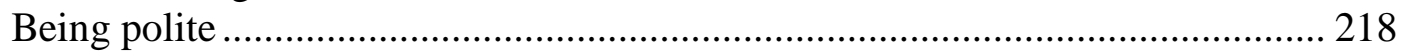

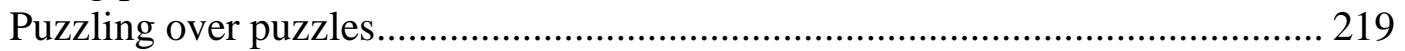

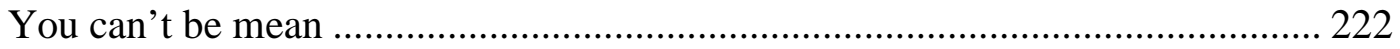

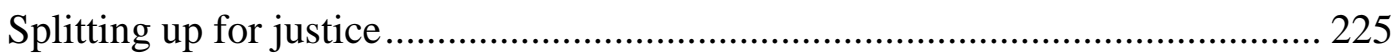

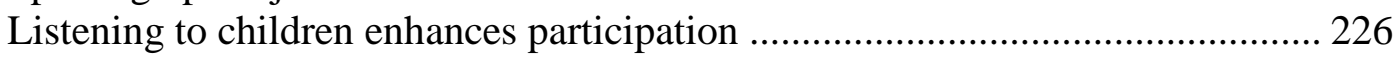

8.3 Participation in a community of learners at Kindergarten ......................... 226

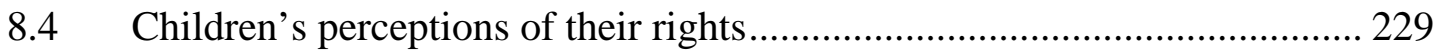

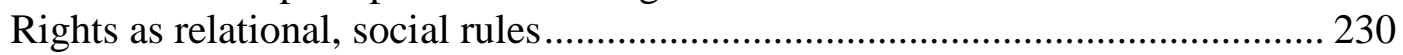

Guided participation: An exemplar of balancing expertise .............................. 231

Tidy-up time - sharing responsibility ...................................................... 233

8.5 Summing up: Protecting children's rights to participate; providing for children's rights to participate............................................................... 236

Chapter 9: Children's rights are interwoven, interrelated, and interdependent ..239

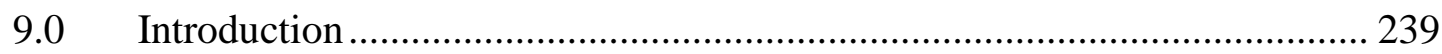

9.1 Children's rights did not exist in isolation ............................................ 242

9.2 Perceptions of rights were influenced by the context ............................. 243

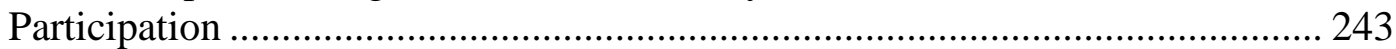

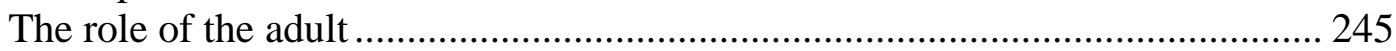

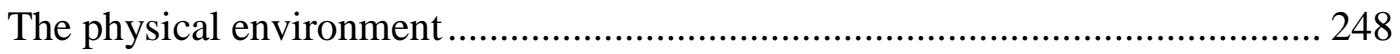

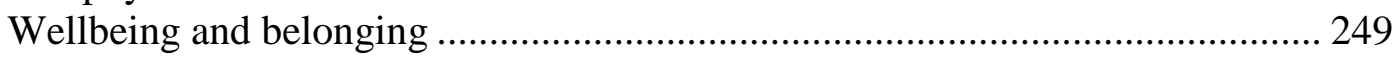

Respectful, reciprocal relationships ........................................................ 250

9.3 Contextual differences influenced how rights are implemented or enacted..... 251

9.4 Protection rights, provision rights, and participation rights are interwoven,

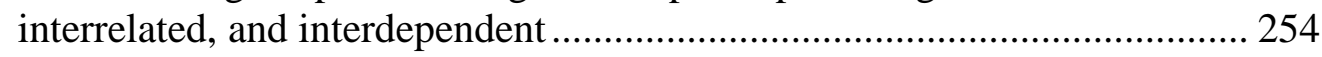

9.5 Developing a rights-based pedagogy: Implications for future research....... 257

Te Whäriki and UNCROC: Supporting children's rights ................................ 259 
Appendices ...................................................................................................................... 285

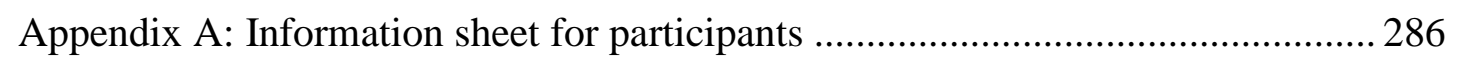

Appendix B: Consent forms for parents and teachers ......................................... 288

Appendix C: Information letter and assent form for children ................................ 290

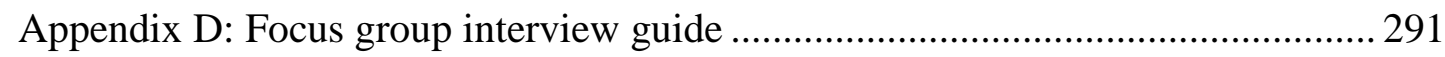

Appendix E: Individual interview guide: Parents and teachers ............................ 292

Appendix F: Transcriber confidentiality agreement and transcript letter to

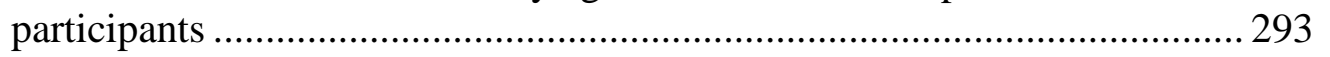

Appendix G: Researcher's check list for data processing ..................................... 294

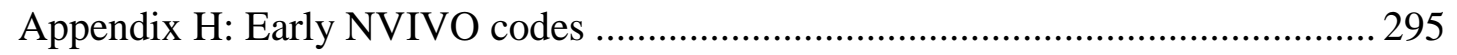

Appendix I: Example of an NVIVO coding report ................................................ 296

Appendix J: United Nations Convention on the Rights of the Child (CRIN, 2009) 301 


\section{List of Tables}

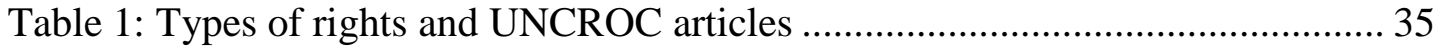

Table 2: The adult participants and their settings ................................................. 123

Table 3: Data generation processes and procedures ……...................................... 126

Table 4: Number of interviews and hours of fieldwork ........................................ 127

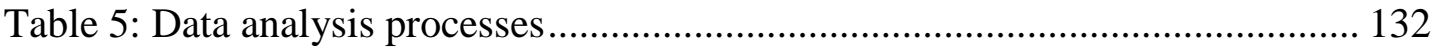

Table 6: Conceptual Junctures and theoretical insights ......................................... 133

Table 7: Protection, participation, and provision rights at Crèche........................... 161

Table 8: Protection, provision, and participation rights are interwoven, interrelated and interdependent.

\section{List of Figures}

Figure 1: Early childhood education: Apparent participation rates by age group

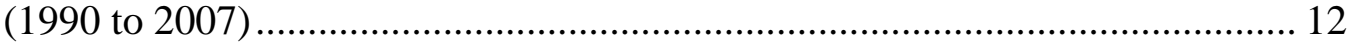

Figure 2: Interweaving theories and interpretations........................................... 13

Figure 3: Phases of rights: Adapted from Alston et al. (2005) ............................... 23

Figure 4: Interweaving categories of rights ......................................................... 36

Figure 5: A typology of community action: Aadapted from Matthews ..................... 58

Figure 6: Similarities between models of participation and assessment................... 60

Figure 7: Theoretical influences: UNCROC, interpretations of rights and

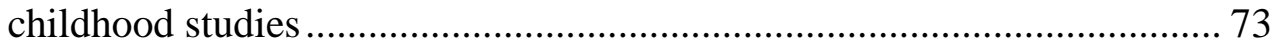

Figure 8: An integrated theoretical framework ................................................... 100

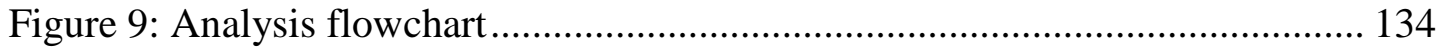

Figure 10: Protection rights at Crèche ….......................................................... 141

Figure 11: The ecology of influence on perceptions of children's rights ................ 168

Figure 12: Provision rights fore-grounded in the Playcentre case study ................. 177

Figure 13: Participation rights at Kindergarten................................................... 207

Figure 14: Relationships between perception, context, and implementation of children's rights.

Figure 15: Protection rights, provision rights, and participation rights are interwoven, interrelated, and interdependent.

Figure 16: Categories of rights and the principles of Te Whäriki 


\section{Chapter 1: Setting the scene}

\subsection{Introduction}

The most fundamental of rights is the right to possess rights. (Freeman, 2007, pp. 7-8)

The word 'rights' is difficult to define (Alderson, 2000; Alston, 1994a, 1994b; Freeman, 1992). There are many diverse and contrary understandings about what constitutes children's rights. Rodham (1973, cited in Guy, 2005, p. 19) suggested "the concept of children's rights is a slogan in search of definition". Alexander (1995) likened the debates to plaiting with fog and knitting with treacle. Michael Freeman (2002, p. 6) described rights as "just claims or entitlements that derive from moral and/or legal rules", and argued that rights, in particular children's rights, are important: "if we have rights we are entitled to respect and dignity" (Freeman, 1992, p. 29). The release of the United Nations Convention on the Rights of the Child (1989, henceforth UNCROC) (Child Rights Information Network [CRIN], 2007) ${ }^{1}$ (Appendix J) prompted questions about what the term 'child's rights' meant in theory and in practice. Researchers and professionals with an interest in children have grappled with interpreting UNCROC and implementing rights for children at an international level, at a national level, and more recently at a local level.

In 1993, New Zealand ratified UNCROC (Smith, 2000, 2003). As a nation state, New Zealand agreed to uphold the 54 Articles of UNCROC, and to submit fiveyearly reports on children's rights in this country to the United Nations Committee on the Rights of the Child (henceforth the UN Committee). An expected responsibility of state parties, beyond obvious compliance issues, is that they promote UNCROC publicly. Campaigns such as the Agenda for Children (Ministry of Social Development, 2002), Building Human Rights Communities in Education (Amnesty International (NZ), Development Resource Centre, Human Rights Commission, Office of the Commissioner for Children, \& Peace Foundation, 2007), and Pathways to the Future (Ministry of Education, 2002), and the New Zealand Children's Commissioner use UNCROC as a foundation document. The process of conscientisation (Freire, 1993) is apparent at the national policy level (Ministry of

1 The Child Rights Information Network (2007) version of UNCROC (1989) was used throughout this thesis. This reference is only cited when the thesis quotes directly from it. 
Education, 1996a, 1996b, 1998, 2002; Ministry of Social Development, 2002), and has been for many years, but less certain is how far this conscientisation process has trickled down to the practical level in early childhood services (Te One, 2004).

Two research disciplines, childhood studies and the sociology of childhood (discussed fully later in the thesis), focus on how children actively construct their own childhood experiences. Children's rights advocates and theories about rights have paid significant attention to Article $^{2} 12$ (CRIN, 2007, p. 5) which entitles children to participate in decisions that affect them. To date, no research in New Zealand specifically investigates perceptions of children's rights when they participate in early childhood settings, and given the high levels of participation in such settings (Education Counts, 2008; UNICEF, 2008), this lack of research is significant. New Zealand advocacy has focused on children's rights to access and participate in early education, and some research certainly investigated children's experiences of participation in curriculum and assessment practices (Carr, May, \& Podmore, 1998, 2002; Early Childhood Education Project, 1996; Early Childhood Long Term Strategic Plan Working Group, 2001; May, 1999, 2001, 2003, 2004; Mitchell, 1996; Podmore, 2004b; Podmore, Meade, \& Kerslake Hendricks, 2000; Smith, 1996).

Early childhood in New Zealand has long courted diverse theoretical ideas about human development (e.g., Ministry of Education, 1996a, 1996b, 1998, 2005) but less attention has been given to theories about children's rights, and the study of childhood sociology. It is almost as if children's rights in early childhood settings are assumed as given, but there is little evidence to show what assumptions exist. Childhood sociologists recognise children as competent and no longer consider it acceptable for the adult to claim to know the view of the child if they do not consult with the child. A view of the child as a subject, not an object, affords him or her agency or power, albeit limited by structures that constrain attitudes and actions. The UN Committee (2005) noted:

Young children are acutely sensitive to their surroundings and very rapidly acquire an understanding of the people, places and routines in their lives, along with awareness of their own unique identity. They make choices and communicate their feelings, ideas and wishes in numerous ways long before they are able to communicate through the conventions of spoken or written language. (Section 11)

2 Unless stated otherwise, the word 'Article' refers to the articles of UNCROC. 
To promote rights effectively requires teachers to move beyond the rhetoric and recognise that children are: "entitled to be participants, not just consumers, in education. Yet so often they have no real role to play in educational decisions concerning them and their lives" (Fattore \& Mason with Sidoti, 2005, p. 20). Seeking children's views is central to the idea of participation rights. James (2004) noted that children "must be seen as active in the construction and determination of their own social lives" (p. 78). Including children's opinions requires consultation. Evidence of such consultation is lacking in New Zealand research about young children's rights in early childhood settings, and this lack provides a rationale for the present investigation.

This chapter introduces the difficult issues associated with defining children's rights. These issues include the power dynamics between adults and children, the challenges of consulting children, and the underlying tension between children's needs and children's rights. These are set in the context of international debates about children's rights, and lead into a descriptive account of children's rights in the New Zealand early childhood education context. This is followed by an overview of the theoretical framework used in the investigation. In the next section, the research questions are introduced. These sections preface the potential contribution the research makes to early childhood education, and the children's rights arena, nationally and internationally. The chapter concludes with brief descriptive overviews of each of the remaining chapters of the thesis.

\subsection{Rights, children, and childhood are difficult to define}

Rights are often complex aspirational statements that defy simple categorisation. To meet a need can also mean implementing a right (say to survival or development), but if in meeting a need, the child's rights (e.g., to be consulted and informed) are disregarded, the issue becomes one of protecting rights. Arguably perceptions of children's rights depend on how childhood is constructed, and on children's ability to exercise agency.

Exactly what role or status children have in our society can be ambiguous (A. B. Smith, Taylor, \& Gollop, 2000) because "it is hard to peer through the tangle of adults themselves" (Mayall, 2000a, p. 127). Mayall (2000a, p. 127) argued, because 
children are part of the social order, "proper understanding of the social order requires consideration of all its members". There are several distinct, but overlapping perspectives that influence our images of children together with our understanding of rights for children. Two words - 'children' and 'rights' - open doors to an intriguing array of concepts, theories, and ideologies from divergent disciplines (education, sociology, law, history, psychology, and anthropology to name a few). The word 'rights' is interpreted differently in different contexts. As well, the words child/children are equally complex. Is it the 'child' or the 'children', or $a$ 'child' that is thought of when considering rights?

UNCROC takes a universal approach to children's rights and this has been problematic (see Chapter 2). Childhood sociologists argue that childhood is constructed differently in different times and places (Bentley, 2005; James, Jenks, \& Prout, 1998; James \& Prout, 1997; Jenks, 1996; Prout \& Hallett, 2003; Prout \& James, 1990; Pufall \& Unsworth, 2004; Waksler, 1991; Woodhouse, 2004; Wyness, 2006). Further, there is no agreement on where childhood ends, or in some instances, begins; it is an arbitrarily wavering and incoherent line (Franklin, 1986, 1995; Tapp \& Henaghan, 2000). In fact "the term child has a connection less with chronology than with power. The question 'what is a child?' is answered by those in authority - those who have power in society" (Franklin, 1986, p. 8). So, exactly what role do children have in society? Their status, let alone their rights, is both ambiguous and contentious (Alexander, 1995; Freeman, 1998, 2002, 2007; Ludbrook, 2000; Smith, 2000). Simon (2000, p. 1) suggested that UNCROC "places more emphasis on obligations and harms than it does on rights and entitlements".

One reason children's rights become problematic is because the words 'children' and 'the future' are often linked. Freeman (1998, p. 434) noted:

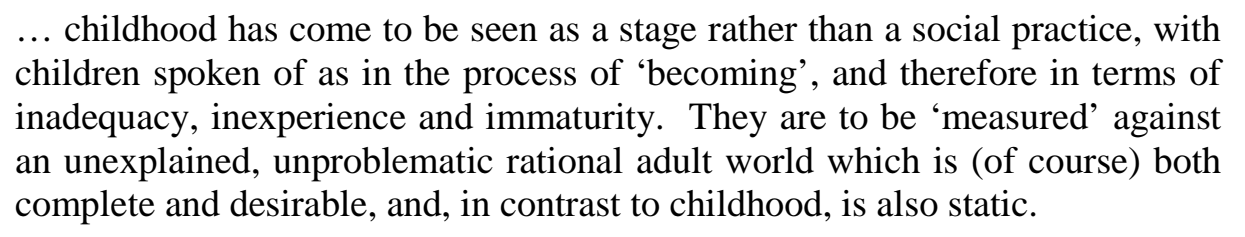

Views of children as adults in waiting, vulnerable, dependent, naïve, and innocent serve to disempower and marginalise them as a silenced, disenfranchised class (John, 1996, 2003a, 2003b; Oldman, 1994). Ambiguous attitudes to children and to childhood confuse understandings about children's rights, often resulting in 
questions about children's entitlements. Are children entitled to the same types of rights as adults, or are children's rights different because they are children? This concept of a child as 'becoming' feeds an enduring obsession with the child in the future, and clouds understandings about children's rights because it presents them as 'not there yet' (Freeman, 1998; Te One, 2004, 2005, 2006).

Questions about children's rights can be divisive (Federle, 1994; Freeman, 2007; Guggenheim, 2005; Reid, 2006; Yelland, 2005). Debates about children's rights can shed light on the nature of human relationships. Those for and against children's rights can be positioned along a continuum. At one end, children's rights are perceived as detracting from adults', in particular parents', rights. Some advocates critical of children's rights argue that the state diminishes the role of parents by granting children a voice in decisions that affect them (Almog \& Bendor, 2004; Alston, 1994a; Alston, Tobin, \& Darrow, 2005; Guggenheim, 2005; Reid, 2006; Simon, 2000). This, it is argued, undermines the sanctity of families, and parental rights to raise their children without risk of social engineering. At the other end of the continuum, advocates for children's rights support consulting children in all matters that concern them, and the balance of power shifts in favour of children (Alderson, 2000, 2004; Alderson, Hawthorne, \& Killen, 2005; Freeman, 1998, 2007; Hart, 1992, 1997; Lundy, 2007; Shier, 2001; Smith, 2000, 2002, 2007a, 2007b). These perspectives illuminate the complexities of balancing the rights of one group with the rights of another.

\section{Politics, power, and childhood}

Cunningham (1995, p. 1) wrote: "we need to distinguish between children as human beings and childhood as a shifting set of ideas". He argued that public actions shape the lives of children, and asked what ideas about childhood are being "fed through into the discourses and actions of philanthropists and governments" (p. 3).

The actions Cunningham referred to are political, and the essence of politics depends on active participation in the democracy, starting with who has a voice, or more pertinently, whose voices are heard, a point of central relevance to children's rights: “The power of the 'expert' has previously served to legitimate their assumed 'right' to speak 'truth' for, and about the lives and learning of those who are younger" (Cannella, 2005, p. 19). Discussions about children's rights prompt a range of 
comments reflective of the diverse opinions within our society. While many adults support increased participation of children, there are many who are challenged. Prout (2003, p. 22) noted: “(f)or children's voices to be really heard, even when the institutional arrangements create a notional space for it, requires change in the way that children are seen". Threats to creating the 'notional space' (Prout, 2003) for the voice of the child continue to provoke investigation (MacNaughton, 2003). While the discourses in the policy arena necessarily remain focused on children's rights to an early childhood education (see Te One, 2004, 2005), this research shifts the focus to children's rights in early childhood education.

The idea of the child as politically active is not new. Children have been described as a minority group that shares the same experiences of prejudice and disenfranchisement as other groups (Holt, 1975; John, 1996, 2003b; Mayall, 1994, 2000b, 2003; Oldman, 1994; Wyness, 2006). Arguably the largest disenfranchised group in New Zealand are children under 18. Education writers and philosophers like A. S. Neill (1968), John Holt (1975), Jonathan Kozol (1967), Herbert Kohl (1967), and many others raised questions about children's status in society at a time when racial inequality, feminism, and war were on the political agenda. Given the increased participation rates in early education, young children's status is relevant to perceptions of their rights. Answers from some, like Neill and Holt, argued strongly for children's rights and presented cogent arguments for democracy in action as something children should experience directly. Children's participation is aspired to (Ministry of Education, 1996b, 1998, 2005, 2006), but without evidence of how children's participation is understood, how to support this remains unclear.

The powerlessness children experience is reflected in the low status childhood has in society. Oldman (1994) used a Marxist analysis to argue that the state of childhood is in fact a class - and that children as members of that class are rendered invisible, subsumed within the family. Qvortrup's (1999) analysis of aggregated statistical data in Europe illustrated how "children are an invisible group par excellence in our society" (p. 88). Invisibility is a recurring theme. Action for Children and Youth Aotearoa's (ACYA) reports $(2003,2008)$ to the UN Committee claimed that New Zealand's children continue to suffer because there are no consistent statistical data gathered on children as a population group. According to ACYA, if all children count in statistical data, that means children as a class of people can influence policy 
decisions that affect their social condition - childhood. Idealised myths about children and childhood continue to de-politicise children based on the "mistaken belief that the problems relating to them are non-controversial and lie outside the political agenda" (John, 1996, p. 9). There are political and indeed moral considerations regarding not just the rights of children, but also the status of children, particularly in relation to parental authority and state responsibility. These considerations include how children are listened to, which is critical to supporting children's rights to be consulted and to participate.

\section{Consulting with children}

Rights have been described as powers (see Franklin, 1995) which can exist on many levels: between children, between teacher and children, between teacher and teacher discussing children, and between teacher and parent discussing children. How to balance the power can depend on how children are consulted. There is evidence to suggest a degree of confusion about the word 'consult'. What does it mean exactly 'to consult'? What are the implications of consultation? What are the responsibilities of those who undertake to consult and on whose terms are these conversations undertaken? These questions are key to participation. Priscilla Alderson (2000, p. 17) suggested further questions to enable this: "Do they understand enough? And if not, could they understand enough if they had more information, or if they were asked in different ways?"

Childhood is essentially a generational phenomenon that "refers to a complex set of social processes through which people become (are constructed as) 'children' while other people become (are constructed as) 'adults' (Alanen, 2001, pp. 20, 21). Research should identify "the generational structures from which children's powers (or lack of them) derive" (p. 21). Although children have rights they need "some sense of personal power to exercise those rights ... almost everywhere they are rendered powerless. ... [T] he struggle has occasionally found a voice and ... been so overwhelmed with nonrecognition that it has been silenced" (John, 2003b, p. 11). The depth of that silence forms a part of investigating perceptions of rights in early childhood settings.

\section{Listening to children: Voice and agency}

Listening to children can be understood as a political act that unites the child with civil society, and as such, is critical to facilitating children's participation in society. 
The pedagogy of listening "is a context ... where individuals feel legitimated to represent their theories and offer their own interpretations of a particular question" which generates understanding and awareness (Rinaldi, 2006, p. 66). How institutions include multiple voices (the hundred languages of children) challenges current organisational structures to recognise social and cultural contexts and move beyond tokenism, to respect children's agency and participation rights, and to acknowledge children as actively contributing to social processes through participation in early childhood education (Dahlberg, Moss, \& Pence, 2007; Mitchell, 2007; Rinaldi, 2006; Smith, 2002).

However, the pedagogy of listening (Rinaldi, 2006) is difficult to achieve. Contemporary research, supported by theory, foregrounds the voice of the child (Carr, 2001, 2003; Clark \& Moss, 2001; Einarsdottir, 2005; Lofdahl \& Hagglund, 2007; Siraj-Blatchford, 2004). Pufall and Unsworth (2004) differentiate between voice and agency as follows: voice refers to "that cluster of intentions, hopes and grievances, and expectations that children guard as their own [and] to the fact that children are much more self-determining actors than we generally think" (p. 8, brackets added). They reiterate: agency is how children express their voice.

Accordingly, childhood sociologists agree that voice and agency are children's rights. Pufall and Unsworth (2004) interpret 'voice' as expressing intent. This can include both verbal and non-verbal communication. Listening to the child's voice includes being heard, and being listened to, the right to express an opinion, and the right to contest, challenge, debate, and question, which translates as agency. While there is some evidence that young children are exercising agency in early childhood assessment practices in particular (Carr, Lee, \& Jones, 2004), perceptions of agency are not explicitly articulated in terms of children's rights.

The next section contributes to this thesis by identifying an underlying discourse of children as needy and discusses how this impacts on perceptions of children as rights-holders.

\section{Tensions between children's needs and children's rights}

Perceptions of infants and young children as needy and vulnerable abound (Dahlberg et al., 2007; Stainton Rogers, 2004; Woodhead, 1997, 2004, 2005). A discourse of 
children's needs has been "a powerful theoretical device for constructing images of childhood, prescribing for care and education, and judging the quality of adult-child relationships" (Woodhead, 1997, p. 79). A children's rights discourse views the child as agentic, capable and competent of expressing an opinion (see for example, Alderson, 2000; Freeman, 2007; Lansdowne, 2005; Smith, 2003, 2007a). This thesis presents a case to support a children's rights discourse as an alternative to a needsbased one. While not a new idea, the data in this thesis suggest that children's rights acknowledge adults' responsibilities to care for children, but these responsibilities include respecting children's rights to express, or form, a point of view, and in so doing, assert their rights to be involved in decisions that affect them.

In one attempt to deal with this tension Stainton Rogers (2004, p. 127) suggests that a “"needs' discourse ... seeks to identify children's basic needs, and ... action is directed to ensuring those needs are met". The needs discourse, she argues, while well-intentioned, "sets up an expectation that we (the adult world) should view children in terms of their needs and seek to meet them" (p. 130). Similarly, a discourse of concern (Stainton Rogers, 2004) casts children as vulnerable and in need of protection. Both discourses are influenced by Western developmental psychology and adopt a rather paternalistic perspective towards children. Both are couched in assumptions, which would be much better replaced by the concept of rights endorsed by UNCROC (Woodhead, 1997), "where action is directed to promoting these rights" (Stainton Rogers, 2004, p. 127).

Discourses of need and concern, as well as developmental discourses, limit both children and adults (Stainton Rogers, 2004). As an alternative Stainton Rogers proposes a 'quality of life' discourse that concentrates on what makes life worthwhile, and supports children's rights. She argues that a rights-based approach holds more potential for enhancing quality for the following reasons: First, it is strengths-based as opposed to a deficit approach; second, it shifts the focus from the individual to the situational and in so doing removes unhelpful perceptions such as blaming a child, or a family for their circumstances. This perception ignores the social, economic, and political context which may have created adverse circumstances in the first place (Stainton Rogers, 2004). In the quality of life discourse, the route to change is political action. Implementing children's rights takes more than moral fortitude and rhetoric to become a reality; it 
needs political conviction to implement policy. The quality of life discourse takes into account children's needs but, in principle, is a rights-based approach.

Woodhouse (2004) attempted to resolve the tensions between needs and rights by interpreting them as either needs-based rights, or dignity-based rights. Needs-based rights include:

... positive rights ${ }^{3}$ to nurture, education, food, medical care, shelter, and other goods without which children cannot survive let alone develop into autonomous adults and productive citizens. Children's needs based rights would also reflect their need to grow and test the wings of their increasing autonomy. (Woodhouse, 2004, p. 229)

Dignity-based rights "remind us that children, despite their lack of capacity, do have rights based on their present humanity as well as on their potential for autonomy" (Woodhouse, 2004, p. 234). Woodhouse contends that while infants "rely on others to articulate and protect their rights [as] they mature, they gain the capacity necessary to act autonomously. Children's ability to reason and understand evolves over time, but their dignity-based rights are fully present at birth" (p. 234). This interpretation attempts to resolve tensions between needs and rights. According to Woodhouse, dignity-based rights hold more potential for empowering children because these recognise children's emerging capabilities, and at the same time acknowledge their competence, and their rights to adult support. The next section introduces more specific detail about children's increased participation in early childhood to further establish a rationale for the research.

\subsection{The New Zealand context}

As early as 1980, Anne Smith (1980) was actively campaigning for very young children's rights. Smith published widely on the relevance of sociocultural, ecological, and sociological theoretical perspectives to quality education and care for young children (1993, 1996, 1998, 2000, 2002, 2003, 2007a, 2007b). Her research and advocacy moved rhetoric to action with rights in early childhood education. Anne Meade's work (Department of Education, 1988; Meade, 2000, 2005, 2006, 2007; Meade \& Podmore, 2002) focused on government process, and in particular on

3 Woodhouse (2004) differentiates between positive rights, ("a right requiring active state intervention", p. 229) and negative rights ("the right to be free from state intervention", p. 229). 
how research on the benefits of early childhood education can influence government policy. Linda Mitchell's (2003, 2007) research and advocacy work prompted the reconsideration of children's ability to contribute to society in democratic ways. Margaret Carr $(2000,2001,2003)$ shifted the parameters of the debate into the assessment of young children's learning and, together with Val Podmore and Helen May (Podmore, May, \& Carr, 2001), influenced learning and teaching frameworks.

New Zealand has extremely high participation rates in early childhood education (Ministry of Education, 2007a, 2007b). Figure 1 illustrates current participation trends (Education Counts, 2008). While some services have experienced decline and closure (particularly Playcentres and kōhanga reo $^{4}$ ) over the past decade, early care and education services have expanded. At July 2007 there were 91,733 children enrolled in early care and education services, representing a $16.2 \%$ increase in enrolments between 2003 and 2007. In 2007, the number of infants under one enrolled in early childhood services stood at 10,580, indicating an increase of $17.9 \%$ since 2003 . One-year-olds' enrolment figures in 2007 stood at 26,401, representing an increase of 16.8\% since 1990. The increase continues for three-year-olds, more than tripling since 1990 from 17,437 to 56,171. So since 1990, enrolments for children aged three and under have gone from 32,795 to 68,865 in 2004 , to 131,981 recorded enrolments in early childhood services in New Zealand in 2007. For four-year-olds, participation rates are even higher, registering at over $95 \%$ for the past decade. Early education is a serious proposition, and given the increased participation and Ministry of Education support for this trend, the status of children and perceptions of children's rights in early childhood settings have relevance for educational reasons and implications for policy development.

\footnotetext{
${ }^{4}$ Kōhanga reo are parent/whānau-led Māori language immersion early childhood centres.
} 


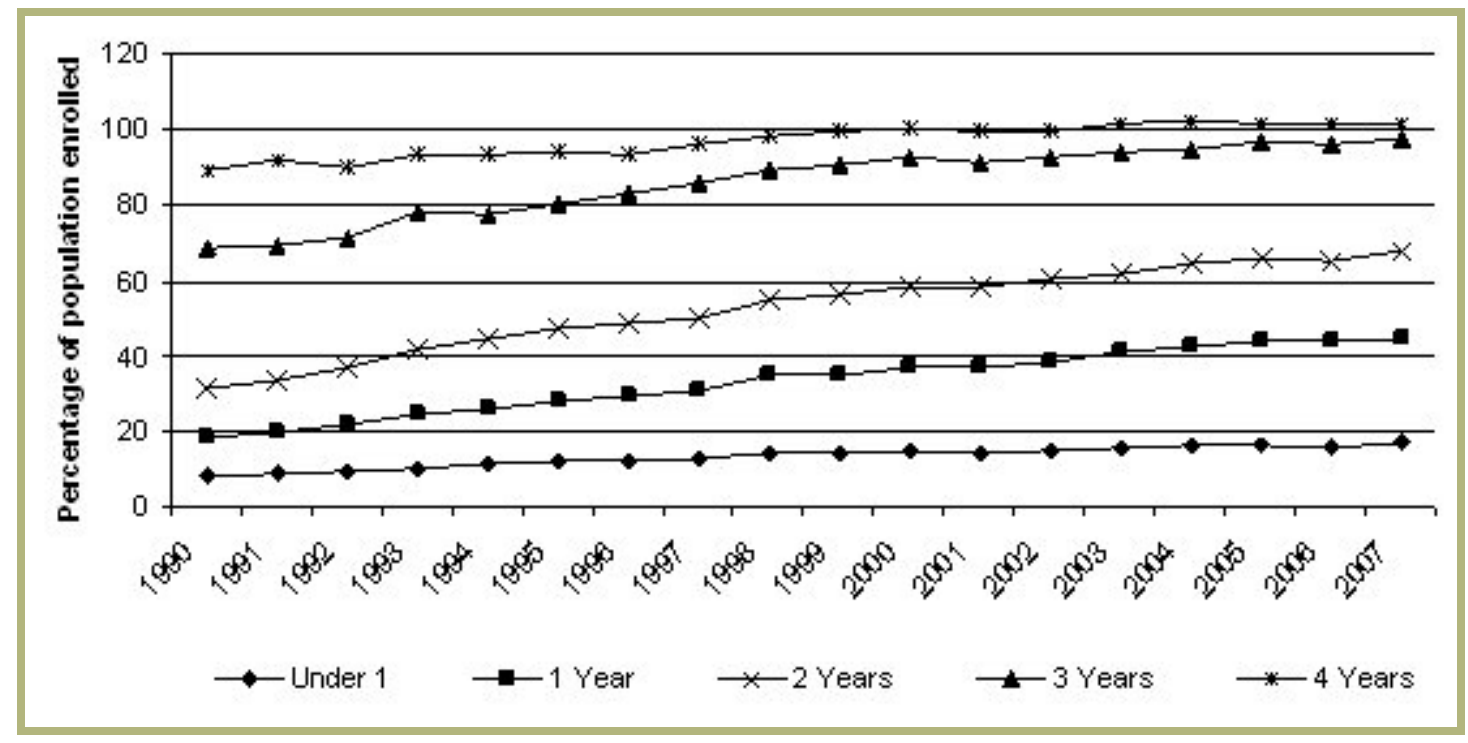

Figure 1:

Early childhood education: Apparent participation rates by age group (1990 to 2007) (Ministry of Education, 2007a, p. 5)

While participation has increased, so too have discourses of children's rights in early childhood gained prominence in New Zealand in the last decade (Dalli \& Te One, 2002; Mitchell, 2003; Noonan, 2001, 2003; Smith, 2000, 2007a, 2007b). Some early childhood policies cite UNCROC (Department of Education, 1988; Ministry of Education, 1993, 1996, 1998, 2002; Te One, 2004, 2005). Many of these early childhood policy initiatives concentrate on children's rights to early childhood education. Access and participation have been key planks in policy documents which use research to show the benefits gained from early childhood education of good quality (Department of Education, 1988; Te One, 2003). Early childhood advocates used Article 29 (CRIN, 2007, p. 13) to argue for free, universal provision of early childhood education services (Noonan, 2001, 2003; Smith, 2000). Still others have advocated on behalf of distinct groups of children. A significant yet marginalised population, embattled on the wider societal front, are Māori tamariki (children) whose whānau, hapū and iwi $^{5}$ have argued for rights to an education that recognises their tino rangatiratanga (self-determination) and their indigenous rights to education in te reo Māori (the Māori language) (Bishop, 1996; Bishop \& Glynn, 1999; Irwin, 1990; Macfarlane, 2004). In this thesis, the focus is on children's rights in early childhood education, and as mentioned earlier, increased enrolments and changes in attendance patterns over the last 20 years suggest that a shift in focus is timely.

\footnotetext{
5 Whānau: family; hapū: sub tribe; iwi: tribe.
} 


\subsection{Theories and interpretations used in the thesis}

The theoretical design of this investigation combines sociocultural historical constructs, ecological theories of human development, interpretations of children's rights, and childhood sociology and childhood studies (see Figure 2).

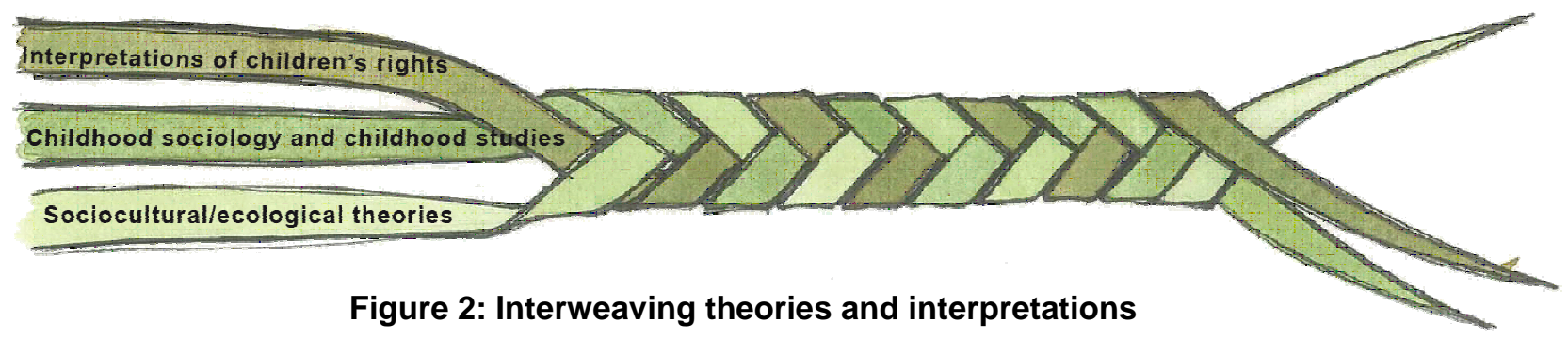

Sociocultural historical concepts of transformation of participation in a community of practice (Wenger, 1998; Wenger, McDermott, \& Snyder, 2002), and in a community of learners (Rogoff, 1998, 2003; Rogoff, Baker-Sennett, Lacasa, \& Goldsmith, 1995; Rogoff, Matusov, \& White, 1996; Rogoff, Mistry, Göncu, \& Mosier, 1993) informed the design of the study. Children's participation in cultural processes is transformed as a result of interactions with more experienced peers. Both in communities of learners and in communities of practice, learning and development are socially mediated (Rogoff, 2003; Vygotsky, 1978). As will be explained in more detail later in the thesis, ecological theory (Bronfenbrenner, 1979, 2005a, 2005c; Bronfenbrenner \& Morris, 1998) provided a framework to explain immediate and remote impacts on the participants' perceptions of rights (see Chapter 4). In this thesis, using current theories of learning and development in conjunction with interpretations of children's rights aided perceptions of these rights in the case study settings.

Numerous definitions and theses of rights are used in law to interpret and apply UNCROC (Alston, 1994a; 1994b; Alston et al., 2005; Archard, 1993; Cairns, 2001; Eekelaar, 1992; Haar, 2004). Models evaluating children's participation (see Hart, 1992, 1997; Lundy, 2007; Shier, 2001) focus on context, and could potentially be used to evaluate children's authentic participation in meaningful experiences. Theoretically, these foci (participation and meaningful experience) align with sociocultural historical theories and ecological theories (Bronfenbrenner, 2005a; Rogoff, 2003; Vygotsky, 1978; Wertsch, 1985). 
These models also introduce the idea of creating space, time, and opportunities to listen to the child's voice (Carr, 2001; Lundy, 2007), and align with childhood sociology (James et al., 1998), and with childhood studies (Kehily, 2004; Woodhead, 2004). Current perceptions are that childhood is socially constructed, and that children actively construct, and contribute to, their experiences of childhood. As a result of the opening of space for children to construct their own childhood, it becomes necessary to recognise that there is not one universal childhood, which is experienced by all children. Rather, there are many childhoods (James \& Prout, 1997). Recognition by some scholars that perceptions of childhood can be diverse, led to debates about cultural relativism, or the idea that a diversity of cultural practices was the norm and necessary. Discussions of cultural relativism dominated the early discussions about implementing UNCROC.

The cultural relativism debates (Alston, 1994b) experienced at a global level are reflected at the local level (Freeman, Henderson, \& Kettle, 1999). In this study, it was reasonable to expect diverse perceptions of children's rights because the investigation took place in three different contexts. Woodhead's (1997, p. 79) notion of "practice according to context of early development" (PACED) assumes that children's rights underpin practice. PACED potentially creates opportunities for using children's rights to evaluate how these practices (in context) support early development. In this research, the three different types of early childhood services investigated the notion of perception according to context, but in relation to a universally accepted human rights treaty: UNCROC.

The binding factor between these different disciplines and theoretical perspectives is a view that children's participation is critical to development. Education has a role to transmit culture, and cultural processes are both transforming and transformative. Children's participation in cultural processes is a right (Articles 12 and 13; CRIN, 2007 , p. 5). The extent to which that happens depends on how adults share power with children, a childhood sociology issue, that integrates sociology with children's rights. 


\subsection{Building a case for the research}

Although there has been an increasing interest in children's rights in New Zealand (Carr, 2001; May, 2001, 2004; Smith, 2000, 2002, 2003; Te One, 2004, 2006, 2007), there is very little specific research into young children's perceptions of their rights in education settings (Casas et al., 2006; Freeman, 2007; Thomas, 2007). While some research investigating children's rights has sought children's perceptions (Alderson et al., 2005; Casas et al., 2006; Clark \& Moss, 2001; Einarsdottir, 2005; Flewitt, 2005; Hviid, 2004; Lofdahl \& Hagglund, 2007; Melton \& Limber, 1992; Sheridan \& Pramling Samuelsson, 2001), Casas et al. (2006, p. 54) conclude that there is "the need to continue this line of research, in which we seek the perspectives of children, their parents and teachers on children's rights".

In terms of this study, investigating perceptions of children's rights could well provide the early childhood sector with useful background information about how to support and promote children's rights in early childhood settings. There is a growing demand for shared care arrangements, particularly for under-two-year-olds (see Figure 1). Research clearly demonstrates that early childhood services of good quality benefit children, but poor-quality early education may be damaging (Ministry of Education, 2007b; Podmore et al., 2000; Smith, 1996). Smith (1996) noted that poor conditions for teachers often resulted in less empathetic interactions with children. This implies that to uphold children's rights in early education, conditions of service for teachers make a difference. Poor conditions result in less beneficial outcomes for children, but the converse is also true - good conditions of service, including training, impact positively on children's lives.

Finally, there is an expectation that early childhood education will remedy in part some of the social ills caused by poverty and abuse (Child Poverty Action Group, 2003; Connolly \& Doolan, 2007; Duncanson, 2006; St John \& Wynd, 2008). Theories about child development and learning, both psychological and sociocultural, emphasise the importance of relationships, and children's rights to loving, caring relationships in all settings they participate in (Dalli, 2006; Te One, 2006).

As part of investigating perceptions of children's rights, this study was designed to add to a growing platform of participatory research with children about childhood and children's rights (see, for example, Christensen, 2004; Christensen \& James, 
2000; Einarsdottir, 2005; Flewitt, 2005; Lindahl, 2005; Lofdahl \& Hagglund, 2007; Sheridan \& Pramling Samuelsson, 2001). Participation is a fundamental right for children - it is through actively participating that children's experiences transform in ways that are meaningful to the individual child, and to the group, or community they belong to/participate in. Kirby and Gibbs (2006, p. 209) commented:

Much literature on children's participation explores methods of engaging children in making decisions and stresses the importance of developing positive relationships between children and adults: far less is written on how to facilitate children's participation and what support roles adults must offer to establish caring supportive relationships.

Research that links structural quality indicators to process quality indicators (Meade \& Podmore, 2002; Podmore et al., 2000; Smith, 1993, 1996) helps shift the focus from merely attending an early childhood centre, to assessing the quality of the experience for children while they are in the centre (Carr, 2000, 2001; Podmore et al., 2001). While there is a growing body of descriptive, experiential New Zealandbased research focused on children's experiences in early childhood settings (see Alcock, 2005; Brennan, 2005; Hedges, 2007), none specifically investigates perceptions of children's rights, nor UNCROC, which is, arguably, a foundational starting point for consideration of children's rights. This thesis begins by identifying gaps in the research and literature to contribute in several ways:

1. it inquires, explores, discusses, and investigates current constructions of children's rights, nationally and internationally;

2. it positions the debates about children's rights in the New Zealand early childhood context; and

3. it combines theories of human development and learning (sociocultural and ecological theories) with childhood sociology, and rights-based constructs to analyse participants' perceptions of children's rights.

\subsection{The research questions}

The research questions were sparked by an interest in perceptions of children's rights while children were in early childhood settings in New Zealand. How did teachers and parents in teacher-led, and family/whānau-led early childhood services perceive children's rights in the context of an early childhood setting? Did they have a list? What informed their ideas? Were they locally derived, nationally required, or based 
on international covenants? This study also canvassed young children's perceptions of their rights as they went about their daily business in early childhood settings. How did they understand their rights, if at all, and what did it mean for them in the early childhood settings in which they participated? Two questions guided the research:

How do children, teachers, and adults ${ }^{6}$ in whānau/parent-led centres, perceive children's rights in early childhood settings?

How are children's rights enacted or implemented in early childhood settings?

Further questions to guide this line of inquiry included:

What influences children's understandings and experiences of their rights?

How do children learn about rights in the early childhood centre?

To answer the research questions, the research design interweaves human development theories (see Bronfenbrenner, 1979; Rogoff, 1990, 2003; Vygotsky, 1978; Wertsch, 1985), interpretations of rights applied to UNCROC (for example Alston, 1994b; Archard, 1993; Hart, 1992, 1997; Lundy, 2007; Shier, 2001; Thomas, 2007), and childhood sociology (notably James, 2004; James \& Prout, 1997; James et al., 1998; Jenks, 1996; Prout \& Hallett, 2003; Prout \& James, 1990; Pufall \& Unsworth, 2004; Waksler, 1991; Wyness, 2006). The research combined sociocultural concepts of participation (Rogoff et al., 1995; Rogoff et al., 1996; Rogoff et al., 1993; Wenger, 1998; Wenger et al., 2002) and UNCROC, in particular Article 12 (CRIN, 2007, p. 5) which establishes the right of the child to participate in decisions that affect him or her. Theoretically, the common strand is a perception of the child as capable and competent. In other words, the child has agency and actively constructs his or her experiences (Pufall \& Unsworth, 2004). Early childhood education potentially enhances children's development by transforming participation within a community of learners, which, in turn, is part of a wider participatory democracy. This is expressed as a right in Articles 28 and 29 (CRIN, 2007, pp. 12, 13) and in General Comment 7 (UN Committee, 2005) on early childhood education. The combination of different theories of human development with UNCROC, childhood sociology, and the study of

6 'Adults' in this context refers to those who hold a position of responsibility in a whānau/parent-led setting. 
childhood are used in this thesis to investigate the participants' perceptions of children's rights in the three New Zealand early childhood centre case studies.

The research took place in three different early childhood education services in New Zealand: a community-based not-for-profit all day care and education centre for under-two-year-olds (the Crèche); a state-funded sessional kindergarten (the Kindergarten) for three- and four-year-olds; and, a parent/whānau-led, sessional, mixed-age playcentre (the Playcentre) for children from birth to six-years-old. Based on an investigative, ethnographic case study approach, and committed to participatory research methods, six months were spent gathering data during 2005. Approximately one month was spent in each setting. During that time multiple sources of data were gathered to build a picture of the participants' perceptions of children's rights in the early childhood settings studied. These data included observations, individual interviews, focus group interviews, photographs, and a researcher journal.

\section{Locating the researcher in the research}

Because ethnographers record/observe the multiple perspectives of participants' social realities, ethnographic approaches demand "that the author's perspective be specified" (Altheide \& Johnson, 1994, p. 490). Altheide and Johnson (1994) question the role of the researcher, first as an argument to support qualitative research, and second, to establish a sense of shared meaning between the researcher, the researched, and the process that led to findings: "How should interpretive methodologies be judged by the readers who share the perspective that how knowledge is acquired, organised, and interpreted is relevant to what the claims are?" (Altheide \& Johnson, 1994, p. 485). In other words, an expectation of the research process assumes a relationship between the researcher and participants, and readers of the research.

The researcher becomes the central protagonist in the process by acknowledging "the social world as an interpreted world, not a literal one" (Altheide \& Johnson, 1994, p. 486). Consequently, to establish robustness and rigour, the research processes, including the write up, require the researcher to establish some 'working boundaries'. Participatory research methods (Christensen, 2004; Christensen \& James, 2000; Clark \& Moss, 2001; Corsaro \& Molinari, 2000) are consistent with an ethic of 
reciprocal, respectful relationships. Questions like "What are you doing here?" and "Why are you here?" deserve honest answers. Respect for children, and children's rights are fundamental to any research process (Alderson, 2004; Cullen, Hedges, \& Bone, 2005). Locating the researcher in the research is a duty of ethical relationships necessary in interpretive, qualitative research (see Cullen et al., 2005).

My interest in children's rights began as a teenager when my father encouraged me to read A. S. Neill's work (Neill, 1968). Listening to children, taking them seriously, and empowering them were added to my emerging philosophy of teaching. When I first began teaching in early childhood in the late 1970s, the focus was not on children's perspectives, but was influenced by developmental psychology. Curriculum debates concerned tabletop activities. It was not until the early 1990s that ideas about children's rights, beyond their rights to education, reified in Te Whäriki (Ministry of Education, 1993, 1996b; Te One, 2003). As a member of the national advisory group to the Ministry of Education, I encountered others who obviously had the same interests in children's rights, not just in early childhood environments, but in society as well.

While Te Whāriki (Ministry of Education, 1993) was being written, I was part of a group establishing a kōhanga reo, and a Māori immersion unit in a mainstream primary school. My interest in rights moved from the professional to the personal as our family and other whānau in our community struggled at every level for support for our children's right to be educated in Māori, within their own community.

When completing my master's thesis, I was employed as a lecturer/researcher in a university. The combined experience of research and teaching provided the impetus to explore children's rights in more depth. I was concerned that the rhetoric of rights did not match the reality. Carmen Dalli and I (Dalli \& Te One, 2002) noted that children and their rights are particularly vulnerable to change - personal, social, and economic. A purpose of this research is to promote awareness of children's rights, of children as active agents, able to contribute and participate within families, and certainly within early education settings.

My experiences in a diverse range of settings, both professional and personal, introduced me to an equally diverse range of opinions, particularly about children and their rights to participate in decisions that affected them. 


\section{Establishing the boundaries}

It is important to set the boundaries for the study at the outset. The purpose of this research was to understand children's, parents', and teachers' perceptions of children's rights and was confined to three discrete, mainstream New Zealand early childhood settings. A case study approach allowed for in-depth observation, meaning that the findings remain unique to the particular cases. Generalised extrapolation of the data was not intended. The nature of the New Zealand early childhood scene is too diverse for such assumptions. Coherence between the case studies was established through a common theoretical approach to analysis.

The findings chapters of this thesis document the settings in which the three case studies were undertaken. The intention was not to compare the case studies with each other. Hence, the findings remain specific to the individual case studies and cannot be interpreted comparatively; neither can the case studies be held up as representative of a particular service. The scope of the thesis was too small to generate comparative data. Acknowledging this limitation binds the cases (Stake, 2005). So, while the findings may be limited to a particular case, the theoretical implications could have a wider applicability. Limitations of the research method, and the theoretical approach, are discussed more fully in Chapter 5.

\subsection{The structure of the thesis}

The next three chapters explore an abundant literature and research base which advocates for, explains, and interprets children's rights. Nevertheless, there exists an acknowledged research gap investigating perceptions of children's rights in early childhood, internationally and within New Zealand, despite a proliferation of national and international researchers in early childhood in the twenty-first century.

Chapter 2 focuses on the history of UNCROC and examines arguments for and against rights for children. Three well-known categories of rights (protection rights, provision rights, and participation rights) are discussed and conceptualised again as a plait. This construct assisted the researcher to investigate how particular types of rights are interwoven, interrelated, and interdependent. As a concept, the notion of a plait symbolised an holistic approach to the research, which sat comfortably with the principles of Te Whāriki (Ministry of Education, 1996b). Chapter 3 discusses various 
interpretations of rights, and models for evaluating how effectively children's participation rights in projects, or in education, are implemented. As well, this chapter draws on the literature from the relatively new disciplines of childhood studies and childhood sociology. The chapter ends by illustrating how this literature contributed two strands of a three-strand plait to form the theoretical metaphor for the research.

Chapter 4 introduces sociocultural historical theories and ecological theory as the third strand of the plait (see Figure 2) used in the research design and as an interpretative device. The common thread connecting the different theories is the importance of participation to children's development and learning. All three categories of children's rights (participation rights, protection rights, and provision rights) are discussed in relation to the theories. The combined theoretical approach to research design is new, and marks a contribution to the field.

The method, ethical processes, data collection, and analysis tools are described in Chapter 5. The early childhood centres are introduced in more depth, and the characteristics of the participants described. Chapters 6,7 , and 8 form the threestrand argument based on the three different categories of rights described in Chapter 2. The common thread underpinning the data chapters is how children's participation in the early childhood settings was influenced by perceptions of their rights. The two central arguments are first, that perceptions of rights are influenced by the early childhood context, and, context also influences how rights are enacted. Second, each case study foregrounds one of the three categories of rights to illustrate how particular contexts influence perceptions of rights, as well as the ways in which they are implemented. Each case study also demonstrates how the categories of rights are interwoven, interrelated, and interdependent.

In Chapter 6, The Crèche: Advocates for infants, the data focus on protection rights for children. Teachers in the Crèche perceived tensions between needs and rights. The chapter also explores how children's participation at the Crèche was influenced by teachers' perceptions of protection rights as both protecting children, and protecting children's rights.

Chapter 7, Providing for Free play at Playcentre, examines data about perceptions of children and childhood from the parents' and children's perspectives. At the 
Playcentre, the lines between community of learners in the setting, and the wider community are blurred. Children and adults alike were influenced through their participation in the Playcentre's early childhood approach.

Finally, data presented in Chapter 8, It's the culture of the place. Promoting participation in a community of learners, concentrate on the Kindergarten setting's conditions for learning and teaching. Teachers perceived that the combination of sessional care, trained teachers, and plentiful resources supported participation rights for children. Based on building a strong sense of belonging to a peer group allowed children to explore what rights meant without actually using the word 'rights'.

Chapter 9, Children's rights are interwoven, interrelated, and interdependent, concludes the thesis and summarises the main themes. First, perceptions of rights are influenced by the early childhood setting, or context; second, enacting rights depends on how participants in particular contexts interpret and implement children's rights; and third, children's rights are interdependent and interrelated with one another. While a certain type of rights might be foregrounded, other rights are critical supports forming the strands essential to a rights-based pedagogical approach. Mitigating factors in the centres are discussed in general terms only because the findings of the case study remain unique to each setting. Highlighting facilitative strategies supporting children's rights as well as the constraints experienced by the participants in the individual early childhood settings contributes to the expanding research interest in the topic. The thesis ends with suggestions for further research into this contested field.

\subsection{Chapter summary}

Chapter 1 has introduced the nature and scope of the research. The study contributes to the academic field by combining several current theories and concepts about child development and the sociology of childhood in a new way that links perceptions of rights to participation in early childhood settings. It does this by drawing connections between current theoretical ideas about children's development, the sociology of childhood, and issues contested in UNCROC, particularly Article 12 (CRIN, 2007, p. 5), which is concerned with participation rights of children. The following two chapters discuss the literature underpinning the research. 


\section{Chapter 2:}

\section{The United Nations Convention on the Rights of the Child}

\subsection{Introduction}

The most significant document in the international children's rights landscape is UNCROC. This chapter describes the historical background to UNCROC, UNCROC itself, and measures used to evaluate how UNCROC is implemented. New Zealand's responses to the UN Committee are discussed generally and in relation to early childhood education. Examples of recent New Zealand early childhood policy are introduced to illustrate the three categories of rights in UNCROC: participation rights, provision rights, and protection rights. The chapter concludes by stating that the three categories of rights can be identified as discrete but that integrated implementation of children's rights is the desired outcome.

Despite the existence of a Convention, there is no universal agreement, about childhood, or children's rights, and there never has been. Bentley (2005, p. 107) asked, “... if childhood is not universally understood, then can there be universal children's rights?" While articles of UNCROC are agreed, there is ongoing debate concerning how UNCROC is implemented in different countries. UNCROC was the starting point for this thesis because it is an internationally recognised benchmark for children's rights.

\subsection{Historical background to UNCROC}

\section{Phase 1: Making children visible}

Alston et al. (2005) describe the historical background to UNCROC in five phases (Figure 3).

\begin{tabular}{lll}
\hline Phase One: & $1901-1947$ & Making children visible \\
Phase Two: & $1948-1977$ & Human rights are children's rights \\
Phase Three: & $1978-1989$ & The child's rights movement \\
Phase Four: & $1989-2000$ & UNCROC \\
Phase Five: & $2000-2006$ & From rhetoric to reality \\
\hline
\end{tabular}

Figure 3: Phases of rights: Adapted from Alston et al. (2005) 
The first phase in the children's rights movement (1901-1947) concentrated on making the plight of the child visible, and had a focus on child labour and sexual exploitation. Post World War One, the Declaration of the Rights of the Child, 1924, was developed by the League of Nations and became the first attempt at an internationally agreed treaty (The New Era in Home and School, 1943). It was motivated by a heightened awareness of the plight of war orphans, as well as by a commitment to social democratic principles. During World War Two the extent of man's inhumanity to man fuelled the momentum to "lay the foundations of a better world on which our young people can build" (The New Era in Home and School, 1943, p. 37). This resulted in a children's charter memorandum that envisaged a "good educational system" as the vehicle for "turning out good citizens", to act as "warriors in the interests of humanity" (pp. 37, 38). Phase 1 was characterised by an underlying humanitarianism that established an international movement on children's rights with long-lasting influences. It raised awareness of the state of children, as opposed to their status, and of powerful political ideas that supported not just nationhood, but also the notion of the "brotherhood of man" (The New Era in Home and School, 1943).

\section{Phase 2: Human rights are children's rights}

The predominantly welfarist perspective at the international level continued through to a second phase (the 1940s and 1950s) with a focus on human rights, including children's rights. Both the 1949 Geneva Convention and the 1959 Declaration of the Rights of the Child (Human Rights Commission, 1959) highlighted provisions relating to children in existing Human Rights Conventions. Based on the principle that "mankind owes to the child the best it has to give" (Preamble to the Declaration of the Rights of the Child, 1959), the 1959 Declaration recognised childhood as a special period of life, and that children needed protection. This focus emphasised the relationship between a child's rights and man's duties. The 1959 Declaration was an international move to create a morally binding document. It was ground-breaking in its use of the term 'children's rights' and for its emphasis on children's emotional wellbeing and their entitlement to emergency assistance - a response to the longterm, disruptive, and disturbing aftermath of World War Two (Alston et al., 2005).

However, the focus on protection also emphasised a view of the child as in need of protection within society, rather than entitled to significant changes that established 
children's rights to civil and political entitlements. The underlying discourse was criticised for being paternalistic protectionism:

While stressing protection and the provision of medical care and so on, the Declaration nevertheless deprived children of the right to work, of the right to live away from home, and of the right to refuse an education. It was not a document aimed at increasing the autonomy of children, but at protecting them. (Coady, 1996, p. 12)

Coady's (1996) critique is echoed by Bentley (2005). It remains a complex argument because of a predominantly Western construct of childhood as a time of innocence, vulnerability, and powerlessness (Bentley, 2005; Dunne, 2006). Alston et al. (2005) commented that the international focus on welfare "effectively excluded any particular significance being attributed to the concept of children's rights" (p. 6). Confirming this powerful assertion was the fact that children still remained "almost inexorably linked" (Alston et al., 2005, p. 6) to their mothers in particular, and to women in general (May, 2001).

Characterising this phase were views of the child as vulnerable and in need of protection. The role of the adult and nation states was cast as the parent who knows best, and that their duties were morally, as opposed to legally, binding except in extreme circumstances.

\section{Phase 3: The child's rights movement (1978-1989)}

It was during the 1970s that the present UNCROC emerged, and an awareness of rights as participatory gained leverage alongside rights to welfare and protection. This has in part been attributed to a growth in non-governmental organisations (NGOs) lobbying for children's rights independently of internationally recognised organisations, but the major reasons for this can be traced back to the civil rights movements and the growth of feminism (Dunne, 2006; Farson, 1974; Holt, 1975; John, 1996, 2003b; Mayall, 2000a, 2003, 1994). A view of childhood as an oppressed, marginalised social class (Oldman, 1994) was part of the children's liberation movement, and challenged the status quo, particularly institutionalised power structures. Educationalists advocated for children's rights to be recognised as equal in status to adults' rights, which would alter the status of children. Commenting on the child liberationists, Archard (1993, p. 45) noted: 
were specifically represented as one of the major oppressed groups in Western society, alongside blacks, women and the proletariat.

Underpinning the child liberationist movement was a belief in children as equally entitled to participate in society. To exercise their rights was not a question of competence so much as one of choice. It is a complex argument that raises several questions: Should children be recognised as a distinct group? If children do not exercise their choices, is it because they are too young to understand? (this is a question surrounding their competence), and, if that is the presumption, do they have rights? However, "an interest in exercising a right does not coincide with a competence to exercise it" (Archard, 1993, p. 50).

Those arguing against child liberationists reinforced the idea of the child as incompetent, in need of care and protection, and not yet mature enough to make responsible decisions in his or her best interests, let alone formulate a viewpoint. Known as the 'caretaker thesis', proponents argue that not only should "caretakers ... choose for their children. It suggests how they should choose ... (but) in the last analysis, is unclear how much should be denied [to the child] and what precise ends are served by the denial" (Archard, 1993, pp. 50, 57).

Entangled in the different perspectives are views of children, and of childhood. Both the child liberationists and the proponents of the caretaker thesis acknowledge the emergence of childhood as an historical construct; both acknowledge the emergence of the child as a 'psychological being', and both acknowledge the different political imperatives of Western education systems. Both perspectives accept children have rights, however, the 'caretakers' and the 'liberationists' represent two distinctly different approaches to rights and to childhood - one has child welfare being the responsibility of adults, and the other takes the view of the child as an active political being.

\section{Phase 4: UNCROC 1989-2000}

Elevating children's rights from declaration status to convention status was first proposed by Poland in 1979, the international year of the child. Negotiations took over 10 years before agreement was reached. Initially, arguments about the principle of acting in the child's best interests dominated the early formulation of UNCROC. Despite the trend in international human rights laws and declarations that supported the notion of best interests of the child, there was still confusion about what this 
meant: Is the child an object or a subject? To act in the best interests of a child could be reinterpreted and applied according to context.

A difference between the 1959 Declaration and UNCROC was the 'best interests' principle. There was a discernible shift from protecting children to protecting children's rights (Freeman, 1998). Debates about cultural relativism were a focus of Western intellectual critique of the 'best interests' principle:

While the significance of national and regional particularities and various
historical, cultural and religious backgrounds must be borne in mind, it is the
duty of States, regardless of their political, economic and cultural systems, to
protect all human rights and fundamental freedoms. (Alston, 1994a, p. 9)

These arguments tended to detract from the purpose of the human rights treaties, which assert respect for all cultures, but not if cultural practices breach human rights (Freeman, 2002):

The Cold War (1945-1989) suppressed "the debate over cultural relativism in favour of an ideologically dominated East-West dispute over whether civil and political rights should be accorded priority over economic, social and cultural rights or viceversa" (Alston, 1994a, p. 6). Intense political battles ensued over who would seize the initiative to move negotiations forward. The Communist regime was keen to promote the social and cultural rights of children to dispel international criticism of the Eastern bloc's poor human rights record. The USA, in reaction to Poland's initiative, argued that civil and political rights were paramount, and deliberately delayed progress towards a unified document.

In a move that generated widespread support, UNICEF assumed a role, and began to encourage and facilitate "more active participation of more developing countries in the drafting process" (Alston, 1994a, p. 7). This added momentum to the negotiations. The deliberate delaying tactics of the USA and the new aspirations of the Communist bloc cancelled each other out. Changes to economic and social rights were accepted, and the approach to cultural rights, "while no means perfect, [was] more sensitive to different cultural perspectives than most of the principal human rights treaties adopted earlier" (Alston, 1994a, p. 7). 
UNCROC broke new ground by providing independent rights for children. Made up of 54 Articles which establish universal standards as basic benchmarks for measuring states parties' compliance, it has four major emphases:

- The consideration of the child's best interests

- The child's right to parental care

- The child's evolving capabilities

- The child's right to be consulted (Ritchie \& Ritchie, 1997).

UNCROC was finally agreed to in 1989 after 10 years of debate, and quickly became the most ratified human rights treaty. Alston et al. $(2005$, p. 2$)$ describe it as:

... the first virtually universal human rights convention, it is the most farreaching, the most forward looking, the most comprehensive, it is the embodiment of a whole new vision for children, a definitive turning point in the struggle to achieve justice for children, and a document with an unprecedented potential to bring about dramatic change.

Alston et al. (2005) also noted that this almost euphoric attestation was not without paradox - the abuse and exploitation of children is horrific, and despite international condemnation, these breaches of children's rights continue unabated. Kofi Annan (2002) reported:

The idea of children's rights then may be a beacon guiding the way to the future but it is also illuminating how many adults neglect their responsibilities towards children and how children are too often the victims of the ugliest and most shameful human activities. (Cited in Alston et al., 2005, p. 2)

UNCROC articulates a universal political commitment to the protection of children by defining the rights of children. These rights are inalienable, indivisible, and interrelated (see UN Committee, 2005). States parties are responsible for providing for these rights. UNCROC is binding on all those who sign and ratify it. The UN Committee examines reports from each of the states parties. These reports are submitted every five years.

UNCROC outlines minimum standards in the areas of health, welfare, and education. States parties are expected to bring domestic laws, policies, and practices in line with these standards and principles of UNCROC. As well, UNCROC provides an ethical framework for what nations shall and shall not do. As a state party, New Zealand is expected to promulgate and discuss the rights of children vis-à-vis other rights as 
defined in similar statements; for example, other international human rights treaties and conventions as well as New Zealand's own Bill of Rights.

Coady (1996, p. 13) noted, "While protection of the child is still a major focus in UNCROC, there is increased acknowledgement of the child as a competent decisionmaker on matters that concern the child's future." UNCROC changed perceptions of "the child from subject of policies directed towards his or her active wellbeing, development and protection, to the child as an active participant in constructing those goals and the means of achieving them" (Funder, 1996, p. 2).

\section{Phase 5: From rhetoric to reality}

Politicians eager to be seen as child-friendly have often paid lip service to the wellbeing of children. But at the end of the day children have usually been let down. In the power game other interests have been stronger. Children have always been, and still are, the victims of hypocrisy. (Hammarberg, cited in Ludbrook, 2000, p. 109)

This final phase of children's rights concerns accountability and implementation (Alston et al., 2005). This is proving to be more and more difficult. The nature of global economies, modern telecommunication technologies, and moves to decentralise governmental bureaucracies mean that the influence, the implicit moral responsibilities and duties, and the more explicit legal obligations of the international convention, are compromised. The interests of a global business company are not necessarily the same as a national interest, not to mention the responsibilities to shareholders' interests. The role of NGOs has changed. Initially they acted as independent critical commentators, offering a less sanitised view of states parties' compliance with UNCROC. Although these NGOs represented particular interests, they recognised the forums created by UNCROC in politically savvy ways to alert and focus international attention on areas of concern. The difference between NGOs (for example, Child Poverty Action Group, and ACYA) and the newer global interests is that previously there was a moral obligation, conducted in the spirit of international fellowship - i.e., one that assumed a common understanding of the rhetoric that aspired to a socially just and fair world for children.

The dramatic increase in global economies does not necessarily ascribe to the same moral code that existed during the formulation of UNCROC (Belgrave et al., 2002; Blaiklock, 1999; St John \& Wynd, 2008; UNICEF, 2005, 2006). This created a 
tension between international bodies and independent ones. Morally, the intention of UNCROC is regarded as binding - it is an 'aspired to' position. However, because the global market is dominated by largely private international corporate interests, the political obligations are harder to assess because there are no longer discrete national borders to bound accountability. This is a very real threat to the status and influence of all human rights treaties, not just UNCROC.

\section{Implementation procedures}

Article 44 (CRIN, 2007, p. 19) outlines states parties' obligations to the UN Committee. Every five years, the UN Committee undertakes a periodic review of the states parties. Periodic reviews detail how UNCROC has been implemented in the five years since the last report. The first stage of this process requires the state party to submit a government report. The UN Committee also receives NGOs' reports. As well as written reports from state parties, the UN Committee hears from the government and from NGOs in person. The next stage of the process requires the UN Committee to submit a report to the state party. These usually include detailed responses and recommendations. As an interim evaluation tool, the UN Committee introduced universal periodic reviews. These reports are short documents (limited to 21 pages) submitted to the UN Committee which then allocate three country representatives to comment on the issues raised. Once again, the government is obligated to submit a report, and NGOs are entitled to submit their own reports.

UNCROC recognises "the importance of the traditions and cultural values of each people for the protection and harmonious development of the child" but also emphasises "the vital role of international cooperation in securing children's rights" (CRIN, 2007, p. 1). Despite Freeman's (2002) desire to expunge arguments about cultural relativism (Alston, 1994b; Archard, 1993), cultural differences continue to affect how rights are implemented nationally and locally. In the process of globalising children's rights, the tensions associated with interpreting and implementing UNCROC cannot be underestimated.

\section{General Comments to guide implementation}

Periodically, the UN Committee releases General Comments. A General Comment offers guidance on how to interpret UNCROC at the implementation level. Most advocacy work using UNCROC has been with older children, and this has increased 
their visibility and status. Recognition and understanding of rights for children under five have not been achieved to the same extent (Lansdown, 2005), but advocacy by many professionals has resulted in a shift from promoting children's development to respecting children's rights "to be involved in decisions that affect their lives" (Lansdown, 2005, p. v). General Comment 7 (UN Committee, 2005, Section I) is specifically directed to early childhood (birth to eightyears old) in "recognition ... that young children are holders of all rights enshrined in UNCROC and that early childhood is a critical period for the realization of these rights". General Comment 7 noted that: “[r]espect for the young child's agency is frequently overlooked or rejected as inappropriate on the grounds of age and immaturity. ... They have been powerless within their families, and often voiceless and invisible within society" (UN Committee, 2005, Section 11). Additionally the General Comment emphasised that: "Article 12 applies both to younger and to older children. As holders of rights, even the youngest children are entitled to express their views" (2005, Section 11).

Additionally, General Comment 7 suggested that children's rights to participate are nested within the principle of best interests - a principle given primacy in UNCROC. The developmentally appropriate focus (Bentley, 2005; John, 2003b; Mayall, 2000a) in UNCROC is tempered somewhat by General Comment 7 because it considers children's social and cultural contexts. Very young children actively make sense of the world, shaped by the cultural beliefs and values of their families and communities; and through relationships with others. Their experiences as participants include care and education arrangements. Citing Articles 18, 28, and 29 (CRIN, 2007, pp. 7, 12, 13) General Comment 7 argues for states parties to support parents; to encourage child-centred practices that include participating in early education; and for early childhood professionals to develop partnerships with parents to realise the intent of the respective articles. Article 28 (1) establishes the right to education, progressively, and "on the basis of equal opportunity" (CRIN, 2007, p. 12) but Article 29 (a) entitles children to an education "directed to the development of the child's personality, talents and mental and physical abilities to their fullest potential" (CRIN, 2007, p. 13) that has direct relevance to the programmes offered in early childhood settings, and affords purchase for the sector to stake claim for children's rights to access affordable early education (Noonan, 2001, 2003; Veerman \& Levine, 2000; Verhellen, 2001). 


\subsection{Implementing UNCROC in New Zealand}

UNCROC was negotiated and agreed to at an international level, but the tensions associated with implementation at a local level cannot be underestimated. There is a danger in assuming that because the world embraced UNCROC so willingly, this equates with respect for children's rights. New Zealand is a case in point. It was the $131^{\text {st }}$ country to ratify UNCROC and made several reservations (see Tapp \& Henaghan, 2000 and Ludbrook, 2000, for accounts of the reservations and the responses to reports from the UN Committee). It is not the purpose of this review to detail these reports apart from noting that there is a difference between constitutional recognition of UNCROC, and a respect for children's rights. There exists a body of criticism directed at successive governments' inaction (ACYA, 2003, 2008; Belgrave et al., 2002; Child Poverty Action Group, 2003; Ludbrook, 2000). The next sections discuss the implementation process in New Zealand. This includes an overview of early childhood policies supportive of children's rights. The discussion begins with New Zealand's implementation process in general.

\section{Issues with implementation}

Implementing UNCROC has not been straightforward in New Zealand. It was one of the last countries to ratify UNCROC and, from the beginning, entered three reservations to full compliance with UNCROC. These were a reservation on age mixing in prisons and other places of confinement; a reservation on a minimum age for employment; and a reservation on children not lawfully in New Zealand. As well, children in Tokelau are not included in New Zealand's ratification of UNCROC (ACYA, 2003, 2008).

The UN Committee's responses to the New Zealand Government reports have consistently commented on the same issues. First, the slow progress towards ensuring legislation and policies comply with UNCROC. For example, the age of childhood differs between ministries and agencies of the Crown. Second, the lack of data gathered to evaluate the impact of social and economic changes on children. Since 2000, the UN Committee has recommended this research be undertaken. Similarly, despite recommendations advising New Zealand to consider children in the annual budget, this is not apparent. Again, since 2000, reports from the UN Committee have recommended that the reservations the New Zealand Governments have put in place be removed (UN Committee, 1995, 2000, 2003). 
In its latest report (New Zealand Government, 2008), submitted by the Labour-led coalition, New Zealand claimed to have been making progress towards removing the reservations. There has also been progress towards aligning legislation with UNCROC. For example, Section 59 of the Crimes Act, 1961 was repealed in 2008, removing a legal defence for adults to physically discipline children. This was highly controversial, and since the 2008 election, the newly elected National Government has promised a referendum about Section 59, a move which may further jeopardise compliance. Despite ongoing recommendations from the UN Committee to strengthen the Office for the Commissioner for Children, the new administration has signalled that the role of the Commissioner is under consideration, and may be merged with the Families Commission (Key, 2008). This could potentially represent a step backwards from a children's rights perspective, echoing a concern expressed by John (1996) that children are rendered powerless and invisible if they are only recognised as family members, and not as children in their own right.

Ludbrook (2000, p. 113) argued that the New Zealand response "smacks of cultural arrogance and misconceives the nature and purpose of [UNCROC] which is to encourage parties to set goals and make progress towards full implementation". Similarly, ACYA has consistently represented the NGOs' view that children's rights in New Zealand are not yet implemented effectively. In its most recent report, ACYA noted that there had been no substantive progress towards removing reservations, and cites evidence to suggest that action is now urgent (Action for Children and Youth Aotearoa, 2008).

\subsection{Interpreting UNCROC}

Theories about children's rights have not, according to Freeman (2007), had the attention they deserve. Research, such as this present study investigating perceptions of rights within an expanding early education sector, draws attention to various interpretations of rights that may contribute towards Freeman's desire for a coherent theory of rights. Before expanding further on matters concerning implementation, the next section explains the approach to interpreting children's rights used in this research. Interpretations of rights have been predicated on interests, on children's competence and capacity, and on protecting rights for the rights-holder in the future. 
Consequently, to implement UNCROC, and act in the best interests of the child, requires balancing of three potentially conflicting ideas:

The child's autonomy to express views and make decisions;

The family's responsibility to nurture and bring up children;

The state's responsibility to provide services which protect and enhance the lives of children. (Ritchie \& Ritchie, 1997, p. 151)

Each of these ideas raises important issues for understanding UNCROC, and for revealing the contradictory aspects to its implementation. They also offer an explanation for the way this thesis is organised. A fundamental difference between UNCROC and previous children's rights treaties is an acknowledgement of the child's autonomy, which can be explained as participation rights; families are responsible for protecting children and protecting children's rights - protection rights; and, finally, the state is responsible for ensuring that services to families and communities support them to participate in society, i.e., provision rights. All three types of rights are interdependent, interrelated, and interwoven.

Some rights can be viewed as 'freedom rights' and others can be regarded as 'welfare rights'. Freedom or liberty rights are the domain of the individual; welfare rights both protect children, and require others to provide the benefits to the right holder. According to Farson (1974), welfare rights protect children; whereas liberty rights, or participation rights, protect children's right to exercise their rights. Distinctions between the two kinds of rights are not entirely straightforward and can be complex, especially with regard to very young children. Welfare rights holders are not simply passive and dependent, and freedom rights holders are not always autonomous and in control "for just as one can claim and defend freedom rights, one can claim and vigilantly defend welfare rights" (Coady, 1996, p. 17).

Three categories of rights identified in UNCROC are widely used in the literature on children's rights (Alderson et al., 2005; Hammarberg, 1990; Lansdown, 1994; Stainton Rogers, 2004):

Provision rights - rights to minimum standards of family life and access to parental care, health, education social security, physical care, play, recreation, culture and leisure. 
Protection rights - including the right to be safe from discrimination, physical and sexual abuse, exploitation, substance abuse, injustice and conflict.

Participation rights - civil and political rights, such as the right to a name and an identity, to be consulted and to be taken into account, to physical integrity, to information, to freedom of speech and opinion and to challenge decisions made on their behalf. (Lansdown, 1994, p. 36)

Table 1 positions the categories of rights alongside the relevant articles of UNCROC. There is an overlap between the categories because to empower children to participate assumes a level of both protection and provision.

Table 1: Types of rights and UNCROC articles

\begin{tabular}{|c|c|c|c|c|c|}
\hline $\begin{array}{l}\text { Protection } \\
\text { rights }\end{array}$ & $\begin{array}{c}\text { Relevant } \\
\text { articles }\end{array}$ & $\begin{array}{l}\text { Provision } \\
\text { rights }\end{array}$ & $\begin{array}{c}\text { Relevant } \\
\text { articles }\end{array}$ & $\begin{array}{l}\text { Participation } \\
\text { rights }\end{array}$ & $\begin{array}{c}\text { Relevan } \\
\text { articles }\end{array}$ \\
\hline Discrimination & 2 & $\begin{array}{l}\text { Minimum } \\
\text { standards of } \\
\text { family life }\end{array}$ & 5,27 & $\begin{array}{l}\text { A name and an } \\
\text { identity }\end{array}$ & $7,8,30$ \\
\hline Best interests & 3 & $\begin{array}{l}\text { Physical care } \\
\text { and special } \\
\text { care }\end{array}$ & 6,23 & $\begin{array}{l}\text { Consulted and } \\
\text { to be taken into } \\
\text { account }\end{array}$ & 12 \\
\hline $\begin{array}{l}\text { Substance } \\
\text { Abuse }\end{array}$ & 33 & $\begin{array}{l}\text { Access to } \\
\text { parental care }\end{array}$ & 18 & $\begin{array}{l}\text { To form an } \\
\text { opinion }\end{array}$ & 12 \\
\hline $\begin{array}{l}\text { Physical and } \\
\text { sexual abuse }\end{array}$ & 19,34 & $\begin{array}{l}\text { Education and } \\
\text { health }\end{array}$ & 28,24 & $\begin{array}{l}\text { Physical } \\
\text { integrity and } \\
\text { privacy }\end{array}$ & 16 \\
\hline Exploitation & $32,35,36$ & Development & 29 & Information & 17 \\
\hline Injustice & 40 & Social security & 26 & $\begin{array}{l}\text { Freedom of } \\
\text { speech and to } \\
\text { challenge } \\
\text { decisions made } \\
\text { on their behalf }\end{array}$ & 13,14 \\
\hline Conflict & 38 & $\begin{array}{l}\text { Play, } \\
\text { recreation, } \\
\text { culture, and } \\
\text { leisure }\end{array}$ & 31 & & \\
\hline
\end{tabular}

A principle underpinning UNCROC is that rights are indivisible. In this thesis, the three categories of rights are envisaged as a plait to illustrate the interwoven, interrelated, and interdependent nature of rights (see Figure 4). 


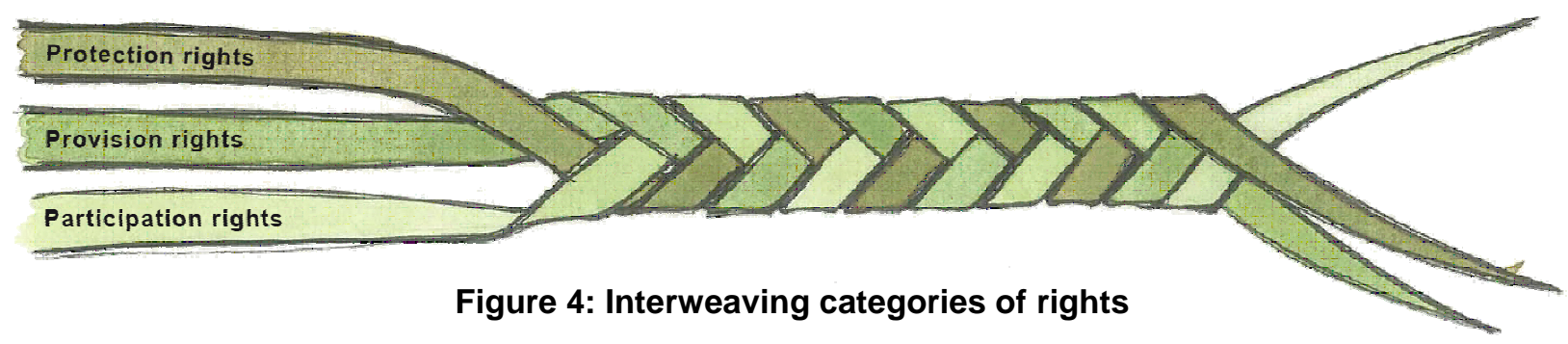

This plait is a potentially useful way to organise the findings and explore the data. While not a new idea to the field of children's rights, how they are applied to the research questions asked in this study is new. Also, it is important to recognise that categorising rights potentially limits their usefulness if the categories are rigidly applied. Some degree of overlap occurs and this is acknowledged throughout the Preamble with an emphasis on the role of the family as the "natural environment for growth and wellbeing of ... children" (CRIN, 2007, p. 1) which includes protecting them, protecting their rights, providing for their health, development, and education, and assisting them to assume "responsibilities within communities" (p. 1).

\section{Participation rights: The child's autonomy to express views and make decisions}

The idea of children's autonomy is expressed in Articles 12, 13, 14 and 15 (see CRIN, 2007, pp. 5-6) which "note that children have a right to express their views on matters that affect them, and that children have a right to assemble, raise questions and voice opinions (Articles, 13 and 15)" (Power, Power, Bredemeir, \& Sheilds, 2001, p. 98). The Preamble to UNCROC signals the importance of autonomy by stating that: "the child should be prepared to live an individual life in society" (CRIN, 2007, p. 2). Article 29 concerns the role of education in preparing children "for responsible life in a free society" which implies that education is an important provision right that supports children's autonomy (p. 13).

UNCROC "challenge(s) all those responsible for the education of children to think in new ways about how to prepare them for democratic citizenship" (Power et al., 2001, p. 98). However, adult and parental perceptions suggest that very young children are constrained by their lack of competence and experience in exercising choices; hence this is a particularly powerful argument confounding perceptions of children's rights in the early childhood sector. Nonetheless, "the fact that adults must exercise what has traditionally been called a paternalistic role over children does not imply that adults are free to ignore children's preferences and views" (Power et al., 2001, p. 99). 


\section{Protection rights: The family's responsibility to nurture and bring up children}

The Preamble to UNCROC acknowledges the role of the family "as the fundamental group of society and the natural environment for the growth and wellbeing of all its members and particularly children" (CRIN, 2007, p. 1):

State Parties shall respect the responsibilities, rights and duties of parents, or, where applicable, the members of the extended family or community.

(Parents, family) should provide, in a manner consistent with the child's evolving capabilities, appropriate direction and guidance in the exercise of the child's rights recognised in the present Convention. (CRIN, 2007, pp. 1-2)

The strongest criticism of UNCROC centres on the role of the family (see Guggenheim, 2005; Reid, 2006). UNCROC is regarded by some as undermining parental rights, an historical perception that derives from laws dating back to Roman times (Archard, 1993). Paternal authority was for centuries unquestioned and it determined how children were regarded. Recent critics claim UNCROC is fundamentally flawed as a rights-based document because it separates children's interests from their parents' interests (Guggenheim, 2005).

Debate about parental rights versus children's rights is particularly evident in the case of very young children who, because they are dependent on adults to fulfil their needs, are involved in "a series of interrelating power relationships that come into play in determining what is in the best interests ... of the child" (Haar, 2004, p. 16). This is complicated further by affective ties - the love that is assumed to exist between parent and child in a family. Arguments against rights state that family relationships and the affective bonds are paramount to rights and duties. But "love is not something which has its own rights and duties" (Archard, 1993, p. 90). Archard argues that children's rights are like an insurance policy that introduces principles of justice and circumstances of justice. He is not alone in acknowledging that relationships are not necessarily reciprocal: "a parent can care for a child, but it is not always obvious that a child can care for its parents" (p. 92).

The relationship between parent and child is a complex forum for discussing rights. Does being the biological parent give the rights over the child? The child did not enter a contract to be born into this or that particular family and so in this sense, the relationship is not consensual. Again, some distinguish between biological parenthood and moral parenthood - in most cases, moral parents will be biological 
parents, and in that sense, just being a parent does not automatically lead to the moral right to rear a child. It is based on "the widely held assumption that parents will always act with their child's best interests at heart" (Geddis, 1980, p. 50). Statements like this assume attachment and imply love. Archard (1993, p. 93) commented:

Parents cannot choose to love their child; they can choose to respect its rights. And that a child should have its rights respected when love fails is surely no bad thing; ... But relying on love alone to secure the wellbeing of children shows a misguided and perilous optimism. It surrenders the child to the embrace of an intimate union without any assurance of minimum protection should the union fall short of its ideal.

Family and the role of parents especially are safeguarded in UNCROC. If anything, the concern should be not diminished parental authority but increased societal responsibility, an argument Guggenheim (2005) and Reid (2006) pursue. States parties should take into consideration both the parental role, as well as the community role. Within that community, what factions might contest interpretations of children's rights?

An increased incidence of reported domestic violence has altered the "perception of the family as a place of quiet sanctity" (Franklin, 1995, p. 4). The family has become a site of contestation for rights "by a reluctant acknowledgement that children's interests and rights could not be presumed to be identical with those of their parents: indeed children's and parents' rights might be antipathetic" (Franklin, 1995, p. 4). The blood bond is regarded as inviolate "as if somehow the conceiving and bearing of a child gives parents the overwhelming right to that child, almost regardless of their behaviour towards that child ... [t] hus do tradition and the prevalence of myths ensure the supremacy of parental authority" (Geddis, 1980, pp. $50-51)$.

\section{Provision rights: The state's responsibility to provide services which protect and enhance the lives of children}

It may be important for a child to know that it does rightfully belong to a public realm with its rules, rights and duties, and not just a member of a private, if loving community. (Archard, 1993, p. 93)

Provision rights articulate children's rights, as members of society, to receive care appropriate to their emerging capacities. Provision rights also obligate others to 
provide care. In other words, children are dependent on others for care. Article 18 (CRIN, 2007, p. 7) acknowledges parents as primary caregivers and at the same time obligates states parties to support parents or caregivers by providing appropriate childcare services. Funder (1996) argues that the notion of dependency assumes 'caring'. Children's rights challenge the assumption that children are neatly dependent and subordinate to authority. Recognition of the dualistic nature of provision rights is required in a strong civil society. Ideally, the bonds created by the need to provide and accept care are, in a sense, individual bonds, but viewed as a whole create a sense of social cohesion. Legislation can never "do the fine work that is the hallmark of a civilised society" (Funder, 1996, p. 10).

Intrinsic to the working of a civilised society is the role that parents have in raising children within secure, functional family units. Parents' rights can be interpreted as looking after the rights of the child. In this sense it is more of a duty than a right. In other words, parents have the right/power to make decisions in the best interests of the child who is not yet able to make those decisions. However, should that power be abused in a way that harms the child, parental rights are forfeited (Coady, 1996, p. 22).

This raises some questions about the role of the state. Is it the 'super parent'? How and when should it intervene in the family? Legislation protects the privacy and integrity of the family, and the child's right to autonomous parents. But, because laws and policies also regulate and define 'family', the family is not only a private concern, but also a public one. When injustices that put the child at risk occur within the family, public intervention is legitimate. The state acts in the best interests of the child to both protect and provide for his or her rights. Establishing a public interest is also where the jurisdiction of the courts establishes precedents that serve to define children's rights.

By contrast, many assume that the private sphere of the family is bound together not by concerns of justice and contract, but by natural ties of affection: Relegating women and children "to a separate domestic world where issues of justice are not recognised, has both caused, and concealed many injustices and abuses" (Coady, 1996, p. 23). Critics of UNCROC argue that increasing children's agency has resulted in a loss of innocence, and that the state, not family, has assumed the 
parenting role. According to this line of argument, the child with agency has the right to act autonomously and no longer requires parental permission to make decisions about matters concerning him or her (Reid, 2006). What this argument ignores is relationships - within families; between families and communities; and beyond between communities, local authorities, and national bodies (Alston et al., 2005; Ministry of Education, 1996a, 1998). The following section describes the context of early education policies and children's rights in New Zealand.

\subsection{New Zealand early childhood education policies and UNCROC}

There is a history of New Zealand early childhood education advocacy that supports children's rights (Dalli, 2002; Dalli \& Te One, 2002; May, 2001; Smith, 1996, 2002, 2007). However, UNCROC has not been identified as the starting point for advocacy. Smith is the only researcher to consistently cite UNCROC. Early childhood policies discussed below all comply with UNCROC, but their direct relevance is not often articulated, but assumed (Te One, 2004, 2005, 2006). That said, the policies discussed below are examples of how provision rights support children's participation in early childhood education, protect children, and protect children's rights.

\section{Te Whāriki - the New Zealand early childhood curriculum}

Of significant note was the release of Te Whäriki (Ministry of Education, 1993, 1996b), the national curriculum framework for New Zealand's early childhood sector. There is no question that there is widespread agreement amongst those working in the early childhood sector with Te Whäriki (Cullen, 2003; Murrow, 1995; Te One, 2003), but enactment, with a specific focus on children's rights, is less clear. Te Whäriki is based on principles of empowerment, of family and community, of relationships, and of holistic development (Nuttall, 2003). The rhetoric of rights is evident to principles of Te Whäriki, especially the principle of empowerment, which is used extensively by teachers in planning and assessing young children's learning (see Carr, 2001). Empowerment is a central concept in UNCROC, especially Article 12 (CRIN, 2007, p. 5), which articulates the child's right to participate in decisions that affect them (Hart, 1997; Lundy, 2007; Shier, 2001; Thomas, 2007), but it is understood differently in different contexts. A contribution of this research is to 
draw from several disciplines to extend understanding of participation (and empowerment). Previous research (Nuttall, 2004) found differences between teachers' perceptions about curriculum, teachers' intentions with regard to the curriculum, and teachers' practices. Therefore, questions about how children's rights are understood and enacted are relevant.

Te Whäriki's official release in 1996 represented a significant step towards recognising New Zealand's youngest children's rights. Te Whäriki has a well-quoted aspiration for children:

To grow up as competent and confident learners and communicators, healthy in mind, body, and spirit, secure in their sense of belonging and in the knowledge that they make a valued contribution to society. (Ministry of Education, 1996b, p. 9)

This strong aspiration supports children as citizens in the here and now. But, underlying the statement is an ambiguous relationship between the present and the future: Are contributions valued for what they are in the context of an early childhood setting, or valued as potentially economic contributions in the future, or valued because of anticipated participation in a democracy? Through a children's rights lens, the curriculum framework encompassed experiences for the child in the centre, thus shifting the rights focus beyond enrolment statistics, or structural concerns with access and participation.

A further question arising from Te Whāriki's aspirational statement concerns the growing interest in the child as a citizen. May $(2003,2004,2005)$ used the notion of citizenship to argue for provision and participation rights in early education. The idea of a child as a citizen encompasses children's rights in early childhood settings, reconceptualising the setting as a site for political activity in which the child has agency. If childhood is a politically determined state, children's actions are political. Children are, in fact, citizens in their early childhood settings, bound by common rules, complying with routines, and in the setting's rituals. But, the extent to which they can and do participate depends not just on the adults in the setting, but also on the wider regulatory frameworks. Who brokers power in the settings, and how teaching practices are structured by wider frameworks are central questions pertinent to perceptions of children's rights. 
Children's rights, and indeed human rights, are not necessarily the same as citizenship or citizenry rights. Children's citizenship rights raise issues about who is excluded, not just from attending, but also from participating. It narrows the concept of rights to limit them to citizenship rights. For example, New Zealand has a reservation against UNCROC excluding refugee children, and children of illegal immigrants from access to public services such as health and education. While legal obligations can be assessed, the moral obligations such as those expressed in UNCROC are not so easily measured. However, research interest in citizenship rights in early childhood represents a positive move towards a deeper understanding of children's rights. This reflects international interest in educating children as citizens in a democracy (Dahlberg, 2000; Dalhberg \& Moss, 2005; Lindahl, 2005; Rinaldi, 2006).

Interwoven within Te Whāriki are curriculum strands of Belonging, Wellbeing, Exploration, Communication, and Contribution (Ministry of Education, 1996b). The contribution strand, articulated in a child's voice question as "Is this place fair for me?" (Carr et al., 2002, p. 119) is relevant to this research. This question is central to any discussion about children's rights in early childhood settings and implies support for children's rights to participate by asking teachers to consider how children contribute to an early childhood setting. How do they assume responsibility? How do they understand justice and fairness? These are questions about power, where it resides and whether or not it is shared. Certainly, principled statements in many of the official documents support power sharing, emphasising well-intended partnerships between teachers and parents (Ministry of Education, 1996a, 1998, 2006). Recent research and professional development extend partnerships beyond a dyadic of teacher/parent to include theoretical ideas about community. A logical implication of community implies notions of democratic participation, hence providing a further rationale for investigating perceptions of children's rights by employing current theoretical ideas about human development and learning with known theses/interpretations of children's rights (discussed in Chapters 3 and 4).

\section{Ngā Huarahi Arataki: The Strategic Plan for Early Childhood Education}

As with all early childhood initiatives, Nga Huarahi Arataki (the Strategic Plan) (Ministry of Education, 2002) provoked criticism during its development, and on its release in 2002 (Dalli \& Te One, 2002; Mitchell, 2002). From a child-rights-based 
perspective, however, the Strategic Plan has much to recommend it as a statement about provision rights.

The Strategic Plan (Ministry of Education, 2002) has several distinguishing characteristics. First, the conceptual framework includes three goals (participation, quality, collaboration) that coexist as 'pathways', with varying degrees of interdependence. This is a potentially powerful strategy because the collaborative work envisaged would require key government ministries and agencies to meet together and discuss policies relevant to early childhood education. Inclusive policy discussions have the potential to increase awareness, certainly about early childhood education and care, but also about very young children and their rights (Te One, 2004).

Second, and further to this collaborative approach, the theoretical framework of the Agenda for Children (Ministry of Social Development, 2002) adopted an ecological model of the whole child as an active participant in, and across, multiple sites. The advantages of a cross-disciplinary approach proposed by the Strategic Plan might establish a mutually supportive environment to promote children's rights. There are, of course, disadvantages to this collaborative approach as well; notably the lack of detail about when and how particular strategies are to be implemented and evaluated is a criticism levelled at the Strategic Plan (Mitchell, 2002, p. 132).

Third, collaborative approaches also have the potential to realise the aims of another thread drawn through from the Meade Report to the Strategic Plan - that the early childhood sector has equal status with the other education sectors. This certainly promotes rights for young children, although what that means exactly still needs to be revealed. Finally, collaborative relationships extend beyond the walls of a centre into communities which should recognise children as citizens participating in society (May, 2004; Te One, 2004).

In a recent review (Mitchell \& Hogden, 2008), research found that the Strategic Plan had positively affected children's learning outcomes and this was linked to increased teacher understanding of Te Whāriki (Ministry of Education, 1996b), improved teacher qualifications, ongoing funding for professional development supported by the release of professional resources, in particular Kei Tua o te Pae. Assessment for Learning: Early childhood exemplars (Ministry of Education, 2005). 


\section{Kei Tua o te Pae: Assessing young children's learning}

Part of the negotiations for the development of Te Whäriki (Ministry of Education, 1996b) included the future development of an assessment framework. Dispositions (Carr, 2001) formed the basis of Learning Stories, a narrative, formative assessment tool. Further research was undertaken to develop a Teaching Story framework designed to shift the focus towards a more rights-based approach using five 'child's voice' questions as a reflective tool for teachers to evaluate their practices (Carr et al., 1998).

A result of extensive research, with a focus on children's rights, is Kei Tua o te Pae Assessment for Learning: Early childhood exemplars (Ministry of Education, 2005). This professional resource features the child's voice contributing to their assessment, alongside teachers' and parents' perspectives. Children's rights are to the fore in exemplars, an acknowledgement that children's voices are important influences on curriculum decisions and directions. A recent report evaluating the implementation of professional development to support Kei Tua o te Pae (Ministry of Education, 2005) noted that even though teachers' documentation did not always record children's engagement in the assessment process, teachers sought children's perspectives verbally. The report noted how "assessment documentation did clearly evidence a credit-based approach to assessment in that items reflected the passions, skills and working theories of individual children, and presented them as confident and competent individuals" (Stuart, Aitken, Gould, \& Meade, 2008, p. 9).

Both Learning Stories and Teaching Stories support children's rights as stakeholders in their own learning (A B Smith, 2007a, 2007b). Whether or not this shifted the actual power dynamics beyond what happens in an early childhood centre is hard to know, but "the idea of focusing on the 'child's voice' in defining and evaluating quality is consistent with current understanding of early childhood centre quality" (May \& Podmore, 1998, p. 24). It is also consistent with UNCROC, in particular Article 12.1 (CRIN, 2007, p. 5), in which the child as an equal stakeholder has the right to participate and be consulted. The resource (e.g., Ministry of Education, 2005 ) is an example of how regulations and practices can cohere to support provision rights for children, which, in theory, improve the quality of the services overall. The government investment in professional development supports teachers to protect children's rights to participate because the resources direct teachers to the child's 
voice. Even if the child is too young to speak, they can form an opinion, and their perspectives are integral to quality early childhood practices.

\section{Provision measures to promote participation, protect children, and protect children's rights}

Mitchell and Hogden's (2008) review of the implementation of the Strategic Plan noted that some populations still experienced disadvantages in accessing and participation in early education services. Several initiatives to increase participation have been implemented since the Strategic Plan inception. The three examples discussed below have a focus on participation, but they are also examples of provision rights (Article 18, CRIN, 2007, p. 7) and measures taken to protect children by providing support for parents to access educational opportunities.

The Promoting Early Childhood Education (ECE) Participation project's primary goal is to ensure that "every child has the opportunity to participate in quality ECE, by assisting communities to address barriers resulting in non-participation in ECE, by children who might otherwise participate" (Dixon et al., 2007). Based on the premise that such participation will "reduce ethnically-related disparities, the project targeted Māori and Pasifika, however, during the implementation, the focus on Māori and Pasifika was widened to include other groups with low ECE participation, including low-income and refugee families" (Dixon et al., 2007, p. 1). Evaluations of this project found it responded to diverse models of early childhood provision, and the project was broadly inclusive of different philosophies within communities, but the funding allowed for flexible delivery of services. As such, it supports a rightsbased approach because it potentially strengthens families by providing a service.

Twenty Hours ECE "is an education policy aimed at increasing participation in teacher-led services and eligible kōhanga reo by reducing the cost barrier to families" (Froese, 2008, p. 1). This policy entitles eligible teacher-led services to claim up to six hours per day and up to 20 hours per week for three- and four-year-old children enrolled in early childhood education. The intention of the government funding is to increase participation rates. An early effect has found this to be the case with more three- and four-year-olds attending for more hours per day, and for more days per week. This initiative was welcomed by some in the sector as a move towards free early childhood education which would place the sector on an equal footing with the 
primary and secondary provision. However, it was not equally applied, and the policy did not include parent/whānau-led services who protested that this disadvantaged them, and their children (Froese, 2008).

Yet another policy supporting parents and supporting children is the Parent Support and Development pilot project currently running in 18 early childhood centres. This project emerged from research evidence showing "that two-generational programmes that combine parent education and support and ECE can raise child outcomes and are more effective than solely parent-focused or child-focused programmes alone" (Ministry of Social Development \& Ministry of Education, 2004, p. 1). The notion of an early childhood centre as a hub is a collaborative strategy reflecting New Zealand and international research suggesting that targeting single risks in isolation is relatively ineffective. The Parent Support and Development project "recognises that better service co-ordination offers opportunities to improve service quality, effectiveness and efficiency" (Ministry of Social Development, 2006, p. 4).

Based in communities, working out of early childhood education services, this pilot project supports the Strategic Plan's vision for New Zealand: "that all children have the best start in life, flourish in early childhood, and are supported to reach their potential" (Ministry of Education, 2002, p. 1). A universally provided service that targets vulnerable families is a non-stigmatising strategy to improve, intervene, and strengthen "families, whānau and communities, and [improve] inter-agency coordination, collaboration and communication" (Ministry of Social Development, 2006, p. 4). Not only does this programme align with UNCROC, it is also evidence of compliance at many levels. There is an intention to protect children, a strategy to support parents in their role, and a commitment to providing access to early education for children based on research evidence demonstrating early intervention has long-term benefits. Participation in early education for vulnerable children supports their development, and protects their rights.

\subsection{How UNCROC contributes to the thesis}

This chapter has backgrounded UNCROC, as a seminal marker for research and debate about children's rights. The chapter sets a platform for further discussion of this aspirational human rights treaty. The chapter has outlined historical phases in 
the development of children's rights (wars, civil rights, and liberation movements), which add depth to the context for the questions driving the research: What are children's, parents', and teachers' perceptions of children's rights in early childhood settings, and how are these rights enacted? Three categories to group the articles of UNCROC were explained in depth, and a brief overview of selected New Zealand early childhood education policies was presented in light of the three categories of rights. The three categories of rights offer a means to understand how rights are implemented in context, and how these manifest as separate categories, and together. The next chapter examines several interpretations of rights and models designed to evaluate children's participation in matters that concern them. 


\section{Chapter 3: Interpreting and implementing UNCROC}

\subsection{Introduction}

The previous chapter discussed UNCROC as a benchmark in the children's rights landscape. The chapter described the implementation procedures, and presented one way rights have been interpreted in three categories: protection rights, provision rights and participation rights. It introduced a model (Figure 4, p. 36) illustrating how categories of rights were used in this research. This chapter discusses various legal interpretations of UNCROC, the contributions of childhood studies, a branch of childhood sociology, and the growth of the child advocacy movement that has developed since UNCROC was first launched as a human rights treaty. The aim of this chapter is to establish an informed approach to answering the research questions. The chapter is divided in two parts: Section 3.1 discusses issues associated with implementing rights from a legislative perspective, an advocacy perspective, and research perspective. Section 3.2 introduces relevant constructs from childhood sociology and childhood studies. Later the section discusses children's rights in the New Zealand context. The chapter concludes with an explanation of how legal debates and childhood studies influenced the present investigation, particularly how these two disciplines form a framework for interpreting data generated by this research.

\subsection{Interpreting children's rights}

Rights have been described as freedoms, as powers, as values (see for example Franklin, 1995; Holt, 1975; Mayall, 2003), as interests (Archard, 1993), as entitlements (Freeman, 2000, 2007), and as tools for change and advocacy (Fennimore, 1989; Smith, 2007a). They can be explained as duties and, particularly in relation to children's rights, as implying responsibilities (Archard, 1993). Children's rights are often described as dichotomies (see Freeman, 1992): children's competence or incompetence; children's capacities or incapacities; and children's autonomy or dependence, including for very young children, their vulnerability. Philosophically, how these constructs are manifest depends on cultural values and beliefs.

Haar (2004, p. 17) noted an "increased discourse on children's rights comprising numerous, often conflicting theories [and an array of] different legal contexts". This 
confirms that "rights are a broad concept, which will be interpreted and promoted or resisted differently depending on the meaning they hold for particular people" (Taylor, Smith, \& Nairn, 2001, p. 138).

What follows is a discussion of three legal interpretations of rights, and how these relate to the three categories of rights. The theses are the 'interest' thesis, the 'caretaker' thesis, and the 'choice' thesis.

\section{The 'interest' thesis}

One way to define a right is to identify the interests that rights protect (see Archard, 1993; Eekelaar, 1992). This definition suggests that the child is a rights holder, and the adult is executor of these rights. Interpretations of what acting in the best interests of the child means are not constrained by views of the child as immature or incompetent, but as entitled to rights endorsed by society's legal and political frameworks (Federle, 1994), for example welfare rights.

Consequently, some would agree, the role of the state is not to interfere except in the most extreme circumstances where, for example, as decided in courts of law, the responsibility to protect the child and to provide for it became the state's. The measure in these circumstances is whether or not rights can be enforced. A countering argument is that rights are not enforceable, but that they set a moral standard and, in that sense, they represent an aspiration - enforcing rights may be unrealistic, but if the moral implications are accepted, that represents a desire to actualise the rights. Gavin (1980, p. 59) argued that "we must not confuse needs with rights. All human beings have need of food and shelter but so far, no society is prepared to secure that need with the support of a legally enforceable right." Rights, he argued, are "not actionable by law" (p. 59).

Many may recognise that children "regardless of their ... immaturity or competency - are rights holders" (Haar, 2004, p. 19). However, "the manner in which such rights are exercised continues to be problematic as they are often defined in terms of parental or state rights or duties to act in a particular manner" (Haar, 2004, p. 19). Some argue forcefully that children's rights undermine parental authority, and further, alter perceptions of children as innocent dependants to active, politicised agents (see Guggenheim, 2005; Reid, 2006). Fundamentalist Christian lobbyists in 
the USA, for example, still regard patriality as supreme - a position that relegates children to a subordinate role, subject to parental will (Almog \& Bendor, 2004; Alston et al., 2005).

Eekelaar (1992) usefully categorised interest rights. One, basic interests actuate at two levels: in the home where parents have a duty to provide care within their social capabilities; and at a national level where the state has a role to enforce the prevention of neglect. There exists, however, a cruel irony compounded by "the unavoidable effects of social inequality" (Eekelaar, 1992, p. 48). The state:

does seem to give children rights to be removed from the adverse consequences of care by parents who suffer social or personal inadequacy. (Eekelaar, 1992, p. 48)

Second, developmental interests are defined as "an equal opportunity to maximise the resources available to [children] during their childhood [so that] their capacities are ... developed to their best advantage" (Eekelaar, 1992, p. 46). Typically the responsibility lies within the family to do this, but the wider socioeconomic and political environment directly impacts on this: "[a]s far as the 'developmental' interest is concerned, ... societies may choose to actualize it in harmony with their overall social goals, which may (but not necessarily) involve creating equality of opportunity and reducing socially determined inequalities" (p. 47). Third, autonomy interests entitle the child to make his or her own choices and decisions, which "can conflict not only with the child's own basic or developmental interests, but also with the interests of the child's parents" (Eekelaar, 1992, p. 53). Eekelaar concludes: "Children will now have, in wider measure than ever before, that most dangerous but most precious of rights: the right to make their own mistakes" (p. 58).

"What interests do children's rights protect in an early childhood centre?" is a question driving this study. This implies including children's perspectives. How rights are perceived might usefully create an awareness of what interests the participants believe they are protecting, if indeed they perceive rights in this way. Notions of interest rights as developmental, and relevant to children's autonomy, resonate with early childhood notions such as 'empowerment' and 'contribution', principles and strands of Te Whāriki (Ministry of Education, 1996b). 


\section{The 'caretaker' thesis}

A recurring theme in the literature on children's rights centres on perceptions of children's capacity, or incapacity, to decide for themselves. The caretaker thesis of rights poses the question: What would the child want if the child was mature enough to decide for him or herself? Infants and young children are dependent on adults to exercise, or claim some rights on their behalf. While this could be the case for children enrolled in early childhood centres, there are no studies in New Zealand specifically focused on this topic. Simply put, the caretaker assumes responsibility for protecting the child's rights because the child is not yet considered competent to exercise those rights. This is particularly relevant to research question two: How are children's rights enacted? Of course, perceptions of rights influence the answers, but day-to-day practices could well provide evidence of an underlying caretaker thesis. Essentially, this is explained as the caretaker (or early childhood teacher/playcentre parent) deciding what the child needs in order to protect and provide for the child's rights, including the right to participate. The onus is on the adult to:

choose what the child would choose if competent to make choices, and choose with regard to the interests of the adult the child will become. ... The caretaker, if you like, chooses for the child in the person of the adult in which the child is not yet but will eventually be. (Archard, 1993, p. 58)

Critics of this interpretation argue "[a]dult 'experts' on children's rights will not know what is of most concern to children in relation to their rights, unless they make themselves aware of children's views" (Taylor et al., 2001, p. 139). Supporters, usually parents, argue that because they know their child, they are in the best position to judge what is in the best interests of their child (see Archard, 1993; Eekelaar, 1992; Federle, 1994; Freeman, 2007). The caretaker thesis is relevant to parents and professionals working with children, because there is "an interest in the manner in which the rights are used" (Gavin, 1980, p. 58):

If [society] permits the delegation of a right to a trustee, that trustee is not only responsible to society for the manner of the performance of his or her own rights but also for the exercise of the rights in trust and the manner of their use. (Gavin, 1980, p. 58)

John (1996, p. 63) noted that Article 18 (CRIN, 2007, p. 7) assigns parents primary responsibility for care, but "the Government must provide help and support to all parents in their child rearing duties". John elaborated further by arguing that "Daycare provision for children represents a central plank in the range of support services 
that parents require in bringing up their children" (p. 64). The status parents have is questionable. Leach (1994) commented, "[o]ur society is inimical to children, and has therefore devalued parents to such an extent that individual good parenting is not only exceedingly difficult, but, ultimately insufficient" (p. xiii, cited in Daniel \& Ivatts, 1998, pp. 225-226). Accessible, affordable services aspired to in policy rhetoric is not matched by the reality and has spawned an advocacy movement for children's rights (Fattore et al. 2005; Fennimore, 1989; Mason, 2005).

The above argument is one driver behind critiques of UNCROC (Freeman, 2007) and highlights the tenuous balance of adhering to such an argument. To achieve childcentred social policies requires an attitudinal change to promote children's rights to be involved in social processes: "the overriding importance of rights lies in the fact that they represent a recognition of children's social value" (Daniel \& Ivatts, 1998, p. 230). In other words, children are not merely family members, they are also citizens. The balance between children's and adults' rights remains contentious and is often perceived as favouring the rights of one group (children) at the expense of the other (adults, especially parents). While children's wellbeing and best interests are possible common ground, the different camps for and against rights for children reflect different philosophical and theoretical approaches which, in turn, define the parameters of the debates about children's rights. These parameters depend on perceptions of children and childhood: Researchers (Casas et al., 2006; Lansdown, 2005; Tomanovic, 2003) question how perceptions of children influence perceptions of children's rights. Relevant to the present study is how the caretaker thesis might be usefully applied to interpreting the findings, given the role of early childhood teachers in the care and education of young children. Clearly these are gaps in the current research knowledge that this thesis addresses.

\section{The 'choice' thesis}

Archard's (1993) account of the discourses influencing children's rights noted that the caretaker perspective argued participation rights were "based on the requirement that, in order for the individual to be recognised as a rights' holder, he or she was to be capable of making and exercising choices" (Haar, 2004, p. 18). Many have suggested that this is problematic, especially for younger children "who may not be competent to make choices. Thus, according to the protagonists of the 'choice' (or 'will') theory, a person cannot be deemed to be a rights' holder unless they are able 
to choose whether or not to waive their rights" (Haar, 2004, p. 18). This rationale has implications for the adults in young children's lives because children are often unable to claim these rights for themselves. Therefore, this depends on the systems in place, first, to recognise these rights and, second, to claim them.

Within early childhood, the notion of children's right to choose is deeply embedded in current thinking and is generally understood to mean that children have the right to choose what to play, and where to play in their early childhood centres (May, 2001; Somerset, 1976, 1986). This derives from several sources. Historically, it has best been described as free play (Somerset, 1976). Spontaneous (or free) play is a fundamental tenet of early childhood: "Play is the natural way in which children go about the business of learning. [...] The relevance of play to early years education is unquestionable, and its status in the classroom should be assured" (Fisher, 2002, p. 128). Learning through play has become a catch cry in early education, and is closely aligned with notions of free choice.

Fisher (2002, p. 128) proposed a Charter for Play. Conceptualising play within a charter is consistent with a rights-based approach because charters imply agreed to principles and obligations. Playcentre philosophy (Densem \& Chapman, 2000; Morris, 1994; Somerset, 1986) in particular popularised the construct of play as children's work, although this principle has long been central to most early childhood education services in Aotearoa New Zealand.

Many advocates argue that learning through play enhances holistic development and cognitive development, which are in fact rights established in Articles 28 and 29 of UNCROC. The benefits of play, and in particular, time to play, are not always to the fore of discussions in the public arena, and perceptions of children at play are not considered deeply, because the constructions of children and childhood are that this is a time when you play (Mitchell, 2007). Mayall (2000b) is among those who argue that situating play in the early childhood sphere further marginalises children as separate from adults. She also points out that the early childhood education and development industry stresses "adult input rather than child agency" (p. 257). Those in favour of accelerated, focused educational play are often at odds with those who advocate for the playfulness of play (Alcock, 2005), and for the important mediating 
role play experiences have in relationships with others to create cultural meaning (Brennan, 2005; Fleer, 2003; Hedges, 2007).

The choice thesis resonates with the early childhood education's advocacy for children's right/freedom to choose what to play, who to play with, and where to play during a session, or over a day (see Densem \& Chapman, 2000). It is also consistent with Articles 12 and 13 (CRIN, 2007, p. 5) because exercising choice is in fact a participation right. Furthermore, the right to choose approach aligns with current practices in New Zealand early childhood education where children's perspectives on their learning are deemed central to curriculum planning (Meade, 2005; Ministry of Education, 2005). While UNCROC does not specifically mention the right to choose where to play, Article 31 (a provision right) refers to "the right of the child to leisure and recreation, and to engage in play and recreational activities appropriate to the child" (CRIN, 2007, p. 14).

Rejecting "an underlying notion of capacity as a prerequisite to having rights" (Federle, 1994, p. 343) is a reconceptualised premise that "envisions rights for the powerless and marginalized and recognises the disadvantaging effects of capacity" ( $p$. 368). Children's rights, therefore, inhibit and limit the actions of those with power (Freeman, 2007). Fundamental to a coherent approach to interpreting children's rights is mutual respect for children that challenges existing hierarchies: "within such an account, children have rights and are able to make claims and have those claims treated seriously and with respect for the power they wield" (Federle, 1994, p. 368).

To conclude this section, the 'interest' thesis is a protection rights argument; the 'caretaker' thesis can be interpreted as a provision rights thesis; and the 'choice' thesis aligns with children's participation rights. All these arguments can be understood in the wider context of considering children's rights to participate, notably Article 12:

1. States Parties shall assure to the child who is capable of forming his or her own views the right to express those views freely in all matters affecting the child, the views of the child being given due weight in accordance with the age and maturity of the child.

2. For this purpose, the child shall in particular be provided the opportunity to be heard in any judicial and administrative proceedings affecting the child, either directly, or through a representative or an appropriate body, in a manner consistent with the procedural rules of national law. (CRIN, 2007, p. 5) 
Article 12 marks a seminal difference between previous children's rights documents and the current Convention. Child advocacy has focused on this aspect of UNCROC (for example UNICEF, 2005, 2006), and has increased the visibility of children "in political arenas from the village development council ... to the UN General Assembly" (Lansdown, 2005, p. v). Advocacy for children's rights to participate has shifted the focus from promoting child development and protection to a "rights-based analysis of children's lives" (p. v). This takes us back to the starting point of this thesis with its interest in how rights are perceived as children participate in their early childhood education. Discussion so far has demonstrated interrelated constructs of protection rights and provision rights are critical to interpreting participation rights.

The next section critiques models developed to evaluate children's participation rights. The section illuminates current perceptions of participation rights and, as such, provides a basis for interpreting answers to both research questions.

\section{Models to evaluate children's participation rights}

Participation [is] a term that is used to describe a great variety of activities taking place in very differing circumstances. Hence the need to ask: what do we mean by participation? (Sinclair, 2004, p. 108)

Earlier in the thesis, it was posed that participation rights at a policy level have focused on enrolment statistics. A desire to investigate the experiences of children and adults while they are in the centres influenced this present study. Article 12 (CRIN, 2007, p. 5) directs adults to respect children's views, or at the very least, consider them respectfully. Many comment that Article 12 is the most contested, and problematic article (Lundy, 2007; Veerman \& Levine, 2000). In support of Article 12's intentions, Moss and Petrie (2002) argue it "is time to welcome children with all their diversity, as young citizens, equal stakeholders with adults in a common social enterprise" (p. 16). Melton and Limber (1992) advocate for "people in power ... to build a sense of community" and suggest that including children in "the definition of their rights ... may have socializing effects" (pp. 170-171), effects that could well influence perceptions of their rights.

Matthews (2003, p. 266) observed that "[t]ypically, the reservations that adults express about children's ability to participate revolve around their lack of competency, perceived disinterest, and a need to shelter them from adult pressures". 
This is the usual argument disputing children's entitlement to participate (Alderson et al., 2005; Reid, 2006). For example, Prout (2003, p. 21) comments:

Too often children are expected to fit into adult ways of participating when what is needed is institutional and organizational change that encourages and facilitates children's voice. Unfortunately children's participation is a subject high in rhetoric but sometimes low in practical application.

Thomas (2007) suggested that a theory of children's participation "would be premature" (p. 215) because "such a theory would need to be both a politics and a sociology of children's participation ... to understand not only institutional and legal contexts and processes, but also the cultures and dispositions that underpin them" (p. 216). Further, Dunne (2006) problematises children's citizenship by comparing and contrasting ancient, modern, and postmodern conditions of childhood to conclude that children's agency, voice, and therefore participation are not autonomous acts, but that the process of participation is an "irreducible reality of human interdependence" (p. 15). Those who work with young children "are too much in the shadow land" (p. 15). This lends support to Thomas's (2007) suggested components for a potential theory of participation:
a) encompass all the sites where children's participation may or may not take place;
b) be located in a broader context of inter-generational relations;
c) understand the distinction between 'participation' meaning activity that children engage in conjointly with adults, and children and young people's autonomous activity;
d) accommodate the new kinds of participatory practice with children and young people that have been developed (particularly in countries of the majority world);
e) account for the demands of children and young people to have the same political rights as adults. (p. 215)

Both Thomas (2007) and Dunne (2006) allude to the fact that the low status of children and childhood, and of those who work with them, influences perceptions of children's participation rights. Even though this study was not evaluative, components of participation theory, if indeed such a theory could exist, may be relevant to this investigation.

Hart's (1992) ladder of participation was cited in New Zealand's Agenda for Children (Ministry of Social Development, 2002). According to Hart (1997, p. 45), there exists “a wide variety of structures for children's participation but it is 
remarkable how rare it is for these to be made explicit". Hart's (1992) 'ladder of participation' model is a staged mechanism for evaluating children's participation in projects ranging from the lowest rungs of token involvement through eight stages to child-initiated/adult-shared decision making. Hart (1997, p. 45) commented:

The best opportunities for democratic experiences for children come from sustained involvement in a group. With regular attendance in the same group, adult facilitators can establish with children clearly understood processes, roles and rules. This offers the best opportunities for all children to develop their own orientations to participation in ways that build upon their own particular proclivities and desires.

Again, evaluation was not the focus of this research, but Hart's (1992, 1997) interpretations of children's participation rights raised issues relevant to understanding participants' perceptions of rights, particularly children's rights to participate. For example, how rights are enacted can be interpreted on many levels. Models to evaluate participation are potentially useful here, and three further models are outlined below.

Matthew's (2003) typology of community action (adapted in Figure 5) "represents a hierarchy of involvement" (p. 268) that aligns with Carr's (2001) concepts of dispositional learning, and acknowledges both the depth and breadth of experiences.

Dialogue: Listening and consulting with young people

Development: Adults working for the benefit of young people

Participation: Young people working within their communities

Integration: Young people working with their communities

Figure 5: A typology of community action: Aadapted from Matthews (2003, p. 268)

Shier's (2001) 'pathways to participation' model included reflective questions across three broad categories: openings - are you ready to, for example, listen to children; opportunities - are you able to listen to children; and obligations - are you required to listen to children? Shier's model was intended "as an additional tool for practitioners, helping them to explore different aspects of the participation process" (p. 109). At the lowest level of participation, children are listened to, but it is between levels three and four (of the five) that Shier argues is the minimum point "you must achieve if you 
endorse the UN Convention on the Rights of the Child" (p. 111). It is at this point that listening intersects with opportunities and obligations.

Lundy (2007) noted "one of the ongoing obstacles to the successful implementation of Article 12 [was] a limited awareness of the provision itself” (p. 930). She grouped adult concerns into three areas that combine to inhibit implementation:

scepticism about children's capacity (or a belief that they lack capacity) to have meaningful input into decision making; a worry that giving children more control will undermine authority and destabilise the school environment; and finally concern that compliance will require too much effort ... . (pp. 929, 930)

Lundy (2007) critiqued current perceptions of participation as 'cosy', where the child's voice is "held out as an unquestionable good" (p. 931), detracting from the purpose and intent of participation rights. Unless voice is located within a rights discourse, Lundy argued, listening becomes an option that adults can either endorse or not. For children to be consulted and involved in decision making is not a choice, but a right. Lundy identified four factors to facilitate this right:

- Space: Children must be given the opportunity to express a view.

- Voice: Children must be facilitated to express their views.

- Audience: The view must be listened to.

- Influence: The view must be acted upon, as appropriate. (p. 933)

How to minimise the power imbalance between children and adults is a common question for many with an interest in children's rights (for example, Alderson, 2000, 2005; Christensen, 2000; Clark, 2001). Thomas (2007) asks "what children and young people have to offer democracy" (p. 216), although the reverse is also true: What does a democracy offer children and young people? For Dunne (2006) the question is one of partnership between children, parents, teachers, and beyond these relationships, to partnership with the wider community, local and national bodies in a “truly civic enterprise” (2006, p. 16). Matthews' (2003) typology identified stages of involvement, indicating that over time and under certain conditions, participation deepens a sense of belonging and responsibility. The models proposed by Hart (1992, 1997), Shier (2001), and Lundy (2007) provide evaluatory tools to assess participation.

It is worth noting at this juncture, that all models designed to evaluate children's participation rights have limitations. For example, they can be critiqued for 
delineating tasks, or factors, to stages. This can make them inimical to work with very young children, where relationships are the core of interactions and experiences. Rigidly interpreted and applied models also create a tension with the cultural relativist positions. On the other hand, models can be useful to articulate an understanding of children's participation rights. The proliferation of models is perhaps an indication of an underlying problem adults still have with Article 12. Perhaps this is because cultural processes accepted and adopted by children's rights advocates are not the norm, and a type of institutionalised discrimination towards children's participation is. Another reason could be that participation is not a misunderstood concept, but avenues or spaces for participation are ill-defined. Models to evaluate participation are limited if the wider context for that participation is not acknowledged. For example, the shift from tokenistic to genuine participation (Hart's 1992 model) has limited meaning for children if the places they participate in do not recognise their rights beyond adult-controlled projects. According to Smith (2009, personal communication):

$\ldots$ one of the first roles of adults in relation to participation rights is to help children formulate a view. This can take place alongside listening. Children cannot develop a voice and agency unless they first have the opportunity to understand and develop an opinion.

\section{Participation rights imply listening to children}

Understanding how children exercise their rights to participate depends on listening to children. In the present study, notions of the child's voice in the assessment process (Carr, 2001) aligned with interpretations of children's rights, and models of participation. This is useful to understanding perceptions of rights, and how context might influence the enactment of rights. However, because this research was not evaluatory, the constructs in the models have been reinterpreted accordingly (Figure 6).

\begin{tabular}{|c|c|c|}
\hline $\begin{array}{l}\text { Carr } \\
(2001)\end{array}$ & $\begin{array}{l}\text { Lundy } \\
\text { (2007) }\end{array}$ & $\begin{array}{l}\text { Shier } \\
(2001)\end{array}$ \\
\hline \multicolumn{3}{|c|}{ Protection rights, protecting rights } \\
\hline Notice & Space; Voice & Openings \\
\hline \multicolumn{3}{|c|}{ Provision rights } \\
\hline Recognise & Audience & Opportunities \\
\hline \multicolumn{3}{|c|}{ Participation rights } \\
\hline Respond & Audience; Influence & Obligations \\
\hline
\end{tabular}

Figure 6: Similarities between models of participation and assessment 
An explanation of how this was arrived at follows, beginning with a rationale for listening to children provided in UNCROC.

Article 12 (paragraph 2) "has an intrinsic motive to recognize children as meaning makers". The right to freedom of expression and freedom of opinion can "be approached from different viewpoints": instrumentally "as a means to improve the quality of the [early childhood service] or to educate pupils to become future good democratic citizens by learning participation skills" (Verhellen, 2001, p. 187). Participation rights have been understood by many as the right to be heard, interpreted as children's rights "to speak, participate and decide" (Canadian Child Care Federation, 2006, p. 2); however, “... for children's voices to be really heard, even when the institutional arrangements create a notional space for it, requires change in the way that children are seen" (Prout, 2003, p. 22). But, acting in the best interests of the child may be at the expense of listening: "The younger the child, the more difficult it will be to place a greater emphasis on self-determination and autonomy than on safety and welfare” (Pugh \& Rouse Sellack, 1996, pp. 121-122). Furthermore:

\begin{abstract}
Historically social policy has not thought of children as persons with a voice. Rather they have been seen as objects of concern. Contemporary societies are perhaps more ambiguous on this point, with different visions of childhood coming into play, sometimes overlapping and sometimes conflicting with each other. Nevertheless, the idea of children's voice remains a contested one. (Prout \& Hallett, 2003, p. 1)
\end{abstract}

To what extent, if at all, is listening to children understood as a participation right in the case study centres under investigation here?

Moss (2006), for example, identified risks to listening, implying that merely being willing to listen is "a tokenistic gesture" that serves management accountability: "You need to want to listen in the first place and no amount of bullet points will help you if you don't have a culture of listening" (Moss, 2006, p. 30, citing a personal communication with Olé Langsted). Therefore, teachers must:

master the difficult art of listening, seeing, hearing, questioning and challenging - and by so doing enable children to see that there are multiple perspectives, complexities and ambiguities. (Dahlberg et al., 2007, p. 137)

Respectfully including the child's voice in assessment (Ministry of Education, 2005) is based on Carr's (2001) three-phase model of notice, recognise, and respond - a mini flowchart of possible teacher and child actions and interactions. Assessment 
exemplars (Ministry of Education, 2005) illuminate multiple perspectives, using the notion of voice (teacher voice, parent voice, and child voice) to deepen and enrich teaching and learning for adults and children in early childhood settings. In particular, the terminology 'the child's voice', stakes a claim for the child as an active participant, able to contribute competently to the assessment process (Carr, Hatherly, Lee, \& Ramsey, 2003). The assessment exemplars and recent research contribute to current understandings of how children participate in early childhood centres and are relevant to the research questions: How are children's rights perceived, and how are they enacted?

There are parallels between Carr's (2001) flowchart, Lundy's (2007) participation model, and Shier's (2001) evaluatory approach to participatory rights (see Figure 6). Empowering children to participate implies adult involvement, although the extent to which this happens depends on, and may be revealed, through answers to the second research question. The response phase in Carr's model requires the teacher to be more than an audience listening to children. The implications of responding, when interpreted from a rights-based perspective, are similar to notions of audience and influence (Lundy, 2007), and opportunities and obligations (Shier, 2001). Carr's response phase of assessment aligns with the audience and influence phases in Lundy's model, and with the opportunity and obligation phases described by Shier. Ideally, Carr's focus on teachers' professional practices should exert pressure on the organisational culture, evaluated by the Lundy and Shier models, to make participation rights possible. How children's rights are enacted in practice was a question addressed in this research, and Figure 6 illustrates a potentially useful way to interpret the findings based on themes to emerge from the literature, and align with the categories of rights in UNCROC. All three models are directed toward adult responsibilities to adhere to the best interests of the child principle.

A corollary to listening to children can include notions of advocacy on behalf of children to others. Because of the age range of participants in this research (birth to 5 years old), an awareness of the advocacy issues associated with understanding and promoting children's rights is an important aspect of listening to children:

In a society that is not used to giving weight to the views of children of any age, we will need to be strong advocates in minute particulars if children without the voice of mature language users are to be listened to and taken account of. (Pugh \& Rouse Sellack, 1996, p. 120) 
UNCROC strives for a balance between acting in the child's best interests and listening to the child. Advocating for young children assumes crucial importance (Fennimore, 1989; Pugh \& Rouse Sellack, 1996), but when it comes to participation rights, this advocacy is not straightforward. Pugh and Rouse Sellack (1996) continue:

Listening to very young children does not necessarily mean taking all their utterances at face value, but it does mean observing the nuances of how they exhibit stress, or curiosity or anxiety, or pleasure in a manner which is congruent to their maturity. It does not mean that their views carry more weight than the powers of wise and loving adults over the outcomes of any decision making process, but it does require that their views are respected. (pp. 120-121)

The tension between children's rights and the role of the adult advocate is one where power needs to be balanced. Scraton (1997) argued that “... childhood is mapped by rituals from above ... [Through] the process of normalization, the ritualisation of childhood is about power relations. The socialization of the child and the definitions of appropriate development are not open to negotiation except between 'knowledgeable' adults" (pp. 163-164). Rituals and routines are a part of everyday life in early childhood centres, and both research questions probe how children are positioned in the centre, particularly how they participate alongside adults in relevant, meaningful decision making.

Sharing power between adult and child is considered by many (for example, Alderson et al., 2005; Bronfenbrenner, 1979) as necessary to the enactment of rights (a question investigated in this research). Griffith (1996) explained power as 'invested' and 'divested'. He defines invested power as "hierarchical, linear and competitive" (p. 214). Invested power hierarchies preserve the status quo, overtly and in hidden ways (see Bishop \& Glynn, 1999).

Divested power, on the other hand, adopts "an organic, regenerative and dynamic view of society that regards change as constant and celebrates diversity" (Griffiths, 1996, p. 215). Divested power is distributed, and social processes are open to include "an infinite number of interdependent and interactive collaborative and cooperative communities" (p. 215), ideas that resonate with early childhood thinking in New Zealand. For example, when the draft of Te Whäriki (Ministry of Education, 1993) introduced the concept of empowerment, the early childhood sector embraced 
the term (Murrow, 1995). Balancing children's needs and empowering them to realise their rights is complex: "rather than being the passive recipient of someone else's decision-making and control, the learner is an active participant in the formation of their own learning experience" (Fisher, 2002, p. 129). Questions about power relations are relevant to the research because power dynamics might influence the ways in which children's participation rights are perceived and implemented.

\section{Summary of Section 31}

Various theses or interpretations of what children's rights mean have influenced research and practice alike. Interpretations of what it means to act in the interests of the child, to assume the role of a caretaker, and to support a child's right to choose were discussed in the context of this research. Recent developments investigated here have focused on how children's participation rights have been defined and explained. Models to evaluate such rights were discussed and, in conjunction with current New Zealand learning and assessment ideas, considered as important to this investigation.

Listening to children, as well as advocating for their rights to be heard, are further aspects of their participation rights. Critical to understanding the role of an advocate, and, indeed, interpreting children's rights, are notions of power which are helpful to illuminate factors influencing how children's rights are perceived. Although positioned here as part of the discussion about participation rights, notions of the child's voice and support for children's agency (i.e., advocacy) are equally important aspects of the study of childhood, discussed in the next part of this chapter.

\subsection{Childhood, children, and rights}

Two separate but overlapping disciplines, childhood sociology, and the study of childhood, or childhood studies, have relevance to this thesis. Childhood sociology investigates what it means to be a child, and what childhood is (Freeman, 1998; James \& Prout, 1997; Jenks, 1996; Morss, 2002; Pufall \& Unsworth, 2004). Childhood studies draw on interdisciplinary accounts of children's experiences, and take a more agentic view of the child's perspectives. 
A purpose of childhood sociology is to understand how childhood is a socially constructed and contested state:

Childhood has come to be seen as a stage rather than a social practice, with children spoken of as in the process of 'becoming' and therefore in terms of inadequacy, inexperience and immaturity. They are to be 'measured' against an unexplained, unproblematic rational adult world which is (of course) both complete and desirable, and, in contrast to childhood, is also static. (Freeman, 1998, p. 434)

Freeman (1998) suggested that children's rights advocates and childhood sociologists shared a respect for children's agency, recognising that "children are persons, not property; subjects, nor objects of social concern or control; participants in social processes, not social problems" (p. 436). Childhood sociologists and child's rights advocates both challenge perceptions of adulthood as more important than childhood, and question why children should not have rights, arguing for children to be treated as individual "rather than [categorised] as a collective and undifferentiated class" (p. 436). Childhood studies move the shared principles of sociology and advocacy forward. Woodhead (2005, p. 85) explains this:

While developmental psychology has been the dominant framework for understanding children's development, social constructionist critiques of conventional theorising have become increasingly influential, and have in turn contributed to alternative frameworks for understanding early childhood notably the new social studies of childhood, or Childhood Studies, with its emphasis on childhood as a social and cultural construction, understanding children's worlds and recognising children's agency, which resonates with respect for children's rights.

Numerous contradictions and disruptions to children, and constructions of childhood, reveal gaps between the intentions of social policy and the social problems children encounter in the modern world. While this present research does not focus on problems per se, the gap exposed between policy and practice concerning children's experiences is one that also concerns their rights. Exploring childhood studies and childhood sociology together with children's rights addresses Freeman's (1998) desire to draw together rights advocacy with sociology. Childhood sociology legitimises the child as social actor, not merely a passive recipient of culture. Corsaro $(1997,2003)$ provides evidence that children actively construct their worlds, and their friendships are fundamental building blocks to make sense of relationships and contexts. Corsaro (1999, p. 28) wrote: 
Preschool children immensely enjoy simply being and doing things together. They often signal recognition of their ability to carry out joint actions with verbal references to friendship such as "We're friends, right?" (Corsaro, 1985; Parker \& Gottman, 1989). However, generating shared meaning and coordinating play are often difficult tasks for young children. Thus preschoolers spend a great deal of time creating and protecting the shared play and peer routines that provide them with a sense of excitement and emotional security.

The child as a social actor is evident in some research (Berger \& Berger, 1991; Carr, 2000; Christensen, 2004; Clark \& Moss, 2001; Einarsdottir, 2005; Gammage, 2006; Hviid, 2004; James, 2004; James \& Prout, 1997; James et al., 1998; Jenks, 1996; Youniss, 1999). Time, place, and space influence perceptions of childhood. Therefore it is important to understand adults' and children's constructions of childhood in order to make sense of perceptions of children's rights. Equally, the wider social concerns reflected in the research from the child study movement are integral to understanding how the sociological effects impact.

\section{Time and place construct childhood}

Aries (1962) researched how perceptions of children and childhood have changed throughout history. Goldson (1997), Prout and James (1990) and others argue that childhood is constructed differently depending on time and place. These constructions illustrate differences between adults' and children's experiences of the world.

Culturally specific notions of childhood are influenced by their particular social and historical contexts. Hulqvist (2001, p. 149), for example, noted "the change that has taken place in the child's relationship to society or to the greater national community". The continually and consistently contested nature of childhood varies: "[t]here is no immutable and unchangeable entity called childhood. Childhood and children's needs are socially constructed. In other words, they are what we think they are" (Smith, 2007b, p. 152). Exactly how these notions are accommodated is interesting. Unless they are recognised as culturally specific, it is difficult to reveal any underlying assumptions. For example, when looking at the past, there is a tendency to simplify the construct of 'child' and of 'children's rights' (Dunne, 2006). This research investigates perceptions of rights in three case studies but, whether or not the participants' perspectives represent a mainstream view is a question beyond what this study can address. However, an underlying question for reflection is in whose interests is a particular view of children's rights (Alanen, 2001; Alderson, 2000; Alston et al., 2005; Franklin, 1995; Ludbrook, 2000; Macfarlane, 2004; Mayall, 2003; Melville Jones, 2000)? 
In the past, sociology did not specifically investigate children and childhood as a separate part of the social world, but now, "new sociology sees children as social actors who are capable of making sense of and affecting their societies" (Matthews, 2007, p. 325). Childhood sociology stems from a social constructionist view of childhood: "the child is not a natural category and what a child is and how childhood is lived is structured by adult norms, aims and culture" (p. 325). This premise underpins criticisms of UNCROC in two ways. First, the fact that there are many definitions of childhood challenges the universal definition of 'child' in UNCROC; and, second, childhood sociology accommodates cultural differences by acknowledging that children experience different childhoods (Bentley, 2005). The next section aims to describe key features in early discourses about childhood and children in New Zealand as a backdrop to introducing some current tensions surrounding children's rights relevant to this research.

\section{Early discourses about early childhood in New Zealand}

Emphasising the fact that childhood is a complex political issue Helen May's (2004, no page) historical analysis of children's citizenship rights noted:

State interest ... began with improving the survival chances of infants. ... Later, support for early childhood services was justified as various kinds of equity issues for children, women and minority groups, and most recently as a prudent economic investment.

McDonald (1978, 1980) provided a useful framework for positioning discourses about children in New Zealand. Starting from the early colonial view, he identified several distinctive phases of childhood, which inform our understanding of the European child in Aotearoa New Zealand. The phases he identified were: the child as a chattel in the 1800s; the child as social capital during the 1900s; the child as a psychological being from the 1940s to the 1970s; and the child as a citizen in 1970s. At the same time as defining these distinctions he added, "( $\mathrm{t}$ )here is a sense in which one can see children's rights as a battleground for wider moral and political issues" (1980, p. 25), particularly when it comes to who is responsible for ensuring that the rights of the child are met - the state or the immediate family? How responsibility is allocated to each party shifts according to wider political, social, economic, and cultural influences, especially when it comes to the provision of early education (May, 2001; Te One, 2004). 
Brian Easton (1980), an economist, regarded children as people with exactly the same rights as adults: "In such a framework the problem of children's rights is how to provide such rights, given that children have important differences from adults in that they are immature and developing" (p. 78). Using an economist's gaze, he argued that the "activity of growing up to the status of an adult (who can earn in the labour sense) is also an economic activity" (p. 78). Therefore, because children are economically active, they have rights.

Easton's claims can be understood in the context of the child liberation movements of the 1970s, which were part of a worldwide questioning that challenged the lessthan-equal status of women and non-white ethnic groups. This broad activism provoked possibilities for change that sought to shift the locus of power from the authorities in schooling more towards the children. Early childhood in New Zealand during the 1970s experienced a willingness to relax a reliance on highly structured environments and routines for children, and to embrace the notion of learning through play (Densem \& Chapman, 2000; Somerset, 1976, 1986).

At the same time there was a growing awareness of the status of Māori as tangata whenua (indigenous people) and the importance of the Treaty of Waitangi as a founding document for Aotearoa New Zealand. For Māori, the combination of language loss and a major urban shift weakened the traditional whānau (family) structures and threatened the future for Māori, and the Māori language. The Kōhanga Reo (literally, language nest) movement began during the 1980s and focused on infants and young children as the future for Māori (Irwin, 1990). Children were an embodiment of hope. The child as cultural capital could be another phase to add to McDonald's (1978) original analysis, and contributes important contextual background to rights issues in New Zealand, especially Māori children's rights to be educated in Māori, an entitlement identified in UNCROC.

\section{Tensions between needs and rights}

Chapter 1 commented on the tensions between needs and rights generally. The origins of a needs-based discourse can be understood in several ways. The following sections expand on that discussion, and locate the tension in the context of New Zealand's history of early childhood. Fundamental to perceptions of children's rights debates are questions concerning children's needs. If children are perceived as 
lacking the capacity to exercise their rights because they are not yet considered competent, can they be autonomous or independent (Jenks, 1996)? Neediness and dependence are commonly associated with early childhood and detract from a rightsbased perspective (Woodhead, 1997). Therefore, it is appropriate to question how children's rights are perceived, protected, and provided for during these years.

\section{The right to work, the right to childcare}

John (1996) was among several commentators who noted that even extreme need does not guarantee children a right. The demand for childcare influenced the growth of the early childhood sector. Women's increasing participation in the workforce led to campaigns for improved provision and access to childcare and to demands for improved quality standards of that care (see May, 2001; Smith, 1996). These are provision rights issues, notably Article 18 that obliges states parties to "take all appropriate measures to ensure that children of working parents have the right to benefit from childcare services and facilities for which they are eligible" (CRIN, 2007, p. 7).

The first wave of influence a needs-based discourse began in the aftermath of World Wars One and Two and is evident in discussions about early drafts of human rights treaties for children (Goldson, 1997; Hammarberg, 1990; John, 1996), where the primary concern was to protect children, and provide for their welfare, rather than protecting children's rights (see also Archard, 1993; Kehily, 2004; May, 1999, 2001). As women's participation in the labour market increased, early advocacy for childcare, closely aligned with feminists' goals, focused on affordable, accessible, and readily available services (May, 2001). Childcare provision is "a civil right to guarantee equality of access to the labour force of mothers of young children" (Phadraig, 1994, p. 77). The economic drivers underlying the increased participation of women in the workforce revealed tensions to achieving a balance between work and home life (Boston, Dalziel, \& St John, 1999; Callister, Podmore, Galtry, \& Sawicka, 1995; Else \& Bishop, 2003). The flow-on effect of these economic drivers impacted on both provision and quality of early childhood services, and resulted in improved conditions and services within the early childhood sector (Dalli \& Te One, 2002; May, 2001). 


\section{Advocates for quality early childhood education: A rights-based argument}

The second discourse of needs and rights is apparent in New Zealand's history of advocacy for children's rights to high-quality environments. The advocacy for quality began in response to critics of childcare, and argued that the need for quality early education was, in fact, a child's right. The quality debates of the 1980s and 1990s debunked myths that childcare posed a risk to normal development. Research indicated that early childhood education of good quality was educationally sound (Podmore et al., 2000; Smith, 1996). Investment in early education had long-term, cost-effective social benefits (Meade \& Cubey, 1995; Schweinhart \& Weikart, 1997).

Quality in Action (Ministry of Education, 1998) and Ngā Arohaehae Whai Hua. Selfreview Guidelines for Early Childhood Education (Ministry of Education, 2006) are recent policy initiatives. Both are examples of regulatory provisions that promote quality by focusing on processes as well as compliance. Defining quality is difficult and problematic particularly when assessing interactions and experiences with children. Research (Carr, 2001; Carr et al., 1998; Clark \& Moss, 2001; Flewitt, 2005) demonstrates that children are able to contribute in meaningful ways to enhance the quality of their experiences. Ministry of Education resources like Kei Tua o te Pae (Ministry of Education, 2005) position the child's perspective as integral to effective pedagogical documentation. This positioning reflects a commitment to respecting children and supports children's rights to be informed, consulted, and participate in decisions that affect them. Consequently, it is clear that the quality of the early childhood experience matters - children need good-quality early education in order to benefit socially and educationally (Ministry of Education, 2002; Smith, 1996). But children also have a right to good-quality early education, which is a rights-based argument relevant to this thesis.

\section{Theories of development: Needs-based or rights-based?}

Early childhood theory and practice has been influenced by developmental psychology, anthropology, sociology, and more recently, socio-cultural historical theories including bio-ecological theory (see Ministry of Education, 1993, 1996b; Te One, 2003). Woodhead (2005, p. 94) posed two questions to distinguish between theoretical perspectives on development:

Developmental theories argue that at a certain age or stage, the child is capable so the key question is 'At what stage does the child become competent to participate?' The role of the adult would be to monitor children's 
growing capacities and make judgements about whether they are ready to participate ... Sociocultural theories of development ask 'How do children's competencies develop through appropriate levels of participation?' ... This way of posing the question draws attention to principles of guided participation and communities of learners.

Arguably, developmental, maturational approaches are deficit approaches based on children's needs. Children are cast as dependent, passive, and not yet competent (Te One, 2004). Conversely, sociocultural theories (Rogoff, 2003) position children as active agents in their development, contributing to their experiences. Woodhead (2005, p. 93) suggests a combination of social constructionist and sociocultural perspectives might balance the tension between needs and rights. "How the balance is struck in turn depends on which theories about developing competence are given strongest weight." Stainton Rogers (2004), as others have done, locates the origins of the needs discourse in the United Nations Declaration on the Rights of the Child (1959) where needs were not "material needs ... but psychological needs" (Stainton Rogers, 2004, p. 94) for love and understanding, optimal conditions at critical times to nurture attachment, and to facilitate cognitive development.

These theories position children as:

- lacking adult capacities of autonomy, rationality and responsibility;

- psychologically and emotionally dependent and vulnerable;

- 'needy' for particular experiences and opportunities which, if not provided, will undermine the child's proper development. (Stainton Rogers, 2004, p. 129)

Yet another perspective is offered by Walkerdine (2004) who argued that childhood is not cemented as truth, but is influenced by time, and the relationship between knowledge and power: "childhood is almost always produced at any one time and place" (p. 101). Walkerdine p. 105) argued that approaches to the study of childhood and children's development need to accommodate the constantly shifting understandings of childhood. Despite this post-developmental approach, James (2004, p. 36) claimed that:

The concepts of childhood and children bear the legacy of deterministic agebased models of the child. They often work to frame our everyday social relationships with children, and thus work as interpretive devices or filters through which children's voices and perspectives must pass.

To sum up this section, age-based maturational theories potentially undermine a child's competence to assert an interest, or right. Commonly held perceptions of 
children's needs are that these are socially constructed (James et al., 1998), as are perceptions of children's rights (Freeman, 1998). Various discourses have influenced this and seem to accept a degree of ambiguity that differentiates between action (the adult role) and agency (the child's participation).

\section{New and alternative discourses of childhood}

A further factor influencing how rights are understood emerges from the reconceptualist movement in early childhood education (Cannella, 1997, 2005; Dahlberg et al., 2007; Dunne, 2006; Hultqvist \& Dahlberg, 2001). This movement challenged the dominant hegemony of Western models of developmental psychology by offering alternative perspectives. For example, by positioning the West as the minority world, this movement argued in favour of multiple models, supportive of distinct cultural traditions and not bound by medical, maturational, or psychological models of child development. These perspectives have been influential at many levels, but for the purpose of this argument, the challenges highlight multiple interpretations of what a child is, and therefore, what his or her rights are across many different contexts. Mitchell and Wild's (2004) thematic review concluded that "the voices of the children themselves, individually as well as in a group, should be foremost, placing the child in childhood" (p. 739).

Dalhberg et al. (2007) identified three distinct discourses in early education. First is the deficit discourse which positions the child as immature, and not yet competent early education, therefore, is a necessary intervention which focuses on outcomes, benchmarked to a mainstream concept of normal development. Second is the discourse of motherhood. Here early education somehow strives to replicate the home, and consequently, the emphasis is on relationships and the pedagogy of attachment. The third discourse concerns the global corporatisation of early education as a financial business investment: children are not commodities and neither are social and educational services. Children's rights are risked if early education provisions are subject to the whims of global economic variables.

The final aspect in this literature review notes commonalities between childhood sociology and social geography. For example, notions of place and space are critical to both sociology and studies in geography, particularly human geography (Holloway \& Valentine, 2000b), which analyse children's experiences of learning, playing, and 
living, and how these experiences "contribute to current debates about spatiality in the new social studies of childhood" (Holloway \& Valentine, 2000a, p. 1). Despite their "empirical diversity [there] is a common engagement with current debates about the nature of childhood" (p. 1). Holloway and Valentine (2000a, p. 9) argue that:

... one of the most important contributions that geography can make to the new social studies of childhood is to illustrate the importance of place. In a very general sense, geographical studies can add texture and detail to the currently rather broad brush analysis of the social construction of childhood ... by arguing that childhood is constructed in different ways in different times and places.

A recent study (De Visscher \& Bouverne-De Bie, 2008) investigated children's neighbourhoods from a social-pedagogical perspective, and posed "the question how and to what extent this environment creates the conditions for realising children's citizenship" (p. 1). Their study found that the neighbourhood, or local community:

influences the relationship between children and society because it is one of the settings in which children can get to know meanings, rules and values of their community and influence them, and where they can experience different social positions. (p. 1)

To conclude, social geography shares principles with childhood sociology (for example, Prout \& James, 1990), and with theories of learning; for example, the idea of situated learning (see Vygotsky, 1978). The studies cited established the relevance of the children's experiences of place and space to perceptions of their rights. The physical location of an early childhood setting may influence perceptions of children's rights, and how these rights are enacted. Similarly, the physical space of a setting could impact on how rights are perceived and, again, how they are enacted.

\subsection{Chapter summary}

Chapters 2 and 3 bring two influences to the theoretical framework used in the thesis and can be visualised using the plait (Figure 7).

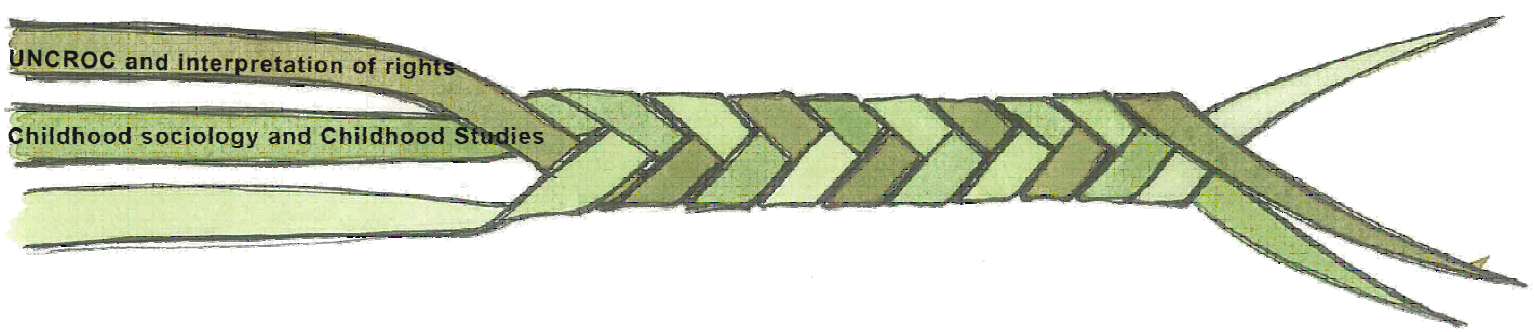

Figure 7: Theoretical influences: UNCROC, interpretations of rights and childhood studies 
This chapter has presented literature from law, childhood sociology, childhood studies, New Zealand and international early childhood research all of which contribute different perspectives on participation that assist understanding children's rights. The issues raised are relevant to this thesis in the following ways. First, the legal perspectives provide an external benchmark for the early childhood sector, which raise some relevant questions regarding children's participation in the early childhood sector, the role of the adult, and relationships between adults and children. These issues include attention to protection rights and provision rights, both of which have legislative obligations. Second, the models of participation problematise rights, and illustrate the importance of context. Adults' relationships with children influence the nature of children's participation in their early education. The challenges of listening to children, and advocating on their behalf, are participation rights issues but these were set alongside examples of protection rights and provision rights to completing an holistic approach to implementation practices.

In Section 3.2, the history of childhood and of children's rights sets a platform for investigating perceptions of these rights. A tension between the adult role to provide for and protect children, as well as to empower children to participate was discussed in terms of children's needs versus children's rights. Themes in this discussion covered states parties' obligations to provide services to families that protected children, and protected children's rights as active agents in their education from a young age. The implications of supporting children to form views impact on the adults working with children. The implications of recognising children's rights were positioned as political acts with the potential to change perceptions of children and childhood from a predominantly developmental psychology perspective to a children's rights approach.

In Chapter 4, theories of human development are linked to children's rights to complete the theoretical framework used in the design and analysis processes of this thesis. 


\section{Chapter 4: Children's rights, and sociocultural and ecological theories of human development}

\subsection{Introduction}

The previous chapter described how the study of childhood (a branch of childhood sociology) and UNCROC are relevant to this thesis. Childhood sociologists point out that there are many constructions of childhood. Childhood studies focus on children's agency, and a premise that children are active participants in their experiences; some children's rights advocates propose that the articles of UNCROC can be categorised rights according to their intention as protection rights, provision rights, and participation rights. How these rights are implemented or enacted depends on cultural beliefs and values, and this aspect is of interest to researchers from the childhood studies movement. Childhood sociologists, childhood studies researchers, and children's rights advocates share a common belief that the social and cultural contexts influence both the interpretation and implementation of children's rights.

The final strand underpinning the theoretical framework for this study draws from sociocultural, historical, and ecological theories. Both theoretical traditions acknowledge the centrality of socially mediated activity to human development and learning. Development and learning are a consequence of participation in social and cultural processes. This is a critical point because it provides a rationale for using these theories as a way to interpret perceptions of children's rights, in particular Article 12 which entitles the child to participate in all matters that concern them. Processes to impart information, and to consult meaningfully, are essential components of effective participation. Therefore, the common thread between sociology, children's rights advocacy, and the theories of human development discussed in this chapter is 'participation'. This study's perspective is relevant because it promotes children's rights as intertwined and indivisible from considerations about their learning.

For over a century, early childhood education "remained tied to psychology, child development, and largely positivist and empirical-analytic paradigms in theory and method" (Bloch, 1992, p. 4). Since the mid-1990s, the New Zealand Ministry of 
Education has supported a diverse approach to learning and development in early childhood - one that retains an alliance with developmental psychology, yet at the same time creates a new paradigm to incorporate ecological theory and recent interpretations of sociocultural theories of development. This current investigation into perceptions of children's rights incorporates diverse theoretical traditions by integrating sociocultural historical theory and ecological theory with childhood sociology, the study of childhood, and UNCROC.

In 1993, when the draft New Zealand national early childhood curriculum, Te Whāriki (Ministry of Education, 1993), was introduced, it positioned four influential theorists (Freud, Piaget, Bruner, and Bronfenbrenner) as 'tall kauri', a Māori metaphorical term for guides, sign posting pathways to development. Te Whāriki (Ministry of Education, 1993, 1996b) marked a seminal point in New Zealand's early childhood history because it managed to accommodate different theoretical approaches to human development by repositioning them within a uniquely New Zealand context, resulting in a reconceptualised curriculum framework (Carr et al., 1998; Te One, 2003).

Since then, the theoretical ideas of the Vygotsky and neo-Vygotskian theorists such as Lave and Wenger (1991), Rogoff (1990, 1995, 1998, 2003; Rogoff et al., 1993), Fleer (2003), and Smith (1998, 2002, 2007a) have been influential in the New Zealand early childhood education sector (see for example, Alcock, 2005; Brennan, 2005; Hedges, 2007; Ministry of Education, 1998, 2005, 2006). Anne Smith (1998, 2002, 2007a) has consistently commented on the appropriateness of both Bronfenbrenner's and Vygotsky's theories to early childhood education, and their relevance to children's rights. Many New Zealand researchers and commentators (Alcock, 2005; Brennan, 2005; Cullen, 2003; Jordan, 2004) are conscious of how cultural and social contexts affect children, and researchers and practitioners alike challenge the constraints of developmental psychology. The combined effect of this dissatisfaction, extensively commented on by the reconceptualists and other postmodern deconstructionists, resulted in a theoretical gap (Canella, 1997, 2005; Fleer \& Richardson, 2004; Kessler \& Swadener, 1992; Walkerdine, 2004). The growing interest in sociocultural theories potentially satisfies the sector as it strives to accommodate diverse social and cultural differences to the mainstream 'minority' world. 
In the sections that follow, descriptive overviews of sociocultural historical theories and ecological theories are proposed as another lens for interpreting children's rights in early childhood settings. This combination of human learning and development theories with the childhood studies and UNCROC is new, and is a potentially useful way to understand rights. The 'golden thread' uniting the theoretical perspectives is how the word 'participation' has been interpreted and applied.

\subsection{The relevance of sociocultural theories to this study}

Sociocultural theories propose that through a process of participation, the values and mores of specific communities of practice and learning contribute to constantly evolving understanding of what community means in that context, as well as how participation in cultural processes is understood. Sociocultural theories and ecological theories consider not just internal development, but also social and political influences on that development. This notion of development appears throughout UNCROC, but is explicitly articulated in Article 12 which states that the emerging capabilities of the child should be taken into account with regard to appropriate participation.

Although not specifically addressed as a rights issue, it can be argued that participating in ways conducive to development (Article 29) assumes that children are safe (protected) (for example, Articles 2, 3, and 19), and that provision rights (see Article 18) are effectively implemented. The implications of Article 29 are that the state will act in the best interests of the child (Article 3) to provide optimal conditions for children and families (Preamble of UNCROC). Protecting children's rights to participate cannot be achieved unless children are protected (from harm) and provided for (within families, communities, and society). Hence, protection rights and provision rights cannot be separated from participation rights. If a child is not safe (protected), it calls into question the quality of provision (how rights are implemented) which might compromise the quality of their participation in social and cultural processes; in this case, in their early childhood education. These points support the notion of an holistic interpretation of rights and are theoretically relevant because non-implementation potentially impacts negatively on children's development. 
The relevance of sociocultural and ecological theories to children's rights has been established in reports and research (Kehily, 2004; Lansdown, 2005; Smith, 2007a; UN Committee, 2005). The study of childhood, sociocultural theories, and UNCROC value the child's experience. There is a synergy between the theoretical disciplines emphasising the importance of participation. Sociocultural theory encourages analysis of the social, cultural, and historical context. Relationships between "adult-child guided participation and children's development point to the importance of achieving a shared focus of attention, with children's participation and social guidance building on the children's perspective" (Rogoff, 1990, p. 192). Similarly, models of participation from theories of children's rights analyse relationships between adults and children in joint activities, educational or otherwise (Hart, 1997; Lundy, 2007; Thomas, 2007).

Further, recent early childhood education research discusses both why and how children participate (Carr, 2003; Clark \& Moss, 2001). Finally, a rights-based approach is essentially concerned with power and status; a community of learners approach also addresses the inherent power imbalance between adult and child; in a community of practice, there is a power differential between newcomers and old timers (Benzie, Mavers, Somekh, \& Cisneros-Cohernour, 2005; Wenger, 1998). Notions of participation form a conceptual bridge, fostering relationships based on jointly shared repertoires of knowledge (Lave \& Wenger, 1996). These theoretical concepts influenced the research design, and the analysis framework. The next section discusses the potential contribution of Vygotsky's (1978) sociocultural theory to the research.

\subsection{Vygotsky's sociocultural theory and children's rights}

Vygotsky is the father of sociocultural historical theories and activity theory (Smith, 2002). To understand his theory, it is important to understand the political climate in which Vygotsky both studied and researched. Post World War One Russia had a population of approximately seven million orphans that constituted a significant social problem. New institutions were established to educate these children; however, the dominant pre-revolutionary, pre-war specialists were not Marxists. As part of "attempts by the new Bolshevik government and by individual scholars to encourage or generate Marxist schools of thought" (Knox \& Stevens, 1993, p. 3), 
Vygotsky proposed a "new, eclectic Marxist view which emphasised cultural, rather than hereditary, influences on development and which drew heavily on his own reading of Western psychology" (Knox \& Stevens, 1993, p. 5).

Vygotsky was highly critical of separatist special schools for homeless, abandoned as well as handicapped children and "insisted that special schools should share with the general educational system the social goals set by the Soviet state: productive labour and self-sufficiency" (Knox \& Stevens, 1993, p. 5). It appears that his short working life was subjected to the whims of political agendas, and while his work was initially praised during the 1928 cultural revolution for its perceived critique of bourgeois, Western ideals, Stalin later dismissed Vygotsky's contributions as too eclectic, too idealistic, and with very little practical application (Reiber \& Carton, 1993, p. 192).

Vygotsky's research was influenced by context. From a children's rights perspective, his focus on orphans matched the international child welfare concern of the era. Penuel and Wertsch (1995, p. 84) suggest that "the major thrust of his work was dedicated to the proposition that all human mental functioning is socioculturally, historically and institutionally situated". A critical point of difference between Vygotsky and Piaget is how the individual is positioned (Rogoff, 1990; Vygotsky, 1993a, 1993b). "Whereas many researchers have examined development as a process taking place within individuals, Vygotsky examined development as a process of transformation of individual functioning as various forms of social practice became internalised by individuals" (Penuel \& Wertsch, 1995, p. 84).

Vygotsky claimed that individual development involved "a fusion of the ontological and the cultural, and individual mental processes have their origins in social interaction" (Penuel \& Wertsch, 1995, p. 86). Wertsch (1985, p. 15) comments "that much of what is unique about this approach is the way three themes are intertwined. This notion resonates for the early childhood sector where a mix of theoretical traditions exists, although it has been argued that the sector has been dominated by developmental approaches that focus on the individual (Bloch, 1992; Fleer \& Richardson, 2004; Kessler \& Swadener, 1992). Vygotsky's approach to genetic analysis did not assume that research could be reduced to a single set of explanatory principles. Instead, the critical issue is "how to account for the changing 
relationships among multiple forces of development and their corresponding sets of explanatory principles" (Wertsch, 1985, p. 19).

Vygotsky critiqued the approaches of his time:

Unfortunately, in common practice, a child's developmental history is usually set out in terms of that precisely misleading dualism of environment and heredity. Practical pedology is rarely able to envision both as one entity, and the child is usually represented exactly like a puppet which can be manipulated by jerking two strings: his development unfolds like a drama manipulated by two powerful influences. (1993b, p. 282)

He extended this argument further to support explanatory approaches to research and expressed concern that misunderstandings about method influence the interpretation of psychological phenomena (Wertsch, 1985). Consequently, Vygotsky argued for a dynamic and holistic approach to both child development and education to counter what he regarded as limitations. For Vygotsky, education was problematic:

Yet it is education broadly speaking that should comprise the basic pivot around which the child's personal development is to turn. A particular line of development should be seen as a necessary and logical result of a particular line of education. Thus without a scientific examination of a child's education, a pedologue (educational psychologist) will never be able to construct an image of child development. It should be understood that, by education, we mean not only teaching, but all educational measures consciously undertaken by the parents in relation to the child. We are referring then to education in the fullest meaning of the word, as it is understood in contemporary pedology. (1993b, p. 282)

This broad definition of education has relevance to the early childhood sector, which emphasises relationships with people, places, and things, and, in principle, promotes working in partnership with parents. An unrealised potential of Vygotsky's question about education concerns not just how parents, teachers, and children perceive children's rights in early childhood settings, but also how the education system perceives children's rights. How policies impact on practices when it comes to children's rights was a question addressed in this research (see Te One, 2004, 2005).

It is not difficult to understand why early childhood scholars in New Zealand have embraced Vygotsky's theories so enthusiastically. He suggests an interwoven theory, holistic and dynamic in its approach with a focus on processes set within a social and historical context: "Any psychological process carries within itself both hereditary predispositions and environmental influences" (Bein, Vlasova, Levina, 
Morozova, \& Shif, 1993, p. 304), which in turn lead to higher mental functions. Vygotsky recognised the child as an active agent in his or her development and argued: "from the first days of his existence, a child finds himself acted upon by his surrounding social environment and interacts with it. This action and interaction determines his development and, as it were, leads it along" (Bein et al., p. 304). This is congruent with theories from childhood sociology, and with the participatory intentions of UNCROC.

Language/speech is developed collectively, and leads to higher forms of psychological activity "completed in the process of a child's social development, in the process of a child's relationships, and in his cooperation with the surrounding social sphere" (Vygotsky, 1993a, p. 192). Language "goes through a whole series of changes during a child's development, [showing] how the most important form of collective behaviour - social cooperation with others - becomes an inner form of psychological activity for the personality itself" (Vygotsky, 1993a, p. 193). For Vygotsky, language and speech acted as critical mediating tools that held the key to participation in social and cultural contexts, concepts shared by childhood sociologists and commentators on children's rights.

Recognising how children communicate (verbally and non-verbally) is critical to children's rights. What processes are possible in the social sphere or, in other words, how is the child heard, or listened to? In this thesis, questions emerging from theories about children's participation rights concerning both space and voice (Lundy, 2007; Shier, 2001) intersect with Vygotsky's awareness that context influences development - an underlying concern of childhood sociologists. Children in early childhood settings have the right to be consulted, and to participate in constructing their own early childhood educational experience.

According to Vygotsky, internalisation is critical to development. During this process "patterns of activity ... performed on an external plane come to be executed on an internal plane" (Wertsch, 1985, pp. 61-62) through the zone of proximal development. This zone is "the distance between the actual developmental level, as determined by independent problem solving, and the level of potential as determined through problem solving under adult guidance or in collaboration with more capable peers" (Vygotsky, 1978, p. 86). 
Smith (2002, 2007b) argued for a serious consideration of Vygotsky's sociocultural historical theory as an appropriate theoretical approach for early childhood education, not just as theory of learning and development, but also because it is supportive of children's rights. The role of the adult allows "for a gradual shift in the balance of power towards the child taking initiatives and having responsibility" (Smith, 2002, p. 81). It is through language and communication (non-verbal and verbal) that children gain entry into the culture, and therefore participate in a setting. However, the quality of this participation depends on the supportiveness of the social and cultural context, as well as the nature of the relationships within that context. Children have rights to be listened to, to have a voice, and to participate on terms that are understood by all members of a community. They also have a right to have these participation rights protected, the right to be protected, and the right to an early childhood service which provides conditions to ensure children's rights can be implemented. Although the extent to which this happens varies, it is widely accepted that if "children can have a trusting and reciprocal relationship with adults, even very young children can communicate their intentions and views, and adults are likely to be responsive to their voices" (Smith, 2002, p. 85).

To sum up this section, central to Vygotsky's theoretical ideas is the concept of internalisation. The child learns/develops as a result of participation in the social world. For Vygotsky, private speech, the internal language of the child as a result of external actions/interactions with others, resulted in learning and then development. Vygotsky believed that internalisation formed the human mind and was a result of "transformations of social interactions" (Berk \& Winsler, 1995, p. 100). A 'plane of consciousness', an idea of Leontiev's, is formed through a sense of unity between external and internal processes (Palinscar, 1998, p. 5). Vygotsky regarded children as participants in social and cultural contexts. By participating alongside skilled others (peers, teachers, adults) within the zone of proximal development, children learn. The process of development is not separated into discrete bits - rather, there is a continual, dynamic process where the social world and the private inner world of a child combine.

From a children's rights perspective, this idea is very important. Teachers and adults in whānau-led early childhood settings need to assume a collaborative role in which they can encourage children to explore through assisted discovery (Berk \& Winsler, 
1995; Bodrova \& Leong, 2005; Kozulin, Gindis, Ageyev, \& Millar, 2003). The social experience directly influences how children learn and then develop. Because of this intersubjective, interactive process, attention to the social conditions of early childhood settings is relevant. Essentially, sociocultural theories focus on conditions for learning, and if, as the official literature suggests, sociocultural approaches are favoured (Ministry of Education, 1996a, 1998, 2002). Good conditions for learning imply respect and recognition for children's rights to protection as well as to certain standards of provision. What follows is a discussion of recent sociocultural theories and how these contribute to understanding perceptions of children's rights in early childhood settings.

\subsection{Sociocultural constructs of community and children's rights}

Recent sociocultural approaches pertinent to this research (for example, Fleer, 2003; Lave \& Wenger, 1991, 1996; Rogoff, 1990, 1998, 2003) include constructs of community (Podmore, 2004a, Rogoff, 2007). The theoretical concepts about communities of learners and communities of practice influenced the research methodology and design. In this research, the case study centres could be envisaged as examples of communities of practice, and as communities of learners.

Constructs of community address the question of how to balance the rights, interests, and activities of the individual child in the collective enterprise of an early childhood setting. The dilemma of 'individual' in the 'collective' parallels a rights-based dilemma of how to balance individual rights with the rights of the wider group. In sociocultural terms, this is resolved through shared understanding achieved through "participating in a three-way process of mutual engagement, joint activity or enterprise to develop a shared repertoire of knowledge" (Podmore \& Te One, 2008, p. 21).

\section{Communities of practice and children's rights}

Lave and Wenger (1996), Wenger (1998) and Wenger et al. (2002) developed the notion of a community of practice, furthering sociocultural theories to include shared understanding of mutual enterprise and co-operative activities. Communities of practice are "an ideal learning context in which new members of the community can engage in 'legitimate peripheral participation' and be inducted into the community" 
(Benzie et al., 2005, p. 181). Wenger (1998) and Lave and Wenger (1991) observed members in communities of practice converting abstract ideas into practical, workable tools to develop a shared understanding: “(a)ctivities, tasks, functions, and understandings do not exist in isolation; they are part of broader systems of relations in which they have meaning" (Lave \& Wenger, 1991, p. 53). For example, if not embedded in the shared understanding of a community of practice, children's rights are vulnerable to an organisational culture that may underrate their importance.

Lave and Wenger (1996) identified that, in a community of practice, "legitimate peripheral participation provides a framework for bringing together theories of situated activity and theories about the production and reproduction of the social order" (p. 143). Lave and Wenger $(1991,1996)$ use Engström's (1987) notion of the zone of proximal development, which they argue, leads researchers to "concentrate on processes of social transformation" (Lave \& Wenger, 1996, p. 144). They were expressly interested in theories of social practice, situated in a socially constituted world that "emphasizes the relational interdependency of agent and world, activity, meaning, cognition, learning and knowing" (Lave \& Wenger, 1996, p. 145). Marilyn Fleer (2003, p. 232), too, acknowledges relational interdependence in the enactment of early childhood curriculum and suggests that:

Meaning does not reside in an individual or even in printed matter, but, rather, meaning exists through a dynamic process of living in the world. Early childhood cannot exist unless a community gives it meaning and brings it into existence.

A final feature of communities of practice relevant to this study is the notion of “benign community neglect" (Lave \& Wenger, 1991, p. 93). Benzie et al. (2005, p. 182) claim this idea:

provides space to learn from other apprentices. In this way, individuals move from peripheral to more intensive participation, and towards full participation in the community. ... There are strong goals for learners because, as legitimate peripheral participants, they can develop a view of what the whole is about and what there is to be learned.

In early childhood settings, sustained individual attention between teachers and adults, and children can be difficult to achieve. Benign community neglect need not be interpreted negatively. Instead, it has the potential to recognise the contributions that peers can make to a shared understanding of joint activities. Benign community neglect as a concept legitimises quiet, individual learning. For example, a new child 
observing the rules and rituals of a morning tea routine in an early childhood setting may copy peers' inappropriate behaviours, motivated by a desire to be part of the group (community). The adult role may be largely silent, in a situation where joint actions result in understanding. Rather than directive, the process of becoming a community member is inductive.

Although the community of practice perspective offers leverage in our understanding of rights, Hedges (2007) raises several flaws with the construct, notably a preoccupation with inducting participants into a norm established from within, which can ignore the funds of knowledge children and whānau bring from other communities. Children's rights permeate across communities, and perceptions of rights need to account for children's experiences beyond the early childhood setting to consider the broad sociopolitical environment. Further, Hedges argues that, theoretically, communities of practice lack an explanation for co-constructed individual learning characteristic of early childhood practice, and perhaps of learning with very young children. Education at this level is not a linear process, but creative, innovative, and individual. Again, conforming to a community of practice could create tension between individual rights and the rights of the collective - everyday tensions in an early childhood setting.

Rogoff (2003) explores these tensions and identifies community generated characteristics. According to Rogoff:

\footnotetext{
Community involves people trying to accomplish some things together, with some stability of involvement and attention to the way they relate to each other. Being a community requires structured communication that is expected to endure for some time, with a degree of commitment and shared though often contested meaning. A community develops cultural practices and traditions that transcend the particular individuals involved, as one generation replaces another.
}

Relationships based around a shared purpose establish a sense of community. Rogoff adapted the principles of community (shared purpose, stable relationships, agreed to structures and practices) to educational settings which she described as a community of learners.

\section{Community of learners}

Rogoff et al.'s (1996) construct of a community of learners repositions children's and adults' roles in learning/teaching situations, shifting the balance of power towards 
the child, and as such support children's rights to be consulted in meaningful ways about their learning. Rogoff et al. (1996) identify three models of learning. First, in an adult-run model of learning, "adults are seen as responsible for filling children up with knowledge, as if children are receptacles and knowledge is the product. The children are not active participants in learning" (p. 391). In this model, the adults determine the curriculum and the ways it is enacted. The role of the teacher is based on the assumption that adults teach and learning is regarded as a "one-sided transmission of knowledge and skills from those who possess them to those who do not" (p. 395).

The direct opposite of the adult-run model is the child-centred approach "in which children are active constructors of knowledge and adult involvement is seen as a potential impediment to learning" (Rogoff et al., 1996, p. 395). This model subscribes to an image of the child as freely and actively discovering and exploring. While it is acceptable for adults to set up the environment to facilitate learning, the adult role is limited. Children are expected to learn the skills, knowledge, and attitudes naturally, following their own course of learning which creates a challenge, not so much in early childhood education, but certainly in the compulsory sector: that natural learning will "somehow correspond with the skills and standards that the community values for the children" (Rogoff et al., 1996, p. 395).

To counter the dichotomy of an either/or model that favours either adult or child, the community of learners model claims to resolve the power imbalance. Inherent in the previous two models is a dualism: when one partner of the dyad is active, the other is confined to passive involvement. So in an adult-led model, the teacher (usually) has the active role, and children are passive recipients of knowledge. In a child-centred model, children determine the course of learning, and the adult supports, or facilitates, this indirectly through controlling the environment.

Alternatively, the community of learners model is based on principles of collaboration that encourage shared endeavours towards learning as a process. In that process, all participants learn, and the responsibility for learning is shared. The model adopts an integrated, holistic approach to learning and highlights the tensions between developmental psychology with its focus on the individual and the alternative community spirited approach (Fleer \& Richardson, 2004). 'Participatory 
appropriation' describes the nature of increasing contributions to and within a community of learners based on certain principles:

In a community of learners, the model is learner-centred; knowledge is coconstructed with teachers weaving the connections between themselves, the subject, and their students. The subject to be learned is the focus and the teacher's role is that of a facilitator of meaning making. The community, then, is a place built on fairness, freedom of expression, and responsibility, where learning is meaningful and relevant to children's lives and experiences. All voices are heard, respected, and an integral part of the fabric of learning. Community is about connectedness and relationships; it is where one learns to value and sincerely appreciate diversity in a multitude of forms. (Bartel, 2005, p. 152)

Sociocultural constructs of community are helpful markers to guide the research because they offer some traction towards insights about how participants might perceive children's rights within their specific communities of learners and of practice. Similarities in these models echo theoretical drivers in rights-based models - voice, space, and children's agency are entitlements fundamental to effective functioning in a community. Interactions, in theory, are underpinned by respect and a sense of justice. However, rather than relying on an uncritical approach to the community of learners model as beneficial and optimal to development, there is a need to attend to what is valued as learning, and how it is being learnt. Investigating perceptions of children's participation rights, as well as their protection and provision rights, might provide insights into the social and cultural practices and processes of particular communities of learners.

\section{Shared understanding}

The concept of shared understanding can be observed in communities of practice and in communities of learning. Wenger (1998) and Rogoff (1990, 2003) described learning as a participatory act dependent on shared thinking. In what Rogoff et al. (1993) describe as a creative process, children's understanding is transformed when they assume different roles and responsibilities in their communities. However, "learning to coordinate understanding and effort is inherent in observation and participation in social activity because, without some shared understanding, communication and shared activity could not proceed" (Rogoff et al., 1993, p. 6). Guided participation (Rogoff, 1990) and legitimate peripheral participation (Lave \& Wenger, 1991), are bridging processes which form "connections between the known and the new" (Rogoff et al., 1993, p. 8). In this process, "children seek connections between old and new through reciprocal relationships with more mature members of 
their community" (Rogoff et al., 1993, p. 8). Early childhood centres constantly accept new enrolments, and staff turnover can be high; therefore, how members of existing communities induct new members could influence how children's rights are both perceived, as well as enacted. Guided participation and legitimate, peripheral participation are explained in Section 4.4.

\subsection{Participation: Legitimate, guided, transformed}

A common theme emerging from sociocultural theories concerns participation, how it occurs, and the effects it has on constructs of community. Participation is also a theme common to childhood sociology and to theories about children's rights. For childhood sociologists and children's rights advocates, participation derives from constructions of the child as active, and from UNCROC, particularly Article 12. For sociocultural theorists, participation is critical to development and is the basis of shared understanding. Community members' participation is enhanced through social and cultural activities of a community. Rogoff (2003, p. 52) observed that "development is a process of people's changing participation in sociocultural activities of their communities" (italics in the original).

\section{Legitimate peripheral participation}

"[Legitimate peripheral participation is] the process by which newcomers become members of a community of practice" (Lave \& Wenger, 1991, p. 55). According to Podmore and Te One (2008, p. 22), "legitimate peripheral participation can be understood in terms of relationships between newcomers and old timers": a person's participation as a newcomer in the "activities, tasks, functions, and understandings (that are) part of the broader systems of relations in which they have meaning" (Lave \& Wenger, 1996, p. 147). The reciprocal nature of legitimate peripheral participation means that learning both enables participation and evolves to accommodate it:

Learners learn by participating in a community of practitioners; they undertake tasks which contribute to the productive activity of the enterprise. The newcomer is not just an observer but also a participant at increasingly multiple levels as a member of the community. (Lave \& Wenger, 1991, p. 98)

Benzie et al. (2005, p. 182) note that "legitimate peripheral participation is not just about the goals, tasks and knowledge acquisition but also identity. In performing new tasks and demonstrating new understanding, learners' identities are transformed.” 
The idea of a newcomer being inducted is equally applicable to adult and child alike. The nature of that participation is critical to children's rights and, in the early childhood setting, involves children, teachers, and parents "undertaking the tasks which contribute to the productive activity of the enterprise" (Lave \& Wenger, 1991, p. 98). How, when, and on whose terms the child participates in these activities becomes a rights-based issue, particularly if the access to the activities is controlled by a different community of practice - the adults.

\section{Guided participation}

Barbara Rogoff described children's cognitive development as an apprenticeship: “it occurs through guided participation in social activity with companions who support and stretch children's understanding of and skill in using the tools of culture" (1990, p. vii). The concept of guided participation develops Vygotsky's notion of the zone of proximal development (Rogoff, 1995, 1998; Rogoff et al. 1993). In a detailed discussion that closely examines both Vygotsky's and Piaget's contributions, Rogoff (1990) asks the following question:

What do children gain from social interaction and under what circumstances? (p. 137)

Rogoff's question focuses on children's advancement, but the question can be interpreted from a child's rights perspective. Consideration of the day-to-day conditions of engagement between children and adults from this perspective adds a new dimension to the notion of progress and even learning. Rogoff (1990, p. 138) comments:

[f]eatures of adult-child interaction and arrangements may have little relation to children's learning. It is important to examine explicitly the influence of expertise of partners, of equality of status, of shared problem solving, of the structuring of children's efforts, and of the transfer of responsibility to children over the course of development.

Guided participation does not assume that the guide is the adult in joint thinking. A community of learners approach supports "active individuals seeking their own understanding" (Rogoff, 1990, p. 189). Accordingly, "guided participation involves collaboration and shared understanding. [It is through] guided participation with others, children come to understand and participate in the skilled activities of their culture" (p. 191). Children's participation rights require guided participation. More experienced participants in a community of learners have a role to support children to 
form an opinion; hence the notion of guided participation in cultural processes has relevance to this thesis.

In a process known as internalisation, Vygotsky (1978) believed that children's thought processes moved from the external, interpersonal domain, into the intrapersonal, internal mind. According to Rogoff (1990), this assumes that external social interactions are separate from individual internal thought. Rogoff argues that participation (as a developmental idea of transforming development) is both interpersonal at the same time as it is intrapersonal:

In the process of participation in social activity, the individual already functions with shared understanding. The individual's later use of this shared understanding is not the same as what was constructed jointly; it is an appropriation of and involvement in the activity. (p. 195)

To understand more clearly children's development, and hence their rights, Rogoff et al. (1993, p. 149) suggested three planes for analysis: the intrapersonal plane, the interpersonal plane, and the community plane:

... guided participation can be conceived as one plane of analysis in the understanding of how people function and develop in sociocultural contexts, one accompanying the other two planes of analysis - processes of community change and individual change - that are inseparable from the process of observation of interpersonal processes.

These interrelated processes have been interpreted and applied to educational settings to understand how relationships between people, places, and things influence development (Fleer \& Robbins, 2004; Haste, 1987; Ministry of Education, 2005; Pollard, 1993).

\section{Transformation of participation through shared understanding}

Rogoff $(1995,1998,2003)$ developed the idea of appropriation further to emphasise the process of participation. With participatory appropriation (Rogoff, 1995), the concept of transformation involves ever increasing levels of participation and responsibility in activities (Fleer \& Richardson, 2004). Fleer and Robbins (2004) explored the notion of learning as interplay between people and contexts using Rogoff's (1998) concept of moving "through rather than to understanding" (Fleer \& Robbins, 2004, p. 48). Transformation of participation focuses the researcher's attention on the conceptual tools of a community of practice: "Individuals and groups, while participating in any cultural activity or community of practice employ a range of tools and artefacts, which serve not 
merely to facilitate mental processes, but to fundamentally shape and transform them" (Fleer \& Robbins, 2004, p. 50). They add, "particular communities of practice tend to have their own context-specific ways of thinking, values, histories and artefacts or tools that they use" (2004, p. 50).

Valsiner (1997, p. 27), another sociocultural scholar, argues:

... all educational settings constitute a reflection of the social power structure in any given society ... all symbolic and action rules used in a particular (early childhood) context are aimed at guiding the children towards internalised reconstruction of models of the given society as their personal values understandings.

An early childhood service "is a special place for a selected set of (educational) activities to take place" (1997, p. 28), which begs the question, what activities do not take place there, but may take place elsewhere? He asks to what extent the roles of the teacher and the pupil are pre-determined and by what mechanisms. In terms of children's rights this is significant as a way to analyse the extent to which interactions and experiences are co-constructed (Jordan, 2004).

Recent writing (Paavola, Lipponen, \& Hakkarainen, 2004, p. 573) discusses learning as a process of participation in social practices:

Speaking very generally, the acquisition perspective focuses on knowledge and knowledge structures in learning and learning processes within individuals' minds. The participation perspective emphasizes the meaning of social practices and activities as the bases for learning. And the knowledgecreation perspective focuses on analyzing the processes whereby new knowledge and new mediating objects of activity are collaboratively created.

Collaborative, community, interpersonal, and individual processes may be foregrounded or back-grounded, depending on the research/observational focus. Once again, an essential component concerns how children participate. What opportunities exist for them to observe the culture? Do they participate on equal terms? These questions relate directly to UNCROC. Articles 2, 12, 13, 28, and 29 have direct relevance to early educational experiences.

Rules, rituals, and routines determine the nature of participation in any community, including the case study centres. The extent to which children participate is a critical aspect of shared understanding, and interrelates with constructs from childhood 
sociology, UNCROC, and theses about children's participation rights. These constructs question the degree of separation between the adult world and the child's world. How children learn to participate in other roles in early childhood settings is a rights-based issue, quietly documented as such in official early childhood curriculum and policy documents (see Te One, 2004, 2005).

\section{The role of dissent in communities}

Participation in a community of practice or in a community of learners is "always based on situated negotiations and renegotiation of meaning in the world" (Lave \& Wenger, 1996, p. 146). Because it is possible for one site to contain several communities of practice, transformation of participation encompasses "the contradictions and struggles inherent in social practice and formation of identities" (p. 149). This theoretical perspective accepts the "contradictory nature of collective social practice [that occurs in a community of practice when] engaged in the generative process of producing their own future" (pp. 148-149). Rogoff (1990) presents the case for problem solving as a jointly shared activity in which children "advance their ideas in the process of participation" (p. 196). The consequence of guided participation can "resolve contradictions or search for the common ground of shared understanding" (Rogoff, 1990 p. 196). This is achieved through simultaneously focusing on individual interpersonal processes as well as cultural processes "by which children develop through their participation in the evolving practices of the community" (Rogoff et al., 1993, p. 5). Lave and Wenger (1996) refer to conflicts and contradictions in communities of practice as 'dissensus'. Ideally, relationships, practices, and biographies (Benzie et al., 2005; Colley, James, \& Diment, 2007) in communities of practice are governed by principles or values that cohere with consensus about rights for children and adults. How these co-exist in early childhood settings, where there are competing demands on and for time for adults and children alike, became a site for inquiry during the research.

\section{Cross-disciplinary interpretations of participation}

As well as sociocultural theories of participation, there are other ideas influencing contemporary understandings of children's participation rights. Freeman (1998) proposed an integrated framework combining the "theoretical frameworks of child's rights and sociology" (p. 151), and Smith (2007b) draws together sociological ideas and sociocultural theory. This combination supports rights for young children as 
agents (the sociological idea), and recognises their activities and experiences as socially and culturally bounded processes (the theoretical idea). Using Learning Stories (Carr et al., 2004), and Te Whäriki (Ministry of Education, 1996b) as examples of sociocultural models of early education, Smith (2007a, p. 7) notes that Learning Stories allow children:

to share meaning and power with adults, and to have their voices heard and acted on, to develop agency, [and it] gives all children, not a selected group of children, the opportunity to be active participants in their communities of learners.

Situated learning, contextualised by place, time, culture, and activity, is a sociocultural concept central to a community of learners. The multi dimensional facets of sociological concepts, and rights-based concepts of participation (Sinclair, 2004) mesh with sociocultural theory in the following ways: first, participation in the cultural activities of a community has a transformative aspect. Shared understanding among community members deepened engagement and developed social sense, which furthered understanding of community practices (Chaiklin \& Lave, 1996; Lave \& Wenger, 1991). Rogoff (2003) claimed that "human development is a process of people's changing participation in sociocultural activities of their communities" (2003, p. 52). Arguably, therefore, children "develop as they participate in and contribute to cultural activities that themselves develop with the involvement of people in successive generations" (p. 52).

Second, the balance between the rights of the individual child versus the rights of the group is proffered as a barrier to implementation. Notions of transformation of participation potentially resolve this barrier because of the ways "in which personal, interpersonal, and cultural aspects of human activity are conceived as different analytic views of ongoing, mutually constituted processes" (Rogoff, 2003, p. 52). It is the combination of "the interpersonal, personal, and cultural-institutional aspects of the event which constitute the activity" (p. 58). Not entirely resolved is how influence is reified (Lundy, 2007) in the context of public services (Sinclair, 2004), such as a kindergarten. As Prout (2003, p. 22) noted, “... for children's voices to be really heard, even when the institutional arrangements create a notional space for it, requires change in the way that children are seen". This notional space intersects with ecological theory (Bronfenbrenner, 1979, 2005a; Bronfenbrenner \& Morris, 
1998) where decisions made at a macrosystems level affect children's and teachers' conditions in their immediate setting, or microsystem.

Third, the nature of the relationship between the expert and the novice, working in the zone of proximal development, is akin to the implications of a rights-based approach where there are degrees of power sharing between adults and children (Hart, 1997; Shier, 2001; Sinclair; 2004).

To sum up this section, participation can be understood in various ways, and because of this, enacted haphazardly, hence providing a rationale for investigating how children's rights are perceived (research question 1). Participation is critical to reification, or enactment of rights (research question 2), but there are levels of participation that can be ascribed to the quality of involvement, consultation, and engagement with children in particular settings (Hart, 1992, 1997; Siraj-Blatchford, 2004; Smith, 2002). Rogoff et al. (1993, p. 158) noted how "a sociocultural approach emphasizes that development occurs not just at the level of the individual but also at the level of societal change". This resonates with principles underpinning ecological theory. The next section of this chapter explores ecological theory, and discusses its relevance to this study.

\subsection{Ecological theory and children's rights}

The ecological environment is conceived as a set of nested structures, each inside the next like a set of Russian dolls. (Bronfenbrenner, 1979, p. 3)

Notions of children's rights within an ecological environment are relevant to this research, particularly for the second research question: How are children's rights enacted? What environmental conditions affect children's rights in an early childhood setting? At the time, Bronfenbrenner's (1979) concept of a child developing in the context of family, neighbourhood, culture, and society was revolutionary. These ideas influenced both the design and analytic framing of the research:

His theory in part reacted against a research culture dominated by studies of 'the strange behaviour of children in strange situations with strange adults for the briefest possible periods of time.' (Bronfenbrenner, 1986, pp. 286-288, cited in Bronfenbrenner \& Morris 1998, p. 994) 
Bronfenbrenner supported research in the social and environmental contexts children participated in (Bronfenbrenner, 1979, 1995a, 1995b, 2005d; Bronfenbrenner \& Morris, 1998). His approach aligns with current participatory research approaches respectful of young children's rights (Sinclair, 2004; Te One, 2007; Thomas \& O'Kane, 1998), and influenced the research design (see Chapter 5).

\section{Nested settings to understand development}

Bronfenbrenner's concept of nested settings begins with the innermost nest that includes the child (or developing person), and then moves progressively outwards to encompass the settings that influence the child, but which do not include the child. The settings are defined as follows:

The microsystem "is a pattern of activities, roles, and interpersonal relations experienced by the developing person in a given face-to-face setting with particular physical and material features and containing other persons with distinctive characteristics of temperament, personality and system of belief" (Bronfenbrenner, 2005a, p. 148). The child participates in this innermost setting. For example, an individual child's day-to-day experiences at a crèche, playcentre, or kindergarten are microsystems, as is the child's home.

How various settings interconnect is referred to as the mesosystem and "comprise the linkages and processes taking place between two or more settings containing the developing person" (Bronfenbrenner, 2005a, p. 148). When the developing person participates in a setting, be it the home, early childhood setting, or a communitybased activity, a new microsystem can be discerned. "A mesosystem is thus a system of microsystems. It is formed or extended whenever the developing person moves into a new setting” (Bronfenbrenner, 1979, p. 25).

Ecological theory is concerned with more than the individual's experience in one setting:

Seldom is attention paid to the person's behaviour in more than one setting or to the way in which relations between settings can affect what happens within them. Rarest of all is the recognition that environmental events and conditions outside any immediate setting containing the person can have a profound influence on behaviour and development within that setting. Such external influences can, for example, play a critical role in defining the meaning of the immediate situation to the person. (Bronfenbrenner, 1979, p. 18) 
To resolve this Bronfenbrenner introduced two new conceptual structures: "The exosystem refers to one or more settings that do not involve the developing person as an active participant, but in which events occur that affect, or are affected by, what happens in the setting containing the developing person" (Bronfenbrenner, 1979, p. 25, bold added). For example, management decisions in most early childhood settings do not directly involve children, a point that could be regarded as a breach of their rights under Article 12 of UNCROC, yet the decisions taken at these meetings could affect the child's participation in the setting. Another possible scenario would be whether or not children are involved in planning the centre's programme.

At the broadest level is the macrosystem which:

consists of the overarching pattern of micro-, meso-, and exosystems characteristic of a given culture, subculture, or other broader social context, with particular reference to the developmentally instigative belief systems, resources, hazards, lifestyles, opportunity structures, life course options, and patterns of social interchange that are embedded in each of these systems. (Bronfenbrenner, 2005a, pp. 149-150)

Referred to as a societal blueprint for a particular culture and subculture, the macrosystem includes a shared repertoire of beliefs reflected in the ideologies and institutional practices within the developing person's culture. These beliefs may both create opportunities for development as well as inhibit it, and therefore impact on perceptions of children's rights. Decisions made in a macrosystem influence early childhood policy and practice, and therefore potentially impact on perceptions of children's rights.

Originally Bronfenbrenner did not consider the impact of time on human development or on the environment. However, he later critiqued his original ecological model as static, and consequently added the chronosystem to account for the impact of time over the life course (Bronfenbrenner, 2005a). Attitudes acquired during a lifetime were frequently attributed to early childhood experiences and occasionally to significant events in young adulthood and adulthood where different roles were assumed such as being a university student living in a hostel, or becoming a parent. The chronosystem encompassed environmental change as well as individual development. How these systems were applied to research is outlined in the next section. 


\section{Process, person, context, time, and proximal processes}

Bioecological theory (Bronfenbrenner, 1979, 2005a; Bronfenbrenner \& Morris, 1998) examines the relationship between environment and development by analysing more than just the context and processes that require "a more differentiated research design" (Bronfenbrenner, 2005a, p. 115). Bronfenbrenner proposed a framework that systematically analysed the interactions to include the processes of the developing person in context. Known as the Process-Person-Context model, Bronfenbrenner (2005a, p. 115) argued "as its name implies, this design permits analysis of variations in developmental processes and outcomes as a joint function of the characteristics of the environment and of the person" (italics in the original). This model enabled researchers to recognise synergies "in which the joint operation of two or more forces produces an effect that is greater than the sum of the individual effects" (p. 117, italics in the original).

Later revised descriptions of this model emphasised time as a critical component that not only situated the developing person in the present, but also recognised their participation as an historical moment that was also significant in the present, and potentially significant in the future. Bronfenbrenner and Morris (1998) refer to this as the third generation of ecological theory, where the environment is differentiated further in a highly specified, revised version termed the Process-Person-ContextTime model. Lerner (2005) described it as having four interrelated components:

a) the developmental process, involving the fused and dynamic relation of the individual and the context; b) the person, with his or her individual repertoire of biological, cognitive, emotional, and behavioural characteristics; c) the context of human development, conceptualised as the nested levels or systems, of the ecology of human development ... d) time, conceptualised as involving multiple dimensions of temporality - for example, ontogenetic time, family time, and historical time - constituting the chronosystem that moderates change across the life course. (Lerner, 2005, p. xv)

Bronfenbrenner believed that this model had the capacity to identify ecological niches in the environment that included both facilitative and inhibiting factors, but which also considered the personal characteristics of individuals. Two propositions are foundational in the reformulated bioecological model, in part to restore the focus on the "individual's contribution to the process of development [which] is made by a synthesis, an integration, between the active person and his or her active context" (Lerner, 2005, p. xix). One, bioecological theory is dynamic; and two, human 
development "especially in its early phases, but also throughout the life course, ... takes place through processes of progressively more complex reciprocal interaction between an active, evolving biopsychological human organism and the persons, objects, symbols in its immediate external environment" (Bronfenbrenner \& Morris, 1998, p. 996).

Bronfenbrenner and Morris (1998) explain development as a result of increasingly complex joint interaction between the individual and the environment that includes genetic inheritance as well as enduring proximal processes over extended periods of time (Bronfenbrenner, 2005d). The importance of enduring, reciprocal relationships with people, places, and things is a principle of Te Whāriki (Ministry of Education, 1996b) and a child's right. Therefore, although ecological theory has not been used extensively to analyse children's rights, it is a useful avenue to explore.

The reciprocal nature of proximal processes (Bronfenbrenner, 1979) influences the environments, or settings, in which a child participates. Just as the child reacts and responds to the environment, the social environment in particular reacts and responds to the child. The form, power, content, and direction of proximal processes vary in significance depending on the dispositions (or attitude) of the child, the resources which are a combined effect of genetic ability, knowledge, and skill at any particular stage of development, and the demand "characteristics that invite or discourage reactions from the social environment of a kind that can either foster or disrupt the operation of proximal processes" (Bronfenbrenner \& Morris, 1998, p. 995). Recognising that children's actions influence others is significant in this study, because these actions might influence perceptions of rights and affect how they are observed in practice.

Proximal processes support facilitative actions that encourage children's active participation in their early childhood settings. Features of proximal processes are:

1. Engagement in activity; regularly over an extended period of time; to become increasingly complex, not mere repetition;

2. Reciprocal, respectful, multidirectional interpersonal interactions between children and adults.

3. Reciprocal proximal processes with places and things (objects and symbols) which invite 'attention, exploration, manipulation, elaboration, and imagination.' (Bronfenbrenner \& Morris, 1998, p. 997) 
Stable environments and enduring relationships over time allow for experiences to become increasingly complex and diverse; and stable early childhood educators become significant others over time (adapted from Bronfenbrenner \& Morris, 1998, pp. 996-997). Because proximal processes are critical to children's wellbeing, they are important considerations for investigating children's rights.

\section{Policy and research - a necessary collaborative partnership}

Throughout his life's work, Bronfenbrenner focused on the developing individual within dynamic mutually influential environments with particular attention to early childhood and the conditions under which children and families live and work (Bronfenbrenner, 1970, 1979, 1995a, 1995b, 2005a, 2005b, 2005c, 2005d). Bronfenbrenner (1979) raised the question of who cares for the caregiver. After comparing public/policy infrastructures internationally, Bronfenbrenner concluded that "like human development itself, the course of child care policy and practice is shaped in substantial degree by its broader context in time and place" (2005a, p. 281):

From an ecological viewpoint I suggest that the impact of day care and preschool on the nation's families and on the society at large may have a more profound consequence than any direct effects for the development of human beings in modern societies. (Bronfenbrenner, 1979, p. 165)

Ecological theory factors in non-social aspects of the environment and, as Bronfenbrenner observed, "developmental potential is enhanced [when there exist] direct and indirect links to power settings" (1979, p. 156). Therefore, questioning how policy impacts in practice is an important consideration relevant to the research questions of this thesis. Bronfenbrenner pointed out that participation at the policy macro level influences the potential effectiveness of a setting to enhance development on the micro level. Children's development and learning are enhanced via significant others' encounters with macrosystem processes. Essentially, many of Bronfenbrenner's hypotheses are potential advocacy tools supportive of children's rights in early childhood settings.

Bronfenbrenner's ecological theory was explicit about the role of the adult in an early childhood setting and suggested that learning and development were enhanced "by exposing pupils to adult roles existing in the larger society, both through bringing such persons into the school setting and through involving the children in 
activities in the outside world" (Bronfenbrenner, 1979, pp. 104-105). This implies that children are entitled to 'membership' in the wider society. Further, the adults' role was to stimulate, create, and maintain environments of increasing complexity "commensurate with the child's evolving capacities and allow her sufficient balance of power to introduce innovations of her own" (Bronfenbrenner, 1979, p. 205).

Bronfenbrenner advocated for small group sizes to enhance potential developmental opportunities, a point used by political campaigns in New Zealand (Dalli, 2002; Early Childhood Education Project, 1996; Smith, 1993, 1996). Later, research found that group size, qualifications, and wages and conditions for teachers were significant in determining the quality of an early childhood service (Podmore et al., 2000). One intention of the present research was to draw on ecological theory as an analytic tool to make sense of the planned case studies.

\subsection{A proposed integrated theoretical framework}

The research used an integrated theoretical framework based on sociocultural theories, ecological theories, the study of childhood, and UNCROC (Figure 8) to investigate how children's rights were perceived and enacted. An integrated approach builds on the arguments in previous chapters in which the contributions from childhood studies and UNCROC were discussed. The view of the child as capable and competent, actively participating in relationships with people, places, and things, was positioned together with children's rights articulated in UNCROC, notably protection rights, provision rights, and participation rights.

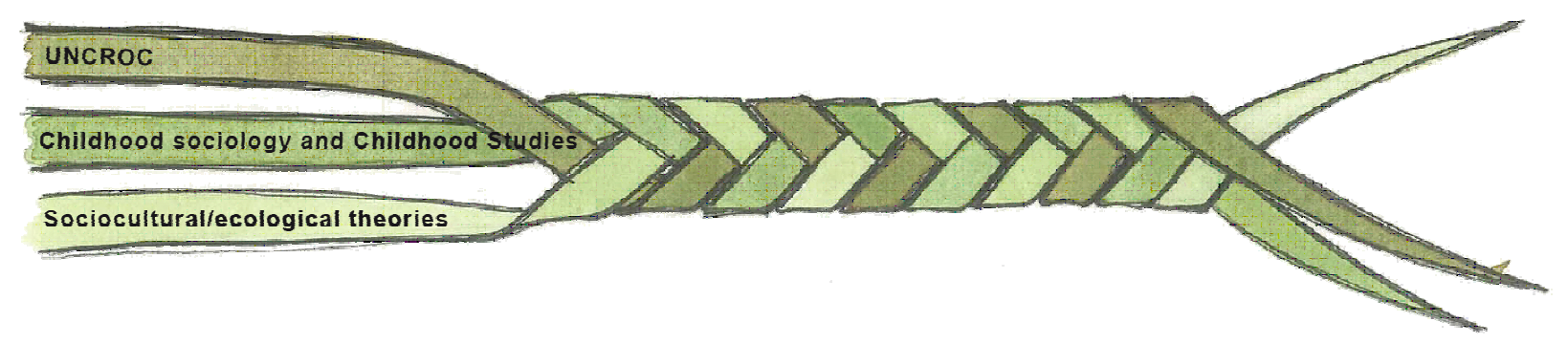

Figure 8: An integrated theoretical framework

\section{Making new sense of existing theories and interpretations}

It was envisaged that the case study settings to be investigated would be sites for development, ecologically, socially, and culturally. The child as an individual is a part of the social environment of the setting. As an active participant, the child's 
interactions influence his or her development. These interactions in turn influence the group. Hence an interesting tension emerges - is development individual or communal? The answer is both (Meade, 1999). Transformation of participation works on two levels - for the individual, as well as for the community of learners, and the setting.

There is a similar dilemma for UNCROC. It focuses on a set of rights for each child as well as for every child but how these entitlements are reified is determined culturally and politically. The tension can never be entirely resolved because the rights of the individual child co-exist with the rights of all children and in fact all of us. Children are both empowered and at the same time trapped by discourses embedded within UNCROC that focus on him/her as emerging, or developing. In some contexts, the unlimited potential of a naïve explorer empowered to learn is recognised as a powerful motivator, but in other circumstances, the fact that the child is not there yet provides a convenient excuse to withdraw support that could bridge the divide between what a child can do alone and what he/she might accomplish with the support of a more experienced adult or peer.

The reality that a child's development may be either enhanced or inhibited in early childhood settings makes early educational experiences a children's rights issue. Sociocultural approaches analyse the conditions under which children and adults act in social and cultural environments. An ecological perspective considers the social blueprint of the macro environment. This includes the immediate settings and how participation is affected, as well as the impact of external factors beyond the early childhood setting; for example, policy decisions and labour market factors. The intersection with children's rights is via participation beyond just being present. A rights-based perspective considers the quality of participation en route to development and learning. In other words, it has a sociological component. Recent New Zealand early childhood research has focused on children's learning and playfulness. This thesis attempts to shift the gaze to examine how sociocultural theories of development and ecological theory can be usefully applied as a pedagogical approach to understand children's rights. It addresses a central question that remains unanswered to date: How do participants in the case study settings perceive children's rights in those settings? 


\section{Common themes to conclude the chapter}

There are common themes to the theoretical ideas discussed across Chapters 2 to 4 . The first is participation. Sociocultural theories assert the centrality of participation as a transformative process, resulting from interactions with more experienced peers in social and cultural contexts. Ecological theory, too, suggests that an individual's participation in more complex activities alongside a skilled significant other can enhance development when the balance of power gradually shifts towards empowering the child to take the initiative. Childhood sociology promotes the child as an active participant, influencing the nature of his or her experiences. UNCROC provides a benchmark aspiration supporting children's participation in all matters that affect them.

Second, time (past, present, and future) is an influential factor. Sociological perspectives consider how children are viewed in different contexts, and suggest that concepts of childhood are dynamic and responsive to historical, present, and future contexts. UNCROC raises questions about accommodating children's rights in response to their emerging capabilities. Sociocultural and ecological theories challenge developmental psychology, and provide an alternative to the more traditional sequential, age/stage models. These theoretical approaches argue for development to be understood as transformation of participation in cultural activities over time. The integrated theoretical approach in this study (Figure 8) accepts that constructs of childhood and adulthood are problematic, but does not view one (adulthood) as more important than the other (childhood). All the theories are significant because they challenge the position held by those against rights for children, based on the premise that childhood renders them incompetent and incapable of making appropriate decisions.

Third, one way children learn is through their relationships with others. Ecological theory suggests that learning and development are facilitated by warm, meaningful, reciprocal relationships between the child and an adult/teacher/guide. Through participation in increasingly complex patterns of reciprocal activity, the balance of power gradually shifts in favour of the developing person (Smith, 1998). Guided participation in the zone of proximal development is a sociocultural idea. A child develops through participation in cultural processes and activities, initially as an observer, peripherally involved, perhaps observing, and over time, as actively 
contributing to the learning community. Sociologically, meaning is created through relationships with others in particular contexts. Childhood is socially constructed through networks of relationships within and across social contexts. UNCROC does not view the child in isolation, but as part of a family, which is part of a community, a society, and a country.

Fourth, the approaches tolerate conflict and tension which support diversity and promote inclusiveness. Vygotsky (1993a), Bronfenbrenner (2005a), and Rogoff (2003) all use examples from socially marginalised groups of children, whether orphaned, disabled, impoverished, or racially discriminated against. Their research demonstrates how participation in socially and culturally diverse communities is transformative, and children develop and learn in ways that lead to appropriate contributions. Childhood sociology accepts multiple experiences of childhood as valid, and Article 2 in UNCROC entitles children to a world free from discrimination.

Fifth, the physical environment, both immediate and external, influences the course of a child's development, and therefore his or her ability to participate. Again, UNCROC specifies that a child has a right to play, as well as a responsibility to care for the physical environment. Resources and the competing demands on them feature particularly in bioecological theory. However, different orientations to learning result in physically different learning environments. The accepted norm in most New Zealand early childhood settings is to set up environments that offer children choices of activity, but how children participate depends on the willingness of the teachers or adults to understand the social, historical, and cultural conditions of the two or more microsystems the child participates in.

Finally, the theoretical tenets of childhood sociology, sociocultural, and ecological theories infer that the role of the adult is more than just protector and provider. Children's rights invoke corresponding adult or more experienced peer responsibilities. It is the nature of the relationships with significant, more experienced others that potentially shift the balance of power towards the developing person, theoretically to enable increasingly complex participation. Combined with theories and models of participation using UNCROC as a guide, the role of the adult determines the nature of support for children's participation. 
This chapter explains the theoretical framework based on first, interpretations of rights from UNCROC; second, the premise that the child has agency, a principle underpinning the study of childhood; and, third, that participation as a right has transformative potential for development and learning. Chapter 5 explains the research methodology, design, and method. This is followed by the individual case studies which explicate this newly conceived framework. The concluding chapter synthesises the findings, arguing that UNCROC, the study of childhood, together with sociocultural and ecological theories of development are potentially useful tools for developing a rights-based pedagogy for early education. 


\section{Chapter 5: Methodology and methods}

Methods are like the kaleidoscope: Depending on how they are approached, held, and acted toward, different observations will be revealed ... the flaws of one method are often the strengths of another, and by combining methods, observers can achieve the best of each while overcoming their unique deficiencies. (Denzin, 2001, p. 126)

\subsection{Introduction}

This was a qualitative study. The research design used ethnographic, case study, and participatory research methods. The design was influenced by sociocultural theories and ecological theory, current literature from the field of childhood sociology, theories about children's rights, and UNCROC. For example, participatory research methods recognise the child as an active participant in the research process, arguably in recognition of Article 12 of UNCROC which establishes the child's entitlement to be consulted and informed. Interpretations of articles of UNCROC, as either protection rights, provision rights, or participation rights, were used to group data during the analysis phase, and to illustrate the interwoven, interrelated nature of rights. Sociocultural and ecological theories, discussed in the previous chapter, added a third strand to the integrated theoretical framework of the thesis. Notions of community, participation, and interconnected micro and macro environments contributed to the research design because, as Chapter 4 argues, there are common elements between these constructs, and those of childhood sociologists and children's rights advocates.

Descriptions of the research processes provided in this chapter outline why and how the early childhood settings were selected, and how the research followed an explicit ethical framework. The chapter then explains how data were generated and analysed. How rigour and robustness were assured is also described. Strategies for interviewing children prior to being in the field (and how these were adapted once fieldwork began) are described in depth. The chapter begins by re-stating the questions and the rationale for the research design. 


\subsection{Rationale for the research methodology and method}

Every method reveals a different slice of the social world. (Denzin, 2001, p. 326)

The research aimed to investigate perceptions of children's rights in early childhood settings, and to observe how children's rights were enacted. The focus on perceptions fitted with the interpretive tradition which emerged as a result of increased dissatisfaction with quantitative research. A criticism of quantitative social research has been that it renders invisible not only the experiences of the child, but also the child her/himself (Campbell \& Smith, 2001; Canella, 1997). Given that participation and consultation are concepts central to children's rights, qualitative methodology was appropriate to address the lack of descriptive research identified in Chapter 1.

\section{Qualitative research}

Commentators agree there are common principles underpinning qualitative research, although various theoretical lenses adopted by researchers differ (Schwandt, 2000). A founding aim of qualitative research is to reveal the lived reality, or constructed meaning of participants (Denzin \& Lincoln, 2005). The recognised starting point for qualitative inquiry acknowledges that there is no single reality, but multiple perspectives co-exist, and these perspectives, systematically and rigorously analysed, provide qualitative explanations about the question under investigation (Lichtman, 2006; Mutch, 2005). Qualitative research can require in-depth observation in natural settings, as opposed to laboratories, and the intention is to move beyond surface understanding. Typically, this involves multiple methods to investigate research questions (for example, participant observation, focus group interviews, and individual interviews). By using multiple methods, qualitative research attempts to understand the question holistically, and/or increase the reliability of the research findings by triangulating sources of data. It also reduces the likelihood of researchers' own perceptions adversely impacting upon the results (see below).

Qualitative research has been critiqued by many, including proponents of qualitative research. One such critique concerns the role of the researcher. In qualitative research, the researcher is the main instrument for data collection and interpretation. Critics have pointed out that the researcher has a subjective viewpoint, and this may 
impact on how data are gathered and how they are interpreted. As a result, the findings of qualitative research may come to reflect the views of the researchers rather than those of their participants (Berg, 2007; Denzin \& Lincoln, 1998, 2005; Gubrium \& Holstein, 2003; Mutch, 2005; Schwandt, 2000). In qualitative research evidence relies heavily, but not solely, on text. Analysis in qualitative research tends to be inductive (Berg, 2007; Lichtman, 2006; Schwandt, 2000), beginning with details and developing themes, which can then be categorised. The final analytical phase is to theorise about these at a deeper level. Holstein and Gubrium (2003, p. 215) describe such theorising as "emerging empirical horizons", to reflect the dynamic and changing nature of qualitative research (Denzin \& Lincoln, 1998, 2005).

Further criticisms of qualitative research argue that it is not satisfactory to merely present multiple perspectives descriptively. Some analysis of context is important. For example, poststructural and postmodern theorists have demonstrated that there is no clear view - a 'gaze' is always filtered by influences such as gender, race, culture, and other social conditions, or contexts. Accordingly, qualitative research has stimulated various macro-theories (Berg, 2007; Mutch, 2005; Schwandt, 2000). The chapter comments more fully on the role of the researcher in a later section. For the moment, however, it is useful to consider interpretivism in more detail.

\section{Interpretivism}

Historically, "all interpretive traditions emerge from a scholarly position that takes human interpretation as the starting point for developing knowledge about the social world" (Prasad, 2005, p. 13). Philosophically derived from Kant, and elaborated on by Husserl (the founder of phenomenology), the premise underpinning interpretivist traditions is that reality exists in the human consciousness, and "what is of paramount importance is how we order, classify, structure, and interpret our world, and then act upon these interpretations" (Prasad, 2005, p. 13). Further, these interpretations are acknowledged as subjective and based on a belief that the world is socially mediated, and constructed by the very human attribute of attaching meaning to people, places, and things (Gubrium \& Holstein, 2003).

Interpretivism can be linked historically to the origins of qualitative research (Berg, 2007; Denzin \& Lincoln, 1998, 2005). Interpretivist research is defined as "the 
systematic analysis of socially meaningful action through direct detailed observation of people in natural settings in order to understand how people interpret their social worlds" (Neuman, 1994, p. 68, cited in Mutch, 2005, p. 64). So, the interpretivist tradition, in a response to positivism, applied an interpretive lens on social action.

\section{The role of the researcher}

In this tradition, the researcher acts as interpreter. It is acknowledged that this is a complex and difficult role (Denzin \& Lincoln, 1998; Gubrium \& Holstein, 2003; Prasad, 2005; Schwandt, 2000). In an historical analysis of interpretivism, Schwandt (2000) tracks how the role of researcher/interpreter has shifted according to theoretical perspectives. The overriding issue facing interpretivist researchers is that there are no objective observations. The implications for reporting such research include open disclosure of the researcher's own positions and potential biases.

Traditional interpretivist epistemologies (Prasad, 2005; Schwandt, 2000) tended to ignore the impact of the researcher and consequently assumed impartiality and detachment, both of which are inimical to interpretivism. Central to this critique was the ongoing difficulty facing interpretivist research: because it is often difficult for participants to fully explain their actions or intentions, logically, it must be difficult for a researcher to explain them as well (Lichtman, 2006).

In order to ameliorate the possibility of 'researcher effects', multiple methods for generating data are necessary. These methods allow for a range of possible interpretations of the experiences observed; for example, ethnographic methods, such as field notes, photographs, and the researcher's journal, combined with case study methods such as interviews and focus groups. In this way the methods support the methodology.

However, whatever the precise mix of methods used, the ethical, political, and moral considerations remain constant throughout the research. As noted, such considerations raise questions about the role of the researcher, and the purpose of the research: What happens to your own perspectives as you attempt to make sense of the situations? What influence do your interpretations have in the context of the research? How is the researcher influenced by political and moral forces? 
These discussions are explained in the literature as hermeneutical acts, or acts of interpretation of text (Prasad, 2005). The origins of hermeneutics can be traced to Habermas (see Prasad, 2005) who categorised three types of knowledge: analytic, hermeneutic, and critical. Hermeneutical knowledge equates to a philosophical understanding (Prasad, 2005; Schwandt, 2000). Prasad identified two types of hermeneutical processes: weak and strong. Weak understanding eventuates at "interpretive and phenomenological dimension of qualitative inquiry" (Prasad, 2005, p. 30). Strong hermeneutics, while necessarily informed by the philosophical ideas, focuses on actively engaging with the interpretation of texts (Prasad, 2005, p. 30). Central to understanding hermeneutics is the notion of the hermeneutic circle which is "integral to establishing linkage between a text and its wider context". Simply put, parts (of the text) can only be understood as part of a whole, but the whole can only be understood from its parts: "an examination of context sheds light on the text itself, whereas an examination of the text, can illuminate our understanding of its context" (Prasad, 2005, p. 35).

This iterative process involves the researcher in a constant process of reflective and reflexive thought, often recorded as journal entries. These have an inherent power dimension which scholars of discourse analysis, for example, explain in terms of particular subjectivities associated with institutions. The "construction of lived experiences" (Gubrium \& Holstein, 2003, p. 225) is not separated from culture, or traditions, or bias. Interpretive methods seek engagement with possible biases: personal, social, cultural, and political. Hermeneutical engagement with text moves beyond content analysis to seek layers of meaning which may appear contradictory, but, in fact, can reveal multiple perspectives: the subtexts (or what is not spoken) may be the more important data source. To investigate perceptions of rights, the focus of this study is an interpretive task reliant on hermeneutic acts to make sense of the data.

\subsection{The research design}

The research design was ethnographic and used case studies and participatory research methods. Ethnographic tools generate both descriptive and interpretive data. Case studies focus the investigation on a particular context, and participatory research methods require ethical consideration of interactions with participants. 


\section{Case study methods}

A feature of most case study designs is to first, bound the case and second, select the case that you can learn most from (Stake, 2005). Case studies can be either typical, and their ordinariness becomes the focus of the research, or they can be atypical because a researcher feels that more would be learnt from that case because it is unusual. This research conformed to the criteria for both a collective case study, albeit with a limited collection of cases, and an instrumental case study, which is "mainly to provide insight into an issue" (Stake, 2005, p. 437). Repeated in three different contexts, the case study approach allowed the researcher to investigate perceptions of rights in three mainstream services.

Case studies are characteristically emergent in design and theorising is inductive (Yin, 2006). They use mixed methods to generate data. Robert Stake's (2005) definition of a case study acknowledges the inextricable relationship between the process of inquiry into a case, and product of the inquiry about the case. Stake (2005, p. 436) commented: "We may simultaneously carry on more than one case study, but each case study is a concentrated inquiry into a single case." The emphasis is not on comparison between the different cases, but on investigating the phenomenon in the context of that particular case - the purpose of the report is not to represent the world, but to represent the case (Stake, 2005). Comparative analysis was not a feature of this research because there were only three sites, and comparative research might have breached ethical agreements.

Two situations are particularly suited to case study design (Yin, 2006). The "questions can be descriptive (what happened?) or, explanatory (how or why did something happen?)" (Yin, 2006, p. 112). Gillham (2000) observed that "case study research (is concerned) with subjectivity: with phenomenological meaning" (Gillham, 2000, p. 7). In this study, the findings chapters represent the cases, but the conclusions drawn are used to "facilitate our understanding of something else" (Stake, 2005, p. 437); perceptions of children's rights in early childhood settings, and how they are implemented. As noted, case studies tend to use a variety of ethnographic research methods. These are discussed more fully in the next section. 


\section{Ethnographic methods}

Ethnography is currently a contested field (Anderson-Levitt, 2006; Atkinson \& Hammersley, 1998; Denzin \& Lincoln, 1998, 2005). In the past, a study could only be called ethnographic if it involved considerable time in the field. The origins of modern ethnography were influenced by the Chicago school of symbolic interactionism, and an anthropological characteristic of "collecting data firsthand" in exotic locations (Atkinson \& Hammersley, 1998, p. 112). Modern ethnography observes diversity within supposedly homogeneous cultures, challenging a Eurocentric, minority world view of difference and diversity in terms of the 'other'.

Ethnography can also consider the physical realities of the contexts studied. Ethnography is a useful method for discovering meanings. Through experiences we develop shared understandings of jointly constructed cultural meanings that are both explicit and tacit. Although we can assume a certain level of shared meaning, we cannot assume that everyone in a discrete group, or community, will necessarily share the same meaning: "(e)ach individual brings together his or her own constellation of cultural meaning making" (Anderson-Levitt, 2006, p. 281).

The research design is modelled on ethnographic principles, in particular Geertz's $(1973,1979)$ idea of trying to understand not just what the researcher observes, but also what the observed understand to be happening. To reveal perceptions of children's rights on site requires at least two levels of reflective observation: first, deciding to record an episode, or event as field notes; and, second, reflexively, deciding to decode the field notes based on personal interpretations as well as on the participants' interpretations of their lived experiences.

\section{Participatory research methods}

By definition, any investigations of children's rights should seek children's perspectives. The value of including children as participants has been advocated for most of this decade (Alderson, 2000; Christensen, 2004; Christensen \& James, 2000, Clark \& Moss, 2001; Greig, 1999; Woodhead, 1997; Woodhead \& Faulkner, 2000 to name a few). Alison Clark and Peter Moss (2001) researched how children's perspectives influenced adults' perceptions of young children's capabilities. Priscilla Alderson $(2002,2004)$ has consistently advocated for including infants' perspectives as essential to her research. Similarly, in New Zealand, Article 12 of UNCROC has 
been implicitly endorsed by the Ministry of Education, which is promoting assessment practices that include the child's voice (Carr, Lee, \& Jones, 2004).

Informing and consulting with children is a right (Article 12, CRIN, 2007, p. 5). Hence, conversations about ethical research with children, where their perspectives are actively sought, are "important for minimizing the power differential between the researcher and those being studied" (Eder \& Fingerson, 2003, p. 34). Powell and Smith's (2006,) review of New Zealand's ethical guidelines for research with children noted specific ethical issues for conducting research with children "mainly resulting from the power difference between adults and children" (p. 127). Understanding the ways that children engage with and respond to research includes considering two key questions: Are the practices employed in the research process appropriate to the context, and what are the ways in which children routinely express and represent these contexts in everyday life (Christensen, 2004)? Advocates of participatory research methods with children suggest that:

\begin{abstract}
A consensus has developed around the belief that the ethics, tools and roles employed in qualitative children's research should empower children. Empowerment is associated with allowing children to choose to become active participants in the research process, employing tools which offer children the maximum opportunity to put forward their views and reducing the social distance and re-negotiating the power relations between the researcher and child. (Davis, 1998, p. 329)
\end{abstract}

This section has provided a rationale for the qualitative, interpretive methodology underpinning the research design used to investigate both perceptions of children's rights, and how they were implemented. The research methods used case studies, ethnography, and participatory methods. The next section explains in more detail the data gathering instruments.

\title{
5.3 Data gathering instruments
}

Observational field notes, photographs, a researcher journal, document analysis, focus group interviews, individual interviews with adults, and conversational interviews with children were used to generate data for this thesis. 
Field notes, photographs, researcher journal, and document analysis

Field notes are the traditional ethnographic researcher's tool (Somekh \& Lewin, 2005). An intention of the field notes was to record descriptive details about the context as part of investigating perceptions of children's rights. When considering data via field notes, some argue that merely being present in the field means that the researcher is a participant, which raises questions about the role of the researcher (Anderson-Levitt, 2006). Later sections of this chapter discuss how this was resolved, particularly with children. The role of the observer, irrespective of the level of participation, has to be understood in relation to the question studied. Tedlock (2005) noticed that "[e]thnography and participant observation ... has become the observation of participation. During this activity, [the researchers] reflect on and critically engage with their own participation within an ethnographic frame" (p. 467). Wolcott (2001, p. 579) reflected on the role of the researcher and asked: "Am I attending as carefully to what is going on as I am attending to what I think is going on?". The researcher journal documented these thoughts, and recorded examples of the hermeneutic act (Prasad, 2005; Schwandt, 2000).

There are various approaches to observing, and "choosing where to look and when to look is also a matter of systematic, principled, reflexive decision making" (Delamont, 1992, p. 115). Observations, including field notes, photographs, document analysis, and a journal were used to elicit perceptions of children's rights by revealing "tacit levels of culture ... to make visible the invisible" (AndersonLevitt, 2006, p. 285).

Photographs potentially act as prompts for field notes, and are an accurate way to capture personal impressions of each setting. Photographs provide visual images that can be consulted as part of the interpretive analysis. This allows for opportunity, or space, to reflectively consider the relationship between the physical structures, the natural environment, and how these impact on perceptions of rights, in particular, children's participation, in the social context. They are also a record of what stood out to the researcher during the fieldwork phase. Of note, and to counter the power of an image, it is important to consider what was not photographed, and why. 


\section{Focus group interviews}

Conducting two focus group interviews can provide a contextual basis for the research and can be useful initially "for exploratory purposes, to inform the development of the later stages of the study" (Bloor, Frankland, Thomas, \& Robson, 2001, p. 8). At the first focus group meeting, the researcher is an outsider, striving to make sense of who did what and why and how. Babour and Schostak (2005, p. 42) note how "observing and facilitating the focus group offers ... an insight into the group dynamics". The second meeting acts "as an interpretive aid while simultaneously generating new insights on the early findings" (Bloor et al., 2001). Accordingly, in this study the first focus group interview sought to capture a collective perception of rights, and some guidance about where to observe. The intention of the second focus group interview was to act as a forum for shared discussion and reflection on data generated from field notes, the first focus group interview, and themes arising from individual interviews.

\section{Individual interviews: Teachers and parents}

Interviews are a major source of data in qualitative research. Open-ended interview schedules (Kvale, 1996) were designed to reflect the integrated theoretical approach: sociocultural theory considers historical and cultural influences on individuals participating in social groups; ecological approaches attend to immediate and wider contexts; childhood sociology and UNCROC recognise the child as an active participant, both entitled and able to contribute.

Initial conversational encounters were opportunities to locate the researcher's position both in the research and in the context of the early childhood setting. The purpose of the research was neither to evaluate participants' professional practice, nor the centre's practices. Rather, the intention was to generate data that could reveal early childhood teachers' and parents' perceptions of children's rights. There is always a potential imbalance of power between the researcher and the researched that can manifest during interviews (Rubin \& Rubin, 2005). Attention to ethical relationships can ameliorate this.

\section{Interviewing children: Semi-structured conversations}

A major challenge of the research was how to interview children about their perceptions of their rights. Several strategies were devised to address this, including conversational interviews which provided data about children's perceptions of their rights. 


\section{Strategies to stimulate discussion about children's rights}

Prior to beginning the fieldwork, the question of how to introduce the topic of children's rights to children became an issue. No assumptions could be made that children would understand what was implied by the term 'children's rights'. Influenced by Margaret Carr's (2000) model of a story in which the children made up the ending, several short scenarios were developed as potential talking points for children to discuss their perceptions of children's rights. However, these scenarios were decontextualised-breaching principles of participatory research by contriving situations, as well as creating unnecessary dualisms between rights as entitlements, and rights as opposed to wrongs.

At the same time as writing these scenarios for the children's interviews, libraries and bookshops were scoured for stories about children's rights to read with children. The majority of these stories were broadly concerned with inclusion and tolerance of difference. Eventually a book containing a collection of well-known children's illustrators' interpretations of various articles of the United Nations Convention of the Rights of the Child (Castle, 2000) was sourced. Because it was not a story as such, but a series of beautiful illustrations, colour photocopies of the illustrations the children responded to the most were made into large, laminated posters.

Another interviewing technique used with children was a persona doll. For many years, anti-bias curriculum developers have advocated the use of persona dolls to introduce difficult and controversial issues to young children in centre-based settings (Brown, 2001; Derman-Sparks and the A.B.C. Task Force, 1989). They are often used to raise an awareness of discriminatory behaviours amongst children and adults. These lifesize (three- to four-year-old child) dolls have their own personality, developed by their user. With a persona doll, the adult acts as both a voice and an interpreter (Brown, 2001). Henry, the persona doll created for this research, did not have a physical voice of his own, but he spoke to the children through the researcher, who asked and answered questions on his behalf. 


\begin{abstract}
Henry the persona doll is four
Henry is a four-year-old part Māori boy from a small New Zealand town and he has come down to this city to stay with his aunty for a holiday. His cousins used to come to this centre. He has got a baby sister and a big brother who is at school. He got a bike for his birthday and he has got trainer wheels. He went to McDonalds and had a Happy Meal and he liked the toys. He goes to a centre like this (either a kindergarten or a playcentre) in his town. At his centre he likes to listen to stories and to play on the trolleys and in the sandpit. He has to share things at his centre but sometimes he doesn't want to.
\end{abstract}

The ethnic mix in the study was predominantly Pākehā (non-Māori) and so there was a remote chance that Henry might act as a minority peer, and prompt some discussion about ethnicity, or cultural differences and rights. However, it was more Henry's newness and naivety about the centre and its day-to-day practices that was most useful. Through him it was possible to ask naïve questions about the case study centres and, hopefully, glean children's perceptions. Henry's persona was developed to encourage another level of engagement with the research questions about perceptions of rights, and how they were implemented.

A small pack of provisions was prepared prior to entering the field. These included a hand-held tape recorder; an exercise book and pens; a laptop computer; a digital camera (plus batteries); and a clear file with extra copies of the ethical assent forms for children and consent forms for parents. Also included were copies of the focus group interview questions (Appendix D), and the individual teacher/parent interview questions (Appendix E). The next two sections outline the processes and the procedures used to generate data.

\title{
5.4 Data generation processes and procedures
}

This section describes the processes and procedures used to generate data. It begins with the ethical approach.

\section{Ethics - designing an inclusive approach ${ }^{7}$}

Ethical requirements arise from an evolving understanding of the rights and duties of human beings. Researchers are part of a changing social system. They are obliged ... to attend to the evolving understanding in a particular society at a particular time. (Snook, 2003, p. 78)

\footnotetext{
${ }^{7}$ Parts of this section were first published by Te One (2007) in NZCER Folio 11.
} 
Ethical procedures guide interactions between the researcher and the researched (Cullen et al., 2005). Alongside a growing interest in children's rights and childhood sociology is a concurrent stream of interest in children as participants in research (Cullen et al., 2005; Hedges, 2002; Powell \& Smith, 2006). It is no longer regarded as appropriate to marginalise children as objects to be studied - there is now an expectation that researchers use participatory research methods to include children's contribution to research into their conditions of childhood (see Article 12 of UNCROC) (Aubrey, David, Godfrey, \& Thompson, 2000; Christensen, 2004; Christensen \& James, 2000; Clark \& Moss, 2001; Sheridan \& Pramling Samuelsson, 2001; Te One, 2007; Thomas \& O’Kane, 1998).

This research adhered to Victoria University of Wellington's Human Ethics Committee guidelines and the New Zealand Association for Research in Education's ethical guidelines (New Zealand Association for Research in Education, March, 1999). Processes were guided by Snook's (1981) advocacy for vigilant ethical considerations in research, and by guidelines for planning, undertaking and diseeminating for researchers in early education settings (Cullen et al., 2005). All participants were informed by letter (Appendix A), and informed voluntary consent was required from all the participants: children, teachers, and parents in the whānauled service (Appendix B). A separate letter and assent form was prepared for child participants (Appendix C).

One ethical consideration included resolving beforehand how to position the researcher, "as an atypical, less powerful adult in research with young children" (Corsaro \& Molinari, 2000, p. 180). The role of the non-authoritarian adult is now well documented (Corsaro, 1997), but there is "some disagreement concerning the extent to which these roles allow adult researchers to interact with children" (Davis, 1998, p. 327). These include the age and authority of the adult, and how that constrains participation in a child's world. As Christensen (2004) noted:

In the process of research, power moves between different actors and different social positions, it is produced and negotiated in the social interactions of child to adult, child to child and adult to adult in the local settings of the research. (p. 175)

The power of adults in early childhood centres is difficult to minimise. This required thoughtful attention about how to build relationships with children at the same time 
as with adults. Serious questions for the researcher were: Who do I talk to first? If a parent asked me something while I was talking to a child (this happened a lot), how do I manage that? On the one hand, adults often expect other adults to interrupt conversations with children to attend to their queries or requests. On the other hand, if you respond to the adults' interruptions, you potentially disempower the child's status in the conversation:

Children often expected me to arbitrate as an adult however my genuine newness was intriguing to them. It altered the power dynamic-I was clearly an adult, but I was not a teacher, and I strategically chose not to wield the teachers' power to stake a claim, advocate, or influence children's choices, unless the situation was potentially harmful. (Te One, 2007, p.22)

Successful strategies for participatory research with young children can shift the balance of power relations between the researcher and the children, and this requires "renegotiating the power relations between the researcher and child" (Davis, 1998, p. 329).

Researchers need to be cautious about building close relationships with the child participants, especially for infants and newly enrolled children, because the relatively short periods of time in the field means maintaining them is possibly unsustainable. To establish a close relationship and then leave could potentially affect a child's sense of belonging (Ministry of Education, 1996b). An important aim is to achieve a balance between distanced, objective questioning and more intimate, subjective conversations. Threats to this balance are characteristic of qualitative research experiences (see Brennan, 2005; Nuttall, 2004; and Te One, 2007 for accounts of ethical dilemmas in research).

\section{Ethical dilemmas}

An early dilemma in this study was how to present the research proposal to the participants. What was the ethical position of the researcher as sole interpreter of the events? There were two issues to consider here. First, the researcher had a degree of professional status that positioned her as an expert. Second, the researcher's interest, investment, and passion in the research was personal, therefore the challenge was to disregard preconceived, personal assumptions about children's rights.

Initial interactions with participants concentrated on allaying participants' concerns about a) not knowing much about children's rights, and b) not being sure that the centre would be one that could help much. A sense of nervousness about being 
evaluated was hidden behind both concerns. How would they be represented? How would their centre 'measure up'? This unease can be described in terms of the subject behind the respondent (Holstein \& Gubrium, 2003). Because there were various responses to the research proposal, it was important to be transparent, guided by the ethical agreement, but assessing the impact of the methods on the participants, as part of a reflexive process (Davis, 1998).

There were, however, unexpected threats to participation as well:

Today, I was 'captured' by a child very early on. This child assumed responsibility for introducing me to other children, thereby acting as my uninvited gatekeeper. The child's enthusiasm for helping was a potential deterrent for other children's participation. As I observed my self-appointed research associate, I consciously acted inclusively to indicate that we (myself, the child, and others) could do this together. (Kindergarten field notes, Day 1)

This experience highlights the importance of boundaries between participants and researchers (Corsaro \& Molinari, 2000; Te One, 2007). Initial encounters can set the tone for the research. While friendly relationships matter, it is important to be everyone's friend, and establish a neutral stance so as to support all to participate freely in the research.

Mutual decisions about the research approach allow the participants to shape the framework for subsequent investigation. This included being sensitive to the language chosen to explain rights, which is arguably an ethical issue. Direct questions like "How or do children participate in decisions affecting them? How do you include children in decisions about their day-to-day life in this setting?" could be considered potentially threatening, and as such, in breach of the ethical agreement.

The researcher's immediate concern was to gain entry. To begin by asking whether or not children were included in decision-making processes could have been regarded as threatening. While the questions were obvious, the answers were not. What if the possibility of participating in decisions about routine events was not a consideration, or if choices about joining in were not feasible? Any such awkwardness may have jeopardised the future of the project. There was no certainty that the researcher's knowledge would not have influenced the participants' insider experience of their particular setting. This limitation was ameliorated by the focus group interviews, and in the field note observations. Opportunities to explore when 
and how children participated in constructing their early educational experiences were investigated in alternative ways, deemed by the researcher to be more conducive. Within-setting discussions about children's participation are discussed in subsequent chapters, but raised here is an ethical concern based on Snook's (2003) premise that ethical behaviour can depend on evolving understanding about an issue, and Stake's (2005) advice to be extremely polite/inoffensive.

\section{The case study settings}

Three typical early childhood centres that met the quality criteria identified by Smith (1996) and Podmore et al. (2000) were selected for this study. Recent Education Review Office reports ${ }^{8}$ provided an external evaluation of quality to assess a centre's suitability as a case study for the research. The standard of quality was considered important because it allowed the research to focus on the topic under investigation, and not be diverted by issues threatening the day-to-day running of the centre, which in turn could impact negatively on the quality of interactions at adult level and between staff and children.

Decisions about what to look for and where to look are inseparable. Choosing three different mainstream services seemed sensible; however, a diverse sample does not necessarily add depth to an investigation. While the rationale for selecting the centres has been explained, these decisions are restricting. On the other hand, the focused case study approach resulted in data specific to the research questions. Limiting the research to perceptions of rights, and not on evaluating the extent to which rights were applied, proved useful because it shed light on the relevance of context. Discrete and distinctly different case studies allowed for in-depth consideration of the actual case, the day-to-day experiences of participants in the case study centres.

The early childhood centre case studies chosen to investigate perceptions of children's rights were a Kindergarten, a Crèche for under two-year-olds, and a parent

\footnotetext{
8 These reports are conducted on average, every three years. They were initially introduced as an accountability measure for government funding, but have since shifted to a more supportive model, termed 'Effectiveness Reviews'. While the managerial accountability is still a prevalent theme, there is a synergy between the stated compliances that equate to structural measures for quality, and the more elusive process quality measures that are of particular relevance to this study (see the Desirable objectives and practices for chartered early childhood centres, Ministry of Education, 1990).
} 
co-operative Playcentre. These are examples of three diverse mainstream services. Different sites revealed more fully the effects and influences of contexts on teachers, parents, and children's perceptions of children's rights. The three settings are now described according to their organisational auspice, their physical characteristics, and their community contexts. All three centres were not-for-profit, community-based services.

The Kindergarten and the Playcentre were sessional centres. The parent/whānau-led Playcentre ran four mornings a week; and the teacher-led Kindergarten ran a morning session for four- to five-year-old children, five times a week, and an afternoon session for two-and-a-half and three-year-olds, three times a week. On Wednesday and Friday afternoons the Kindergarten teachers had non-contact sessions. This time was used for administrative and professional duties. Over 90 families were enrolled in the Kindergarten, more or less equally divided between morning and afternoon sessions. Because of the large numbers in the Kindergarten setting, the research focus was on the morning session for four- to five-year-old children. The Playcentre had 23 families on the roll and was licensed for 15 overtwo-year-old children and eight children under-two-years-old per session. Given the fact that the major growth in New Zealand early childhood services has been in the education and care services and notably for the under-two age group (Education Counts, 2008), a case study centre for the under-two-year-olds (the Crèche) was a rational and relevant choice. The selected centre was licensed for 22 children and operated from 8.00am until 6.00pm daily.

The Playcentre and the Crèche operated in turn of the century villas, altered to meet regulatory requirements. The Kindergarten was purpose built, with a landscaped environment. The impact of the physical environments on children's rights to play was potentially an area to investigate. Although photographs were taken, ethical agreements prevent showing these here.

A further contextual point concerns the service type. The Crèche was one of several early childhood services based in a large tertiary institution. The users of this service were students, full-time and part-time. Crèche users did not tend to live nearby, and there was no sense of a neighbourhood. Unlike the Crèche, the Playcentre parents tended to live close to the well-known Playcentre house, and were part of an 
identifiable, wider community. Similarly, the Kindergarten was located in park-like surroundings in the midst of a medium-sized suburb. While not all families enrolled in the Kindergarten lived in its immediate vicinity, the teachers promoted belonging to the local community, and had established networks with many local social services.

To sum up these descriptions, the Crèche acted as a community made up of children and teachers on site during the day; the Playcentre was visibly part of its local community, socially, educationally, and historically; the Kindergarten was located in a community, but the teachers were not residents of the immediate neighbourhood, and while many families from that community chose to attend the Kindergarten, some chose different early childhood services.

\section{The participants}

Once the centres were selected, key personnel were contacted by telephone to request permission to conduct the research in their centres. This was followed up with an information sheet (Appendix A). The experiences of gaining entry varied considerably between the centres but there were, however, some common threads: All the adult participants asked the following questions:

What did they (teachers, parents, and children) need to do?

How much time would it take?

Why was their centre chosen?

How would the findings be presented?

These concerns reflect a broader ethical concern about the research-participant relationship (Merriam, 2002).

Participants in the research included teachers, parents in the Playcentre, and the children in each of the case study settings. Child participants in the Playcentre were aged from birth up to five years old; in the Kindergarten they were all four-year-old children; and in the Crèche, participants were aged from birth to two years old. All adults working or participating in the settings consented to being in the research, but not all consented to interviews. All participating teachers were trained and registered; and all participating parents in the Playcentre were in training. These parents had between two years' to nine years' experience in the Playcentre 
movement. The names of the adult participants and the settings appear in Table 2 (below).

Table 2: The adult participants and their settings

\begin{tabular}{|l|l|l|}
\multicolumn{1}{|c|}{ Crèche teachers } & \multicolumn{1}{c|}{ Playcentre parents } & \multicolumn{1}{c|}{ Kindergarten teachers } \\
\hline Christine & Mike & Paula (head teacher) \\
\hline Harriet (supervisor) & Bernie & Jackie \\
\hline Loretta (supervisor) & Karen & Sharon \\
\hline Peggy & Melissa & Carla (ESW) \\
\hline Fiona & Brie (team leader) & Amber (student) \\
\hline Peta & Donna (team leader) & \\
\hline Katrina & Angela (team leader) & \\
\hline
\end{tabular}

Christine, Harriet, and Peta did not consent to being interviewed initially, but requested a group interview (not the same as a focus group interview) once the transcripts from their colleagues were received. During the research period in the Kindergarten a student and an ESW volunteered to participate in the research.

\section{Beginning the fieldwork}

Entry to each of the centres was relatively straightforward. The researcher was well known in the Kindergarten, and had trusting relationships built up for over 10 years. The teachers welcomed the invitation to participate in the research. Gaining access to the Playcentre was harder than expected, but not because of any anxiety from the participants about the research, because families with infants and very young children are incredibly busy. A flexible approach to the process was essential in this setting. Entry to the Crèche became a matter of negotiating when to begin. At an initial meeting with the manager and one of the supervisors, it was decided to start in the month most people returned to work. The combined effect of staggered summer holidays meant some staff members were still on leave, new teachers were being recruited, and an influx of newly enrolled infants and children were starting for the first time.

9 Education Support Workers (ESWs) are employed by the Ministry of Education to work with children identified as having special educational needs. They are allocated a certain number of hours depending on the severity of the disability and the number of hours the child is enrolled in the early childhood setting. 


\section{Focus groups}

The original intention was to hold two focus group meetings with each setting. Each meeting was scheduled for an hour due to the time constraints of the participants. All focus group interviews were audio-taped and transcribed to create a text to be consulted, and subjected to critical scrutiny later.

The first meeting was a mix of reassuring the participants that this was an investigative study, not an evaluative one, as well as a time to introduce the purpose of the investigation in person (Bloor et al., 2001) - what did they think about children's rights per se and how were these enacted in their centre? The following memo recorded the reaction of teachers in the Crèche to an early question during the first focus group interview:

The long silence after that first question seemed to last forever. It was really awkward and the effect of the tape recorder, tiny but powerful, amongst the bread rolls and salad on the table was really obvious. (Researcher journal, Focus group interview 1, Crèche)

A conclusion drawn from that experience was to not talk so much, and to practise feeling comfortable with ambiguity and uncertainty. The second focus group meeting/interview took place at the end of the fieldwork. By then, some insider knowledge had been gleaned based on the individual interviews and the field notes. The transcript of the first focus group meeting and the photographs taken during the fieldwork phase were made available to all the participants for comment both privately and publicly. In the end, only five focus group interviews were conducted because the Playcentre parents found it increasingly difficult to find time to meet for the second focus group. An informal, but open, conversation with parents was recorded during an end-of-session meeting in the final week of fieldwork, and in a later conversation with the Playcentre president, she suggested that this recorded conversation replace the second proposed focus group meeting. Accordingly, it was transcribed and submitted to the parents for comment before it was used as a data source.

\section{Observations in the field}

This research used direct and indirect phenomenological approaches (Titchen \& Hobson, 2005) to investigate the lived experiences of children's rights in the early childhood centres. Routinely, the first day in all the centres was spent on introductions to parents, teachers, and children. The display folder (an A4 clear file) 
about the research and the researcher proved useful, and was placed in a prominent position in each centre. This contained extra information packages, and consent forms and assent forms. A large white box file became a posting box for adults and children to deposit consent/assent forms. Consent forms were colour coded according to setting.

From the start, conscious decisions were made about what to observe and when to observe. Typically, it took about three days to 'get my bearings' on the centre and its routines. By Day 4, choices were made to either follow a group of children, a child, a teacher, or sit in an area for at least an hour at a time. Because the research focus was on perceptions of children's rights, the observational interest focused on how children participated in the daily life of the centre and how individual children and groups of children engaged in activities and routines.

In each setting, the field note observations began with descriptions of the physical environment, observations about routines and rituals, plus questions to follow up on. These notes, together with photographs, provided data to illustrate how rights were enacted. The walls usually contained a wealth of information about the early childhood settings (for example, daily notice boards, permanent displays of notices, and information for parents). All policy documents in each setting were analysed for statements specifically referring to children's rights. Education Review Office reports were also consulted. Recent newsletters were collected to understand better the nature of the relationship between the settings and the parent communities they served. As all data were considered relevant initially, it was important to capture this in all its richness. An early research aim was to learn the names of all the participants in the settings - children, parents, teachers, and in two cases, managers.

Even though the outcome of the first focus group interview was an invitation to observe "anywhere and everywhere", as a researcher, it was important to be aware of my status as an invited guest (Silverman, 1993, 1997). Deliberate decisions were made not to observe in the toilets or nappy changing areas, and very limited time was spent in the sleep rooms, merely spending enough time in them to see, as an outsider, how they functioned. Researcher presence in these areas felt both invasive and intrusive. 
Every area of each setting was deliberately photographed including entrance ways, notice boards, and displays. Photographic accounts of first impressions on entry to the field reflected the significance of certain physical features. Conscientious efforts were made to record similar images in each setting, despite their different physical and social environments. Photographic images were shared with the participants and questions prompted by these visual impressions were followed up in the interviews with teachers and parents. They were particularly useful supports for discussion about the impact of the physical environment. Table 3 (below) charts the relationship between the research questions, the methods and the data generation instruments, and processes.

Table 3: Data generation processes and procedures

\begin{tabular}{|c|c|c|c|}
\hline $\begin{array}{l}\text { Research } \\
\text { questions }\end{array}$ & Method & $\begin{array}{l}\text { Data gathering } \\
\text { instruments }\end{array}$ & Process \\
\hline $\begin{array}{l}\text { How do children } \\
\text { teachers, and } \\
\text { adults perceive } \\
\text { children's rights in } \\
\text { early childhood } \\
\text { settings? }\end{array}$ & $\begin{array}{l}\text { Case study } \\
\text { interviews }\end{array}$ & $\begin{array}{l}\text { Focus group } \\
\text { interview with } \\
\text { teachers and } \\
\text { adults } \\
\text { Individual } \\
\text { interviews with } \\
\text { teachers and } \\
\text { adults; audio- } \\
\text { recorded }\end{array}$ & $\begin{array}{l}\text { Focus group interviews } \\
\text { transcribed, returned to } \\
\text { participants for comment, } \\
\text { returned to researcher as } \\
\text { data }\end{array}$ \\
\hline \multirow[t]{4}{*}{$\begin{array}{l}\text { How are children's } \\
\text { rights enacted in } \\
\text { early childhood } \\
\text { settings? }\end{array}$} & Interviews & $\begin{array}{l}\text { Semi-structured } \\
\text { conversational } \\
\text { interviews with } \\
\text { children; audio- } \\
\text { recorded }\end{array}$ & $\begin{array}{l}\text { Interviews took place during } \\
\text { the fieldwork, at the } \\
\text { participants' convenience }\end{array}$ \\
\hline & Case study & $\begin{array}{l}\text { Document } \\
\text { analysis } \\
\text { Centre policies, } \\
\text { and procedures }\end{array}$ & Observed during fieldwork \\
\hline & $\begin{array}{l}\text { Ethnographic } \\
\text { tools }\end{array}$ & $\begin{array}{l}\text { Observational } \\
\text { field notes; both } \\
\text { hand written and } \\
\text { typed directly } \\
\text { onto a laptop } \\
\text { computer; } \\
\text { photographs }\end{array}$ & $\begin{array}{l}\text { Began after the first focus } \\
\text { group interview and } \\
\text { continued throughout the } \\
\text { fieldwork period }\end{array}$ \\
\hline & $\begin{array}{l}\text { Ethnographic } \\
\text { tools }\end{array}$ & $\begin{array}{l}\text { Researcher's } \\
\text { reflective journal }\end{array}$ & $\begin{array}{l}\text { Regular entries, often daily } \\
\text { during the fieldwork period }\end{array}$ \\
\hline
\end{tabular}

Table 4 depicts the number of interviews and the number of hours spent in each centre. Four to five weeks were spent in each setting. On average this equated to between four hours and six hours a day, three to four times a week in the Crèche, (120 hours); three to four hours, four to five times a week in the Kindergarten (100 
hours); and three hours, three to four times a week in the Playcentre (75 hours). Time spent in the field included at least two staff meetings per centre (usually two to three hours long), and the time used for conducting individual interviews and focus group meetings.

Table 4: Number of interviews and hours of fieldwork

\begin{tabular}{|l|c|c|c|}
\hline & $\begin{array}{c}\text { Focus group interviews } \\
\text { (up to 1 hour per } \\
\text { interview) }\end{array}$ & $\begin{array}{c}\text { Individual interviews } \\
\text { (1 hour per interview) }\end{array}$ & $\begin{array}{c}\text { Fieldwork hours } \\
\text { (excluding interviews) }\end{array}$ \\
\hline Crèche & 2 & $\begin{array}{c}6 \\
\text { (1x group of three) }\end{array}$ & 120 hours \\
\hline Playcentre & $\begin{array}{c}\text { 1 plus one } \\
\text { conversation }\end{array}$ & $\begin{array}{c}6 \\
(1 \times \text { couple })\end{array}$ & 75 hours \\
\hline Kindergarten & 2 & 6 & 100 hours \\
\hline Total & $\mathbf{5}$ & $\mathbf{1 8}$ & $\mathbf{2 9 5}$ hours \\
\hline
\end{tabular}

\section{Interviews with teachers and Playcentre parents}

Over the course of the study 18 interviews were conducted with teachers, parent educators, one teacher trainee, and two ESWs. A two-part open-ended interview schedule was prepared. Part A invited participants to share their personal experiences of rights as children; Part B investigated participants' professional experience (Appendix E). The underlying intention of the open-ended format was to create a responsive context (Rubin \& Rubin, 2005) that incorporated a sense of personal and professional practice. This conversation-type dialogue was initially guided by explanations about the research.

The interviews usually took approximately an hour, and were held at the participants' convenience, wherever they chose to hold them. All the interviews with adults were audio-taped. The researcher made written notes during the interviews. Not all the interviews were with individuals - one couple at the Playcentre chose to be interviewed together and three teachers in the Crèche opted for a group interview using the individual teacher/parent schedule.

Participation in the interviews was entirely voluntary ${ }^{10}$. Participants were provided with copies of the interview schedule prior to the interview. A clear file of the interview

\footnotetext{
${ }^{10}$ In all the teacher-led centres, the relieving teachers chose not to join in this part of the project.
} 
schedule was made available to the interviewee while the interview was in progress. This deepened the sense of shared responsibility as, at times, we considered where some answers to the questions fitted within the schedule. In some individual interviews, the nature of the responses moved between Parts A and B - an indication of how the personal and the professional can be intertwined. Interviewees controlled the tape recorder, which added to a sense of shared responsibility for the process. All interviews were transcribed in full, and sent to the participants with a covering letter and a reply paid envelope. A confidentiality agreement was signed by the transcriber (Appendix F). It took six months for all the transcripts to be returned.

\section{Conversational interviews with children}

Children, especially young children, acquire social knowledge through interaction with others as they construct meanings through a shared process. (Eder \& Fingerson, 2003, p. 35)

The most effective method of interviewing children was to participate as a newcomer alongside them in the daily routines and activities. In the Crèche, interactions were a mix of verbal (usually the adults) and vocal (usually the infants). Body language and facial expressions were examples of children's communications which were considered participatory acts in this centre.

To establish a research relationship between children and the researcher in the Playcentre and Kindergarten involved serious consideration of their status, as regular participants in their centre, and the researcher's status as a visiting adult. Children in the Playcentre and the Kindergarten often expected all adults to arbitrate, to provide solutions, and to understand the setting. Assuming the role of a naïve adult can give children a sense of empowerment: questions about their perceptions were usually regarded as genuine and generally answered conscientiously. "Insight can also be gained from how children react to the researcher's role in their world" (Davis, 1998, p. 330), as the following story illustrates:

I was wondering why when I asked the groups of children 'What I could do at Kindergarten?' they came up with such sedentary and sedate options. I could paint, or do collage, or the book corner or dough. It was only after I prompted one group about the outside area ('What about the obstacle course?') that I realised they were thinking about what I, Sarah, was able to do. It was a good reality check - they saw me, quite rightly, as too big and too grown up to play as they did outside. (Field notes, Day 12, Kindergarten) 
In context, 'conversations' with children proved to be effective, and while interactions began from Day 1, conversational interviews did not take place until the final weeks of the fieldwork. This allowed time for the participants to get to know the researcher in a limited way. These were naturalistic conversations in the field, with and without a tape recorder. In fact the tape recorder was not successful for two reasons. First, the conversations tended to be with groups of children and recorded sound was blurred by several voices talking at once, and second, the microphone picked up a lot of extraneous noise, beyond the immediate conversation. That made transcribing difficult, but despite the difficulties, the recorded comments were transcribed for analysis.

Children's recorded comments were played back to them at the time. Usually children requested that the recording be played several times, and this became a source of great amusement for those children. In more than one instance a child chose to re-record what he or she had said, but this appeared to be more about gaining control of the tape recorder than it was about accurately reflecting their comments. A jointly constructed set of rules applied to using the tape recorder, and once the machine's workings were understood, in a shared trial and error manner, participants controlled the record button:

Erica: I know how, I know how.

Sally: I know, you push that one.

Thomas: No! No! You push them together.

Some shoving going on here. The machine starts squealing as the play and rewind buttons are pressed together.

Alice: $\quad$ You need to have turns.

Thomas: That button goes it away [wipes the recording].

Sally: I know (she pushes the buttons too).

Sarah (researcher): We could have turns.

Erica: $\quad$ Yeah, we can. (she starts pushing all the buttons starting from the left) I can be next eh? (Field notes, Day 12, Kindergarten)

\section{Challenges with the strategies}

Henry (the persona doll), the book, and the posters were critical resources in the Kindergarten, but were not used in the Crèche setting because the infants and toddlers were largely non-verbal. Retrospectively, the rationale for not using research resources in the Crèche can be critiqued as unfounded-infants' and toddlers' reactions to images and props articulate perceptions, and could have been considered which would have addressed, in part, the overwhelming silence of infants in New Zealand research. 
Requests to use the book, posters, and the doll in the Playcentre were denied because it was deemed contrary to one of the supervisor's perceptions of Playcentre's philosophy of child-initiated play. Her concern was that these data gathering tools might direct children's attention from their choices. This concern was not personally directed towards the researcher, but was part of an ongoing argument about appropriate parental input to the Playcentre's programme. Research demonstrates that this is not the case in other Playcentre settings (see Podmore, 1992; Podmore \& Te One, 2008). Limitations of the method are discussed further in Section 5.7.

\subsection{Data management and analysis procedures}

\section{Data management}

Data management was influenced by the qualitative methodology, and required several methodological strategies to reveal the different contexts in the research situation (Kincheloe \& Berry, 2004). Data management was crucial because there were multiple data sources (Davidson \& Tolich, 2003). Hard copies of all data were stored in lever arch files - one per centre. In accordance with the ethical procedures agreed to, all data were kept secure, in a locked office and with passwords known only to the researcher.

NVIVO - a qualitative data analysis software program - was used as a management and analysis tool. NVIVO allows the user to generate data reports based on selfselected codes. These reports were filed with the rest of the case study data. Most field notes, all the individual interviews, and focus group interviews were typed and saved in folders for each case study. Where possible, field notes were recorded directly onto a laptop computer. These were filed daily, and are cited according to early childhood service type and date. Interviews were tape-recorded and transcribed, with each line enumerated. Citations from the interviews credit the participants' pseudonym and place of work. The focus group interviews are similarly acknowledged. Photographs taken during the fieldwork phase were filed with titles and notes. Sometimes it was not possible to use the laptop computer, and so data were recorded by hand, and then transferred onto the computer.

At the end of the fieldwork phase in each of the three case study centres, a researcher-generated working document summarised key ideas and impressions. A transcript of the first focus group interview was provided for the second focus group, 
and, together with the working document, was used as the basis for discussion at the second focus group interview. Although the working document was not shared with participants, photographs and extracts from the field notes were shared to clarify meaning and to confirm accuracy (for example, regarding centre policy and implementation procedures). NVIVO coding reports, together with the researcher's working document allowed the researcher "to communicate and connect with the data to facilitate comprehension" (Basit, 2003, p. 152).

\section{Analysis processes: From field notes to conceptual junctures}

Analysis has several purposes: It should answer the research questions but it should also make transparent how the answers to the questions were arrived at. Punch (1998) underlined the point that "there is no single right way to do qualitative data analysis - no single methodological framework" (p. 199). There is widespread agreement that the data collection and analysis occur simultaneously (see Atkinson \& Delamont, 2005; Delamont, 1992).

Data analysis began on Day 1 and the process was tracked by using a table to record stages of the analysis (Appendix H). Early analyses identifying potential field note episodes were titled according to context and content. For example, "Splitting up for Justice", a title for an episode (see Chapter 8), was coded as relevant in the following ways: textually because justice was a recognised children's rights issue; contextually because the actions of the children seeking justice used kindergarten conventions of sharing, including and acting in a co-operative way; and theoretically because the relationships between children, teachers, and the environment could be explained using sociocultural interpretations of intra, inter, and community-level experiences in a particular cultural milieu.

All data sources were subjected to interrogation and 'reduced' (Huberman \& Miles, 2002), initially using inductive coding categories as collection points for data that appeared similar. 'Justice' is an example of a code that acted as a collection point. Collection points, recorded in the researcher's journal, and later in the working document, were the result of both reflective and reflexive insight. Collection points, or categories, became potential units of analysis and acted as spurs not just for thinking about the questions (a reflexive act), but also for thinking about the types of data being generated (a reflective act). Basit (2003, p. 144) commented: 
A category, however, cannot be created in isolation from the other categories we want to use in the analysis. When we devise a category, we are making decisions about how to organise the data in ways which are useful for the analysis, and we have to take some account of how this category will 'fit' into this wider analytic context.

It was important in the early phases of the fieldwork to not draw any conclusions about initial reactions, or responses to events. The ideas needed 'excavating' (Millar, 1992) as part of a self-reflexive process that further emphasised the interactive nature of data collection methods and analysis. This developed largely through "a continuing conversation with the data" (Strauss \& Corbin, 1994, p. 280), weaving together combined inductive category coding with a simultaneous comparison of all units of meaning, or concepts.

The analysis process aims "to make sense of what is going on, to reach for understanding or explanation ..." (Wolcott, 2001, p. 574). Consequently, the analysis process began with descriptive data but interwove analysis and interpretation based on inductive codes and conceptual junctures. The process of description, analysis, and interpretation is dialectic, not linear. Table 5 (below) depicts the initial analysis process.

Early analyses of the descriptive accounts centred on two types of questions. First, consistent with a descriptive approach, they were reflective and probing: For example after a description of routine, a note might ask, "What more is going on here? Ask Hannah tomorrow." The purpose of these prompts was to understand the routine and how it was conducted. The research question shifted into the background because not enough was understood about the context to analyse the data. But once the context was understood, the research questions were fore-grounded again.

Table 5: Data analysis processes

\begin{tabular}{|c|c|c|c|}
\hline Process & Question & Action & Researcher's role \\
\hline Description & What is going on here? & $\begin{array}{l}\text { Inductive coding } \\
\text { Collection points }\end{array}$ & Direct observations \\
\hline Analysis & How do things work? & Identify conceptual junctures & $\begin{array}{l}\text { Indirect observations } \\
\text { Researcher's journal }\end{array}$ \\
\hline Interpretation & What does it all mean? & $\begin{array}{l}\text { Integrating codes with } \\
\text { concepts } \\
\text { NVIVO coding reports } \\
\text { The working document } \\
\text { Select data episodes to } \\
\text { illustrate theoretical findings }\end{array}$ & $\begin{array}{c}\text { Building a theoretical } \\
\text { framework } \\
\text { Select codes } \\
\text { Generate working document } \\
\text { Select data to explore thesis }\end{array}$ \\
\hline Representation & What is to be made of it? & $\begin{array}{l}\text { Weaving together concepts } \\
\text { and interpretations }\end{array}$ & $\begin{array}{c}\text { Faithful analysis } \\
\text { Responsibility to participant }\end{array}$ \\
\hline
\end{tabular}


The second phase of the analysis process took a more distanced stance as data sources were interrogated differently from a more knowledgeable, experienced perspective. The conceptual junctures (Table 6) show the relationships between categories of rights, case study contexts, and theoretical analyses.

Table 6: Conceptual Junctures and theoretical insights

\begin{tabular}{|c|c|c|c|c|c|}
\hline $\begin{array}{l}\text { Conceptual } \\
\text { junctures: } \\
\text { Playcentre }\end{array}$ & $\begin{array}{c}\text { Theoretical } \\
\text { analyses }\end{array}$ & $\begin{array}{l}\text { Conceptual } \\
\text { junctures: } \\
\text { Crèche }\end{array}$ & $\begin{array}{c}\text { Theoretical } \\
\text { analyses }\end{array}$ & $\begin{array}{l}\text { Conceptual } \\
\text { junctures: } \\
\text { Kindergarten }\end{array}$ & $\begin{array}{c}\text { Theoretical } \\
\text { analyses }\end{array}$ \\
\hline $\begin{array}{l}\text { Provision rights } \\
\text { to enable } \\
\text { participation } \\
\text { rights }\end{array}$ & $\begin{array}{l}\text { Preamble; } \\
\text { Articles 3; 4; } \\
\text { 18; } 27 \text { (3); 26; } \\
28 ; 29 \text { (a \& d) } \\
31\end{array}$ & $\begin{array}{l}\text { Protection } \\
\text { rights to enable } \\
\text { participation } \\
\text { rights }\end{array}$ & $\begin{array}{l}\text { Preamble; } \\
\text { Articles 2, 3, 4; } \\
6 ; 14 \text { (1); 16; 19; } \\
\text { Early childhood } \\
\text { regulations; }\end{array}$ & $\begin{array}{l}\text { Participation } \\
\text { rights } \\
\text { dependent on } \\
\text { protection and } \\
\text { provision rights }\end{array}$ & $\begin{array}{l}\text { Preamble; } \\
\text { Articles 12; 13; } \\
\text { 14; 28; } 29\end{array}$ \\
\hline $\begin{array}{l}\text { Community of } \\
\text { learners in a } \\
\text { local } \\
\text { community }\end{array}$ & $\begin{array}{l}\text { Sociocultural } \\
\text { theory: } \\
\text { perceptions of } \\
\text { Playcentre as a } \\
\text { social } \\
\text { institution } \\
\text { Ecological } \\
\text { theory: impact } \\
\text { of education } \\
\text { policy on the } \\
\text { microsystem, } \\
\text { e.g., education } \\
\text { regulations; } \\
\text { Playcentre } \\
\text { policy } \\
\text { statements re: } \\
16 \text { areas of play }\end{array}$ & $\begin{array}{l}\text { Community of } \\
\text { learners } \\
\text { external to the } \\
\text { local } \\
\text { community }\end{array}$ & $\begin{array}{l}\text { Sociocultural } \\
\text { theory: } \\
\text { community of } \\
\text { practice and } \\
\text { community of } \\
\text { learners } \\
\text { Ecological } \\
\text { theory: itatus } \\
\text { of childcare; } \\
\text { education } \\
\text { regulations and } \\
\text { policies; }\end{array}$ & $\begin{array}{l}\text { Community of } \\
\text { learners } \\
\text { alongside a } \\
\text { local community }\end{array}$ & $\begin{array}{l}\text { Sociocultural } \\
\text { theory: } \\
\text { community of } \\
\text { practice and } \\
\text { community of } \\
\text { learners as } \\
\text { part of a wider } \\
\text { society } \\
\text { Ecological } \\
\text { theory: status } \\
\text { of childcare; } \\
\text { education } \\
\text { regulations and } \\
\text { policies; focus } \\
\text { on teaching, } \\
\text { learning, and } \\
\text { relationships }\end{array}$ \\
\hline $\begin{array}{l}\text { Curriculum } \\
\text { adult-led, child- } \\
\text { centred } \\
\text { Power with the } \\
\text { child }\end{array}$ & $\begin{array}{l}\text { Sociocultural } \\
\text { theory: cultural } \\
\text { processes in a } \\
\text { community of } \\
\text { learners } \\
\text { Ecological } \\
\text { theory: } \\
\text { relationships in } \\
\text { the } \\
\text { microsystem } \\
\text { Constructs of } \\
\text { childhood }\end{array}$ & $\begin{array}{l}\text { Curriculum } \\
\text { teacher-led, } \\
\text { but child- } \\
\text { focused; } \\
\text { determined by } \\
\text { rosters and } \\
\text { routines } \\
\text { Power with the } \\
\text { adult }\end{array}$ & $\begin{array}{l}\text { Ecological } \\
\text { theory: roles } \\
\text { and } \\
\text { responsibilities } \\
\text { of adults and } \\
\text { children in a } \\
\text { microsystem } \\
\text { Constructs of } \\
\text { childhood }\end{array}$ & $\begin{array}{l}\text { Curriculum } \\
\text { teacher-led, but } \\
\text { negotiated } \\
\text { according to } \\
\text { children's } \\
\text { interests } \\
\text { Power with } \\
\text { adult, but } \\
\text { shared more } \\
\text { with children }\end{array}$ & $\begin{array}{l}\text { Sociocultural } \\
\text { theory: } \\
\text { transformation } \\
\text { of participation } \\
\text { in a community } \\
\text { of learners } \\
\text { Constructs of } \\
\text { childhood } \\
\text { Ecological } \\
\text { theory: roles } \\
\text { and } \\
\text { responsibilities } \\
\text { of adults and } \\
\text { children in a } \\
\text { microsystem }\end{array}$ \\
\hline $\begin{array}{l}\text { Child-centred } \\
\text { approach, } \\
\text { individual child }\end{array}$ & $\begin{array}{l}\text { Sociocultural } \\
\text { theory: } \\
\text { particularly } \\
\text { community of } \\
\text { practice } \\
\text { Tension } \\
\text { between } \\
\text { philosophical } \\
\text { position; family } \\
\text { values and } \\
\text { educational } \\
\text { beliefs }\end{array}$ & $\begin{array}{l}\text { Adult-led, } \\
\text { adults provide } \\
\text { resources to } \\
\text { facilitate play. } \\
\text { Adults protect } \\
\text { children's right } \\
\text { to play } \\
\text { Influenced by } \\
\text { infants' and } \\
\text { toddlers' } \\
\text { needs, but } \\
\text { organised for } \\
\text { the group }\end{array}$ & $\begin{array}{l}\text { Sociocultural } \\
\text { theory: } \\
\text { community of } \\
\text { learners } \\
\text { Children's } \\
\text { rights: role of } \\
\text { adult as an } \\
\text { advocate to } \\
\text { protect rights } \\
\text { and to protect } \\
\text { children } \\
\text { Tension } \\
\text { between } \\
\text { children's } \\
\text { rights and a } \\
\text { perception of } \\
\text { children as in } \\
\text { need }\end{array}$ & $\begin{array}{l}\text { Group focus } \\
\text { with emphasis } \\
\text { on social } \\
\text { conditions, and } \\
\text { cultural } \\
\text { practices. } \\
\text { Teacher-led, } \\
\text { teachers } \\
\text { facilitate play } \\
\text { via open access } \\
\text { to resources. }\end{array}$ & $\begin{array}{l}\text { Sociocultural } \\
\text { theory: } \\
\text { Group } \\
\text { processes } \\
\text { transform } \\
\text { participation in } \\
\text { community of } \\
\text { learners } \\
\text { Constructs of } \\
\text { childhood } \\
\text { Sociocultural } \\
\text { theory and } \\
\text { ecological } \\
\text { theory: role of } \\
\text { the adult, } \\
\text { relationships in } \\
\text { the } \\
\text { microsystem }\end{array}$ \\
\hline
\end{tabular}


NVIVO is a software program designed to manage qualitative data. The program allows the user to categorise and code large amounts of data and then retrieve these together in coding reports. Codes are organised like trees with roots and branches. This is undoubtedly a benefit. However, there was a very real temptation to overcode. At first, every line was categorised and coded with multiple meanings. This had the effect of decontextualising the data. As Coffey and Atkinson (1996, p. 52) warn “... segmenting and coding may be an important, even an indispensable, part of the research process, but it is not the whole story".

An early mistake was not deciding in advance how to define codes clearly. Another early fault was to categorise data segments using several codes, but not consistently transferring these codes between files. After some trial and error, this over-analysis was resolved by writing memos with a rationale for each code, even if it was not yet clear how it might illuminate perceptions of children's rights (Appendix I). These memos, part of the researcher journal, were descriptive definitions of the emerging codes, and established congruence across the different data sources. This is not an uncommon experience and is to be valued as part of the intellectual process associated with making sense of data from several sources.

Memos, recorded in the researcher's journal, acted as a decision-making trail (Figure 9). Coding the same section of data for several reasons established a robust and reliable analysis process that ensured consistency, and coherence within, across, and

\begin{tabular}{|l|l|l|}
\hline \multicolumn{2}{|l|}{$\begin{array}{l}\text { Multiple Data sources } \\
\text { Field notes } \\
\text { Interviews } \\
\text { Research journal } \\
\text { Photographs } \\
\text { Focus groups }\end{array}$} & $\begin{array}{l}\text { Multiple methods } \\
\text { Working document } \\
\text { Research journal } \\
\text { NVIVO coding reports }\end{array}$ \\
\cline { 2 - 3 } & $\begin{array}{l}\text { Multiple theories } \\
\text { Sociocultural } \\
\text { Ecological } \\
\text { Children's rights theses } \\
\text { Childhood studies } \\
\text { Childhood sociology }\end{array}$ \\
\hline
\end{tabular}

Figure 9: Analysis flowchart 
The initial inexperience of coding electronically was transformed as the research progressed, and more consistent categories were clarified, ambiguities resolved, and there were fewer surprises and anomalies in the data.

\subsection{Robustness, rigour, clarity, and consistency}

For qualitative researchers, the ultimate challenge is to produce a report that demonstrates rigour and robustness in a scholarly way (Altheide \& Johnson, 1994; Glesne, 2006; Toma, 2006). Processes need to be systematic, and disciplined, but there is a strong case for them to be strategic as well, framed by "principled relationships" (Atkinson \& Delamont, 2005, p. 836).

Atkinson and Delamont (2005, p. 836) argue that it is not "productive for analysts to represent the social world primarily or exclusively through just one analytic strategy or data type". Denzin and Lincoln $(1998,2005)$ suggest that a repertoire of intratriangulation analysis techniques can be applied to the same body of qualitative data to illuminate different aspects. These include source triangulation, theory triangulation, and method triangulation.

Multiple data sources met the criteria for source triangulation; the combined theoretical framework enabled the data to be analysed from different theoretical positions: different theories of participation were used to analyse context in relation to perceptions of children's rights. For example, observations of children's participation could be analysed socioculturally to understand the nature of that participation, and its impact on the individual, on the group, and at the community plane (Fleer \& Richardson, 2004; Roberts, 2003; Rogoff, 2003); ecologically, to analyse the influences both within the microsystem observed, and externally at a macrosystem level (for example, policies and regulations). From a children's rights perspective, data coded as 'participation' were analysed using internationally negotiated and agreed to interpretations of Articles 12 and 13 (CRIN, 2007, p. 5). Consistent with macro-level theory (Mutch, 2005), the theoretical lens was applied across all three case studies, but particular contexts remained discrete. Finally, method triangulation (for example, focus group interviews, field notes, photographs, interviews, and the researcher's journal) generated different data sources that could then be compared and contrasted as measures of rigour and robustness. 
Terms such as 'validity', 'reliability' and 'generalisability' derive from quantitative research and imply a degree of rigour, tested by random experimental designs and controls, and analysed using pre-determined statistical procedures (see Denzin \& Lincoln, 2005). Comparable qualitative concepts assess rigour, clarity, and consistency. Particular attention to the complexity of the data was important so as not to reduce findings to "deterministic views of social reality" (Kincheloe \& Berry, 2004, p, 2). Active engagement with data generated by a range of research tools allowed for some empirical investigation across data sets, as well as within data sets.

Because case studies are specific and particular, the 'measures' used should enable "outsiders (to) concur that given the data collected, the results make sense - they are consistent and dependable" (Borman, Clarke, Cotner, \& Lee, 2006, p. 130). Yin (2006, p. 117) suggested that case study researchers "need to present the evidence in [their] case study with sufficient clarity to allow the reader to judge independently [their] interpretation of the data". In qualitative research, the onus is on the researcher to act ethically and rigorously in conducting the research, because he or she is the main instrument in ethnographic case study designs (Borman et al., 2006).

Qualitative research is more robust if researchers state "their positions vis-à-vis the group being studied, triangulating data collection methods, and providing details of data collection and analysis processes" (Borman et al., 2006, p. 130). Using many methods can be a limitation in itself because it may divert the focus of the research. However, it also has the potential to "broaden, thicken and deepen the interpretive base of any study" (Denzin, 2001, p. 326). The combination of methods generated opportunities to triangulate data (Denzin, 2001).

As discussed in the previous sections, rigour and robustness were assured in this research in several ways, within method, across data sources, and by using different theoretical lenses. For example, understanding protection from a children's rights perspective as protecting their rights, as well as protecting their right to survival and development, was a defining factor in the final analysis. But, to reach that position, interpreting and checking across data sets, across and between theoretical perspectives and methods was necessary. Knowing the concept of protection rights was important for some participants was not enough on its own; an appreciation of the context out of which a particular interpretation of children's rights emerged was essential. 
Such analysis is typical of interpretivist research, and is an example of philosophical hermeneutics where there is a dynamic relationship between the parts (an individual perspective shared in an interview, or the researcher's field notes); and the whole (when all the data sources are set alongside one another, and where common themes and categories emerge). The methods, too, were subjected to rigorous analysis. For example, field notes and photographs acted together to represent authentic observations in the settings. The level of commonality across the methods indicated a consistency, but there must always be questions about subjective researcher focus. The focus groups were grounding in that sense - deviations in interpretation were set in context by the wider group of participants and this ameliorated the researcher's bias. One example of this was in the Crèche where the researcher's fieldnotes recorded gates and closed doors, which were perceived as barriers to children's rights to participate freely. In the second focus group interview, the teachers explained these barriers in terms of children's protection rights in a difficult environment, not well suited to free-flow play usually associated with New Zealand early childhood education. More interpretive, case study interview methods added a layer of participants' personal opinions. The researcher's journal provided a daily record as well as an account of the conceptual junctures arrived at by interrogating the data, the theory, and the methods.

Final decisions about how to construct the writing were based on playing with the data, constructing and reconstructing them variously to reveal the findings honestly, but remain ethically responsible for protecting the participants. Sánchez-Jankowski (2002, p. 145) expressed concern not just about how phenomena were represented but also "how should they be represented". This question has implications for the participants whose private and professional lives should be protected by the ethical contract with the researcher and not just during the fieldwork phase, but beyond to the dissemination phase (Snook, 2003).

\subsection{Reflections on the limitations of the methodology and method}

All research methods have limitations. There are many ways to investigate children's rights. Postmodern and poststructural theories attempt to reveal hidden scripts in the hegemonic constructions of human realities. An investigation into specific breaches of rights would have required a different lens. For example, a more 
specific question about rights for tamariki Māori would sit within a kaupapa Māori research paradigm and would entail different ethical obligations. A survey, or questionnaire, could reveal perceptions of children's rights quantitatively, with some qualitative explanations, but would not have generated such rich data.

Case studies usually employ a range of methods to answer questions about the case. This study presented a collection of cases, but with an instrumental focus on providing insight into an issue. The intention was not to create cases for comparative purposes, but to illuminate understanding of how children's rights were understood. The risk to presenting data from three cases invites comparison, but this was not an intention. Each case revealed perceptions of rights pertinent to the case in question, not to all cases. To observe and investigate these experiences in only one part of the child's microsystem, the early childhood setting, is a limitation, and does not account for participants' funds of knowledge which derive from many contexts, past and present.

\subsection{Chapter summary}

Method and theory need to align to successfully answer the research questions and allow for a thorough exploration of the findings. Ethnographic, interpretive studies like this one contribute to a platform of research about children's experiences in early childhood settings by adding research-based, descriptive data.

This chapter has discussed the methodology, the methods, and the design of the research. The methodology was interpretivist, and the study employed several qualitative methods. Participatory research methods and ethnographic methods were used to investigate perceptions of children's rights. Sociocultural theory and ecological theory provided a theoretical perspective that influenced the methodology. Ideas from childhood studies, a branch of childhood sociology, and UNCROC influenced the methods, particularly strategies used with children. As well, the chapter described the case study centres and the rationale for selecting them, characteristics of the participants, and data generation procedures. Limitations of this particular study, including ethical constraints, have been discussed. 
Data were analysed for comparative points of similarity and difference once they had been categorised into broad conceptual themes. An intention was to learn as much as possible about perceptions of children's rights from three different case studies, and so a level of comparison was inevitable. However, to remain trustworthy and ethical, a deliberate decision was made to present each case separately so as to avoid comparisons, and none of the case studies are representative of other services of the same type.

\subsection{Preface to the findings chapters}

Before embarking on a discussion of the case studies, it should be noted that UNCROC itself was only ever mentioned in passing by the adult participants in all three case studies, and not at all by the children. From the first encounters in the field, it became obvious that, while the adult participants had heard of UNCROC, it was not their reference point for discussions about children's rights in early childhood education. UNCROC was perceived as more remote:

It's almost like human rights, it's what everyone should be entitled to, to be able to say what they want and be safe and be protected and nurtured, for everything to be fair and happy ... for it all to be well. (Brie, Individual interview, Playcentre)

I think, I mean, besides the standard ones - love and housing and those - I think they just deserve respect. For who they are and for what they are. And for their backgrounds. Just that individual person needs respect. (Peggy, Individual interview, Crèche)

UNCROC's specific relevance to early childhood education was discussed by only one participant:

Like I said, shelter, love, the right to be heard, respected, to be understood. And that's where we don't have here ... I think people do their best. But often people don't have understandings about children's development so they get cross with children for doing things that are just part of ... you know, the developmental process of growing up. And it's nothing to be cross about. And I mean I get cross too. But I think [about] those basic [children's] rights here at Playcentre all the time. (Diana, Individual interview, Playcentre).

Of more direct influence was Te Whāriki (Ministry of Education, 1996b), the early childhood curriculum document. As Paula commented:

Well yes, rights-that's part of responsive, respectful, reciprocal relationships. (We all laugh at the Te Whäriki words.) That sounds like jargon now. (Paula, Focus group interview 1, Kindergarten) 
Previous chapters discussed the background literature, outlined the theoretical framework, and described the methods used to answer the research questions: How are children's rights perceived in early childhood settings; and how are these rights enacted? The following three chapters describe the individual case studies in depth. One intention of these chapters is to illustrate teachers', parents', and children's perceptions of children's rights in their particular early childhood contexts, taking into account the relationship between perception, context, and implementation. Numerous factors act as filters between perception and implementation and these are explained using sociocultural and ecological theories, children's rights, and constructs from childhood studies; in particular, notions of voice and agency. 


\section{Chapter 6: The Crèche: advocates for infants}

If you work with young children, you need to advocate for them. You need to talk for them if they can't talk, especially the really young children that we work with here. More than anything else, that has made me be an advocate for children. (Loretta, Individual interview, Crèche)

\subsection{Introduction}

Three categories of children's rights (protection rights, provision rights, and participation rights) were used to interpret how perceptions and contexts interacted when rights were implemented. Categories though can limit perceptions and can restrict possibilities for implementing rights (Stainton Rogers, 2004). The way data are presented in the next three chapters is intended to reveal the dialectic between perception and context (Woodhead, 1997) by fore-grounding a particular category of rights. In this chapter, the Crèche case study is used to present the first stage of the argument that perceptions of rights, and how rights are implemented in particular contexts, are related. Perceptions and contexts influence one another, and how rights are enacted is affected by perceptions, by social, cultural, and political processes, and by the physical environment; that is, the context.

The Crèche teachers' perceptions of rights appeared to coalesce around their role as advocates, protecting children and protecting children's rights (Figure 10). The evidence suggested that the participants' fore-grounded protection rights as a way to facilitate children's participation at the Crèche. Teachers explained why they did this in terms of provision rights (Article 18, CRIN, 2007, p. 10) and disclosed that, at times, their focus on protecting children constrained infants' and toddlers' participation rights. Lansdown (2005, p. 1) noted that Article 12:

$\ldots$ is a substantive right, which entitles children to be actors in their own lives, not merely participants of adult care and protection. However ... it is also a procedural right through which to realise other rights, achieve justice, influence outcomes and expose abuses of power.

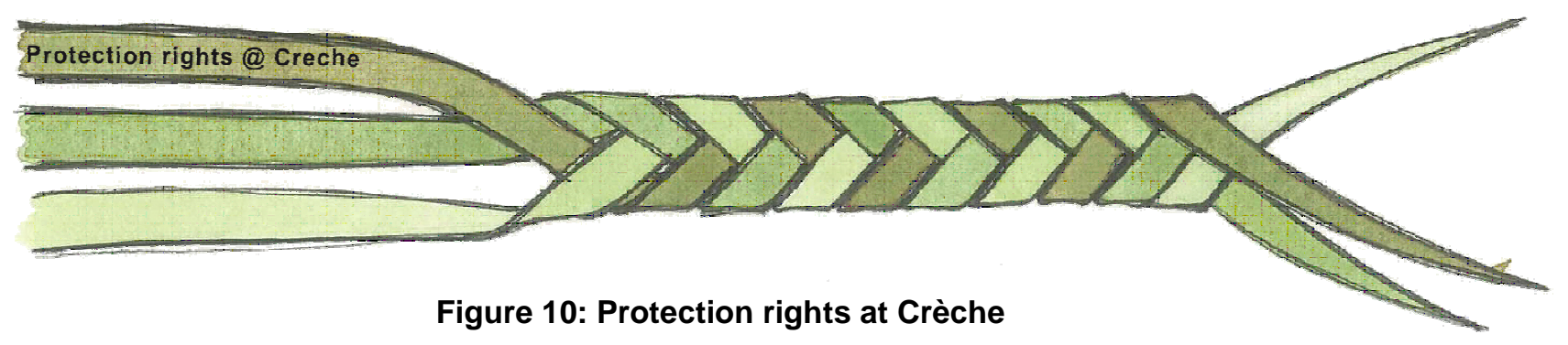


It is important to recognise that these participants understood protection rights in two ways. First, the teachers believed that acting in the child's best interests (Alston, 1994a, 1994b) protected children's rights (Article 3, CRIN, 2007, p. 3); and, second, they believed in protecting children's rights to survival and development (Articles 6 and 29, CRIN, 2007, pp. 5, 13). Their perceptions were tinged with constructs of need, dependence, and vulnerability. Further, wider societal influences indirectly affected how children's rights were enacted, aligning the evidence with sociocultural historical theory, ecological theory, and ideas from the sociology of childhood and the childhood studies. Theoretical constructs from the integrated framework are used to explain the teachers' perceptions of rights, and how these perceptions were observed in the day-to-day practices at the Crèche.

The chapter has three sections. Section 6.1 discusses tensions between protecting children and protecting children's rights. This is followed by an argument (Section 6.2), demonstrating how teachers' perceptions of children's rights were primarily needs-based. Section 6.3 frames the Crèche, firstly as a community in its own right, and as containing two theoretical types of community: a community of learners (Rogoff, 1996, 2003), and a community of practice (Lave \& Wenger, 1991; Wenger, 1998). In this section, the participants' experiences and actions combined to influence how participatory rights for infants and toddlers were both facilitated and constrained by regulatory requirements or interpreted in this thesis as provision rights. These requirements were implemented through work rosters for the teachers, and enacted through the daily routines in the Crèche.

The chapter is organised under three thematic headings drawn from the data:

- Protecting children's rights;

- Teachers' advocacy to support children's rights; and,

- Perceptions of children's rights in the Crèche community.

\subsection{Protecting children's rights, protecting children}

Conventional understanding of protection rights was reinterpreted by teachers in the Crèche to mean rights concerned with belonging and wellbeing in early childhood 
settings (Carr, 2001; Carr et al., 1998; Ministry of Education, 1996b). Belonging and wellbeing are strands from Te Whäriki (Ministry of Education, 1996b), both of which can be traced to attachment theories and notions of trust. Given the centrality of socially mediated learning in Te Whāriki, these are not simply imported from developmental psychology. The teachers' focus on wellbeing and belonging was influenced by the age of children (all under two years old). Consequently, they felt their role was to protect children's health and wellbeing by meeting their needs, as well as advocating for their rights to be heard - a participation right but with a concomitant responsibility on the teachers to protect rights per se.

The terms 'rights' and 'needs' were interchangeable in the Crèche. Teachers perceived themselves as advocates for protecting children's rights and protecting children's health and well-being. Teachers described protecting children in terms of their needs, but their position, vis-à-vis needs and rights, was not always clear. Critics of developmental psychology (e.g., Canella, 2005; James, 2004; Walkerdine, 2004; Woodhead, 1997, 2005) argue that this perspective traps children in an age and stage, and is divorced from social and cultural contexts. The effect of this discourse is to cast the child as incompetent, vulnerable, and immature. The age and stage of a child's development is used as a rationale to argue against children having rights, particularly participation rights. The division between adult and child is clearly defined and often assigned to an age. While there is not disagreement that children have a right to be protected, the tension emerges when focused on protecting children's rights to be provided for, and their rights to be informed and consulted (participation rights).

Participants from the Crèche identified themselves as advocates for infants and young children, but it was not always clear to whom they were advocating, and whether or not they were advocating to protect children's rights, to protect children, for provision rights (better resources and conditions), or for participation rights in the centre. Was their advocacy directed to policy-makers, on behalf of the early childhood profession? Or, was their advocacy on behalf of the children attending the Crèche directed to parents, a perception that could be interpreted either as protecting children's rights, or protecting children's rights to health, wellbeing, and sense of belonging? Yet another possible analysis could be that their advocacy was directed at protecting children's rights to participate, or, at the very least be consulted about 
their participation (attendance) at the Crèche. Data revealed that the answer is all three lending weight to the argument that children's rights do not exist in isolation: how they are perceived and how they are implemented, or enacted, in practice are related constructs. The Crèche teachers directed their advocacy for children's rights towards government policies, to parents whose children attended the Crèche, at times to one another on behalf of children, and on behalf of one child to another. This chapter expands on the teachers' perceptions of rights and their self-appointed role as child advocates. In the next sections the data present the teachers' perceptions of the impact of increased enrolments on infants' and toddlers' rights to be consulted (a participation right) as well as provision rights' issues concerning teachers' perceptions of children's entitlement to 'quality' early education, something teachers believed was under threat due to increased participation rates in the Crèche.

\section{The right to work, the right to early childhood education}

Since the late 1990s, trends indicate that women are returning to work earlier after the birth of a child than was previously recorded (Boston et al., 1999; Else \& Bishop, 2003). In the past decade, there has been a significant increase in the numbers of children under one in full-time childcare (Education Counts, 2008), which in turn impacts on social policy decisions with a flow-on effect that influences perceptions of children's rights (Daniel \& Ivatts, 1998; Prout, 2003). At the time the research took place, Helen Clark, the Prime Minister of New Zealand's Labour-led Coalition Government (1999-2008), had issued a statement that suggested early childhood services might provide dawn-to-dusk childcare. The teachers at the Crèche responded to this suggestion in relation to children's rights throughout the fieldwork period. The Crèche teachers perceived the idea of dawn-to-dusk childcare as unrealistic. In their opinion, increasing women's participation in the workforce did not take into account children's best interests, or their views:

[Helen Clark] wants to see more women in the workforce. If you work early in the morning ... if you work in the afternoon, or start at 6.00am, there will be someone to look after your child - even during the night. (Katrina, Focus group interview 2, Créche)

The promise was perceived to be based on two assumptions. First, those services would be available to enable women to return to work, and second, that this was desirable. All the participants interviewed in this setting perceived the notion of 
dawn-to-dusk childcare as inconsiderate of young children's rights to family time, arguably a right expressed in the Preamble to UNCROC (CRIN, 2007, pp. 1-2):

When they think about full time childcare, I don't think the child is considered really. ... [do they ask] is this actually good for children? (Harriet, Focus group interview 1 , Crèche)

Harriet's comment indicated a reflective questioning stance (Dahlberg, 2000) concerning the status of children and childhood in relation to incentives to encourage women to return to work. One participant expressed concern about the lack of discussion from the child's perspective:

Now do we stop and ask ourselves what it must be like for a child [under two], to be in childcare from a very early age? (Peggy, Individual interview, Crèche)

This teacher bemoaned the fact that early childhood education was invisible "to the [men wearing] suits in the CBD [central business district]." (Katrina, Individual interview, Crèche). Her perceptions were that young children and the work of early childhood teachers lacked status. She was one of several in this setting who expressed concern that a proliferation of childcare businesses might emerge to provide dawn-to-dusk childcare:

It's a business. And the children aren't really considered in the equation. And you're not supposed to say things that are anti about childcare to parents because it is their right to put their child in a childcare centre full-time. 'I'm paying; it's my right to do that. My [the parent's] job comes first.' (Katrina, Individual interview, Crèche)

Indicators of tensions that exert effects on parents, teachers, and children included questioning the motives of private, for-profit childcare service providers. A parent's right to work was a counter point to the child's right to parental care. Whose rights were paramount? The data above exemplify a dilemma for the teachers at the Crèche. Their opinions about increased provision for childcare could be interpreted as advocacy on behalf of the early childhood profession directed at policy-makers to protect children's rights, by ensuring states parties' obligations to provide services to support children's rights (Article 18, CRIN, 2007, p. 10).

Two further points are notable. These teachers believed that there was no capacity to accommodate extended early childhood services, and they also believed children had not been consulted or informed, and had not participated in the decision-making processes (Article 12). This created an observable degree of discomfit. Teachers' 
perceptions were first, that policy-makers had not considered children's opinions when suggesting parents return to work. Second, teachers believed parents did not consider consulting their children's opinions about returning to work. In other words, parents' rights to return to work were perceived as overriding children's rights to be consulted. However, teachers believed that voicing their opinions to parents was professionally inappropriate. There was a perception amongst the teachers that if a service is paid for, it is accorded the status of a right. This perception highlighted a tension between parental rights to work and teachers' views about children's rights to be consulted. Katrina's critical comments touch on the moral complexities underlying children's rights (Federle, 1994; Freeman, 2007; Guggenheim, 2005):

It's a balance isn't it: between the children's rights and the parent's [rights to work]. We can't really say anything because we're just the service ... The children are the most important to us - it's their well-being and sense of belonging too. (Peggy, Individual interview, Crèche)

Describing teachers' perceptions of the tensions between parents' rights and children's rights as a balance was an appropriate analysis. Sociocultural theories suggest that shifting the balance toward the child supports participation in cultural activity, and that in turn promotes development (Bronfenbrenner \& Morris, 1998; Rogoff, 2003; Smith, 2002, 2007b). The question for the teachers was one of positioning: "the children are the most important", but "we have to fit in" with parents' requests for care. The process of fitting in potentially compromised children's ability to participate. The teachers' work complied with their professional requirements; the parents' occupations, although not specified here (partly in the interests of preserving confidentiality), exerted influence on these requirements. Further, even though the rhetoric of the teachers in the Crèche advocated for children's agency, the low status of the early childhood sector, and of children, worked against this notion of the child as a social actor. Evident in the comments from the teachers were the underlying economic policy drivers, in particular women's increased participation in the workforce; the profit motive alluded to establishing new services for infants and toddlers; and perceptions of early childhood education as a low-status profession. 


\section{The impact of increased participation on 'quality' early education}

Some participants in this case study questioned the impact and quality of the experience of full-time childcare and education for children. Others wondered how a focus on profit might compromise quality:

I really worry what will happen now in the private centres because there is no financial incentive to have better ratios? It's going to affect the quality. I mean, we have 1:3, but we don't get extra for it. It's got to affect the quality and for the kids - that's not good for their rights. (Fiona, Individual interview, Crèche)

Teachers in the Crèche argued that a quality early childhood experience, albeit difficult to define, was a child's right as well as a need:

They need to have the right conditions in order to realise their potential. It's a [child's] right ... to have that really good quality early childhood education. (Katrina, Individual interview, Crèche)

While the main message in the above can be analysed in terms of acting in the child's best interests (Article 3), implicit in this comment are provision rights and participation rights. The right conditions need to be provided, and the experience of participating in a programme of good quality enhances development (Rogoff, 1995, 1998). The teachers' perceptions focused on protecting rights to an education directed to the development of the child's potential (Article 29). Positive learning outcomes for children are a result of good-quality experiences, but the converse is also true: mediocre and poor-quality early education has a detrimental effect on children's development (Smith, 1996). Research suggests that children are not passive recipients, but that they actively construct their own experiences (Jordan, 2004; Prout \& Hallet, 2003). The quality of the experience matters. Article 29 entitles children to an education that prepares them for:

responsible life in a free society in the spirit of understanding, peace, tolerance, equality of sexes, and friendship among all peoples, ethnic, national and religious groups and persons of indigenous origin. (CRIN, 2007, p. 13)

Fiona's and Loretta's perceptions were that children had a right to certain standards, broadly described as good quality, and they expressed concern that children's rights to a quality early childhood experience were under threat if financial profit was a factor motivating early childhood service providers. This is not only a protection right; these comments also reflect perceptions of participation rights and provision rights. 


\subsection{Teachers' advocacy to support children's rights}

The previous section noted that early childhood care and education services are needed for younger infants and toddlers, and for longer periods of time. Articles 5, 6, and 18 (which are provision rights) obligate states parties to provide support and services for children and parents as well as professionals who care for children. Advocacy for early childhood education based on the experiences of teachers and children contributes towards an awareness of how childhood is experienced in New Zealand (see Dalli, 2002; May, 2001). Advocacy in the Crèche was based on a concern for children, a commitment to them, and "a belief in the power of the early childhood profession to influence children's lives for the better" (Fennimore, 1989, p. 2). Arguably, advocacy is concerned with changing social attitudes and political imperatives "to expand the moral arena of early childhood education into the family, greater society, and government" (pp. 2-3).

Rights and advocacy are interrelated concepts in which adult power and control hold sway, and the asymmetric, unequal relations are legitimated through institutionalised, regulated practices (Mason, 2005). Advocacy at the Crèche, however, was overtly not understood as activism in the political arena, but rather stemmed from an implicit 'best interests' approach, with 'inbuilt assumptions that adult-child relations are based on concerns to protect children's best interests (p. 95). The Crèche teachers assumed the role of an advocate for the child, in this case advocating for the protection of children, to protect their rights, and to provide for their wellbeing as they participated in the Crèche. Lansdown (2005, p. 8) noted “... children who are encouraged to express their views are ... better able to contribute to their own protection". While broadly conceived by teachers as protection rights, a child's right to express a view is a participation right as well as a provision right's issue.

As noted, the teachers often described children's rights as needs, and data suggested that their perceptions of rights provided a rationale for their role as advocates for the child. This section provides evidence to answer how rights were implemented in the context of the Crèche, illustrating the dialectic between perception and enactment. Five advocacy themes emerged from the data and these were supported by a range of responsive advocacy strategies.

- Health and wellbeing; 
- Choices and opportunities;

- Listening to the child;

- Promoting the philosophy of teaching and learning; and,

- Advocacy strategies for a range of audiences.

Teachers explicitly stated that infants and toddlers in their care were dependent on them for protection (Article 6). They perceived that some rights protect children and echoed Archard's (1993, p. 47) view that this approach did "not require children to do anything. Rather it is up to others to act so as to secure appropriate conditions for children." Consequently, teachers believed it was their adult responsibility to uphold children's rights, and assume the role of advocate - a role that dovetails neatly with Archard's (1993) notion. Securing appropriate conditions focused teachers' advocacy on children's wellbeing, sense of belonging, and educational experiences:

Fiona: We advocate for the child. They communicate their needs to us and because they are so young, we've got to be really aware of their needs. They communicate by crying and things like that, you know gestures and things and so the communication thing. (Focus group interview 1, Crèche)

Collaborative partnerships between teachers and parents support children's identity and sense of belonging to communities of learning (Ministry of Education, 1996a, 1998; Podmore \& Te One, 2008). Relationships between teachers and parents, and teachers and children in the Crèche both facilitated and constrained conditions supportive of children's rights. At times these relationships resulted in a confused form of advocacy, influenced by the age of the children, and teachers' personal professional understandings about what children were entitled to. A dilemma for the teachers was: To whom should they advocate? While it was clear their advocacy was for the child, it was not always clear to whom the teachers were advocating. Despite the value teachers in the Crèche appeared to place on working in partnership with parents, and respecting parental views, conflict emerged when teachers disagreed with parents' decisions. In some situations, teachers believed that they were supporting children's rights by, for example, presenting their understanding of a child's view, but this advocacy could negatively impact on the relationship between teacher and parent. In her individual interview Katrina said:

I think early childhood teachers are a bit wimpy. They don't speak up enough. I think they get walked over by parents. (Katrina, Individual interview, Crèche) 
A few days later I recorded the following:

Yesterday Harriet [Supervisor] rang Cassie's (5 months) mum about her rash and recommended that she go to the doctor. Today when I arrived Katrina came storming up to me waving a note. 'Look at this,' she said, 'it's not even on a doctor's letterhead.' It was a note about Cassie's rash saying that it was fine. 'It's not any better than yesterday. I hate it when parents do this - do they think we're stupid?' (Field notes, Day 6, Crèche)

It was interesting that the advocacy was rarely, if ever, re-directed to a higher, more influential policy level within the setting, or externally. Loyalty to the group meant that at times changes to the environment or routines were discussed, but not implemented if not everyone agreed. This caused some discomfort for Fiona:

Sometimes things don't happen if we all don't agree. ... We don't want to hurt that person's feelings and things like that. We wanted to turn one of the big rooms upstairs into a sleep room then we could use the playroom all the time and the manager said we couldn't. (Fiona, Individual interview, Crèche)

The examples of difficult advocacy situations illustrate Bronfenbrenner's concerns about caring for the caregiver, but they are also examples of tensions in communities of practice, which highlight how cultural processes, while transformative, may not always support children's rights.

Teachers advocated on behalf of infants and toddlers to a range of audiences: parents, colleagues, and other children in the Crèche:

You're an advocate for the child here and you need to be able to communicate to the other [teachers] or parent ... what that child needs when it's in our care. ... It is being an advocate for the child and being able to speak out for the child in the centre, and to communicate with the parent or caregiver. (Peggy, Individual interview, Crèche)

\section{Health advocates-a conflict of interest}

A prevalent theme for advocacy was infant health. Two reasons emerged as significant here. First, the ages of the children ranged from two weeks up to 24/25 months old; and second, teachers believed that attending to the welfare of the child was in the child/children's best interests. Stainton Rogers (2004) suggests socially constructed images of the child allow for differences in how:

... people may understand what is a child's 'best interest'. [Social constructivism] looks beneath the different perspectives to consider 'where they come from' ... it also highlights the practical consequences for children of different viewpoints ... and alert us to ... issues, for example, of power. (p. 126) 
Below is an extended extract from Focus group interview 1 illustrating how the teachers advocated for child/children's health, something they perceived as supporting children's rights; and how this caused tension in the parent/teacher partnerships:

Peggy: We will advocate very strongly for the child's health which can be very stressful for the parent ...

Harriet: $\quad$ Yes ... today we had to ask the parent to take a sick child to the doctor to have some tests done but we haven't had those results back and so until we have the results back, well ... (Shrugs, meaning the child cannot come back just yet.)

The conflict of interest arose because a sick child for the parent meant time off work and the teachers were mindful of this:

Christine: Well the parent does have needs and the parent often gets really distressed - it creates enormous stress, but we still feel we must advocate for the child.

Peggy: $\quad$ You feel for the child but you also feel for the parent. ... Because maybe they're working or something, and suddenly they have got a sick child, and what are they going to do because they hadn't planned to have a sick child.

The impact of ill health on the immediate family was a concern, but the teachers had to consider the implications of illnesses for the wider group, so it was not only an individual child's rights they advocated for, but also other children's rights:

Harriet: You see, we also have to advocate for the rights of the other children at the centre. ... You've got the rights of the sick child, but for babies, who [don't have the] communication skills and go down so quickly we must advocate - and [sometimes] we may be wrong. ... But often the parents are actually quite grateful, aren't they. They come back and thank us - they may have been stressed at the time, but they do realise that we are speaking for the rest of the centre children.

Professional interest, using the existing networks established with the Crèche, served to promote children's rights within the large group. The advocacy depended on good information:

Loretta: I think it's a communication thing. We're advocating for the child here, but also for outsiders as well. Like if something like diarrhoea is going around, like an outbreak, well some families will ring in and say the child is not coming today and sometimes I might just ask are they OK?, and sometimes they may say, we had diarrhoea over the weekend, and we might say oh, well we've had five cases today. 
Teachers supported infants and toddlers when they became unwell. The supervisors spent time communicating to parents and informed them about policies and procedures for administering medications. Wherever possible, the parents' wishes were followed, but this caused some ethical dilemmas, which the teachers felt compromised their professional status as educators, and created a barrier to participation for the child:

Katrina: Oh, well you know when children have got runny noses and might not be feeling the best and parents still bring them to Crèche but don't want them to do water play, which is something we don't feel comfortable about - you know the child doesn't really have a right to choose because they are not feeling well. That is kind of a sticky one. What does the child want? Is it their right to play where they want?

Health advocacy issues were discussed regularly, and not only at staff meetings, but due to the nature of the dilemmas, teachers had a unified response to act promptly and in the best interests of the individual child and on behalf of the whole group. They were obliged to provide the service to all children, and to protect children's rights to participate while there. As such, protecting children, and protecting their rights, included protecting their rights to a certain standard of provision (Article 18, CRIN, 2007, p. 7) and protecting their rights to participate (Article 12, CRIN, 2007, p. 5) - if a child was unwell, participation at Crèche was not appropriate, and not in the best interests of the sick child, or the wider community of learners.

\section{Advocating for choice: Opportunities and considerations}

The right to choose thesis (Archard, 1993; Haar, 2004; Somerset, 1976) and associated tensions were apparent in the Crèche. Working in a converted villa posed constant problems for the teachers who believed that children had a right to choose what they wanted to play with, and that children should also be able to access resources independently. Teachers commented on how recent changes to the furniture arrangements had made resources for children more accessible, and this offered them choices:

Well, we let children choose what they are going to make. We recently changed it [the shelving] so that children have got access to toys that they might like to play with. And then they are safe and accessible to, so they are not going to be pulling a big basket on top of them. (Fiona, Focus group interview 1 , Crèche) 
Another observation details the transition from outside to inside before lunch and illustrates how the access to resources (arguably a provision right) and belongings facilitated participation in the group:

In the Middle Room there are low shelves where the toddlers' belongings are stored. While Peta and Loretta are changing them into dry clothes, and changing nappies, the toddlers play with toys and books they select from the low shelves and baskets. The children are really considerate of one another. Hannah (18 months) finds a duvet belonging to Paul (19 months) and brings it to him. ... Loretta comments: That is kind. .... You know that Paul loves his duvet don't you Hannah. You are being so helpful today Charles (21 months). He is handing Loretta Jack's (15 months) clothes and trying to put the damp ones into a plastic bag. (Field notes, Day 2, Crèche)

Supporting the toddlers' helpfulness during the transition time builds a shared understanding of what "constitutes the practices of the community" (Lave \& Wenger, 1991, p. 95). While not a usual form of advocacy, the teachers' use of praise in the example above was recognised as a strategy to support shared responsibility in the group, and, at the same time, encourage empathy with individuals. As Loretta said, "we give like lots of praise when they are starting to understand these things - encouragement" (Field notes, Day 2, Crèche). Choices for the children were considered as a right, but how these were exercised depended on the teachers a), understanding what the child intended to communicate, and b) supporting children's intentions, which was not always straightforward:

Children [were] into transporting things and we weren't too sure if we should keep the sand in the sandpit or if we should respect what the child wanted which was to take it everywhere else. That was an example of us thinking about what does the child want? Is it their right to take [sand] where they want? (Fiona, Individual interview, Crèche)

While transporting sand might have been perceived as the child's right, in reality this was unrealistic because first, it was not acceptable to transport sand inside, and second, sand was a limited and costly resource. The locus of power in these situations was often shifted, like blame, to another party. Both physical and temporal dimensions directly affected children's rights to exercise choices. Economic constraints also restricted children's participation. There was either not enough space, it was nearly time for something else (provision rights issues), or the ratios of adults to children would not comply with regulations. Rational explanations as to why a child's choice (a participation right) could not be exercised were the purview of adults, and generally, it was the adult right, enacted as a power that prevailed. 
Again, these were examples of how provision rights and participation rights were linked closely with protection rights, illustrating how these were interwoven.

\section{Advocates for listening to the child: Protecting children's rights to participate}

Listening to very young children (Alderson, 2000; Carr, 2003; Mitchell \& Wild, 2004; Moss \& Petrie, 2002; Prout \& Hallett, 2003) aligns with Article 12 of

UNCROC and requires adults to act as advocates:

In a society that is not used to giving weight to the views of children of any age, we will need to be strong advocates in minute particulars if children without the voice of mature language users are to be listened to and taken account of. (Pugh \& Rouse Sellack, 1996, p. 121)

A focus on listening to the child - accessing the child's voice - was apparent in teachers' interactions with infants and toddlers. Infants' vocalisations were accepted as communicative, and very often revolved around providing for their needs - food, sleep, nappy changes. Interpretative advocacy, especially with infants, required high-level responsiveness from the adults:

We advocate for the child - they communicate their needs to us and we've got to be really aware of their needs, because they are so young. They communicate by crying and things like that, you know gestures I think we are all aware of it because at times we do talk about children's rights. (Peta, Individual interview, Crèche)

Teachers aspired to meet children's needs and at the same time respect their rights; in this case, their rights to participate. Awareness of children's rights and their proclaimed role as advocates required teachers to observe "the nuances of how [children] exhibit stress, or curiosity or anxiety, or pleasure in a manner which is congruent to their maturity" (Pugh \& Rouse Sellack, 1996, p. 122). The interdependent nature of provision, participation, and protection rights is evident in the observation below:

Harriet was feeding Sam (9 months) smiling and raising her eyebrows at him as she was telling me about the routines. Sam is reaching out and trying to grab the spoon. Quickly, Harriet finds him another spoon to use. 'Do you want more? Can you do it? Yes, and now we are going to ring you mother, and tell her that you enjoyed that and tell her about giving you water in a cup.' (Field notes, Day 5, Crèche)

Harriet utilises a range of strategies to meet Sam's rights in the above observation. Her respectful interactions (Nutbrown, 1996a, 1996b) can be interpreted as providing for Sam's rights to food, to health, and to wellbeing (Articles 6 and 18) and respecting his right to feed himself. How rights are enacted, the second research 
question, is apparent through the conditions Sam experiences. He has opportunities which support his growing independence, and self-sufficiency, enhancing his participation rights. There is more than one spoon for Sam to use, evidence of attention to provision rights. The interaction between Harriet and Sam illustrates Harriet's commitment to relaying Sam's achievements to his mother: a professional advocacy on her part that also coincides with a respect for Sam's right to be informed of Harriet's intentions.

In this next example, the teachers facilitated Sam's growing confidence with movement. Once again, Harriet is attuned to non-verbal cues:

Sam crawls on down the hall and gets stuck trying to sit up. He is too close to the wall and Harriet, with Chelsea (infant, 4 months) in her arms, is encouraging him to keep trying: 'Nearly there Sam, keep trying, yes that's right, keep going.' She is smiling at him. He manages to do it. 'Good boy Sam, isn't he getting good at crawling?' Harriet asks Chelsea in her arms. ... There is a bit of a squash, as Sam cannot quite negotiate his way around Jordan. Harriet asks Jordon (infant, 10 months) to wriggle forwards, which he does, and Sam makes his way across the hall. (Field notes, Day 6, Crèche)

Evident in the observation is Harriet's support for infants' persistence, allowing them to experience difficulty, in this case, with negotiating enough space to sit down, without interfering. Comments and encouragement are expressed to Sam's peers, and respect for others is observable. In response to Harriet's requests, Jordan moves to enable Sam's progress across the hall. Perhaps this interchange, facilitated by the adult, might build a sense of respect for others in the Crèche setting. Examples like this illustrate how Harriet perceived children's rights were enacted in practice. Her role was to articulate to the children her understanding of the situations, and as such was a form of advocacy for protecting children's rights to participate in the programme.

Advocating on behalf of some children to other children extends this idea. In the following example, Fiona does this by encouraging William to let others have a turn on the slide:

Fiona is sitting on the path next to the slide and several children are gathered around it, climbing onto the platform and sliding down the short slide.

Look at William. Are you coming down? ... William doesn't move. Fiona counts to encourage him to go. 1, 2, 3, go! ... It's a no go. It's not working, Fiona says to the children waiting behind William. How about tahi, rua, toru go! No? ... How about eins, zwei, drei go? William is grinning from ear to 
ear. He stands firm, rocking as if to move, waiting for Fiona to count, and then stopping again. William, Hannah is behind you, she wants to have a go. (Field notes, Day 3, Crèche)

\section{Advocates for the Crèche philosophy: A provision right}

The Crèche's statement of philosophy was perceived as useful to support children's rights. As a statement, it complied with regulation requirements to implement an early education service (Article 18, CRIN, 2007, p. 7). A small excerpt appears below:

In order to thrive and learn, an infant must establish an intimate, responsive and trusting relationship with at least one other person. ... Programmes for infants need to provide: ... An adult who is consistently responsible for, and available to, each infant. (Te Whāriki, Ministry of Education, 1996b, p. 22, cited in Welcome to Crèche, Information for Parents folder, no date, no page)

This philosophical approach was perceived as an advocacy tool for children's rights outlining principles of practice for the teachers:

I think that [the philosophy is] a way of showing a child too that you respect him for who he is. That if he's hungry you will meet those needs, if he's tired you will meet those needs. (Loretta, Focus group interview 1, Crèche)

Loretta explains her interpretation of the statement of philosophy, pointing to the reciprocal nature of children's needs evoking their rights, which in turn oblige adults to respond appropriately. Theoretically Loretta's explanation expresses two ideas. First, respectful practice could be interpreted as an expression of the caretaker thesis as well as the best interests approach to rights (Archard, 1993; Federle, 1994). Acting in the best interests of children should be based on respect, irrespective of age or maturity. Demonstrating respect is an adult responsibility. The caretaker thesis assigns adults the responsibility of caring for children' rights In other words, the caretaker acts as if he or she were the adult the child might become. So by respecting the child, by addressing the child's needs, Loretta was also respecting the child's rights.

Another example representing the Crèche's philosophical position illustrated a communal approach to nurturing the child, by respecting their choice of caregiver:

I think one of the things we do well here is allowing the child to go to the teacher [they want]. The child has the right to choose what teacher they want to. (Peggy, Focus group interview 1, Crèche) 
On the other hand, attachments to a particular staff member were potentially difficult:

We don't have one teacher who only takes care of your child's needs every day, we all share it. And I think that's a good thing. ... Down in the babies end, they do [have a primary caregiver] but not when they come to the toddlers' end. ... I think in our specific case, with children leaving and coming and going throughout the day [a primary caregiver system] could be difficult. Also some of our children don't come every day and what if that person is not [rostered on]? (Loretta, Individual interview, Crèche)

Managing an ever-changing roster to suit attendance times meant that a primary caregiver system did not operate for the toddlers. Teachers believed the structure provided by the routine actually created a sense of security supportive of children's rights. How this was managed is the key. One of the teachers said:

[Children] come first. ... They need to know that this is a space where I want to be. Where I can say bye-bye to Mummy in the morning, and feel safe that I'm here. And not feel like I'm just a little number on a locker kind of thing. I have a special place in this community of children. (Christine, Individual interview, Crèche)

Reference to the group as a community, and specific reference to the space of the child at Crèche fits sociocultural theories where learning, in this case emotional learning, is situated (Lave \& Wenger, 1991) both within the group and individual (Rogoff, 1998; Walkerdine, 2004). Also clear is Christine's opinion that children have rights to physical and emotional space and place. These rights are also needs, further evidence that teachers' perceptions of rights and needs were inextricably mixed.

\section{Advocating to a range of audiences; using a range of strategies}

Teachers drew on their understanding of professional knowledge to advocate on behalf of children to parents, and to each other using a range of strategies illustrated by the data below. The centre's policy on settling children required a parent to visit at least twice and for two hours per visit, but this was not usually enough time to settle children. To minimise the homesickness many children experienced at being left at Crèche for the first time, teachers discussed the settling process with parents. One strategy was to use the phone:

Parents ring in all the time. I asked Peggy about this, not sure if it was expected or regarded as an interruption. 'We really need them to ring in and we want them to - it's part of the policies. We're open and honest with the parents and we describe what the child is doing at the time, and how they have 
been prior to the phone call. But it can be a double-edged sword: To know that their child has been unsettled. But it is the parent's right to know.' (Field notes, Day 4, Crèche)

Another advocacy strategy was to involve parents in programmes to settle their child over time:

At the water trough Reece (14 months) is clinging to his father. Peggy comments to me that there is a really low level of trust between Reece and the centre at the moment and so they have a little settling in programme to follow. ... Five minutes later, Dad's mobile phone rings and ... he comes up to Peggy and says that he had hoped to get away today ... and that he needed to re-park his van. Ok, says Peggy. Now tell Reece what you are going to do and that you will be back really soon. How about ten, fifteen minutes, alright? Tell him where you are going and what for and that you'll be back shortly. Peggy is very clear with him about this and, as the news is broken to Reece, who cries loudly, she takes him from his father, who leaves quickly. She moves to the fence in the hope that Reece will be able to see his dad getting into the van and driving off to look for a park. Peggy is very talkative to the children and to the teachers around her, explaining to Reece and to other children about what Reece's dad is doing and why he feels upset. She turns to me and says this is a way we advocate for the child. (Field notes, Day 5, Crèche)

The focus in the above is on settling the child. At the same time as attending to his needs, Peggy's strategies were attentive to the child's right to feel secure, mindful of the conditions experienced by the toddler in a new setting. In this case, the parent appeared to comply with the advice offered by the teacher. However, advocating for the child to the parent was not always comfortable, nor did it result in a clear resolution, and as such is an example of the tension between children's rights, teachers' role, and parents' expectations. The following example illustrates this:

Peggy explains that it is now nearly two hours since Kahu's mother left. 'She left without saying goodbye, and he is desperate - he has been crying non-stop and saying he loves his mummy. We can't contact her, and she hasn't phoned in. We agreed yesterday that she would only go for 15 minutes today.' ... Peggy comments that children can understand much more than you give them credit for and she talked about how she'd encouraged Kahu's mum to discuss what was going to happen with him last night, after his second induction visit. (Field notes, Day 11, Crèche)

To effectively advocate for children's rights requires an understanding of children's experiences, which implies a degree of consultation (Article 12, CRIN, 2007, p. 5). At times, the Crèche teachers dealt with extremely stressed children, and their kindness, tolerance, and patience (as evidenced in the data above) was admirable. Professional experience enabled teachers to interpret infants' and toddlers' vocalisations. Teachers' respect for the child's viewpoint caused tensions between 
the parents' wishes and the teachers' perceptions of children's rights. This created tensions that required delicate balancing. Several strategies helped to ameliorate the tensions. like the teachers' insistence that parents comply with simple requests such as ringing in regularly; using the daily diary to record events. The teachers' advocacy upheld children's rights to have their needs met, as well as protecting their rights.

At other times, the audience for advocacy for children's rights was colleagues, and the venue was the staff meeting:

I can think of a recent example [of supporting] a child's rights. Jeremy (15 months) just wasn't coping. It was too busy, too many people. ... So we moved him back down to the babies' end where there are fewer children and the area was smaller and in two ticks he was fine eh? He liked being in that space. He would venture to the door, peek down the passage to see where everyone else was, and then go back into that space until he was ready to move. (Peggy, Focus group interview 1, Crèche)

An advocacy strategy was to give voice to the children at the Crèche by allowing them the space or opportunity to exercise their right to choose. Archard (1993) explains this as follows:

On the other hand there are those rights which it is up to children themselves to exercise if they choose. The duties of others are defined as requirements not to prevent children from doing as these rights allow them. ... The core ideal common to these rights is that of self determination or freedom. (p. 47)

These strategies were an example of how participation depended on certain provisions being in place, and that these two categories of rights supported children's participation at Crèche.

\section{Summing up Sections 61 and 6.2}

The discourses of rights identified by Stainton Rogers (2004, p. 130) "do not merely 'describe', they also carry moral invectives. They prescribe action (what should be done) and agency (attribute responsibility for action)." The teachers perceived themselves as child advocates who actively sought to meet those very basic needs, by assuming responsibility, or agency, for children's rights. The teachers' commitment to their advocacy role was based on an implicit assumption that they were supporting children's rights by acting in their best interests. Knowing and understanding the children, and something of their family background, contributed to advocacy on their 
behalf in ways that were mutually beneficial. First, the teachers' advocacy for the child included personal, professional expertise to support parents, as the child moved from the Crèche to home, and vice versa; second, teachers were heard advocating for children with other teachers, offering explanations and interpretations of voice. As well, teachers advocated for children's rights to participate in activities on behalf of some children to others in the group. This advocacy supported children to join in, and reassured children that there was someone who accepted and interpreted their actions and expressions.

This latter form of advocacy was critical to establishing a sense of community in the Crèche. The routines protected children's physical and emotional rights. Conventional early childhood experiences, such as opportunities to explore, are important to a child's development. UNCROC specifies the right to development to the child's fullest potential (Article 29, CRIN, 2007, p. 13). The examples discussed in this section addressed both research questions: What were teachers' perceptions of children's rights; and how were these rights implemented or enacted in practice? Teachers perceived infants' and toddlers' physical and educational rights as needs, as well as rights. Their perceptions were that children's rights and needs were mixed, and they used the terms interchangeably. The context (that is the conditions children, teachers, and parents experienced at Crèche) influenced teachers' perceptions of rights, and how these were implemented.

The next section discusses the rights of participants in the group, and examines how the routines, rosters, and experiences fore-grounded protection rights. Interview data, field notes, and the researcher journal revealed that teachers critiqued the status quo using the research focus on children's rights. The balance of power now shifts into the centre, and competing interests (or rights) between children and teachers.

\subsection{Rights in a community}

[It is a] child's right to know that 'I have my own space, (talking here as the child) and I can come to Crèche the adults that are there are going to teach them, the children and people around me, [about my] right to space.' (Loretta, Individual interview, Crèche) 
The final section of this chapter considers rights in a community. It argues that the Crèche had its own sense of community, and that a combination of regulations, rosters, and routines (the ways in which provision rights were implemented in the local context), including traditional early childhood activities, determined the organisational culture. This, in turn, directly impacted on power relations in the setting and these relationships both facilitated and constrained participation for children. The combined effect tended to reflect a concern with wellbeing (a protection right) and belonging (a provision right), which appeared to influence participants' perceptions of children's rights.

Sociocultural notions of a community of learners (Rogoff, 1998), communities of practice (Wenger, 1998), and shared understanding (Rogoff, 1995) were relevant to the investigation of children's rights in the Crèche. Ecological theory assisted the analysis of the different intersecting, and at times, competing interests of children's rights, teachers' rights, and parents' rights. The third theoretical idea draws on childhood sociology as well as theories of development. Carr et al. (2002) developed a set of child's voice questions connected to key dispositions for learning and linked to belonging and wellbeing, two curriculum strands of Te Whäriki (Ministry of Education, 1996b) (Table 7). The questions (for example, the focus on interests and abilities, meeting daily needs) have direct implications for providing experiences, and ensuring a level of protection. Further questions highlight the child's perspective on exploration, communication, and contribution - the remaining three curriculum strands.

Table 7: Protection, participation, and provision rights at Crèche (see Carr et al., 2002, p. 119)

\begin{tabular}{|l|l|l|}
\hline \multicolumn{1}{|c|}{$\begin{array}{c}\text { Theoretical ideas } \\
\text { Protection rights }\end{array}$} & \multicolumn{1}{|c|}{$\begin{array}{c}\text { Children's perspectives } \\
\text { Participation rights }\end{array}$} & \multicolumn{1}{|c|}{$\begin{array}{c}\text { Reflective question } \\
\text { Provision rights }\end{array}$} \\
\hline Belonging & $\begin{array}{l}\text { Do you appreciate and } \\
\text { understand my interests and } \\
\text { abilities and those of my } \\
\text { family? }\end{array}$ & Do you know me? \\
\hline Well-being & $\begin{array}{l}\text { Do you meet my daily needs } \\
\text { with care and sensitive } \\
\text { consideration? }\end{array}$ & Can I trust you? \\
\hline
\end{tabular}

The reflective questions are relevant to this section in the following ways. During the fieldwork phase, an influx of new enrolments occupied the teachers in the 
Crèche. As well as structural issues (for example, those determined by regulations and the constraints of the physical environment), teachers were concerned about how to ease the transition from home to centre for those infants and toddlers about to start. Table 7 locates theoretical ideas (belonging and wellbeing) alongside suggested questions for teachers to reflect on how learning is mediated by context. There is an explicit acknowledgement that the child's perspective is central, which is the essence of participation rights. In this chapter, belonging and wellbeing encapsulate protection rights in the Crèche, but, when considered in this way, the interdependent nature of these constructs also includes children's right to a wellresourced environment that facilitates their participation. Evidence presented in this section points to teachers' heightened awareness of the child's perspective, but also how the reality of the conditions experienced by teachers and children alike impacted on children's rights.

\section{Defining community at Crèche}

Rogoff (2003) defined community in terms of relationships and the cultural practices, developed over time. Community in this setting was "constructed and made coherent by practice" (Wenger, 1998, p. 73). A community of practice establishes "a common base line - as a place to move forward from" (Wenger et al., 2002, p. 35). Through mutual engagement, joint enterprise, and a shared repertoire, communities of practice integrate knowledge via participation and reification: "Communities of practice ... depend on membership and the relationships, practices and biographies therein" (Benzie et al., 2005, p. 182). Within such communities, "activities, tasks, functions, and understandings do not exist in isolation; they are part of broader systems of relations in which they have meaning" (Lave \& Wenger, 1991, p. 53).

The Crèche, one of three situated in three dwellings next-door to one another, was not part of a neighbourhood, in the traditional sense, but the adults working in the Crèche identified with the other early childhood services on the site, and formed a broad community of practice for the teachers (Rogoff, 2003; Wenger, 1998; Wenger et al., 2002). Service users were diverse, and did not necessarily share work environments, but their point of common interest was a child, or children enrolled at the Crèche.

The Crèche is an example of a community of interest (Rogoff, 2003) bound by the structure of regulations and professional codes, routines, and rosters, and also joined by 
less tangible relationships, based on a "shared understanding in a culture of practice (Lave \& Wenger, 1991, p. 95) that included "sharing tacit knowledge ... and informal learning processes such as storytelling, conversation, coaching, and apprenticeship of the kind that communities of practice provide" (Wenger et al., 2002, p. 9).

\section{Regulations, routines, rosters}

The Crèche was the most complex social system observed during the fieldwork. Management were obliged to provide a service for parents and children that complied with regulations and, although not acknowledged as such, met the statutory requirements of Article 18 (CRIN, 2007, p. 7). The daily roster and routines were constant markers for all the participants. A mix of sorting the roster to meet statutory funding requirements and the flow-on effects for the routines dominated the supervisors' discussions during the fieldwork.

Daily routines provided structure for the Crèche. Loretta spoke of the importance of routines, but the need, on the part of the adult, to remain responsive to children:

The routines give children structure, and children thrive on things that they know. When they know that we are going to eat at this time, even though they don't know that it's ten o'clock, they associate the fact that it's ... morning tea time, with the fact that we're all sitting on this carpet singing. When we say, it's now time for karakia ${ }^{11}$, they sit down and say karakia. And they know after that it's morning tea time. ... But like I've said before, we don't stick to it like $100 \%$, it's there as a guideline and there as something that makes the day flow. We still take each child's needs and wants into consideration. (Loretta, Individual interview, Crèche)

Routines were a way to develop shared understanding (Rogoff, 1995, 1998) in a community of practice (Lave \& Wenger, 1991; Wenger, 1998). By participating in the routines, the children developed an understanding of practices at Crèche. Teachers relied on the group's co-operation to facilitate routine requirements in ways consistent with legitimate peripheral participation. The routines acted as tools for the teachers to induct new children into the group - in fact they were essential:

Routines mark the day out here. Children in the [toddler section] move as one. It seems to be important to the running of the day that the children conform. If they want to stay in the playroom when it is morning tea time, the teachers strongly encourage them to move through to the kai room. Lots of tidying up in the play room is a message to move as well. (Researcher journal, Day 2, Crèche)

\footnotetext{
${ }^{11}$ Māori blessing or prayer
} 
It struck me today, how the routines support the group to act as a mini community. If the children and teachers didn't have the routines at the moment, settling the new children might be more stressful. The older children don't really buddy the new ones, but because they are familiar with the routines, the teachers talk to them about helping the new children. It sort of sustains the idea of a community. (Researcher journal, Day 3, Crèche)

Elements of co-constructed understanding reified during daily routines were positioned as "part of broader systems of relations in which they have meaning" (Lave \& Wenger, 1991, p, 53). In other words, "learning involves the co-construction of identities" (Benzie et al., 2005, p. 182), but the extent to which children were included as active participants was questionable. Over the next few days, as I observed the routines in action, I recorded notes to interrogate the data in the following ways:

I am curious as to how notions of active participation are revealed here. In what ways is it feasible and possible for these under-two-year-old children to influence the programme? How are they included in collaborative ways as members of this community? (Researcher journal, Day 2, Crèche)

These questions were echoed by several of the Crèche teachers who were exploring the work of Emmi Pikler and Magda Gerber (Gerber, 2002). The 'Gerber' approach (Elam, 2005) is characterised by a respect for infants, but this was compromised by routines and rosters, which created a tension articulated by some teachers. Philosophically the Crèche senior management supported routines that were responsive and respectful to the individual child, but at times the reality afforded a different picture:

In some ways [the children] don't have choices ... we have a routine, it's flexible, but there is meal time here, and sleep time here, so on and so on. So in that respect, children can't just say 'Oh, I' $m$ not feeling that hungry today, I don't really want to sit at the table for 20 minutes while everybody else eats.' They don't have a choice [and they have to] follow the group. I think it's to do with the ratios as well. There isn't enough staff and there's too many children to actually [be flexible] and say 'Oh maybe we'll go through to lunch later.' It really has to work like clockwork. (Fiona, Individual interview, Crèche)

For the toddlers, to act outside of routine arrangements challenged perceptions of rights. Fiona had observed the dichotomy for some time and noted the obvious difference between an ideal, flexible, responsive routine, where children were consulted about their participation, and the reality which meant children were expected to comply and conform. Fiona also observed a tension expressed in rights debates-one person's rights or one group's rights can be at the expense of others. Fiona's explanation linked the disparity between the ideal and the reality to structural management issues, and her 
perception is an example of Bronfenbrenner's (1979; Bronfenbrenner \& Morris, 1998) ecological theory. Decisions made beyond the immediate microsystem the child experiences directly influence the conditions of learning, and because the balance of power described by Fiona was firmly controlled by adults, the desired shift towards sharing that power with children was not apparent during routines. In this case, macrosystem influences were the regulations which prescribed adult:child ratios, and were linked to external government funding. However, the Crèche management interpreted these in a certain way, and implemented accordingly. Thus the regulations can be interpreted as a provision rights issue which impacted on children's ability to participate due to teachers' notions of protecting children.

As Rogoff (2003, p. 80) noted, "Different participants have different roles and responsibilities and their relations may be comfortable, or conflictual or oppressive." Variations between, within, and among communities - different views, ideas, and practices - form a common link that Rogoff regards as culture in a community. For the toddlers, it was expected that the routine functioned according to a timetable. For infants, however, there was more flexibility, and individual routines were accommodated wherever possible. For example, during Focus group interview 1, teachers discussed routines as following the infants' body clocks:

If they need to be breast fed in a couple of hours and they need it when mum isn't here, we will ring [her] up and tell [her] to pop down. We ask them when they drop them off, How did they feed? Or mum might say, They haven't had a very good feed - I might ring you in a couple of hours ... and they ring up and we say, no Baby isn't [awake] ... well would you like to come back then when we ring they usually come down. (Harriet, Focus group interview 1, Crèche)

UNCROC specifies the rights of the individual child, and, as noted throughout this thesis, this is a contested point (Bentley, 2005; Guy, 2005). Balancing an individual child's rights and the rights of all the children in the group (for example, when there is an outbreak of illness) was a constant challenge for teachers. Theoretically, intrapersonal, interpersonal, and community planes of activity are constantly present in a community of learners (Fleer \& Richardson, 2004; Rogoff, 1995). Therefore the question of rights had cultural implications for the group care of children. Children's participation in the routines was almost compulsory. In this context, they were expected to participate as a group. There was a distinct reluctance to criticise the regime. Even though Fiona could see that a more flexible approach to routines could 
enhance children's agency as participants in their daily experiences, she had an awareness of the delicate nature of relationships in any small workplace. Plus, she was loyal to the manager of the Crèche, whom she respected, and this meant she was reluctant to raise critical questions.

From the teachers' perspective, routines assured individual and community rights were met. However, the balance of power resided with the adults, and shifting that towards the child was problematic. For example, teachers' breaks were aligned to routine events which had been timetabled and then presented as a roster of contact and non-contact hours, morning and afternoon breaks, and lunch times. Several of the teachers in the Crèche acknowledged that this approach potentially compromised children's rights - even though choices were available, they were constrained by routines and the roster:

We have routines, for the security of the child, because it becomes a familiar time and they know what's going to happen. But there are times when someone really wanted to continue playing [and it's time to go to morning tea]. ... But that would probably be the only time that you're taking them away from something - when you've got mealtimes and things like that. Which is still there for their needs, but they might have been totally involved in something they were doing. (Peggy, Individual interview, Crèche)

Children's rights to choose were constrained by how the Crèche management and teachers interpreted and implemented regulatory requirements. Respect for the individual child's routines was subsumed by the Crèche's management routine, designed in the best interests of the group, along the line of least resistance and the entitlements of the adults:

Today I watched as Katrina and Harriet changed shifts. Harriet was feeding Angus (9 months) and they literally changed in between spoonfuls. Angus appeared totally unconcerned. It is an incredibly busy place and the teachers are flat out - not in a mad rush sort of way, but there is constant activity, either playing with the babies or feeding a baby, or changing a baby or talking to a parent on the phone or ... showing a new parent around - the induction process. Plus there is the busyness of going on breaks, coming off breaks and administrative tasks like recording sleep times and nappy changes and feeds and the general observations in the daily diary. (Field notes, Day 11, Crèche)

The rationale for routines and rosters appeared to be aligned to an underlying needsbased, best interests approach to children's rights (Alston, 1994b). Infants' wellbeing, security and health concerns (that is, their protection rights) were to the fore in the minds of the teachers, but also in the balance were teachers' entitlements 
to their conditions of service. The next section describes and discusses the process of settling new children into the Crèche to illustrate how routines and rosters were observed as both supporting and constraining children's rights.

Ecological systems (Bronfenbrenner \& Morris, 1998) could be observed influencing the ways children's rights were enacted in the Crèche. The regulatory environment, the daily roster allocating teacher responsibility in the centre, and the routines structured the daily activities of the Crèche. Enactment of rights and perceptions of rights cannot be investigated in isolation. Regulations decided in circumstances remote to the child, exerted influence indirectly on proximal processes in the microsystem the child participated in at the Crèche.

Decisions made at the regulatory level (for example, staff:child ratios) directly influenced the teachers' working conditions, as well as their professional educational expectations that translated into a roster, allocating actions and routines, where actions were afforded agency. The roster and the daily routine were a mix of obligations to comply with regulations, and to comply with professional expectations. These included curriculum expectations, as well as expectations to attend appropriately to children's physical wellbeing and emotional security. Parents' working hours tended to reflect the number of hours their children were enrolled. This, in turn, determined the number of staff employed at any one time, and this impacted on the rosters, but also at the routine level, where a responsive attitude to meeting their individual child's rights was expected. However, parental access and participation in the service were controlled at the policy level by their respective employment contracts.

Regulations exerted influence over the teachers' employment and conditions of service, both structurally and in terms of the processes, and at the routine level, through management practices. The largest group affected directly and indirectly by regulations, rosters, and routines were the infants and toddlers enrolled at the Crèche (see Figure 11). 


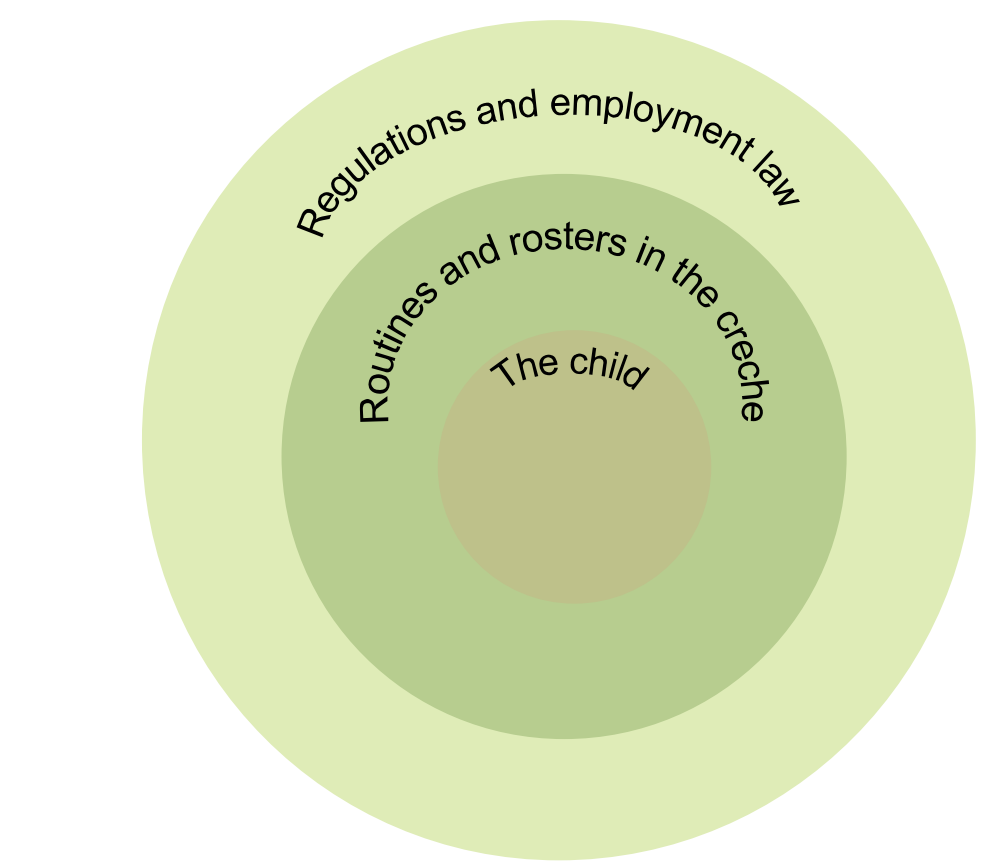

Figure 11: The ecology of influence on perceptions of children's rights

As noted, this research took place in the Crèche at the start of a term. An influx of new enrolments was expected, and the consequential implications for the small group of children who had been coming for some time were considered by the teachers. From a children's rights perspective, the following observations illustrate how difficult it became for teachers to maintain relationships, let alone build relationships with the children when the group dynamics alter:

Quite a few of the teachers have pointed out to me that they are concerned that the influx of new children next week will have a dramatic impact on the ones who have been coming for a while and are really settled into a 'routine' but more than that, the four teachers who have mentioned it have all had questions about how the expectations of the current group of children will not be met when the new ones start because there is just not the time. Those children will just have to manage. (Field notes, Day 4, Crèche)

The supervisors were struggling with how to manage the rosters:

Harriet and Loretta (the supervisors) are constantly talking about who is coming, who is starting and how they are going to manage next week. They met over the weekend to plan the rosters and to organise extra gear. (Researcher journal, Day 6, Crèche)

Developing a sense of belonging to a community (Rogoff, 1998, 2003) was important for the group. Teachers rightly predicted an unsettled climate, and expressed concern for both the new children about to start and the children who were already relatively experienced participants in the community of practice (Lave \& Wenger, 1991). The teachers' concerns parallel the concept of 'benign community 
neglect' (Benzie et al., 2005). The level of attentiveness children had experienced in the first weeks of the fieldwork could no longer be sustained, and consequently teachers were reliant on more experienced community members (still infants and children under two-and-a-half) to uphold routine activities. The impact of newly enrolled children on the pre-existing group was immediately noticeable:

The calm, relaxed and peaceful atmosphere has been shattered this week, and Peggy, Harriet and Loretta are struggling to establish a sense of security. Since the beginning of that week, the roll had doubled, and there has been non-stop crying from several children who have been left by their parents for the first or second time. Not only were the new children upset, one of the younger staff members had her application for leave denied and, as Loretta explained, this wasn't personal, but all staff were needed now. The Crèche are advertising for trained teachers, but none had yet been formally appointed, so there have been a series of relievers employed to cope with the extra numbers. (Field notes, Day 9, Crèche)

Childhood sociologists (James et al., 1998; Jenks, 1996; Pufall \& Unsworth, 2004) argue that the conditions or circumstances of children's lived experiences contribute to their sense of agency, or lack of it. Notions of peripheral participation in group activities applied here as new children observed how to join in (Chaiklin \& Lave, 1996; Lave \& Wenger, 1991). Children's attempts to learn the specific practices of the community were observed as Ruby's story (below) demonstrates. Ruby, aged 14 months, provided an example of how one new child strategised to build meaningful, reciprocated relationships. It was difficult to comprehend the reasoning from the data. Interview and focus group data indicated that strong attachments between toddlers and staff in the toddler group were recognised as important and rewarding, but teachers were wary of encouraging these attachments because circumstances at the Crèche meant primary care arrangements for newly enrolled children were considered unattainable:

Amy (a teacher) returns from the Sleep Room with Ruby (14 months) in her arms. Ruby is still very tearful. They have been trying to rest. Loretta (Supervisor, Toddlers) takes Ruby from Amy and carries her to the dough. She cries and reaches up as she sees Amy leaving. There is no reaction from Amy. Loretta tries to interest Ruby in the dough. ... Ruby moves to the door because Amy has gone outside. Loretta asks her if she wants to go outside. ... Amy has returned from outside and is sitting at the crayons, colouring in. Ruby ... babbles to Amy, cocking her head to one side and moves from foot to foot, trying to gain eye contact. Amy's interactions are intermittent, and she doesn't look at Ruby. Ruby starts crying and, she goes outside ... She finds Peta (teacher), who is friendly but makes it clear that she is not available. Peggy (teacher) is with a small group, but she stands up and moves away as Ruby tries to get close to her. The different heights are a really strong statement. Ruby is really using a whole range of strategies to find an adult - 
she puts her head on one side and chats to Fiona (teacher) who smiles broadly and then holds out her arms - when Fiona encourages her onto her lap she snuggles in and rests. Ruby looks exhausted both physically and emotionally.

Phoebe (Ruby's mother) has arrived and is asked if she would like to sit by her to feed her lunch. When she sees her mother, all Ruby wants is to breastfeed so Phoebe begins to breastfeed her in the Kai Room. Loretta asks Phoebe if she would like to feed her upstairs and Phoebe [stops breastfeeding] Ruby. Ruby starts screaming and Phoebe tells Loretta [that she thought] ... the centre was happy to support existing routines from home. Phoebe looks embarrassed and says several times that she is unsure and just wants to fit in. Well, we prefer [parents to feed their babies] upstairs Loretta says. OK, that's fine and then can I lie with her to settle her to sleep? She likes me to lie with her, Phoebe explains. Loretta tells her that that is not really appropriate here because there was not enough room in the sleep room. I can sense Phoebe's unease and distress. ... She takes Ruby upstairs. The crying is really loud now. I overheard Loretta comment to the others that settling Ruby was going to be difficult. (Field notes, Day 10, Crèche)

The dilemma described above is rich with contradictions. At a fundamental level, Ruby should be entitled to breastfeed. Arguably she was, but the uncomfortable conversation between Ruby's mother, Phoebe, and Loretta is an example of how misunderstanding affected Phoebe's (parent) participation at the Crèche. Throughout the exchange, an emotional one for both Phoebe and Ruby, there was no move by Loretta to accommodate these emotions by tolerating a change to the normal practices. A journal entry reflecting on that day recorded how induction procedures do not always result in their intentions to establish shared understanding (Rogoff et al., 1993):

There is a mismatch here - I have watched the induction talks with the parents as they come on their visits to the centre and there is a strong emphasis on home and centre partnerships. Every teacher talks at length about respecting the culture of the home and encouraging the parents to ease the separation by sharing rituals and routines from home. But, there is not a lot of time for discussion about this because the parent is usually holding their child as well as being handed a folder of papers, as well as being shown around. And there are always other children and lately, other parents there as well. Because it is so busy, it would be virtually impossible to cover interpretations of the induction talks - what the teachers mean are toys or blankets that help settle the children at sleep time, or special comfort toys. I noted that one of the policies states that toys from home are not to be brought to the centre unless they fit this category of security (pretty broad - see Parents' pack). (Researcher journal, Day 10, Crèche)

Harriet, Loretta, and Peggy sought to explain the situation, somewhat defensively, through an invitation to visit again beyond the agreed fieldwork times. The researcher journal recorded the following comments: 
I do not know the children or their background stories, nor do I understand fully the circumstances the teachers are working under, and so it is not a good idea to draw conclusions from observations taken over three - four weeks. I am in awe of how difficult this job is, particularly at the moment with so many newies and so many, as Christine, Peta, Loretta and Harriet have pointed out, who are now staying all day, every day. The teachers are acutely attuned to the moods of the children, and comment constantly to one another about how so and so is feeling, and when Mum might be coming back for a feed or a visit. (Researcher journal, Day 12, Crèche)

Routines, induction processes, and children's rights were misaligned for many children at the time they started. Tears, homesickness, and confusion were observed amongst the infants and toddlers. Teachers worked extremely hard to comfort distressed children, and the structured environment afforded them a sense of security based on shared understanding. Their emphasis was on integrating children into the Crèche's community of practice. Their rationale was that initial adjustment to being left for the first time was difficult, but eventually, the children adjusted and participated happily as members of the Crèche community. However, the comments and observations indicated an awareness that the distress caused in the transition from home to Crèche might not be perceived as supporting children's rights and acting as advocates for the child. During this phase, teachers' advocacy was for the routines and rosters. Based on experiences during previous new enrolment periods, teachers believed that, in time, and supported according to the culture of the Crèche, children would, and did, settle.

\section{A community of learners in a gated community}

As is often the case, the Crèche was located in a residential area. The original twostoried homestead would have been impressive, but converted into an early care and education service, it was a challenging physical environment: a silent 'voice' that controlled flow and access of participants.

Two impressions dominated initial reflections on the first day of fieldwork. The first was how access to space was controlled using barrier gates, and the second was how only one space at a time was available to the children, which meant large rooms were left unoccupied for a lot of the day, despite space being at a premium. Free flow between the rooms or to the outside was not observed in the month spent in the Crèche. My journal noted the following:

Why is there so much pressure to put everything away? One explanation has been that because the space is so limited, it quickly becomes chaotic. And one 
teacher commented that the chaos can upset some parents. From a teacher's perspective, it might not be that pleasant either. Combining that with the constraints that the teachers feel with their conditions of work makes this an issue when it comes to children's rights. (Researcher journal, Day 2, Crèche)

The outside area was also challenging. Sloped and on two levels, it was dominated by large retaining walls, and the fact that it was lower than the building made these walls appear higher. It was a small, suburban sized back yard, on an eighth of an acre section. Again, my journal noted:

It makes me think about the combined effect of the house itself, with its constraining environment and very small outside area, the numbers of children enrolled at any one hour, the numbers of teachers needed to meet the ratios, the obligations of the employers to the teachers for breaks and non contact times, not to mention the high professional standards the teachers themselves set regarding their working in partnership with the parents - keeping them informed about what is going on with their child, and the relationships and involvement they have with the children. (Researcher Journal, Day 6, Crèche)

Access to the outside was a serious issue. It was possible, and the spaces met the required square metre per child allocations, but areas not used by children were included in the calculations. The infants rarely left their allocated space:

I did wonder if the babies were ever taken outside. Not really Harriet told me, because of the ratios and the fact that the set-up in this old house is not ideal. Harriet was telling me about the breaks and how they inhibited the free flow together with the environment. She very nervously suggested that they breached children's rights. I thought then: adults can have a break and come upstairs to the teachers' study. [Even though this area is] roomy, spacious, slightly cluttered and messy, it is still a space that they can come to and escape and be on their own for a while. The children aren't able to do that at all and when I put that to Harriet she did look a bit worried as she acknowledged 'it was really hard to do. We just don't have the room.' (Field notes, Day 2, Crèche)

The physical environments were restrictive. Children's access to areas of play was controlled, presumably to protect them from harm, and to ensure adult surveillance. Privacy and uninterrupted time alone was only for adults, and at least half of the teachers mentioned this as an issue for the children who were enrolled for eight hours or more. Peta commented on this during the focus group interview and in her individual interview:

I am here at the end of day, and Matthew (22 months) is the last one here every day. By about 3.00 o'clock you can just see he's had enough of the place. He needs some quiet time and I take him down to the [infants' area]. (Peta, Individual interview, Crèche) 
Teachers used regulations, rosters, and the routines to resist changing the way space was used at Crèche. A plausible explanation for this was the unexpected change in attendance patterns. The Crèche had been designed for short-term usage. Bookings in the past year had changed from the usual one to two hours, two or three times a week, to more children enrolled all day, every day:

Harriet and Peggy have been here the longest and are talking about how the way parents are using the Crèche has changed, even since last year. They are concerned that the system is being abused which means that the way the Crèche was set up isn't working anymore. Katrina agrees. She thinks it's because the Crèche is close to town. Katherine starts to tell me about how long the days are for some of the children: 'They are travelling in the dark to get here and get home in the winter.' (Field notes, Day 4, Crèche)

The restrictive physical spaces were not so obvious when children were constantly coming and going, but the increased demand for full-time childcare had accentuated the need to address the space issue. Both the manager and supervisors were meeting outside work hours to resolve basic resourcing issues, and at the same time maintain their reputation as a quality provider:

Just while the babies are quite settled I peek over into the Sleep Room. Fiona is looking worried. 'I have to fit 16 beds in here today and leave room between them for the teachers to sit. I think we'll have to move all the equipment out but I don't know where it will go. The equipment is not the thing that worries me - it is the crowded room.' (Field notes, Day 12, Crèche)

Initially, teachers did not mention the physical surroundings as a children's rights issue. An influx of new enrolments highlighted awareness of the environment's limitations as well as putting pressure on teachers. In some cases, this raised questions about how children's rights were implemented in the Crèche. These were clearly provision rights issues that potentially threatened children's protection rights and children's entitlements to participate in the centre in ways conducive to development.

\subsection{Conclusions: Who's right, whose rights?}

The aim of this chapter was to illustrate the Crèche teachers' perceptions of children's rights as predominantly focused on protection rights. The chapter also revealed the relationship between perceptions of rights and the realities of implementing/enacting these rights in the Crèche. This case study illuminated the experience of early care and education for infants and toddlers from a 'rights for the 
child' perspective, and argued that the indivisible nature of rights, a specific tenet of UNCROC, is difficult to achieve:

although the rights listed in the United Nations Convention on the Rights of the Child might suggest that experiences of childhood are universal; the ways these rights come to be exercised and articulated for children in the course of their everyday lives vary extensively both within, as well as between cultures. (James, 2004, p. 25)

Conditions of service for teachers influenced the regime of routines, activities, and rosters. Further compounding these conditions were the service obligations of the Crèche to its community of users, which accommodated the parents' and caregivers' working conditions. Flexible variations to the routines were difficult to accommodate, but this was not due to a lack of willingness on the part of the teachers. Within these adult-defined boundaries, opportunities for children to participate, on their own terms, were constrained.

This chapter has argued that provision rights and participation rights are intertwined with protection rights issues. Tensions about the lack of flexibility and responsiveness in the way routines were managed were revealed in the interviews particularly. The teachers in the Crèche responded to these tensions as individuals in a single institution, a response that is not conducive to effective children's rights advocacy (Stainton Rogers, 2004). Sociocultural theory (Rogoff, 2003; Vygotsky, 1978) allows us to examine the conditions under which learning/development are taking place. It was evident in the data that the community of practice experienced by the teachers was not necessarily transformative in a positive sense (Benzie et al., 2005; Hedges, 2007). The focus was on harmonious relationships amongst teachers, and that meant disregarding some disquieting insights about children's experiences of their rights, not just protecting their rights, but empowering them to claim their rights. Similarly, there were disruptions to the community of learners - in this case the children. Conforming to the group was an essential requirement to surviving at the Crèche. Teachers encouraged participation in the community of learners, and although questions were asked about how reasonable such expectations were, data revealed there was a degree of benign neglect (Benzie et al., 2005) to maintain the status quo. The quality of that participation is a critical point, and central to the notion of a community of learners. What is being learnt here? Relationships with the teachers were controlled by a management policy that privileged adults, be they teachers or parents. 
The difficult physical environment had a major impact on highlighting a difference between the teachers' perceptions, and how children's rights were enacted in reality. Free movement between rooms was curtailed, and a series of barrier gates prevented children moving between play areas. Access to the outdoor area was extremely limited, and during the month of fieldwork, infants were not taken outdoors on a daily basis. This fact aside, the outdoor area, while compliant with regulations, was impractical. It was sloping, and on two levels, dominated by imposing retaining walls. This is a provision issue. Teachers and management were forced to address the protection issues because the provision was poor, and this impacted on children's ability to participate freely.

Notions of the child's voice and agency (participation rights), while an ideal, were both facilitated and constrained by conditions that influenced teachers and children alike. The macro policy environment determined the work roster for the adults, which in turn directly influenced the infants and toddlers. Policy requirements and their effects on the teachers in the Crèche exemplified how decisions made in a wider, more remote setting affected the immediate setting in which the child participated (Bronfenbrenner \& Morris, 1998). Teachers were coping with a constantly changing roll as children arrived and departed on an hourly basis, and teachers struggled to align their perceptions of rights with their values, and with current early childhood discourses and theories.

Teachers in the Crèche used numerous strategies to advocate for children's rights. They took on the challenge of acting in their best interests, a protection right, but also a provision right, to facilitate children's participation in the Crèche in meaningful ways. Experiences at the level of the individual, in interpersonal interactions combined with environmental conditions (Fleer \& Richardson, 2004; Rogoff et al., 1996) in complex interplays to reveal a dilemma central to the enactment of children's rights: who's right and whose rights (Fleer \& Richardson, 2004)?

Needs and rights remain intertwined (Stainton Rogers, 2004; Woodhead, 1997, 2004), both in theory and in practice exercising "power over our thinking and our acting as well as how we govern ourselves" (Dalhberg, 2000, p. 14). Rights discourses challenge "the dominant, discursive regimes" (Dalhberg, 2000, p. 14). Critical analysis can reveal not just the strengths but also the weaknesses in 
perceptions of rights. For example, separating needs from rights for infants and very young children creates a tension between those who care for the children, and the nature of that care. The unavoidable fact that infants are dependent on others, some argue, does not mean they have foregone their rights (Funder, 1996). How that manifests can be interpreted according to the various theses about rights (see Archard, 1993). Adults take responsibility for children's welfare and wellbeing, and make decisions in the best interests of children by acting in their stead - both are legitimate interpretations of protection rights.

These issues are never straightforward or simple, as the case study presented here illustrates. Teachers focused on the protection of rights, and on protecting children so that they could participate in the daily activities on offer (Lansdown, 2005). The physical environment of the Crèche presented a unique set of circumstances which cannot be divorced from this perception of protection rights. Nor can the teachers' perception that their professional status was undervalued generally by society. Their advocacy for children's rights was limited, and political action at a higher level was not discussed by staff. In the next chapter, the Playcentre case study is used to illustrate an interpretation of provision rights at a grass-roots level, and the data suggest that Playcentre parents' attention to provision of resources, for example, supported children to participate. 


\section{Chapter 7: Providing for free play at Playcentre}

\subsection{Introduction}

Chapter 6 argued that the Crèche teachers' perceptions of children's rights was to protect children's rights, and that the context in which they worked focused on protecting children's health and wellbeing, and developing a sense of belonging to the group, a participation right. This chapter presents the second case study where the dialectic between context and perception is explored in a very different setting: the parent/whānau-led Playcentre. The Playcentre case study is used to fore-ground the Playcentre parents' perceptions of children's rights as provision rights (Figure 12), one of the three categories of rights identified in the literature and used in this study to interpret participants' perceptions of children's rights.

The Playcentre parents believed it was child's right to participate in free (spontaneous) play (Densem \& Chapman, 2000; Morris, 1994). Consequently the parents assumed responsibility for providing an environment to support children's participation, or, in Playcentre terms, to support children's learning through play, something which they believed would encourage learning and development (Article 29, CRIN, 2007, p. 13; Somerset, 1976). A clearly articulated philosophical approach influenced the parents to focus on how they, as a community of learners and as a community of practice, could provide support for children's free and spontaneous, child-initiated play. Parents experienced a transformed understanding of play in childhood as a result of participating at the Playcentre. This appeared to influence their perceptions of children's rights, and their responsibilities to uphold these.

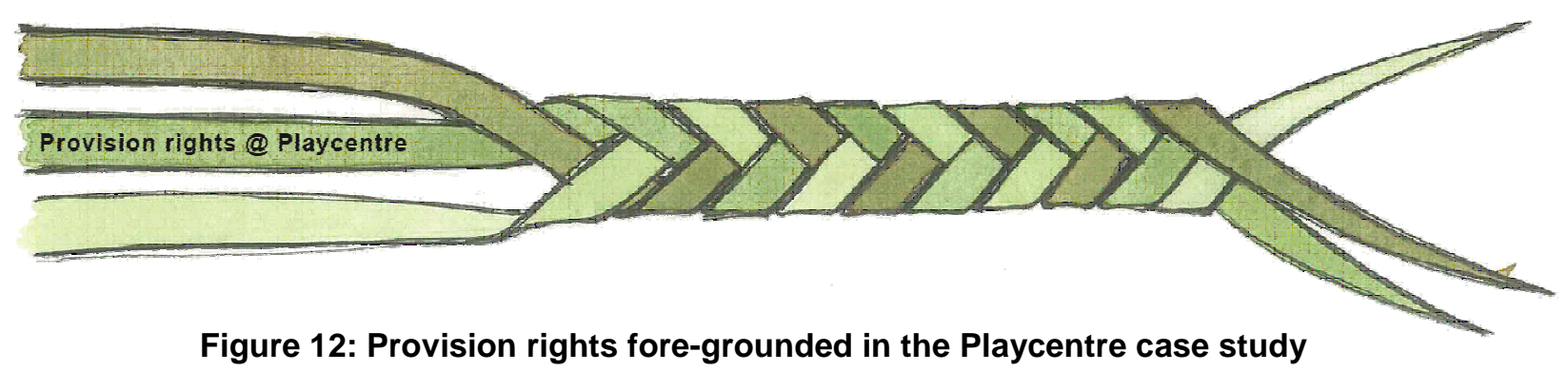

The chapter presents further evidence that both the early childhood context and perceptions of participants in that context are inextricably mixed (Archard, 1993; 
Franklin, 1995; Lansdown, 1994; Stainton Rogers, 2004; Verhellen, 2001). The Playcentre case study is another example of why children's rights cannot be regarded as isolated articles in UNCROC. The chapter begins with a discussion of provision rights (Stainton Rogers, 2004) in the context of Playcentre's philosophical approach, an approach which supports children's rights to play, and guides adults to provide opportunities for play (Densem \& Chapman, 2000; Morris, 1994; Somerset, 1976, 1986).

As such, it addresses the research question by investigating Playcentre parents' perceptions of children's rights, in particular, children's rights to play. UNCROC itself does not enshrine the right to play, but Article 31 (CRIN, 2007, p. 14) entitles children to time for recreation and leisure (play). Similarly, Article 29 (CRIN, 2007, p. 13) can be interpreted as supporting children's rights to play because it aspires to enhancing opportunities for children to develop to their fullest potential. Both these articles can be interpreted as provision rights: the right to leisure and free time to play obliges parents, institutions, employers, and whoever else cares for children to take account of this entitlement. Article 29 articulates an entitlement to conditions for optimal development, and, according to Playcentre philosophy, provides opportunities for play to meet that obligation.

The themes to emerge from the data in this chapter concern:

- Playcentre and the right to play;

- The Playcentre as a community within a wider community; and

- Accommodating differences within the Playcentre community.

The next section of the chapter discusses the Playcentre's educative role, and how parents perceived this as supporting children's rights. In the final sections of the chapter, minor tensions and conflicts illustrate how participants in the Playcentre community sought to resolve their different perceptions of children's rights. These data provide some insights into the second research question: how were rights enacted? The chapter concludes by suggesting that the perceptions of children's rights at Playcentre are situated both in a community of learners (Rogoff, 1998; Rogoff et al., 1995) (the Playcentre itself), and in the wider community - the town the Playcentre was located in. The chapter concludes with a discussion about how, 
based on the data generated in Playcentre context, protection rights and participation rights were interrelated and interwoven with provision rights.

\section{The Playcentre case study - providing for families and children}

Playcentres are a parent/whānau-led co-operative early childhood service, partially funded by the state. They fall within the early childhood regulatory framework, and follow the national curriculum guidelines of Te Whāriki (Ministry of Education, 1996b). The Playcentre parents adhered to a philosophy of child-initiated, free (spontaneous) play (Somerset, 1976).

The twenty-three families enrolled at the Playcentre also lived in the community where the Playcentre was located. They were visible as Playcentre families, and also as families from a particular town. The Playcentre provided a venue for children to play, as well as for parents to meet and discuss a wide range of issues concerning children at Playcentre, and wider issues concerning children in that community and in society. Somerset (1976) commented that the role of adults in the Playcentre movement was to construct the play environment to create optimal conditions for learning the 'Playcentre way':

Young children in our society are no longer dependent only on what their immediate environment has to offer. It is in our own hands to arrange a child's world so as to provide equipment, space, time and models in order that each may develop skills, imagination and logical thinking. (p. 15)

From a children's rights perspective, the emphasis on providing resources for children prompted a reinterpretation of provision rights, localising them in an early childhood setting. Provision rights focus on what is needed, or required, in order for children to not just be protected, but also to participate. In this way, provision rights act to integrate protection entitlements with participation rights. Provision rights can be interpreted as enabling: the onus for provision lies with the adults. Provision rights address the responsibilities of adults to both protect children and ensure that provision is made to meet their needs. This is a pathway to, but not a guarantee of, participation.

Provision rights assign responsibility to state parties to provide services that ensure that children's rights to protection and to participation are possible (Erikson, 2001; Verhellen, 2001). Education services have a responsibility to prepare the child for 
"responsible life in a free society" (Article 29, CRIN, 2007, p. 13). Echoes of this intention are evident in Te Whäriki's (Ministry of Education, 1996b) aspirational statement that hints at children's rights to citizenship (see Chapter 2). The Playcentre was a parent/whānau-led service responsible for providing early childhood education to a community. Perceptions of rights in this setting subscribed to the New Zealand Playcentre Federation's philosophy of play as a child's right. The next section discusses how the right to play was interpreted as a provision right.

\subsection{Playcentre and the right to play}

Historical accounts of the New Zealand Playcentre movement note that progressive educational ideas such as free play and parent involvement broke new ground (Somerset, 1976). The benefits of play were inextricably mixed, and an integral part of the Playcentre philosophy centres on the child's right to free play. The importance of play was founded on the following premise: Once we accept that to play is to learn we cannot do other than appreciate the freedom of the child to choose his or her own play and play until satisfied with the result.

In the decade before UNCROC was finalised, Somerset (1976, p. 25) argued for:

... the acceptance of children as people [and] giving children the same consideration, courtesy and approval as is extended to adults. When this attitude is present, a child feels that the adult approves of play, and values his efforts. (Italics in the original)

Somerset was a pioneering advocate for children's rights to play, and promoted adults' active involvement in that play. This became a driving tenet underpinning Playcentre philosophy (Densem \& Chapman, 2000; May, 2001; Somerset, 1976). It should be noted that play is not articulated as a right in UNCROC although further exploration of how UNCROC is implemented has identified participation in meaningful activities as an essential ingredient promoting development (Lansdown, 2005; United Nations Committee on the Rights of the Child, 2005). Playcentre advocates would argue that play is a meaningful activity. Data discussed below were gathered during conversational interviews with three- to five-year-old children at the Playcentre. They reveal children's perceptions of what they were entitled to at Playcentre, and support Somerset's $(1976,1986)$ articulated position. 


\section{Children's ideas about play at Playcentre}

Children at the Playcentre had clear perceptions about their rights to play. The following conversational interview took place inside in the dress-up area with a group of four-year-old children in response to the question: What can you do at Playcentre?

Liam: You're allowed to play - you can play with the toys, to eat lunch, to paint, to play, to mow the lawn, to play the games. You can play inside or go out of the house to play.

Ashley: $\quad$ You can play with the play dough; play with the dollies and the ponies.

Sarah $^{12}$ : Does anyone tell you what to play?

Sally: $\quad$ Not really. (Field notes, Day 13, Playcentre)

Liam's answer, "You're allowed to play", could be interpreted as articulating a general entitlement to play which is then further explained by describing what he thought his claim meant, listing an interesting array of activities, including eating. The most revealing comment was Sally's response to the researcher's question at the end of this short conversation, indicating that these children felt able to choose where to play and what to play. Theoretically, this places children in a powerful position, as self-determining agents of their experiences and actions (Fisher, 2002). The children's comments resonate with descriptions of learning through play (Densem \& Chapman, 2000; Somerset, 1986). Similarly, childhood sociologists would interpret the choices claimed by the children as an example of children's agency. In this way, the data can be interpreted as evidence of children's perceptions of rights. Two points emerge in the following example. First, children's perceptions about being free to play, and second, how this freedom is interpreted by Millie in terms of choices about what to play. So, the right to play - expressed as an allowance by Liam - is refined to choices about what to play in Millie's responses:

Millie: Well, you're allowed to do anything you want. You're allowed to play with the blocks; you're allowed to play with the puzzles; you're allowed to draw, and paint and you can swing, and play with anything.

Sarah: How do you know?

Millie: Because they don't say that [you can't], and the other children play with everything.

Sarah: $\quad$ Who is 'they'?

\footnotetext{
${ }^{12}$ The researcher.
} 
Millie: The grown-ups. And the children just play with everything and that's all I want to say. (Field notes, Day 13, Playcentre)

Millie observed how rights to play were enacted at the Playcentre. She actualised her rights through her experience of parents' non-interference, and in a positive sense, by observing other children as they engaged with the activities. Millie, Liam, Ashley, and Sally all hint at an environment rich in choice, where the role of the adult is passive (Fleer \& Richardson, 2004; Rogoff et al., 1996). Sylvia confirmed the free play ethos:

Sylvia: $\quad$ You're allowed to do anything at Playcentre.

Sarah: Anything? How do you know?

Sylvia: My mum told me. She told me I could do everything at Playcentre.

Sarah: $\quad$ Are there any rules at Playcentre?

Sylvia: No, no I don't think so. Would you like to talk to Krystal now? What are children allowed to do here Krystal, at Playcentre?

Krystal is busy drawing.

Krystal: You can draw.

Sylvia: Well, at Playcentre [children] can do anything, anything they like. (Field notes, Day 13, Playcentre)

Sylvia's comments express a perception that children are free to choose to do anything at Playcentre. Her opinion, confirmed by her mother, reflects an underlying assumption that the children will be supported in whatever choices they make when they are at this particular Playcentre.

\section{Parents' perceptions about play, choices, and rights}

Based on children's responses to the research question, one could assume that the freedom of choice might constitute a child's right in this setting. That they could play anywhere, and with anything, appeared to be understood by some children, but was not articulated as a child's right. Adults perceived the right to play as part of the Playcentre ethos. Various implications of providing for that entitlement were evident in the adult participants' explanations of what free play as a right for children meant. Several parents believed that the New Zealand Playcentre Federation expected 16 areas of play to be set up for every session. Angela (parent), who had recently completed Part Two of her Playcentre training, was among those who identified providing for the activities as children's rights: 
I believe the 16 areas of play is like their right. And sometimes ... I think that we endeavour ... I don't say we achieve it all the time ... to give them learning or extend their learning in the direction that they're trying to go to. (Angela, Parent interview, Playcentre)

Provision to enable children to exercise their right to play across 16 areas was seen as an adult responsibility. The above quote indicates that this involved more than merely preparing the environment; adults had a responsibility to a) identify what children were learning and, b) extend learning. A significant implication of the data concerns the role of the adult, who Somerset (1976, p. 27) believed should be "models with whom we identify and who contribute to our personal growth ... who gets into play in spirit ... and is thus able to employ the living world to help stimulate a child's search for meaning". The parent's reference to "we" indicates a sense of shared responsibility to make sense of children's learning. As well, reference to the 16 areas of play indicates a common understanding of parental expectations. One couple described it as a responsibility:

Karen: We have a responsibility to ensure that they've got those emotional things, and physical things and [we need to make sure that] creative things [like paint and collage] are available for them to reach. They can reach them, they're low enough, and they are accessible to them. So we have to do that ... to ensure they can reach them and they know where they are. Theo said to me ... I said if you feel tired you can always go into the library and read books. And he said: 'but the sofa's not there anymore.' He didn't know. This is a whole term later. We moved the library to another corner. And he just assumed it just didn't exist anymore. He didn't kind of think ...

Melissa: We should have let them know about that, shouldn't we? Taken them on a tour? (Karen and Melissa, Parent interview, Playcentre)

Adult responsibility for providing learning opportunities was the Playcentre's way of supporting children's agency in the present - provision rights were perceived as supporting participation rights. As Bernie (parent) said:

Because [children] are put first, that's the most wonderful thing in the world. It's all, you know the maxim: child-initiated play? By doing, they will learn. By doing that very thing, by putting the children first and saying that we're the support for them. We're not here to tell them what to do. We're not here to intervene in their learning and their living, unless behaviours are inappropriate. And it's also about thinking outside the square, too. ... Instead of just play dough and books and sandpits everyday, you have to actually think of new things to excite them and challenge them. (Bernie, Parent interview, Playcentre) 
Bernie's perception of children's rights at Playcentre located children as in control of the environment (within reason), with the adult assuming a more passive role. The onus for establishing the right type of environment, one which empowered children and also provided for their play, was an adult responsibility. Extending and exploring children's play interests were also perceived by Bernie to be in the adults' domain. While there is clearly a respect for children's rights, the perception that the adults' non-intervening role allowed for free choice ignores the fact that the 16 areas of play were pre-determined and, in fact, conformed to Playcentre's organisational expectations. According primacy to the child shifts the balance of power towards the child, and supports development (Bronfenbrenner, 1979; Bronfenbrenner \& Morris, 1998). Tenets of childhood sociology (Jenks, 1996; Pufall \& Unsworth, 2004) and sociocultural historical theories (Kozulin et al., 2003; Vygotsky, 1993b), including bioecological theory, were apparent in parental responses to questions about their perceptions of children's rights.

A further example of adults' perceptions of children's rights perceived the Playcentre ethic as respecting children's rights to explore in a rich environment:

Angela: At Playcentre she knows if there's something she wants to do, she can do it. If she wants to do baking or whatever ...

Brie: $\quad$ Or paint the table with paints or something ...

Donna: So in that respect, you know, she's got the right to be able to create and do whatever she likes pretty much at Playcentre ...

Brie: $\quad$ Children are entitled to respect. They're entitled to safety, a safe environment. They're entitled to be listened to, their contributions are valued ...

Donna: To be nurtured. I mean, you just go through Te Whäriki basically. They're entitled to ... well we create an environment where they can explore ...

Bridget: A rich environment. (Focus group interview, Playcentre)

Reference to the rich environment iterates a parental perception that adults could, and would, provide opportunities for play. This provision was possible because of the cooperative nature of the early childhood service which drew on parents' skills and labour:

Well, there's always an opportunity, a learning opportunity, you know, there are lots of parents around and there are opportunities to learn one on one. Fantastic. [Our] responsibility is to create an environment where you are helping children, supporting them in their learning. I think we've got heaps of resources because we've got all this free labour, our voluntary labour. (Donna, Parent interview, Playcentre) 
The focus on help and support for children to capitalise on learning opportunities, and for the parents to recognise these, could be perceived as positioning the child as a passive decider. There is some ambiguity because the role of the adult as creator of the environment suggests that the adult is more aware of the learning opportunities lying in wait to be discovered by children, if they so choose. Learning opportunities are perceived as a product of the environment. While all adults might not be aware of the learning potential of these opportunities, the collective experience of the co-operative creates opportunities for adults to learn, as well as children. The perception of rights is child-centred in approach, free for children, but directive for adults. Letting children be, by providing space (Lundy, 2007), was a theme for some parents:

Karen: $\quad$ They have the right to learn to be themselves. Some kids just want to do the same thing over and over again. And I think that is just fine, just to celebrate what they want to do.

Melissa: They have the right to learn to be in a learning environment.

Karen: $\quad$ Somebody quoted Dr Spock to me - a bit out of fashion - he said, 'love 'em, feed 'em and leave 'em alone'. I thought, [and] I was thinking of myself, 'Oh gosh, we are sometimes too in their face." (Karen and Melissa, Parent interview, Playcentre)

Other participants perceived the child-centred approach as "trying to empower the child to make their own decisions" (Donna, Parent interview, Playcentre). Empowerment has been a significant theme in early childhood discourses in New Zealand, particularly since Te Whāriki (Ministry of Education, 1993, 1996b). The Playcentre philosophy's emphasis on a child's freedom to exercise initiative is an expression of empowerment (Carr, 2001; Nuttall, 2003). In the Playcentre setting, the adult assumed the role of facilitator, either providing actual resources, or creating conditions to both extend and support play, and this was enacted via children's and adults' participation during Playcentre sessions.

\section{The right to belong, as a child, as children, as a family}

Yet another facet of provision rights included supporting children's sense of belonging, which was perceived by parents to be a right enacted on several levels: There were individual children's rights to belong, and family rights to belong to this Playcentre's community. Donna commented:

Playcentre is very supportive, in ways such as theoretically, like, you are taught that as a child enters, they are welcomed ... they are introduced to an activity. They need to get involved and feel a sense of belonging straight-away. So [the adults] introduce them to other children. And until they get to know about the 
activities, you are their buddy and you support them to make friends with the other kids. You know, you portray a feeling of being really glad to see them and happy that they're there. (Donna, Parent iInterview, Playcentre)

Parents went to some lengths to include children in the Playcentre as the following illustrates. Mia was a child with special needs, and her parents felt well supported to participate, even before she began:

Melissa: [Playcentre parents] had heard about me and they were very welcoming. They felt like it was a good thing for Playcentre to have her there.

Karen: It was great. People were very welcoming.

Melissa: And especially for Mia, the whole thing of rights for her are that much more ... I don't know, uppermost I suppose, just because it's hard for her to communicate and understand what's going on. And they've been really, really fantastic. I think five of the Playcentre parents learnt sign language ... the type of sign language that she does, so that they can understand what she wants, yeah. So that sort of thing has been great. (Karen and Melissa, Parent interview, Playcentre)

Mia's right to belong, and participate, required strategies to support her needs, and complied with UNCROC Article 21, in which a child with disabilities "should enjoy a full and decent life, in conditions which ensure dignity, promote self-reliance, and facilitate the child's active participation in the community" (CRIN, 2007, p. 8). Enactment of Mia's rights translated in real terms through other parents learning sign language. While communication skills are arguably a participation rights issue, for Mia, these skills could not be automatically assumed, and so became a provision rights issue, rights that are the focus of Article 23 (CRIN, 2007, p. 10), and which obligate states parties to ensure the disabled child has access to resources and opportunities. In order to communicate effectively, the adults provided a means to enact Mia's rights. Another strategy to enhance children's sense of belonging was for a team leader to telephone a child, and tailor the environment accordingly:

Melissa: That's the team leader and they ... that's something they've done before, so they often say let's ring up Liam or whoever it is ... Mikey ... and see what they want to do. So the team leader kind of does that. And they have done that a few times with the kids.

Sarah: $\quad$ So do the kids ring, or do the adults ring?

Karen: The adult from Playcentre rings the kids and says, what do you want to do, do you want to do something special today?

Sarah: $\quad$ Oh, I see, before they've come down. 
Karen: $\quad$ So we can set it up. (Karen and Melissa, Parent interview, Playcentre)

Although they developed separately, clear parallels exist between the philosophy of the Playcentre approach and UNCROC. For example, General Comment 7 (UN Committee, 2005) noted the crucial role of parents, who are required to act in the child's best interests. It is through relationship with significant others in the context of the family that children "construct personal identity, and acquire culturally valued skills, knowledge and behaviour. Parents (and other caregivers) are normally the major conduit through which young children are able to realize their rights" (Section IV, No. 13). The participants in the Playcentre commented that the children felt confident in the Playcentre environment because it was a family-type service, and the fact that families met at Playcentre, and outside of the session times, developed a strong sense of belonging. One parent described the Playcentre "not completely child-focused, it's kind of family-focused" (Brie, Parent interview, Playcentre):

Brie: I think most of the Playcentre children, well pretty much all of the children feel comfortable and confident with the adults because they see us all so often in and out of Playcentre. It's not a teacher-pupil sort of thing, it's more like ...

Angela: I think it's more like the children probably find it more of a family, you know really close friends ...

Brie: And they have a really strong sense of ownership of the Playcentre.

Sarah: $\quad$ So is that a right?

Donna: The right to ownership - their space and their place! Yep, it certainly is.

Brie: $\quad$ Yes, you hear them say 'this is $\boldsymbol{m y}$ Playcentre.' (Focus group interview, Playcentre)

Playcentre parents' approach to children's learning and development was considered to provide a framework supportive of children's rights to participate. But, it can also be interpreted as a form of protection rights. The focus on the family, and ensuring that families felt welcome, afforded a protection to children (see Lansdown, 2005; and the Preamble to UNCROC, CRIN, 2007, p. 1). The way the environment was set up, the strategies used by the parents, and a belief in children's rights to choose and to play uninterrupted, cohered in observations of rights in practice, and analysis of the adults' perceptions of rights articulated in individual interviews and in focus group interviews. 
A sense of belonging, evident in the above, identifies the parent body as an extended family and fits Rogoff's (2003) definition that a community acts coherently and with purpose. Further analysis of the dialogue resonates with the concepts of children as actively expressing their citizenships as users of a common space. Christensen et al. (2000, p. 139) note that social space is part of social order: "Social space is part of the process of identity-making." From the Playcentre parent perspective, social space entitled children to a dedicated (protected) place and time:

\footnotetext{
Playcentre would be the one time that my children will know that when they ask for something or they want to talk to me, I'm available to talk to them. Cos so much of the time I'm saying 'your rights and needs ... wait, wait, I'm talking, be quiet.'. Whereas at Playcentre, I'm there and the adults are there to listen to them, to do what they want to ask. (Bernie, Parent interview, Playcentre)
}

In summary, this section addressed the central questions posed by this thesis: How are children's rights perceived and enacted at Playcentre? The section described adults' perceptions of rights in the Playcentre as supporting children's learning through play by providing opportunities to explore (a facet of play), untrammelled by overly intrusive adults. Adults believed they supported children's rights by nurturing a sense of belonging to the Playcentre. While the focus was on provision rights, there was also tangible evidence to suggest adults protected children's rights by providing resources in a child-centred space, and in so doing, enhanced children's participation rights, and this included supporting children's rights to express their emotions.

\section{Children's rights to express emotions - a participation right}

Parents commented that children's rights to express their emotions empowered dispositional learning. Perceptions were that the Playcentre developed children's emotional resources, as the following examples illustrate:

Brie came up to me at the end of session: 'I have thought of something else about rights and Playcentre. Another right for children at Playcentre is to feel how they are feeling - they can be supported to be in whatever mood they are in and they don't just have to snap out of it.' (Field notes, Day 3, Playcentre)

The Playcentre parents perceived children's rights to express emotions was healthy, and the Playcentre environment supports children to form an opinion by expressing their emotions in a safe environment. A comment about children's rights to express emotions was visualised by one parent moving along a power continuum: 
There's that whole continuum where the power is with the child. We try to encourage children to develop their own resources so that they can solve their own problems, instead of jumping in and solving them. (Donna, Parent interview, Playcentre)

In the example, the parent's perception that power moves along a continuum both acknowledges the children's right to express emotions, alongside the parental role to support children to express their emotions appropriately. This in turn was perceived as empowering children. John (2003) observed that although children have rights they need "some sense of personal power to exercise those rights ... almost everywhere they are rendered powerless" (p. 11). In the Playcentre context, the interview data suggested that children's personal power was recognised. The childcentred approach, supportive of children's rights was summed up by a parent as "the Playcentre way":

I guess that's just the way it is at Playcentre. They love it. They have a great time, probably because they're allowed to do exactly what they please within a few boundaries. They're encouraged to talk, and we talk to them and they talk back to us. And they say 'Can I paint the fort?' And the answer is always 'Yes' Or you know, ' want to dress up like a fairy, or a dragon' and we facilitate whatever they are interested in. So they learn pretty quickly that 'yes' is pretty much the answer. (Angela, Parent interview, Playcentre)

The right to play uninterrupted was an associated theme of free play for some parents at the Playcentre. Mike staked the claim for protecting children's "right to play uninterrupted, to have their work treasured" (Mike, Parent interview, Playcentre). Bernie articulated the importance of creative integrity, expressed through uninterrupted participation in meaningful activity as:

The right to play with what they want, and not have their work interfered with or destroyed, or written on, if they don't want [that]. All that sort of stuff. Their creativity is theirs. (Bernie, Parent interview, Playcentre)

\subsection{The Playcentre: A community within a wider community}

What are you doing in my Playcentre? Tina's (four-year-old) comment to the researcher. (Field notes, Day 1, Playcentre)

Communities are often assumed to be homogeneous; however, there exist identifiable ethnic communities, religious and cultural communities, communities bound by common interests, and communities defined by physical location. Social 
geography, an adjunct of sociology, focuses on physical aspects of a place, and how these impact on children's rights (Gerber, 2001; Holloway \& Valentine, 2000a).

The Playcentre was both a community of interest, and a community resource, defined by its physical location. Perceptions of children's rights were influenced by Playcentre's overtly family and, by implication, community focus. In her historical account of the Playcentre movement, May (2001) noted that Playcentres acted as "a political community for parents" and were described by one of its founders as "an experiment in better community living" (pp. 24, 25). In the next section the transformative effect of participating in the Playcentre is discussed to illustrate how the Playcentre philosophy changed parents' attitudes toward children and influenced parental perceptions of children's rights. This is followed by examples from a morning tea session where Playcentre parents' perceptions of children's rights do not necessarily mitre neatly with how rights are enacted in practice.

\section{Playcentre's effect on perceptions of children's rights}

Morris (1994) noted that in a service totally organised and run by parents, challenges include accommodating pluralistic values which blur "guidelines provided by the past" (p. 11). Parents are "the experts where their own children are concerned and they should have confidence in their own decisions" (p. 11). As a parent cooperative, the responsibility for providing an environment took time as well as a commitment to learning about the Playcentre approach to early education. Donna (Parent interview, Playcentre) commented:

I think the fact it's a parent co-operative means you have to be pretty committed. You can't just drop off and go away. It's people who are willing to find out about what childhood is about and the involvement in a child's education.

Engagement in the Playcentre required a degree of tolerance and acceptance that in turn led to changes in parenting. This transformed perceptions of children's rights:

I think our parenting has gone through a big change. Before we shifted here, we were working and everything was very regimented. We didn't tend to listen to what our children wanted and we thought we were the bosses ... they do what they're told and that's end of story. So they basically didn't have many rights at all, which was quite bad! But then shifting up here, and especially going to Playcentre, we started talking to a lot of other people about their approaches to children and we realised that, hang on, they are turning into human beings, we need to acknowledge that they do have an opinion on 
most things and they need to be listened to, and things like that. So we sort of changed our way of thinking. (Angela, Parent interview, Playcentre)

Interactions with others in the Playcentre parent community transformed how this family acknowledged their own children's opinions, and thereby accorded them agency in the home. Participation in the Playcentre's community of practice inducted some parents into a new paradigm where children were regarded as having opinions, hence, participation rights:

Prior to [Playcentre] we'd provide direction and structure for the kids, whereas Playcentre completely reversed that. Now it's 'children come first' - they should choose where they want to go in any given day, and I think that's wonderful. And the children's rights? I think [Playcentre] really supports children's rights. (Mike, Parent interview, Playcentre)

The informants reported that their perceptions of children's rights changed as a result of participating in the Playcentre's community. Parents commented that their awareness of children's rights was enhanced through belonging to the Playcentre. Wenger et al. (2002) noted the dynamic nature of communities of practice do not reduce knowledge to a static object, but define the knowledge base that unites the community of practice as social and the role of the community is to use shared understanding of the knowledge base to move forward. In this a shared understanding of this Playcentre's approach to child-centred free play shifted the knowledge base for some parents, which then altered how these parents perceived children's rights. Further, the Playcentre's communal base supported "the collective nature of knowledge ... we need others to complement and develop our expertise" (Wenger et al., 2002, p. 10). From a rights-based perspective, the communal base and the collective nature of knowledge shifted Angela's perceptions of her children's rights within her family as a result of her family's involvement at the Playcentre.

Brie also experienced a change in attitude towards children, which she believed was a result of involvement at the Playcentre:

My whole perception has changed. We [husband and I] looked at [our ideas] and decided we make a big deal over big issues, but little issues, like what they wear, don't really matter. At the Playcentre you learn that emotional needs are right up there - respect, empowering the child. (Brie, Parent interview, Playcentre)

The move from being a novice to developing a shared understanding about children's emotional rights as an outcome of participation is evident. There were openings and 
opportunities for children to express emotion (Shier, 2001). A notional space was provided (Lundy, 2007), and this was interpreted as protecting children's right to express a viewpoint, an act that empowered the child. Overt respect for children's perspectives supports development. For example, adults' discussions about what matters shifted perspectives within the Playcentre's community of learners and practice, often resulting in a more tolerant approach. Over time and as a result of learning more about children's development, Brie's concerns about children not conforming to her original behavioural expectations were confidently articulated as her thinking relaxed.

Involvement in the Playcentre also created opportunities to develop new ideas (knowledge) in an informal way, and more formally. Parental responsibilities at the Playcentre established a community of practice for the adults: The focus was on providing opportunities for the children to play uninterrupted for the duration of the 21/2-hour sessions. Mike said:

When I turn up to Playcentre for my duty, at 9 o'clock in the morning, I look at myself as being there totally for [children]. I come second and they have to come first. You're focusing on how can I make their morning - how can I stimulate them. (Mike, Parent interview, Playcentre)

Mike positioned children at the centre of the Playcentre's approach, which reflects a child-centred model of teaching and learning (Rogoff et al., 1996). In that model, the balance of power sits with the child, and adult participation is passive and responsive. The corresponding model places the adult in the active role, distributing knowledge as a product; the child assumes a passive role, as a vessel of the adult's received wisdom. This model has some resonance with the caretaker theory of rights where the adult acts in the child's best interest to provide for the child as an adult in the future (see Alston, 1994b; Archard, 1993). The alternative community of learners' model integrates ideas of transforming participation (Wenger, 1998) through collaborative processes in which all participants are active, and no-one is passive. The Playcentre operated as a community of practice for the adults to support their children's learning within the Playcentre philosophy, and within the local community. 
The Playcentre as an extension of family in the community was observed during the fieldwork. In the next example, social relationships beyond the Playcentre were enhanced by an excursion:

A neighbour of Johanna's, who lives across the road from the Playcentre, has just rung up to say that her kitchen had just been ripped out and would the children like to see what it looked like. A small group of eight children lined up at the gate to go for a walk. (Field notes, Day 1, Playcentre)

The friend was not a parent, but had an interest in her friend's child. The visit introduced children to a member of the wider community, as well as to a demolition site. Regular exchanges with community members served to deepen children's experiences of their own sense of community:

Mrs Smith was walking past the fence and called out to the children on the fort, asking them about their game. 'Where are you going?' Sam asked her. 'Shopping.' 'My mum is shopping too.' 'In the village?' 'Yep at [name of shop].' 'That's where I'm going too.' (Field notes, Day 3, Playcentre)

Another example of a shared sense of community is evident in the next example:

'Hey, Hey,' calls out Harry. 'It's your nana Sylvia, your nana is by the fence. Hi Nana,' he calls to Sylvia's grandmother. Sylvia appears at the top of the stairs and waves to her grandmother. (Field notes, Day 5, Playcentre)

Within the Playcentre, children and adults spend time organising social contact outside of the sessions:

Lily (a parent) is telling Jacqui (a parent) that Krystal has been invited by her daughter, Maisie, to come and play for the afternoon. 'Is that OK?' asks Lily. Jacqui looks pleased. 'That means I can have a sleep this afternoon.' Lily comments, 'Well, I thought it was kind of cute that they made the arrangement.' (Field notes, Day 7, Playcentre)

Parents differentiated between the Playcentre and home, illustrating how there are variations between, within, and among communities: "Different participants have different roles and responsibilities and their relations may be comfortable or conflictual or oppressive" (Rogoff, 2003, p. 80). These differences contribute to the dynamic nature of culture - participants' mutual engagement in the joint enterprise of running the Playcentre resulted in constantly re-adjusted perceptions of what being a Playcentre family involved. In the next example, the differences between the Playcentre parents illustrate how minor conflict can connect families when there are processes in place to resolve these. During the focus group interview, the 
participants discussed what united them as a Playcentre. One parent noted that "the whole Playcentre thing is very specific to Playcentre":

Brie: $\quad$ I remember going to gym class with Harry when he was twoand-a-half or something. And some mothers there ... like so directive and negative, and this whole Playcentre thing was ... being really encouraging and positive ...

Donna: And often not understanding the reasons why the child is doing what it's doing - maybe tired, or hungry? It's just reduced to 'being naughty' rather than ...

Angela: Understanding the child. We learn about that I think, [Playcentre training] courses, modelling, and watching other parents who have been through Playcentre.

Bridget: I think it's sharing with other parents about how [they] deal with situations, and get their take on it. (Focus group interview, Playcentre)

The flow of conversation during this interview indicated a shared understanding of what being a Playcentre family entailed. Experiences in the wider community solidified the Playcentre parents' commitment to the 'Playcentre way' and might be construed as breaking down the silence identified by John (2003) when it comes to recognising children's rights in a community.

\section{Morning tea time: The politics of children's rights}

The research questions elicited responses from parents about their perceptions of children's rights, and sought evidence of the enactment of rights in the Playcentre setting. One site where both perceptions and enactment were noted and observed was during morning tea, which in this Playcentre was a sit-down affair, which was not the norm for many Playcentres nationally (Podmore, 1992) ${ }^{13}$.

Parents were expected to act collaboratively within the Playcentre's philosophical framework. While play might be a child's right, freedom to play was bounded by both familial and societal interpretations and expectations. The environment was intensely susceptible to political events - peculiarly local, but also national:

Vera and Bonnie (mothers) are breastfeeding Max and Archie. Susan, with baby Julia, joined them and the discussion turned to the meningococcal B immunisation campaign that is about to roll out in the area. Bonnie asked Susan what she was

13 Podmore (1992, p. 9) noted, "There was some diversity, then, in the way in which snacks were provided for the young children ... $106(67 \%)$ of the playcentres, the children brought their own food." The way the Playcentre conducted its morning tea time routines may not be typical of all playcentres. 
going to do. 'No,' she said, 'I'm not going to. There was a documentary on TV about it all and it doesn't necessarily work. One child was fully immunised and then she died. Anyway, the government should spend the money on fixing up the real problems like overcrowding and bad health. That's what you get if you run down the health system.' Vera came in at that point and said she was terrified and was definitely going to have the immunisation. Bonnie told them that she was going to do the same. (Field notes, Day 1, Playcentre)

The depth of thinking was notable as the diverse experiences of the parent community struggled to accommodate various perspectives to keep the Playcentre's community running smoothly. These were not perceived by parents as children's rights-based discussions, but in this section, data and theory are used to locate the debates as concerning children's rights.

As noted throughout this thesis, rights do not exist in isolation, but a challenge for establishing rights-based approaches to education includes how to balance the rights of the individual with the rights of others. The Playcentre was overtly child-centred, but it was also family-focused. Accommodating individual rights jarred with some, as the next example illustrates:

Angela (the team leader), was standing by the door and she said, 'Hey everyone, Solomon is allergic to peanuts and so we can't really use the peanut butter anymore.' Bernie (a parent) said, 'I think we should talk about that in a meeting - he's only one child. ... Does that mean that we can't have any more peanut butter?' asked Bernie. 'Well, it sort of does,' replied Angela, 'because he can stop breathing if he goes into shock and it is potentially fatal.' Bernie wasn't impressed and said 'The chances of that happening are so minimal that it's not worth it. Why should we all have to go without because of one child who might not even be that allergic?' ... 'Well,' answered Angela, 'Solly has the right to come here too - it's a health and safety thing.' (Field notes, Day 8, Playcentre)

There was a Playcentre policy banning the peanuts as a food for children, but the issue of balancing the rights of the individual in the group with the rights of the group was openly discussed. Playcentre provided a community-based forum where issues could be raised. Because peanuts posed a life-threatening risk, a decision had been made beyond the immediate microsystem. In that sense, this was a protection right for the child concerned, because peanuts posed an obvious threat to that child's participation. The decision to no longer offer peanut butter had been made at a national level (the exosystem) and exemplified how Bronfenbrenner's (1979) ecological model operated. The immediacy of the issue, Bernie's articulation of his 
perception, and the policy are an example of the complex, interdependent nature of balancing rights for the individual child and for the group, and add weight to the argument that perceptions of rights are embedded in context.

The next observation illuminated this complexity further. It begins with a description of the morning tea itself:

There were three tables set this morning and there were nine adults including myself, present. On the tables were crackers with honey and jam, freshly baked bread bun, some plain, and some with raisins and seeds, and a variety of fruit, already cut up into small slices. The bananas and the oranges were peeled and sliced. The pears and apples were just sliced. China plates and plastic cups were set and the smell of fresh coffee and bread had enticed everyone into the kitchen. (Field notes, Day 4, Playcentre)

The atmosphere was inviting. Rick (a parent), and Felicity (a parent) who had prepared the morning tea had made an effort to provide a welcoming, domestic scene. However, to realise children's rights, adults have to do more than just provide resources (Lofdahl \& Hagglund, 2007; Shier, 2001). During this morning tea time, food was plentiful, but how to access it appropriately emerged as an issue for two children in particular:

Liam (almost five years old) and Larry (five years old), the biggest boys, literally raid the plates and pile their own plates high with fruit and buns laughing as they do so (were sort of aware that this grab was pushing the boundaries). Two smaller boys (both three years old), one sitting next to Liam and the other behind him, are impressed by this display. They giggle and laugh too. They try to copy, but are cautious about taking so much food. There are at least 10 other children at the table and by the time the two big boys are finished piling their plates, there is not enough fruit or buns left.

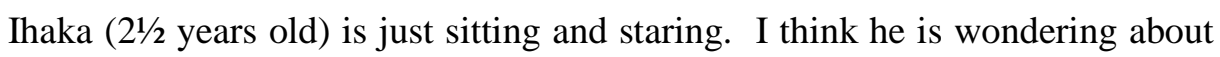
the rules. Can he just help himself? It is his second day alone, and yesterday Angela, the team leader, helped him. His plate remains empty. Maisie (four years old) who is also new and has only recently been left by herself, tentatively reaches into the middle of the table and takes a piece of pear. At that moment, Rick (a parent) reaches down and picks up the fruit plate and the bun plate and offers it to the other children around the table, effectively removing it from Maisie. Maisie and Ihaka follow the food plate with their eyes. (Field notes, Day 4, Playcentre)

Integrating into a new group can be challenging, and it can be a rights-based issue. Both Ihaka and Maisie were uncertain about Liam's and Larry's behaviour. As novices in the community (Lave \& Wenger, 1991; Rogoff, 1990), Ihaka's and Maisie's participation was curtailed by the unexpected raid on the communal morning tea. Other children at the table either helped themselves to what was left, or 
called out to Rick or Donna for food. Neither of the two newest members of the group appeared confident enough to act like this, although Maisie attempted to. She eventually took some fruit, but Ihaka's plate remained empty:

Rick takes some more bread from the oven, this time a small plaited loaf and puts in on the table where his son, Larry, and daughter, Christa (three years old) are sitting. Larry immediately grabs the whole loaf for himself and smiles, almost triumphantly at Liam who laughs and laughs. Rick intervenes and asks Larry to share it - 'it is too much for one child' he says, but Larry ignores him and Rick turns away. Liam's mother, Julie, is by this time aware that her son has a disproportionately large amount of food on his plate and comments as he stretches for more that he needs to eat what is in front of him first. 'He never eats much breakfast,' she comments. (Field notes, Day 4, Playcentre)

One perception of this situation is that rather than a shared understanding of what is acceptable, there is an element of discomfort and a degree of uncertainty about how to manage the boys' behaviour in front of peers. As an example of rights, it reifies the Playcentre parents' perceptions that children are entitled to express themselves, a participation right. So, on one level, the boys were entitled to take more than their fair share of the food. But on another level, the adults engaged with the obvious challenge the boys issued: Rick attempted to deal with Larry, but withdrew, and Julie excused Liam. Reflections on the observation noted:

Both adults were aware that the food grab was inappropriate, but neither advocated for the whole group, nor did they help Ihaka and Maisie who seemed to find the morning tea routine confusing and overwhelming. None of the other parents appeared to notice.

Even though the bread buns and most of the fruit were co-opted by the bigger boys, Rick did make sure that what was left was shared between the remaining two tables. No-one went hungry and so my discomfort that there mightn't be enough food was unfounded. I think though I was troubled not so much by the boys' food grab, but by the fact that it went apparently unnoticed, and largely unchecked. Is it manners? Is it rights?

It made me think about the different cultural contexts. I did wonder about how Ihaka and Maisie might interpret this free for all morning tea. Angela helped Ihaka yesterday, his first day by himself. There was much more attention, during that morning tea, to making sure that all the children were offered a range of foods. Ihaka stunned Brie (parent) yesterday, by taking his plate and cup to the bench. I remember her thanking him and claiming it as a first in the five years she has been involved at the Playcentre. Ihaka appeared overwhelmed by today's morning tea experience - I noticed that he chose absolutely nothing for his plate, and sat there staring at Liam and Larry. Maisie, who is visiting from overseas, was also cautious about serving herself and looked up every time she selected fruit and biscuits for her plate. She took a while to help herself and I was reminded of how difficult it can be to gauge how to behave in new situations. This was a new situation for her. (Researcher Journal, Day 4, Playcentre) 
Concerns about sharing were based on a provision issue - would there be enough food for everyone? There was, and so the analysis concentrates on how merely providing resources does not equate to accessing them, or participating in cultural activities. In this situation, the role of the adult as the more experienced member of the Playcentre community could have supported children's rights to participate more comfortably in the morning tea time by guiding children's participation (Rogoff, 2003) towards a shared understanding of the Playcentre's community of practice (Wenger, 1998). During this morning tea time, some children's rights to participate were potentially jeopardising others' participation rights. At the same time, some adults felt constrained by the group, and were uncertain about how to protect children's rights to participate during morning tea.

Adult modelling or scaffolding co-operative support strategies to the children not only supports children's rights to participate, it can also protect children's rights by explaining accepted social and cultural conventions. Brie's surprised reaction to Ihaka returning his plate to the sink highlighted different social and cultural expectations between home and Playcentre, a conflict explored further in the next section.

\subsection{Accommodating differences}

The Playcentre parents believed that a child-centred approach in a free play environment supported children's rights per se, and that children had rights to uninterrupted play. However, the set morning tea routine at this Playcentre was perceived by some parents as contradicting that right. Differences in how the Playcentre's philosophy was enacted (research question 2) caused dilemmas in some situations. In the following example, the parent found negotiating on behalf of the younger Playcentre children a challenge:

Felicity (a parent) is wheeling Daisy (15 months, her daughter), Emily ( $2 \frac{1}{2}$ years old), and Pippa (three years old) in the trolley. She is stopped by Andy and Mikey (both three years old), Liam, and Fred (both over 41/2 years old). The boys all want a turn in the trolley immediately and insist that the girls get out. They comply, and the boys try to pile in but can't fit. Felicity starts to explain about turns and how not everyone can fit. She explains that it was the girls' turn in the trolley, and when she is finished taking them around the house, 'then you [meaning the boys] can have a go.' Daisy starts to climb back in, but is blocked out by Andy. She starts to cry. 'It's our turn' the boys clamour. 'They [meaning the girls] have already had a turn.' The boys 
support each other to stake a claim here. Felicity decides not to continue her reasoning and begins to pull the trolley with the boys in it. The little girls stare after her. (Field notes, Day 3, Playcentre)

In this example, the confrontation with the older boys proved too difficult for Felicity to resolve fairly. Her attempts to explain about turn-taking were co-opted by the boys to justify their claim to the trolley. In a later conversation, Felicity expressed her dilemma:

I was curious to find out how Felicity was feeling about the trolley takeover. 'I am never quite sure how to handle those situations,' she tells me. 'You know, the boys can have a turn, but how far should I [to make it fair]? Like how free should it be?' (Field notes, Day 3, Playcentre)

During an interview, Donna, an experienced Playcentre parent and team leader, acknowledged the complexities of interpreting free play:

That whole free play thing is not really free. We may think we are [free] but there are still sort of rules - like you just don't take outside toys inside and you can do this or that kind of exploring, but it's influenced by what's out [the equipment], but for some people, it might be so foreign to their home environment that they'd feel really confused. (Donna, Parent interview, Playcentre)

Participants in the research critically reflected on some fundamental Playcentre tenets, and explored the implications of child-initiated play from a children's rights perspective. The Playcentre parents perceived it was their responsibility to provide for free play, and to develop children's sense of belonging. However, mediating between newly enrolled children (novices) and confident members of the group (experts) created tensions and conflicts, accepted as part of normal cultural processes; for example, guided participation (Rogoff, 2003). This can lead to transformation of participation (Rogoff, 1995, 1998; Wenger, 1998).

The implications of child-initiated play were critiqued by some parents, including Donna:

There are some children who find it much safer when they don't have to initiate social interaction, or activities. Because it is so outside their comfort zone when they come to Playcentre, and they are expected to initiate everything, they're lost. They feel very insecure. There's nothing to hang on to. So I can see that for them, Playcentre could be difficult. If there's a routine, there's a group activity that everyone has to participate in, and if it's something that they're feeling not particularly confident in, if it's kind of compulsory, there's safety in the group, do you know what I mean? Everyone's doing it, so they're not stepping out on their own to make this big 
decision. [Some children] may never sit inside and hear a story, but if everyone is sitting inside and reading a story, then they would. And they may find they enjoy it. But they wouldn't make that choice by themselves. (Donna, Parent interview, Playcentre)

The right to participate in the Playcentre environment depends on more than just articulation. The personality and disposition of the child influenced how he or she might participate in the Playcentre environment. Donna grappled with structured approaches to group situations, such as a group story session for children. She acknowledged that the structure of a routine could protect children's rights and facilitate their participation in the wider environment. Comments about the role of the adult imply a 'best interests' approach (Alston, 1994b) that this parent interpreted further as:

Well, it's all about participating in the activities at Playcentre. It's our job to create an environment where you are helping [children], where you can help them and support them in their choices. (Bernie, Parent interview, Playcentre)

These comments resonate with statements on the role of adults (Rogoff, 1998, 2003; Somerset, 1976; Vygotsky, 1978). In this case study, parents perceived they were responsible for providing an environment that protected children's participation rights. Some parents recognised that provision alone would not lead to this, and alluded to different interpretations of the words "free play".

\section{Tidying up: Rights and responsibilities at home and at Playcentre}

Children's participation in the tidying-up time was a quietly contentious issue, and relevant to this thesis because it raised questions about children's responsibilities and rights. If children can exercise their perceived rights to play (see Archard, 1993), the corollary is an expectation that they assume responsibility for tidying up. Whether or not this was a reasonable expectation proved to be an ongoing issue at Playcentre. A range of responses to support children's involvement during the tidy-up time were summed up by Susie (parent):

It's hard here, because at home I make her tidy up before dinner or when she's finished playing, but here, they don't have to and so I wonder about the message that they are getting. (Comment to the researcher, Field notes, Day 7, Playcentre)

These parents' responses connected two ecological systems - the home and the Playcentre. Activities, processes, and relationships are elements of the microsystem, and these vary across place and time (Bronfenbrenner, 1979). In one system (the 
home), the child's help was expected (which can be interpreted as valuing the child's contribution to the family by participating in real, meaningful tasks). Tidying up can be interpreted as a cultural practice and, according to Rogoff (2003), participation in cultural practices is intrinsic to human development. Conversely, some parents believed that tidying up was an adult expectation, and for a variety of reasons, were not concerned by children's non-involvement at Playcentre. Brie's insight noted:

It's really just the adults that mind here, not the kids. They need to be able to choose and they don't need adult ideals forced on them. (Brie, Parent interview, Playcentre)

The rationale for tidying up aligned with creating an environment suitable for children to access materials:

Sometimes I think it is quite hard for some of the kids to find things and even for us to find things. We get it really sorted out at the beginning of the term and then, very quickly, it gets in a mess again. (Donna, Parent interview, Playcentre)

There appeared to be very different values competing here. First, the strands of the argument encompass dimensions of adults' responsibilities to provide an environment that enables children's participation, according to the Playcentre's philosophy. Second, adults perceived it was their responsibility to maintain the Playcentre, not just the paint and the collage, but also the building and the more permanent equipment. Finally, the concerns raised questions about children's responsibilities to one another and to the adults. Respecting the rights of others is fundamental to implementing children's rights, not to mention human rights.

Tidying up at Playcentre can be interpreted from a rights-based perspective. In this context, the main reason against children participating at tidy-up time was that this potentially interrupted children's play. Perceptions of who was responsible created a clear division between child and adult: childhood was a time to play, and tidying up was an adult's responsibility. However, the relationship between rights and responsibilities was not mentioned by the Playcentre participants, hence a perception that children's rights to choose tended to prevail even when sessions were drawing to a close, illustrating the point about imbalance inhibiting participation in completely child-centred situations (Rogoff et al., 1996). 


\section{Free play at Playcentre meets structure at school}

Many discussions at the Playcentre concerned formal schooling. On one hand, parents expressed a strong commitment to the Playcentre's philosophical approach, but also apparent were concerns that the Playcentre experience might not adequately prepare children for school:

Because the Playcentre philosophy is that children can have free play, do whatever they like, work out who they are as a person and what they like, which is great. But then ... when they hit five and they go to school, all of a sudden there's a routine. (Angela, Parent interview, Playcentre)

In response to many of the older children's interest in writing, Lucy, who was also a primary school teacher, developed an early literacy programme for the Playcentre children:

It is very school-like - with large letters to cut out and encouragement to find or draw pictures to match the letter's sound. Teaching literacy in any formal sense will jar with the Playcentre philosophy, which distinguishes between school learning and the free play ethos. Tangled up in all of this is the fact that this family belong and contribute to the Playcentre and are well liked. Lucy has status as an educator and she is often involved in discussions about early schooling success. (Researcher journal, Day 11, Playcentre)

The literacy programme highlighted several tensions. First, Playcentre's childcentred focus, including the child's right to free, spontaneous play, was perceived as a challenge to the reality of formal schooling. Second, Playcentre parents regarded children as free agents, with rights to choose where, when, and to a certain extent, on whose terms, they would participate in the 16 areas of play. They also constructed early childhood as time for free, uninterrupted play. Childhood was the time that children could explore the Playcentre physically and emotionally in an environment constructed especially for them, and their families (James, et al., 1998; Jenks, 1996).

The example that follows suggests that parents at Playcentre perceived children's freedom might be curtailed at school, which implied that children's rights would be as well. Parents joked about the power of the Playcentre child to disrupt the more structured routines of the school day. For example:

Brie: I wonder how [new entrant teacher's name] is going to cope with this influx of Playcentre children. They are so rowdy and they will tell you what they think. I know Sam is just going to leave the room if he wants to go to the toilet, or have something to eat. 
Angela: [At Playcentre] they are used to being allowed to do what they like, uninterrupted and even when it is morning tea, or we (the adults) are starting to tidy up, they know that they can keep going ... I think that will be a problem for the school. (Focus group interview, Playcentre)

Both of the above comments suggest (rightly or wrongly) that the school may need to accommodate the Playcentre child, not the child as needing to adjust to the school. The ethos of the child as an active, self-determining agent is also problematised (Prout, 2003). These Playcentre parents retained a belief in the child's rights to "tell you what they think", and doing "what they like, uninterrupted". On the other hand, some parents who had children at school already and several who were teachers themselves took a slightly different view, articulated in the next quote:

I'm taking my child to kindergarten when they're four, just to get them used to a more structured environment where they have to listen to the teacher. That will get them ready for starting school. (Heather, parent, commenting to the researcher, Field notes, Day 5, Playcentre)

This discourse was not uncommon, and even the leading figures in the Playcentre reserved the right to exercise their choice of early childhood service once their child reached four:

Kate, the team leader, was telling me about her daughter, Alice. 'I am going to start Alice at the kindergarten as soon as she turns four. I checked it out the other day. It just means that she gets a little more structure, and learns to listen to the teacher. Plus, I'm going back to study and to have four mornings child-free will be great.' (Kate, parent, commenting to the researcher, Field notes, Day 4, Playcentre)

Not only was the kindergarten service perceived as beneficial to the child for providing a structured environment, it was also an attractive option because it was a teacher-led service and not dependent on parental involvement to the same extent. In both examples, kindergarten was considered good for the child. In the second observation, the mutual need of both child and parent was part of the equation. Unpacking the messages in the above indicated that while free play and family involvement were important, these Playcentre principles were conditional and moveable. 


\subsection{Conclusions: Provision rights: protecting children's rights to participate}

The data show that the Playcentre provided a physical space conducive to parents cooperating as a community of practice (Wenger, 1998) in which to support children's participation in activities. In answer to the first research question, parents' perceptions of children's rights focused on providing opportunities for children to participate in a culture that valued child-centred, free play. These data also addressed the second research question, investigating how children's rights were enacted. As well, within this setting, participants (children and adults) interacted as a community of learners (Rogoff, 1996) using cultural processes and practices associated with the wider Playcentre movement's philosophy. Through peripheral participation (Lave \& Wenger, 1991), parents (via Playcentre's parent education and training programme) and children (via experiencing the Playcentre's early education programme) alike had opportunities to observe the Playcentre's philosophy in action. This led to a transformed understanding of what parenting and playing meant in the Playcentre setting.

But, like any community, different values and interpretations emerged (Rogoff, 2003). For the Playcentre parents, the philosophy of the Playcentre, together with the training courses, provided a means to mitigate differences between "communities of rule users", and "provided a type of elastic glue" (Alston, 1994a, p. 19) which retained the Playcentre's integrity as a functioning, community-based early childhood setting. However, certain risks to this community potentially undermined a committed approach to facilitating children's rights to play. Limited understanding and critique of the community of practice, and the community of learners, often resulted in a stalemate situation for parents (yet another meeting), and some personal infringements of rights (in Playcentre terms) for the younger children. Some practical application of how to solve problems might have eased Felicity's dilemmas with the trolley (see above), but this needed to be community-wide. Again, tensions in a community of practice need to be aired constructively and positively for children's rights to be supported.

In the data presented, there were plenty of opportunities to resolve differences, but the theoretical understanding of how to support conflict resolution between children was not observed during the fieldwork, or interviews. The focus on providing resources and encouraging free play failed at times to take account of the reality 
facing this Playcentre. Protecting children's rights to participate was difficult to achieve, and not all children, particularly two- and three-year-olds, could participate equally at all times, because it was not possible to provide resources for all children at all times. However, the Playcentre's willingness to learn sign language and ensure that Mia and her family could participate illustrated an awareness of rights for children and families with disabilities.

Adults in the Playcentre believed that by providing an environment to support children's learning through play, they were supporting children's participation rights. However, merely providing resources was not enough to secure children's rights to participate; to be effective requires protecting children's rights to participate, and this was difficult at times. Participation was not confined to the immediate Playcentre environment, and belonging to the Playcentre provided parents and children opportunities to engage with the wider community. Families' social geographies (De Visscher \& Bouverne-De Bie, 2008; Holloway \& Valentine, 2000b) contributed to a sense of belonging to society due to Playcentre's parent/whānau-led approach. Personal empowerment was not confined to children, and networks initiated through the Playcentre facilitated friendships in the local community.

Provision rights to support both protection rights and participation rights were perceived as important by the Playcentre parents. This perception contributes to this thesis's argument that rights are interwoven, interrelated, and interdependent. The Playcentre case study illustrates how this context influenced perceptions of children's rights, positively and negatively, and how the context influenced the way rights were implemented.

In the next chapter, the Kindergarten case study fore-grounds children's participation rights as the last strand of a three-part argument to argue that context influences how rights are implemented (Bronfenbrenner, 2005d; Woodhead, 1997). Perceptions of children's rights also have an influence on how rights are enacted in practice. 


\section{Chapter 8: "It's the culture of the place": Promoting participation in a community of learners}

\subsection{Introduction}

The focus of this chapter is on participation rights of children in the Kindergarten case study (Figure 13). It builds on the previous two chapters where children's protection rights (in the Crèche) and provision rights (at the Playcentre) were foregrounded to reveal the relationship between perceptions of rights and the contexts in which they were enacted or implemented. Data from the Kindergarten illustrate how participation rights form the final thread of the argument: that perceptions of rights, and the context in which children's rights are enacted, are interrelated (Woodhead, 1997). As well as answering the first research question "How do children, teachers, and adults in whānau/parent-led centres, perceive children's rights in early childhood settings?", these data address the second research question "How are children's rights enacted?" by providing evidence about what influenced children's understandings and experiences of their rights, and how children learnt about rights. Theoretical ideas from sociocultural theories and childhood sociology, as well as children's rights theories, were used to interpret data.

Article 12 (CRIN, 2007, p. 5) entitles children to express their views and requires due consideration of these. Qvarsell (2005, p. 103) wrote "[Participation] has to do with activities, joint tasks, environmental affordances, private and personal spaces and places in childhood cultures". The Kindergarten was a place where children engaged in joint tasks and activities, and the quality of their experience depended on the environmental affordances provided within that setting. These experiences supported children to form a view, an essential element of participation.

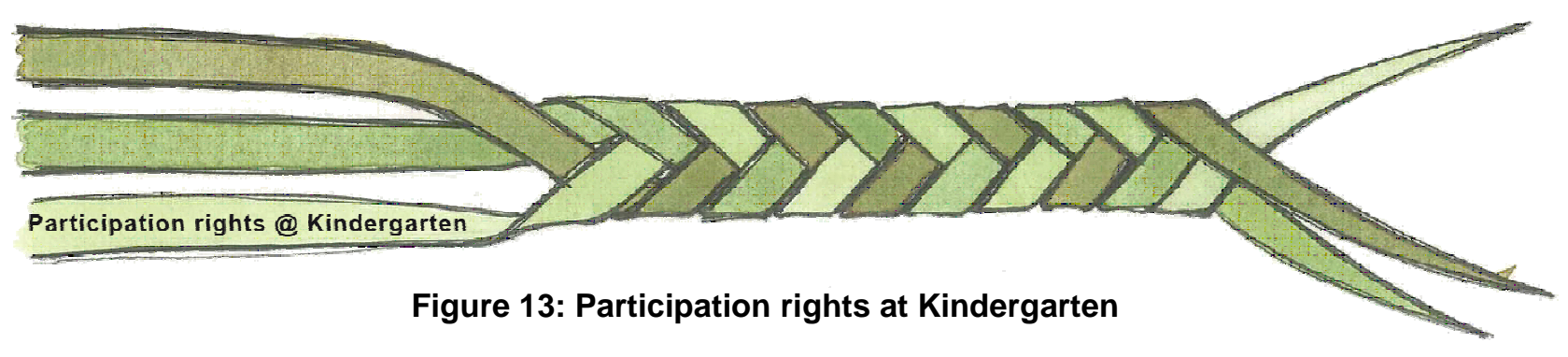

The Kindergarten data illustrated how teaching strategies developed collective understanding of the organisational culture, which increased meaningful participation 
for children, perceived as a right to support their agency. Strategies were based on a shared (teachers and children) commitment to "the culture of the place" (Paula, Focus group interview 1, Kindergarten), and included messages for children like 'being a good friend', and 'not being mean'. These values, perceived as contributing to children's understanding of their rights, were taught using conventions such as mat times; Kindergarten-produced books with photographs of the children and teachers depicting kindness, turn-taking, and helping; large posters (and brainstorms); puppets; songs; and stories. Multiple approaches ensured individual rights to participate were considered within the wider social group, using existing social processes (Smith, 2002; Qvarsell, 2005).

The environment at Kindergarten, which included human and physical resources, created opportunities for joint activity that supported children's interests in people, places, and things (Ministry of Education, 1996b). Participation was to the fore, and access to a wide range of materials was facilitated in a purpose-built environment with ample resources, appropriately designed furniture, and a stable trained teaching staff. In other words, the conditions of work for both the teachers and the children supported participation rights, which in turn supported (transformation of) participation within a community of learners (Rogoff, 1998, 2003).

The Kindergarten teachers believed that their professional practices facilitated children's rights, reconceptualised here as participation rights. Data from interviews, focus groups, and observations identified three themes:

- Nurturing a sense of belonging;

- Expressing a point of view; and

- Participating in a community of learners.

The themes intersect with the literature on participation theories (Hart, 1992; Lave \& Wenger, 1991; Lundy, 2007; Sheridan \& Pramling Samuelsson, 2001; Shier, 2001), theories of human development (Bronfenbrenner, 1979; Bronfenbrenner \& Morris, 1998; Rogoff, 2003; Vygotsky, 1978), and theoretical ideas from childhood sociology and social geography (Holloway \& Valentine, 2000b; James et al., 1998; Jenks, 1996; Prout \& James, 1990). 
In the Kindergarten, children's participatory rights were enacted in a cultural climate supportive of the individual child, and the group. The Kindergarten teachers described it as "the culture of the place" founded by nurturing a sense of belonging.

\subsection{Nurturing a sense of belonging}

Lundy's (2007) concepts of space, and Shier's (2001) notions of openings, opportunities, and obligations were evident in the Kindergarten teachers' perceptions of children's rights. A sense of belonging was nurtured and encouraged by teachers' welcoming practices:

It's like a culture. ... Like it starts when they come in the gate - everyone is greeted by their name and they'll get a nice hullo and a comment so you know I think that right, that sense of belonging, is created then. (Paula, Focus group interview 1, Kindergarten)

Initial focus group discussions revealed that a sense of belonging was considered a prerequisite to participation. If children were not protected, and their rights were not protected, this would directly impact on how they participated in the Kindergarten:

We foster wellbeing and belonging first and foremost ... if a child does not have that sense of wellbeing and belonging the next step to exploration is not going to happen. Why is exploration not going to happen? Because they don't feel they belong and they don't have a sense of wellbeing. (Sharon, Focus group interview 1, Kindergarten)

Teachers valued their relationships with children, and their families, and the Kindergarten community used well-established social processes to build responsive, respectful relationships, and nurture a sense of belonging. The physical environment, teachers' conditions of service, and the Kindergarten's professional teaching ethic supported children to join in, and contribute to the community of learners. This supported perceptions of children's rights to belong as a prerequisite to participating in Kindergarten activities.

\section{The physical environment}

The Kindergarten's physical environment was designed to encourage interactions and engagement. In this case study, the physical environment facilitated children's participation as active agents of their own experiences. Malaguzzi suggested that it is a child's "right to a quality environment, to beauty, [and] to contribute to the construction of that environment" (cited in Rinaldi, 2006, pp. 77, 78). Effective use 
of educational spaces stems from "a philosophy, a way of thinking about education, [and] must be the result of careful, in-depth dialogue between the pedagogical and architectural languages" (p. 80):

Down a well sign-posted drive with ample parking, the Kindergarten is positioned in a small park with large trees and plenty of open spaces - all grassed. It was a fresh, sunny day and there were many children outside, playing. The outside area is well planned and there are many, many opportunities for children to choose from. Lots of child-sized picnic tables with umbrellas. I can see three decks built around the larger trees and the sand pit - small pockets of children playing or eating outside. All across the grass and asphalt area are rugs and large cushions as well as books, clay, water troughs, and painting easels. The equipment is in very good condition and there is a comfortable feel to the environment. It suggests that the activities and toys are well used. There are lots of interesting places for the children to play - the sand pit is along one fence. The swinging equipment is set out along another fence in a bark chip area; down the other end of the Kindergarten is the obstacle course, climbing area with large box-like structures - these look new and they can be used in a variety of ways. (Field notes, Day 1, Kindergarten)

Articles 5 and 18 (CRIN, 2007, pp. 3, 7) specifically address states parties' responsibilities to ensure "appropriate assistance to parents in child raising" (CRIN, 2007, p. 7). This Kindergarten was purpose-built and designed so that children could access equipment and resources themselves. It was an appropriate environment that protected children, and protected their rights through meeting states parties' obligations to provide for children (Articles 29 and 31, CRIN, 2007, pp. 13-14). The outdoor area had been landscaped to create distinct areas for play, and for contemplation. Sand pits, water troughs, compost bins, worm farms, and several gardens could be seen in and around the large outside area. An animal enclosure and aviary, large enough to walk into and sit down, had been built in a quiet area. The interior of the building was mainly open plan. Spaces had been designed to maximise versatility, and for ease of access, not just for adults. There was one locked cupboard where the cleaning materials were stored. The positive effects of space were noted by a teacher:

We have a purpose-built building. I think it must be really hard in those converted houses with lots of different rooms, and working on top of one another. I think it must add to the stress of the teacher because houses are built on smaller sections, and children need space. So they need more rights to have space like ours. (Paula, Individual interview, Kindergarten)

The teachers regarded the physical environment as a resource to nurture a sense of belonging. There were areas to sit quietly; there were private spaces; and there was 
room to greet and welcome parents to the space. All the teachers agreed that they were very well resourced, and commented that this supported their work with children. Children were party to decisions made about the resources:

I watched Sharon going through a newly arrived catalogue of resources today. It was on the table, and about six or seven children were talking about what they thought the teachers should get. 'I think we need those blocks.' 'Can we get some more trains?' Sharon gave them some stickers to put next to the things they liked. 'We really need some medical toys. Can you find any? Is there a stethoscope?' she asked. 'We could do with some vets' equipment,' said Paula as she went past. 'Yeah, then we could fix up the baby birds' (Child 4). (Field notes, Day 3, Kindergarten)

Children's perspectives were included as part of the decision-making processes. For example, when the outdoor environment was re-designed, children had been invited to contribute ideas that were displayed pictorially around the walls. Paula commented further:

We've just done an improvement plan for the year. Because we are very well resourced, financially as well, we [requested] quite high-quality equipment that we want to get, and it's been approved. (Paula, Individual interview, Kindergarten)

The teachers at the Kindergarten were proud of their building and their outdoor area, and claimed that the high standard set in this environment should be available to all children, as of right. The environment went beyond minimum standards of safety to provide a physical space to support children's participation. Teachers' decisions about providing resources, or alterations, included the children's perspectives.

\section{Conditions of service, conditions of practice}

Financially, these teachers claimed they were well supported in their work. This was augmented by their conditions of service which included two non-contact sessions per week, where teachers could meet during the day as a whole team:

Yes, and they're very valuable! We're all together working. I think that is a right for children-that all the teachers know about each child and are working for that child. (Sharon, Individual interview, Kindergarten)

Non-contact time was perceived as critical. This is a provision right. Article 4 specifies an obligation for the state to "do all it can to implement the rights contained in [UNCROC]" (CRIN, 2007, p. 3). Time to reflect on observations of children allowed teachers to consider their teaching programme as a staff, sharing knowledge and understanding about the impact and direction of the programme (Jordan, 2004). 
This, they believed, enabled teachers to nurture a sense of belonging by 'working for that child': protecting children's rights to belong so that they could participate; and providing for children so they could participate.

Decisions about activities were discussed during non-contact times, based on teachers' observations of the environment, and of children's interests. For example, teachers described how they noticed how messy the dress up area had become, and that children were not using it:

Paula: We've selected a few pieces and ... it's becoming much more purposeful play.

Sarah: How do you decide what gets changed around?

Sharon: Well, it depends on the interest, we'll put out the butterfly wings or if the children are into super-hero play, we'll put out the capes. Or into dressing up dolls, we'll put out more dolls' clothes and things.

Paula: They do come and ask. They know that [they're] likely to get a favourable reply or a good reason for not having it out. (Focus group interview 1, Kindergarten)

The children can choose has 'catch-cry' status in New Zealand early childhood services but the question is, to what extent can the children choose, and what are the circumstances in which they make these choices? The Kindergarten's physical environment was well resourced, and there was open access to all areas of the Kindergarten apart from the cleaner's cupboard. Teachers believed that children learnt to access resources independently through a mix of planned availability and modelling:

They probably see that modelled. We tell them: 'There's a bottom shelf for the children to choose from. The top shelves are more dangerous to get up there, so that's for the teachers to choose from - you just need to come and ask.' (Sharon, Individual interview, Kindergarten)

Another condition of service included professional development opportunities. Professional development provided access to resources, including opportunities to discuss ideas with other kindergarten teachers. Senior teachers, employed at a regional level, delivered tailor-made advice and support to the Kindergarten:

Well, recently Sharon and I did the course 'Playing as a Good Friend' and we followed that with parent workshops and totally immersed it into the programme. (Paula, Individual interview, Kindergarten) 
Teachers perceived this condition of service as supporting children's rights indirectly through providing professional development opportunities as a condition of service. Conditions of service, which co-exist with children's experiences in the kindergarten microsystem, are examples of how a policy initiated at the macrosystem level (Bronfenbrenner, 1979) influenced the environment children participated in. According to the Kindergarten teachers, their conditions of service helped them to protect children's rights to participate at Kindergarten. Furthermore, the teachers' answers suggested a link between children's rights to an appropriate environment (a protection and provision rights issues) and children's participation rights. Specifically, the purpose-built facility facilitated all participants' participation rights in Kindergarten activities.

\title{
Nurturing the individual
}

Teachers' interactions with individual children were perceived to be supporting children's rights. Through knowing a child, teachers felt able to support him or her to form a view, a process fundamental to meaningful participation in the Kindergarten. First, teachers believed that nurturing the individual child's interests facilitated his or her rights as a participant in the Kindergarten. This is also a protection rights issue, in particular, Article 3 (CRIN, 2007, p. 3) where acting in the best interests of the child (the responsibility of the adult) is informed by the child's perspective. What sometimes started as an individual child-initiated event could grow into a large group affair:

\begin{abstract}
Matt $^{14}$ (child) came up to Paula (teacher) and asked her if she could come and do a puppet show with him. 'What a good idea Matt.' said Paula. 'Where did you think of that idea?' 'I just saw the puppets and, but, I need to set up the puppet theatre.' 'Is it going to be a proper theatre?' asked Paula. 'Yep.' 'Well, do we need some chairs for the audience?' 'Yes, we need lots and lots of chairs and I need these puppets.' 'Shall I organise some chairs and you organise the show?' 'Yeah, I need these puppets,' comments Matt and he emptied a huge basket full of puppets onto the ground behind the theatre. (Field notes, Day 8, Kindergarten)
\end{abstract}

The observation provides one example of evidence to answer the second research question - how are children's rights enacted? Paula's willingness to support Matt's interests demonstrated the four elements of Lundy's (2007) model of participation. Matt had space to express a view (a protection right to enable participation), his voice, found a facilitative audience in Paula, whose influence (via responsible provision) made the puppet show possible.

\footnotetext{
${ }^{14}$ All the children at the Kindergarten were four years old.
} 


\section{Being a good friend - nurturing relationships}

'Well,' said Greg, 'you have to be a good friend. You have to be kind and you have to share. That's what being a good friend is here.' He thought a moment longer and added: 'And you're not allowed to hit!' (Greg, four years old, Field notes, Day 12, Kindergarten)

Children's rights to participate were supported by messages like "Be a good friend", "Use your hands to make, not break", and "This is a no hitting place". These were explicit messages about protection (Article 19, CRIN, 2007, p. 7) and inclusiveness (Article 2 and Article 8, CRIN, 2007, pp. 2, 4). They were discussed as social rules, rather than with specific reference to rights, but these issues are rights-based. Interview data and field notes built a picture of a place which explicated how children and teachers were to conduct social relationships. However, these data communicated the Kindergarten programme's focus to parents, and that, in turn, supported children's sense of belonging to a new place, away from the home. The connection between belonging, relationships, and participation was vital. If the group, or community, could not function harmoniously, children's opportunities to participate in the experiences offered would be curtailed. Being a good friend was a strong message in the Kindergarten, and supported children's sense of belonging because it prompted discussion about the nature and purpose of friendship in this setting. Parent workshops, newsletters, and notice board displays focused on relationships, with clear messages for parents about how to be a good friend. Children had their own views about this:

$\begin{array}{ll}\text { Sam: } & \text { Well, you have to be a good friend. } \\ \text { Erika: } & \text { Yes, you have to be a good friend. } \\ \text { Henry }: & \text { Can you be my friend? } \\ \text { Paul: } & \text { Well, he's my friend, but ... } \\ \text { Sam: } & \text { But you aren't allowed to hit. You have to use your words. } \\ \text { Henry: } & \text { I don't like hitting. } \\ \text { Paul: } & \text { Yea, you can say 'Stop it I don't like it', can't you? } \\ \text { Sophie: } & \text { But you can say, you can say ... } \\ \text { Erika: } & \text { You can say 'I don't want to play just now' ... But you can't be } \\ & \text { mean. (Field notes, Day 14, Kindergarten) }\end{array}$

\footnotetext{
${ }^{15}$ Henry was the name of the persona doll. Sarah, the researcher, spoke on his behalf. See Chapter 5 for a more detailed explanation of persona dolls.
} 
The importance of this message was pervasive as the following example illustrates:

Sharon is telling a small group on the veranda about how to be a good friend. You don't say: 'You're not my friend' - you say 'When you do this or when you say that I feel this or that.' OK? So, you need to let people know how you feel but you don't say you're not my friend. We are all friends here. (Field notes, Day 5, Kindergarten)

Sharon used the cultural norms of the setting to protect children's emotional rights, and empower children to participate. Article 19 (CRIN, 2007, p. 7) supports "parents and others responsible for the care of the child [to] establish appropriate social programmes" to protect children. Building on Lansdown's (2005) notion of protection as a route to enhancing participation rights, providing spaces, and hearing children's voices (Lundy, 2007) express emotions, are participation rights. However, the role of the adult, as an influence, and as an audience (Lundy, 2007), has to be considered. A challenge for teachers was to interpret situations appropriately, without disenfranchising children's rights to express their views. At the same time, teachers had to avoid marginalising, alienating, or privileging either a child's perspective, or an adult's.

During a conversational interview with the children, Greg's comments reflected on the nature of friendship:

'Well, when you are a friend you have to be kind and care about it. That's about being a friend but, you know you can have a feeling about friendship and friendships are about being kind and friendships have different feelings too. They are about being kind and you have to care about it too.'

It was morning tea for the adults but Greg went off to find his friend, Lulu - as he left he said again how his friendships had 'different feelings', but he couldn't say much more than that.

At morning tea I told them about this and Paula laughed. 'Well it's a bit of an up and down friendship that Greg and Lulu have. They used to carpool but now they can't because they argued too much in the car coming up here.' (Field notes, Day 12, Kindergarten)

Inclusiveness mattered to Greg, and the right to be included was worth protecting. Nurturing relationships in terms that the children could understand (you have to be a good friend) was a strategy the teachers developed to establish a sense of belonging to the Kindergarten's community of learners (Rogoff, 1998). Friendships were perceived relevant to children's rights because a sense of belonging prefaced participation. 
The Kindergarten teachers' conventions supported children's sense of belonging by using the group time to discuss experiences of individuals and small groups. An important right was implied here: recognising that others have rights. Data gathered during a morning provided topics for discussion at the end of a session. These lasted no more than 10 minutes, but were opportunities for teachers to assert some pedagogical and moral point. Discussions about friendship and sharing used examples teachers had noted during the session:

I saw Dylan being a good friend to Sam. He held his hand and comforted him when he fell over. 'That was very kind Dylan.' (Sharon (teacher) at mat time, Field notes, Day 3, Kindergarten)

Public acknowledgement of being a good friend exemplified how a perception of a right was reified. In this case, the fact that the large-group setting was the forum supported children feeling good about their community of learners. It was a way of endorsing cultural conventions. Children were expected to join the mat times, and the teachers used the mat times to encourage contributions between themselves and the children, building on an emerging sense of social responsibility expressed in Article 29, "preparing children for responsible life in a free society in the spirit of ... friendship" (CRIN, 2007, p. 13).

A recently introduced teaching strategy was brainstorming. While I did not see this in practice, the notes and pictures displayed on the walls where this group time was held provided evidence of how the brainstorm proceeded:

There is an explanation of the curriculum focus on the parent notice board where the links to Te Whäriki are cited. In the mat and music area at the far end of the Kindergarten there are many photos and quotes displayed which illustrate a brainstorm the children participated in earlier as the theme was introduced. (Field notes, Day 3, Kindergarten)

Brainstorming at mat time was another example of the methods used to work alongside the children. Teachers believed that brainstorming sessions supported children's rights to contribute by valuing their 'voice', and this developed a shared understanding of the culture of the place. The brainstorm posters were teaching tools the teachers referred to at mat times. For example, several large pieces of paper displayed in the mat time area attributed quotes about friendship to individual children. Sharon used this regularly: 
Can you find your words, Delia? Well done. Can we show Sarah our messages about being a good friend? Can you find your one Isaac? (Paula at mat time, Field notes, Day 4, Kindergarten)

Books produced on site were another strategy that nurtured belonging. Teachers' informal observations explored children's interests as well as key messages supportive of the Kindergarten culture:

I have seen some of the term books and also some of the other little books the teachers have made. There is one in the book ... about being a friend and sharing. There are photos of the children, which are intended to illustrate having turns (on the trolley) and being kind. (Field notes, Day 7, Kindergarten)

As well as the 'Playing as a good friend' programme, volcanoes had been an ongoing interest throughout the term, possibly because there had been a significant eruption in the recent past. A large plaster of Paris model had been designed and decorated; geological maps of the area displayed; and a parent had compiled a PowerPoint show about volcanoes for one mat time. The pedagogical documentation process was interesting:

Sharon is outside on the small deck under a big tree. She lays out the photos and the comments that she has collected about the [volcano] project. These are gathered on little pieces of yellow sticky paper. There are quite a few of them. 'I am trying to put this together now as a book that they can refer to about the rocks and the volcanoes. It's really important that we get the child's voice in here. They ask the important questions and we get to know what we can do from them.' (Field notes, Day 15, Kindergarten)

Books were a teaching tool that featured photographs of the children at the Kindergarten and, in that way, built a sense of belonging to a community of practice. Teachers used digital technology to feed back images which reinforced selected messages:

I noticed that there are many such little books kept in the storage cupboard so that tells me that this idea of using the children's voices to emphasise and exemplify aspects of the programme is a method well used by these teachers as a way of documenting their work. (Field notes, Day 10, Kindergarten)

\section{A sense of belonging enhances participation}

Teachers believed that nurturing a sense of belonging was a prerequisite to children's rights to participate at Kindergarten. The teachers identified a range of existing strategies supportive of children's participation rights. Including children's photographs and quotes as part of a display was an example of how their voices were 
given space in the environment. Children's words added meaning to their experience in the Kindergarten programme. Pedagogical documentation highlighted children's agency. Their contributions, as a group in the brainstorm, and as individuals, or in pairs interacting with teachers, on the pages of the Kindergarten books, and in other Kindergarten documents, legitimated their participation. Mat time was an example of democratic enterprise that established a sense of belonging to a wider group, and via the democratic experiences, children were gently inducted into a community system where cultural processes were articulated in various ways to promote contribution, which in turn was perceived as supporting children's rights to participate.

\subsection{Listening to children}

Teachers in the Kindergarten were clear: children had a right to be heard, and adults had a responsibility to listen:

Even though [children] are small, they still count, and they have got a voice. ... If only we stopped to listen. [Children] have a right to have people take time to listen [to them]. (Sharon, Individual interview, Kindergarten)

Her comment can be interpreted to mean that listening to children, per se, and in the Kindergarten context specifically, is not always guaranteed. Despite a commitment to including children's views, their stature jeopardised the intention of Article 12 (CRIN, 2007 , p. 5) to accord due weight to the child's opinions. The noticing and recognising phases (Carr, 2001), that promote the voice of the child are evident in the teacher's aspirational tone: "if only we stopped to hear and listen ..." Several scenarios will illustrate how children expressed their views, how they were listened to, and what responses their 'voices' elicited. The scenarios provide evidence of how children's rights, re-conceptualised as participation rights in the Kindergarten, were enacted. In this case study, unlike the Crèche, semi-structured conversational interviews were possible because the children were all four to five years old.

\section{Being polite}

Keith, in tears, rushes up to Paula (the teacher). 'He took my cushion, Davy took my cushion.' 'Oh,' says Paula, looking around for Davy, 'tell me about what happened?' Mick comes up with the cushion for Keith. He gives it to him and Paula says, 'You've got a good friend there Keith. What can you tell him?' There is a moment's silence. 'Thank you Mick.' she models. Keith grabs the cushion and rushes off, yelling 'Thank you Mick.' Paula tells Mick that he is a very good friend. (Field notes, Day 2, Kindergarten) 
Paula's response was both to act as audience, acknowledging Keith's distress, and Mick's response to the situation, which she positioned within the framework of the Kindergarten programme. Teachers' modelling of appropriate social mores was valued as a strategy to promote participation rights. The next example illustrates this:

Sally's mum has done some baking for the teachers' morning tea. Sally quietly sidles up to the table and Paula says, 'Thank you Sally and thank your mum for thinking of us. These muffins are delicious and they have got a little surprise in them haven't they - some white chocolate. Did you get one in your morning tea?' Sally nods and then asks, 'Um Paula, can I please visit the guinea pigs?' 'Yes, you may, I think the door is open. Thank you for asking.' Sally runs off to the animal enclosure. (Field notes, Day 2, Kindergarten)

Politeness characterised many of the teachers' interactions with children. It modelled a way of being and set a standard that created notional space to listen to children. The result created options for children to negotiate participation, framed within the teachers' perceptions of participation rights. The next example illustrates how children negotiate and modify rules to suit their play agenda, but it also illustrates communicative conventions bounded by the participatory ethos of the Kindergarten. The following sections provide evidence to answer the second research question: How were children's rights enacted?

\section{Puzzling over puzzles}

Data in this section are from Day 6 of the fieldwork.

Phoebe starts to do a puzzle on the floor - mixing up animals so that their bodies and heads do not match. Conrad is helping her.

Conrad: Let's do it again.

Phoebe: Lets' do the horsey.

Conrad: Yes, the horsey, but with the sheep's legs.

Phoebe: And the sheep with the horsey legs.

Phoebe places the pieces and Conrad helps to decide how to mix up the animals. They make pretend animal noises to match the creatures, giggling and laughing at their strange animals and their strange noises. Once it has finished Phoebe decides that they should do it all again.

At this stage, the co-operative elements of play are clear. Both children understand the rules of their invented game, and both are enjoying the outcomes. Another boy, Mick comes to join them and he is inducted into the game. He immediately understands the concept: 
Mick: $\quad$ A kitty's legs - he giggles, and puts them onto a duck's body.

Conrad: And the sheep should have cow's legs.

Next Mick and Phoebe start putting the puzzle pieces together correctly, changing the rules again. The three of them are playing co-operatively although Conrad is the most passive. The field notes continue:

They take turns to fit in the pieces and there is no discussion about whose turn it is, rather the turns are determined by who has the pieces of the animal they are trying to complete. When they finish they grab the pieces out of the puzzle frame and visually check with each other to see if they have about the same number of pieces: Phoebe takes one from Conrad and gives it to Mick. The pieces are not all facing the right way up, but it is the number of pieces that matters at the moment. Mick starts the puzzle again and this time Conrad decides it is another muddled up version. They giggle a lot and are trying to figure out what noises the animals might make.

Phoebe: Look at this puzzle - it's floating on the sea.

Conrad: Hey guess what, we muddled it up by putting the legs in the wrong place - like the sheep legs with the cow.

Conrad has come to explain it to me about their 'jokey game'. The other two laugh together at their jokes. There is some scrabbling around for the pieces and then they decide to do it properly once more. They grab the pieces out of the puzzle frame.

Mick: Hey it's mine!

Phoebe: No, no, it's mine!

Lulu comes over - she tells them that she wants to join in.

Lulu: $\quad$ Can I join in, I can join in?

Phoebe: But you have to share.

Mick: $\quad$ Yeah, we are [sharing].

Lulu's question indicates her desire to participate, and in her second statement, she asserts her right to do so. Phoebe and Conrad both express the conditions for joining in, and in so doing, further establish an agreed set of guidelines for participating. This exchange illustrates shared understanding in the Kindergarten's community of practice. Lulu is about to be inducted to this mini-communal experience:

Lulu: [To Conrad] You're doing it all wrong. You have to match them all up.

Conrad: No, we are doing it all muddled up.

Phoebe puts her cow body onto the horse's legs. Lulu holds onto her pieces.

Lulu: You are doing it all wrong. You have to do it like that.

She moves the cow body to the cow legs. 
Lulu: $\quad$ Now, now we take turns. Now what you need to do now you all have had a turn haven't you so, now I have a turn right?

Lulu wants to play with the puzzle in the conventional way, and is unaware that the others have been playing their own version of the puzzle for the last 15 minutes. She attempts to negotiate her way into the group by demonstrating her expertise with the puzzle, and by articulating the Kindergarten rules. In this case, the effect works negatively, to her detriment:

Mick tries to re-establish the old way of doing the puzzle which involved everyone having a turn at putting the mismatched animals together and laughing at the results.

Mick: $\quad$ My turn, my turn.

He puts the cow's body with the duck's legs.

Lulu: Nnooo! My turn! You can't put a cow with the ducks!

She puts Mick's piece back in his pile. Conrad leaves and comes to sit next to me. Phoebe takes a piece to help Mick with the muddled up version, and puts the cow's body back with the duck's legs.

Lulu: No! My turn!

Phoebe: No, we all have turns! We all have turns together.

Mick gets up to leave and Conrad moves closer to me. Lizzie and Emma come and ask to join in. Phoebe moves around in a non-verbal invitation, and offers Lizzie one of her pieces.

Lulu: I'm not playing with you! (Emphatically to Lizzie and Emma!) I am already playing with someone else now (meaning Phoebe). You can go over there (again directed to Lizzie and Emma).

Mick: I'm you're friend eh Phoebe? (Mick's response to Lulu's directive.)

Lulu: $\quad$ You can go and play with the castle now (to Lizzie and Emma).

Mick, Phoebe, Lizzie, Emma and Conrad move outside, ending the cooperative 'jokey' game. Lulu is left alone playing. She completes the puzzle, correctly and shows me. (Field notes, Day 6, Kindergarten)

Children's rights to participate were not disputed in this episode, but the terms for participation were vulnerable to alternative interpretations of turn-taking, joining-in, and playing with puzzles in different ways. Lulu assumed the right to establish control with reference to the common laws of the Kindergarten: children take turns; they share; and they are inclusive. The episode concluded at morning tea:

The student commented on the effect Lulu had had on the small group. 'How do you deal with that?' she asked Paula. 'Well at this age they can be very egocentric - you need to work with them on joining in,' explained Paula. 'She can be very controlling,' said the student. Paula laughed, 'Yes it is something they need to learn about. That's what they can learn here with lots of other children.' (Field notes, Day 6, Kindergarten) 
Rather than judge, Paula's interpretation drew on her professional knowledge and experience in a way that located Lulu's experiences in the wider group. The tension between an individual's right to participate, and a small group's rights were mediated by appealing to the overall culture of the community. Rogoff (2003) noted that conflicting interests within communities transformed the participation of all community members, resulting in a dynamic, ever changing set of cultural processes.

\section{You can't be mean}

There were numerous observations of children monitoring one another's participation rights by articulating clear understanding of why it is important to protect others' rights. In the next example, the interrelated nature of rights is visible:

Lottie and Cherry are busy with some little Polly Pocket-type toys. Tommy comes past and wants to join in.

Cherry: Hey, hey, you're not playing with that one. Here you are you can have this one.

Lottie: This is on the TV and it's just girls to play here with this because that is on the TV.

James comes over and looks. He stands near Tommy.

Lottie: $\quad$ These are girl toys, they aren't boy toys.

James pokes his tongue out at her. The boys start to do a little haka [traditional Māori ceremonial war dance]. They are laughing at each other.

Cherry: Don't be mean. Don't come in you're not coming in.

James is still trying to join in and makes spluttering noises with his tongue. Sandy (a child) notices and she comes up to Lottie.

Sandy: You can't be mean, you have to be kind and you have to be especially kind because there is a baby coming and she is only one.

Lottie: (earnestly) But this is a girl's game. (Field notes, Day 13, Kindergarten)

In this observation, two participatory rights are clear. First, Sandy notices a breach of the Kindergarten's established rule supporting inclusiveness (a potential breach of Article 2, CRIN, 2007, p. 2). She argues Tommy's case on the basis of kindness, and with an awareness of her peers' more competent status in relation to the baby. However, in Sandy's view, the baby is equally entitled to participate; but in this case, she is arguing that her peers (all four years old) have a shared responsibility to assure the infant's right to join in (participate), by protecting the infant (from harm). The second entitlement concerns social justice. Lottie uses gender as a reason for excluding Tommy. Sandy manages to incorporate wider concerns for the social 
group with her responses that address Tommy's unjust exclusion and, at the same time, she appeals to a shared social concern that protects participation rights for all who come to the Kindergarten. In other words, Sandy is a caretaker acting in the best interests of the child, to protect the infant's rights (Archard, 1993; Article 3; CRIN, 2007, p. 3).

In the next section, another example of how children assumed responsibility is discussed with a focus on another Kindergarten rule: No hitting, an obvious protection right issue (Article 19, CRIN, 2007, p. 7):

Phoebe, Conrad, and Greg are sitting at a table making circuits. Phoebe is quietly looking for a battery connection to make an alarm sound. She finds an already working circuit alarm:

Phoebe: (chanting) I made the alarm work, I made the alarm work.

Conrad: $\quad$ Excuse me, it worked before.

Phoebe: (keeps chanting) I made the alarm work.

Conrad moves around to where Phoebe is sitting. He stands next to her. She is sitting down. He tells her again:

Conrad: Excuse me, but I made it work. I made it work before.

Greg, who has been trying to make his own circuit without success, now moves in between Phoebe and Conrad, to see the alarm. He comes in very close and picks up a battery unit in front of Phoebe.

Conrad is very confident with circuits and tries to explain to her what is happening to make it work.

Conrad: I knew how to do it first and I'll show you why it works.

At this point, Conrad is insistently informing Phoebe that he connected the circuit. He asserts his ownership of the process, and seeks her acknowledgement of this. In other words, there is no opening (Shier, 2001) for his claim. His persistence meets with unexpected repercussions:

Phoebe leans past Greg, over to Conrad and smacks him and pinches his hand. Conrad bursts into tears and nurses his hand. It has gone red. He is quite shocked.

Clearly Phoebe has heard, but her resistance to Conrad irritates her so much she smacks him, breaking a shared code of trust the teachers explicate almost daily. At this point, Greg intervenes and acts as the mediator:

Greg: (To Phoebe) You don't smack. You aren't allowed to smack here. You need to say sorry and you need to tell him and look into his face and tell him. 
Phoebe is very preoccupied with the alarm and fiddles self-consciously. Conrad comes over to me and shows me his hand. He is crying quietly. Greg is trying to capture Phoebe's attention and make her apologise. He has very clear ideas about what she needs to do and why she shouldn't hit.

Greg: It hurts if you hit Phoebe, you need to say sorry and you don't hit.

Phoebe is determined to ignore both Greg and Conrad but Greg still persists with his line of argument. They now refer to me. Conrad crawls onto my knee. There is a visible scratch. Greg asks me and tells me at the same time:

Greg: You shouldn't hit at kindy eh? You need to say sorry at kindy, and you need to take turns too.

Sarah: What do you think Phoebe? What is another way to get the battery?

Referring to the only adult in close vicinity indicates an expectation children have of adults when the rules fail. Children could articulate the rule, and the consequence for breaking it. The problem was how to influence and assure an apology. Greg appealed to adult authority to intervene, even though it was not based on a close relationship (like between one of the teachers and child), but was sought merely because of adult status. The researcher's question was highly moral in tone, and drew the following response:

Phoebe looks sideways at me.

Her scepticism can be interpreted as a healthy response to a relatively new adult in the Kindergarten environment. The researcher was not a teacher; Phoebe's glance eloquently dismissed the question "What is another way to get the battery?" as facile, and unusual in that setting. Phoebe was aware she had breached Conrad's person, but was not going to tolerate an adult stranger who asked confusing questions in the role of mediator. The episode continued:

The mood is quite light, even though Conrad is upset. Phoebe is not keen to interact.

Greg: $\quad$ You need to use your words.

Conrad: Yes. You could have said 'Please' and not scratched and pinched my hand.

Sarah: $\quad$ (to Conrad) What do you think should happen now?

Greg: $\quad$ Phoebe should tell him sorry.

Conrad nods.

Sarah: $\quad$ (To Conrad) Would that make you feel better?

Greg: Yes.

I look at Conrad and he nods. 
Sarah: What do you think Phoebe?

Phoebe: (Mumbles and fiddles with the alarm.) Sorry.

Greg: $\quad$ Not like that - you need to look in his eyes and say sorry.

She does.

Conrad: Thank you. (Field notes, Day 7, Kindergarten)

This upsetting incident was resolved with children, by children, and for children. Arguably that could only happen in a facilitative environment which supported children's right to participate and as such is a descriptive account of how rights were enacted in the Kindergarten case study.

\section{Splitting up for justice}

The final example in this section is discussed as an example of empathy for the rights of others, including birds and animals. Note the language the children used.

Colin, Reuben, and Jem are in close discussion on the bottom step of the veranda. They are talking about being a gang. 'We've got to split up for justice,' says Colin. 'Yeah,' the others agree. 'Yeah, we have to split up for justice.' 'Yeah,' says Colin again. 'We need to split up, and find Paula (teacher).' 'Yeah,' says Jem, '... but, what does 'split up' mean?' Colin explains it all. 'Well, you go that way (directs Reuben to the climbing area), and you go that way (directs Jem to the sand pit), and I'll look in here.' They rush off in different directions and Colin, who sends himself inside, comes out onto the veranda shouting 'I've found her (meaning Paula) - now we will get justice.' [They all] cross to the far boundary where they stop by a red piece of wood covering a hole in the fence.

I was too far away to hear what was being said but when she came back I asked Paula about the 'gang' and the story seeking justice. ... 'They want justice for the chickens. The other day when I brought my chickens in, one of them ran through the fence and they are worried about her.' (Field notes, Day 13, Kindergarten)

What struck the researcher in this example was Jem's question, "What does 'split up' mean?". The word justice seemed potentially relevant, especially as it was unproblematic for the children. The data also illustrated how the culture supported notions of responsiveness as evidenced by Paula's willingness to use her influence (and establish that the chickens would be safe), and the children's sense of trust in her attending to their anxiety about the chicken. It also provides a snippet of evidence demonstrating the children's willingness to support one another, as friends, to achieve a common goal. Here, the children used their influence to advocate for the hen, and a sense of responsibility prompted 'the gang' to protect her rights in the Kindergarten environment. 


\section{Listening to children enhances participation}

This section explored the implications of Article 12 of UNCROC (CRIN, 2007, p. 5), sociocultural theories, childhood sociology, and children's rights. A combined theoretical perspective framed the Kindergarten participants' perceptions of the child's voice as a facet of participation rights for children. Both teachers and children assumed responsibility for assuring participation rights. In some cases, the teacher facilitated children's expressed views, and in other situations children mediated participation rights on behalf of others, acting, in a small way, as advocates for children's rights themselves. The data suggest that in this case listening to children was valued, and that space, voice, opportunity, and influence (Lundy, 2007; Shier, 2001) combined to create a supportive milieu for participants in the Kindergarten.

In the next section, the conceptual idea of a community of learners is used to illustrate how the teachers' professional practices and their conditions of work established a cultural modus operandi, inclusive of all participants.

\subsection{Participation in a community of learners at Kindergarten}

[Children] have the right to belong here; the right to explore; the right to have emotions; and the right to express those emotions. (Sharon, Individual interview, Kindergarten)

In the Kindergarten context, expressing a viewpoint occurred within a cultural milieu, a community of learners, and supported children's rights to belong, to express emotions, and to resolve disputes in their own ways. This section discusses the various ways participation rights were understood. Data, including conversational interview data from the children, individual and focus group interviews, and field notes, provide evidence of the interrelated nature of participation rights, as understood by the Kindergarten teachers. Sharon (teacher) explored the implications and meanings of 'belonging rights' more fully in the second focus group interview:

Well, the right to belong here means ... that there's a place to put their belongings; that their needs are met; that they are listened to; that we encourage them with friendships. (Sharon, Focus group interview 2, Kindergarten) 
Sharon's comments include needs-based rights, provision rights (a place to put their belongings), and participatory rights which incorporate space, voice (Lundy, 2007), opportunity and obligation (Shier, 2001). Her conceptualisation of how this happens is evident in what follows:

We are very aware that belonging comes first, and ... belonging is also support for their friendships. If you see a child is lonely or just not fitting in we try everything ... [Children] have the right to friendships; the right to take part. (Sharon, Focus group interview 2, Kindergarten)

The right to belong was perceived as a building block for other rights, in particular, social participation rights, but again, the indivisible nature of rights is obvious.

Teachers shared an understanding of their role in assessing the individual child's experiences within a community of learners, alongside other participants. A fundamental idea of community of learners/communities of practice approach is their dynamic, changing nature. Rogoff (2003) explains it as transformative, not just of the individuals participating in the activity, but also of the community where the activity takes place. Learning, acquiring knowledge, is creative, innovative, and a social process (Paavola et al., 2004). Knowledge creation is not the domain of the individual alone, but emerges from "a whole community or organisation" (Paavola et al., 2004, p. 564), and that individual experience is part of "a stream of social activities" (p. 565). The teachers' discussions can be interpreted as an example of a collaboratively created perspective:

Sharon: Emotional [rights] and then flow into ... equity [rights]: being able to have a turn on the truck; ... the right to dress up in a frilly frock if you're a boy; and, ... the right to throw the dolly down in order to express what that feels like - the right to express some of those not nice things which are maybe hard for us to see, but maybe there is something in that. Like there is a depth of understanding that comes through that. The right to be who you are ...

Paula: (Laughing) Yes, and, the right to experiment, and to make a mistake and try again and know that when you make a mistake you haven't failed but you can keep on trying. It's the right to take a risk, yes; they won't be risk takers if they've been pushed down, and not given rights; not given a voice. (Focus group interview 1, Kindergarten)

The discussion framed teachers' perceptions of rights as more than merely knowing the routines and how to engage with the activities. 
Their perceptions indicated an awareness of fundamental entitlements for children to an inclusive, tolerant, social environment, attentive to equity issues. A key question in this research investigated how children learnt about their rights. How did children actively contribute to the culture of the place? One explanation was described by the teachers as a sense of ownership:

Paula: [Children will] often ask: Whose Kindy is this? And then they answer each other, Ours!

Sarah: How do they know that?

Paula: That's what I often wonder. Somehow we have taught them that as part of the culture of the place.

Sharon: Well, I think that is right - it's part of the culture that they know that. (Focus group interview 1, Kindergarten)

Evident here is a perception that a Kindergarten culture existed, and that it somehow supported children's sense of ownership, or belonging. Paula's reflective comment suggested that teaching practices (somehow, we have taught them) aligned with perceptions of the culture of the place. Theoretically, this can be visualised using an ecological framework (Bronfenbrenner, 2005d). The children's sense of ownership, mediated by the teaching practices and strategies, formed a microsystem in which children's rights were supported by 'the culture of the place'.

Teachers perceived children's participation as influencing the programme, themselves as teachers, and the children's peer group:

Paula: To a certain extent they learn off each other.

Sharon: Yes, that's right.

Paula: That's part of responsive, respectful, reciprocal relationships (we all laugh at the Te Whāriki words). That sounds like jargon now. ... You want to listen to children, and extend them and appreciate what they are giving to the programme and what they are challenging themselves with. And celebrate that with them. (Focus group interview 1, Kindergarten)

The teachers explained their culture with reference to the founding principles of $T e$ Whāriki (Ministry of Education, 1996b). Listening to children was appreciated because it offered teachers insights into children's learning processes and interests. Children's opinions were valued because teachers believed these contributed to the programme, and consequently could be interpreted as participatory actions. A shared understanding of what it meant to listen was multifaceted: teachers believed that 
extending, challenging, appreciating their contributions, and celebrating these were all aspects of the Kindergarten culture. In other words, the teachers appeared committed to reciprocity, which enhanced participation. The Kindergarten teachers' respect for children influenced how they participated and contributed to the programme.

The teacher can act as a catalyst for change in educational settings (Verhellen, 2001) but "listening to, communicating with, and involving young children requires a cultural climate that understands children and takes them seriously" (Pugh \& Rouse Sellack, 1996, p. 134). Children's agency and participation rights were facilitated by teachers' beliefs that relationships were the basis of good teaching, and that responsive, respectful, reciprocal relationships were also a foundation for learning, not restricted to one party, but applicable to all participants in that community of learners.

\subsection{Children's perceptions of their rights}

A challenge in this study was how to ask children a) what they thought rights were; and b) what that meant in practice. 'Rights' was not a common-use word. The first focus group interview data revealed that the teachers could talk about rights, but it was a term imposed by the research. Teachers believed that children could not talk about rights per se, but if phrased and described in alternative ways, they were likely to be more articulate about their entitlements in the context of their Kindergarten:

If you said 'What is your understanding of rights here?', I think it would go right over their head, but if you broke that down into like, 'Do you think you can choose here?', and 'What can you do here?' you would get a better sense and understanding of what they think their rights are. (Paula, Focus group interview 1, Kindergarten)

Paula's comment guided the research. By way of reminder, a book, posters, prepared scenarios, and a persona doll were tools used to stimulate discussions with children about rights, with mixed success. In the end, the combination of these strategies with the daily presence of the researcher (for a month) resulted in a comfortable degree of familiarity (Corsaro \& Molinari, 2000) that meant conversational interviews (Christensen, 2004) were the most satisfactory method to discuss children's ideas about their rights. 


\title{
Rights as relational, social rules
}

Children's perceptions of rights were about social relations and processes, like not hitting, or being a good friend, or taking turns and sharing. There was a high level of consensus. In the following examples, children explain the social rules:

\begin{abstract}
Henry (the persona doll) noticed the trolleys outside and asked about having a turn. 'Do you have to have turns at this kindy?' Henry told them that he had to wait and wait and wait for a turn at his kindy, and then when it was finally his turn, someone came and took the trolley off him. In response to Henry's story the children commented: 'I know,' said Lisa, making a suggestion. 'You say you want a turn and then you can go away and then come back later.' 'Yes,' added Jimmy, 'we have to share here and share and then you get a turn.' Eric then said, 'We could take you on the trolley. We could give you a turn.' (Field notes, Day 12, Kindergarten)
\end{abstract}

In this scenario, Henry's novice status as a legitimate peripheral participant (Lave \& Wenger, 1991) led to Eric welcoming him to the community of practice in a way that did not overstretch or overburden him (Colley et al., 2007). Sharing, turn-taking, and a system for waiting appeared to be an agreed to entitlement for children. They were well able to explain how it worked, and even offered Henry a ride. Einarsdottir (2005) noted children's ability to articulate in her study, as did Clark and Moss (2001). Children in the above example created space and opportunity, and used the Kindergarten's rules to legitimate Henry's (the persona doll) ride on a trolley.

In a mat time session, Henry once more resorted to his novice status to question children about their perceptions of rights. In response to the prompt suggested by the teachers: "What are you allowed to do here?" the following observation was recorded:

\footnotetext{
'Well,' said Amy, 'you aren't allowed to hit and you have to share.' Several children echo this. Carlos adds: 'And you have to be a good friend.' Willie refers to the poster behind Henry and told him to look at that. 'Use your hands as tools?' he commented with a questioning tone. (Field notes, Day 12, Kindergarten)
}

Of note here is Carlos's reference to the poster on the wall, used here to support his opinion. His photograph was in the poster and this was an example of how children's contributions were influential participatory acts, consistent with the negotiated ethos of the Kindergarten. Conversations about the code of practice (for example, no hitting, sharing resources) shifted to the notion of friendship:

Tommy told Henry, 'You have to be a good friend and that means you can't say 'I don't like you and I don't want you to play here.' You have to share the toys here.' Henry asked if he brought his bike would he have to share it. 
'No,' said Lulu, 'it's only for the toys that are the kindy toys - the play dough and the trolleys and the books.' 'Who would be my friend?' I made Henry ask. There were lots of offers. 'What would you tell me about this kindy?' 'Well, you can have a locker and you can put all your stuff and morning tea in it and then you could go to the screen printing or the collage.' Sally and Emma answered this at the same time. 'I know,' said one enterprising child (Jed), 'I could be your friend and I could show you all the stuff.' Michael came up. He pointed to the 'brainstorm' behind us and told Henry to be kind and 'To use your words.' (Field notes, Day 12, Kindergarten)

Friendship and the implications of being a friend was a 'right' commonly used by the children to negotiate access to play spaces, to legitimate their advocacy on behalf of others, and as a reason to be together, but children were very clear about their interpretations of friend status. Jed summed it up:

Jed: $\quad$ Well, when you are a friend you have to be kind and care about [friendship]. (Field notes, Day 12, Kindergarten)

\section{Guided participation: An exemplar of balancing expertise}

Teachers expected children to participate in the Kindergarten programme. They believed that the culture of the place and their teaching skills combined to support individual children. The observation below is an example of how Paula, the teacher, supported Saul, a child with special needs, to engage with the volcano theme running in the Kindergarten programme at that time.

The interactions between Paula and Saul (four years old) shifted as they shared responsibility for providing expertise. Saul, the artist, at times sought Paula's expertise; for example, about echoes. Paula supported Saul's imaginary role, where he assumed responsibility for safety during an imagined eruption. Saul retained the power over his story. Prompted by Paula, he expressed his feelings, and what he had learnt about volcanoes. His thinking process was acknowledged; Paula recognised the depth of meaning for Saul, and her responses indicated an easy transition between her role as a legitimate peripheral participant in Saul's story, and her role as an experienced member of the Kindergarten's community of learners. The final actthe photograph for his portfolio - legitimated Saul's work as valued in all its complexity:

Saul is doing a drawing about an eruption. Paula notices and sits next to him.

Saul: $\quad$ Here is your house next to the apple tree and it is not safe because the lava will come and come and everything will be destroyed and so we will run away. 
Paula: Oh, how will I know it's an eruption?

Saul: $\quad$ You will see the smoke and the lava and I will have to run away with you. Here is the house and it has lots of windows.

Paula: I like that. I like lots of windows. Will the birds be safe? (Saul is drawing birds.)

Saul: $\quad$ Yes they will fly ...

Saul explains about smoke and lava to signal the time to escape.

Saul: $\quad$ You will know and I will come and we will run away.

Paula: I am glad to live by an apple tree and I am glad you will help me to run away.

Saul now draws Biff, Paula's puppy who comes with her most days to work.

Paula: Will he be safe?

Saul: $\quad$ Yes.

Saul talks as he draws the smoke and the hot lava. A river gets added into the story and there is lots of steam. Paula is asking him questions about what is going on.

Paula: You are running out of room. Do you need more paper?

Saul: $\quad$ Yes, where is the sellotape? I want it here.

Paula: How do we make it? Like this - do you want it like this?

Saul: Here is the volcano. (He is drawing this as he tells Paula about it.)

Paula: It looks huge - is there a safe way out? This is a natural disaster. That's what this is called. Are you safe?

Saul: $\quad$ Yes, I am running away.

Paula: How are you feeling?

Saul: $\quad$ I feel frightened, and I feel sad.

Paula: $\quad$ So do I, Will we be ok?

Saul: $\quad$ Yes, we will be but Biff might get hurt.

While this is going on, Lizzie (a child) is drawing a picture of a sunset. Saul notices and adds the sun to his picture.

Paula: Do you remember how orangey the sky looked in the eruption?

Saul: $\quad$ Yes, it was orangey and now this is the sun.

Paula: There is a great deal of detail. What is happening over here?

Saul: $\quad$ The lava has stopped. The sun stopped it and dried it up.

Paula: You were doing good listening to Malcolm (a guest speaker on volcanoes).

Saul: $\quad$ And here is the Kindergarten.

Paula: That's a lovely place for a Kindergarten! On a mountainside. We can have skiing lessons.

Saul: $\quad$ Yes and there will be echoes.

Paula: Has the mountain stopped erupting?

Saul: $\quad$ Yes the lava has stopped now and the sun has dried it up. 
Paula: Do you know that when a volcano stops erupting it's called extinct?

Saul: $\quad$ Extinct. And this is me. (He draws a figure with a smiley face.)

Paula: You look so happy.

Saul: $\quad$ Yes, I am making an echo. How do echoes get made? How do you make an echo?

Paula: The sound vibrates around the mountains. ...

More characters are added into the picture - there is lots of talking.

Saul: $\quad$ taDaaa!

Paula: Why did you say that? Are you proud of your achievements?

Saul: $\quad$ Yes! taDaa! taDaaa!

Paula: You have told me such a good story about the volcano and the mountains. I want to take your photo. Can I take your photo please? I think this would be good in your portfolio. (Field notes, Day 7, Kindergarten)

This story is an example of activities, roles, and interpersonal relations at the Kindergarten. Saul's participation in the activity was supported by the environment, arguably a powerful and meaningful factor shaping individual growth (Bronfenbrenner, 1979; Kirby \& Gibbs, 2006; Qvarsell, 2005). In this example, the Kindergarten environment allowed the balance of power to shift between adult and child, and resulted in a memorable experience for Saul and Paula as well as a permanent artefact for the Kindergarten records - the photograph of Saul's picture.

\section{Tidy-up time - sharing responsibility}

Sharon (teacher) asks Maggie (child) 'Would you like to ring the tidy-up bell?' ... The bell rings out and there is an immediate response. All the children rush to the areas that they have a job in. Harry (child) comes into the puzzle area and is told by Jess (child) that this is not his area. 'Go to your area' - she goes to the list on the wall with the names on it and points to her name. 'Your name isn't here.' He sits on the couch next to me. Sharon comes in and directs Harry to the outdoors where he has a job gathering up the balls. He leaves quickly. (Field notes, Day 1, Kindergarten)

It could be argued that participation of very young children can be by proxy. There was limited, albeit powerful, evidence of children participating in decision-making in the Kindergarten. Tidy-up time was a managed process determined by the need to order the physical environment between sessions, or before going home. Teachers decided that a jointly negotiated procedure for tidy-up time was a way to develop a 
sense of responsibility for care of the Kindergarten environment. During the mat time sessions at the beginning of each term, the teachers discussed tidying up with the children and instigated a system of tidy-up teams. The teachers organised children into as many groups as there were areas for tidying, excluding bathrooms, storage rooms, and kitchen areas. They allocated children to groups, and groups to areas, but allowed children some negotiating power in this process.

There were two rationales operating here. The first was to allocate a group of children to an area they did not usually spend time in and, in so doing, perhaps encourage a broader interest in what was available in the Kindergarten. The idea was to open up possibilities for new exploration; however, it is questionable that making children tidy up, not a favourite activity no matter how it is dressed up, risks further alienating the potential attractiveness of, say, sand or block play. The other rationale was to mix up the social groups. Children tended to play with the same friends or groups of friends on a daily basis. If children had to co-operate in the tidy-up time, they might well meet and make new friends. The whole process was underpinned by several implicit theories about children's rights. As well as promoting care of the environment, it also had the potential to promote a sense of responsibility among the children - their actions - tidying the blocks, or the dough, or the sand pit toys, which would or could, potentially enhance ownership, develop a sense of care for the environment, and a concern for others, as described in the next observation:

It is tidy-up time and the bell is ringing. It is an old-fashioned bell that one of the children walks around with. Jem (child) comes rushing into the sandpit because that is his area for tidying up.

'I was the first here,' he says breathlessly.

He looks around and picks up two of the metal spades.

'Are there afternoon children today?'

'Yes,' I tell him.

'Oh,' he says. 'Then we need to pick up all the metal toys and spades and some of the big wooden diggers because the afternoon kids are just up to here.'

Conrad (child) comes over to help Jem. 'Yes we have to put away the metal toys because the afternoon children are so little and they might hurt themselves on them.'

'They are only this big,' says Jem and he stretches his hands about a metre apart to show Conrad how tall he thinks they are. 'Do you think they are this tall?'

Conrad adds: 'Yes. And when I was an afternoon kid I was only this tall.' He puts his hand at his chest height. 
Jem puts his hand on his waist and says 'And I was only this tall.' He looks at where Conrad's hand is and then moves his up slightly higher.

Paula (teacher) comes out to see how things are going. She smiles at the boys' concern for the afternoon children. 'That was very forward thinking of you, but you don't need to worry. Everything is OK for the afternoon children here.' (Field notes, Day 7, Kindergarten)

A further rights-based notion can be extracted from the boys' perception that the younger children needed protection - taking responsibility for the environment counts as contribution. Tidying up developed a sense of others - the child or children who were not present, but who would come. It moved the frame of ownership in time, from the present, to the future:

Emma R and Emma W (children) have built a swimming pool in the block area. The tidy-up time bell rings, and as Paula (teacher) walks past she compliments the girls on their clever design. Shall we put up a sign to say 'Please leave'? The girls agree, and then ask for a photograph too. 'Good thinking, just in case it gets knocked over,' says Paula. (Field notes, Day 8, Kindergarten)

Tidying up was something that had to be done at the end of every session everyday and occasionally during sessions. The teachers were not overly concerned about how tidy things were - Paula and Sharon (teachers) allowed the standards to emerge, and these were established by the children. Maintaining and subverting the norms was monitored by children as well as teachers. For the most part, only one or two children stretched the rules. Interestingly, it was not about tidying up per se, but about who was with whom, and where. The teachers were also aware that some areas were more difficult to tidy, and involved more work too; for example, packing up the outside shed. Realistic timeframes and expectations were discussed as a group with the children.

The teachers' interest in tidying was to create a sense of order to ensure that the environment remained accessible. Availability was threatened if things became too chaotic and that hindered access. By including children in the process, albeit in a tokenistic manner because they did not really have choice not to participate in this work, teachers were able to share their purpose in a different way. They believed it was more difficult to support children's interests if the physical environment became unmanageable. By explaining the benefits of tidying up to children during mat times, the teachers aligned themselves with the children in a shared purpose - facilitating children's work and play. Once the tidy-up time (10 minutes only) was over, it was mat time - something most of the children enjoyed participating in. An ethos of rights, coupled with responsibilities, was promoted respectfully during the tidy-up times. 


\subsection{Summing up: Protecting children's rights to participate; providing for children's rights to participate}

Interpreting participation rights for very young children has been problematic, particularly the relative weighting of children's opinions and adults' experience. Lansdown (2005, p. 8) notes that: "UNCROC does not give children full adult rights. Rather, it gives children the right to be heard and to gradually take increasing responsibility for decisions as their competence evolves." The intentions of Article 12 (CRIN, 2007, p. 5) are very often diminished and over-simplified by arguments about adult/teachers' power compared to child/children's powerlessness. Young children's participation rights in early childhood settings "cannot be discussed without considering power relations and the struggle for equal rights" (Hart, 1992, p. 8).

There were three issues to consider about power relations in the Kindergarten context: What are the structures impacting on children in the Kindergarten? How do children understand them? Are power relations considered? To answer the first question, teachers perceived the organisational structures in the Kindergarten as supportive. In their view, they were well resourced, and had good conditions of employment. The first and second questions were answered by the teachers' emphasis on children belonging, and on listening to children. The role of the teacher was to build a sense of community using a range of participatory actions and opportunities. Depending on the situation, the teacher's role could be as novice in a child-initiated game, as peer, or as a more experienced peer in a supportive role. Ultimately, though, the power (and responsibility) in the Kindergarten resided with the teachers. However, a variety of strategies empowered children to understand that this was their space and place. Their intellectual, social, and emotional investment in the Kindergarten was recognised and supported, despite the power relations being unequal.

Power is a recurring theme in the literature on children's rights (Alanen, 2001; Alderson, 2000; John, 2003; Hart, 1992, 1997; Lofdahl \& Hagglund, 2007; Mayall, 2000, 2003; Shier, 2001). It connects the three themes of this chapter: nurturing a sense of belonging; listening to children; and learning in a community. Teachers believed that children's participation would be enhanced by a strong sense of belonging, supported by the environment and facilitated by the culture of the place, where participation was valued. Through a range of strategies, teachers developed a 
community of practice that included basic rules of social engagement: you had to be a good friend, you had to share, and you were not allowed to hit - protection rights and protecting rights to establish positive relationships were central to participating at Kindergarten. These rules encompassed elements of protection rights, and were dependent on provision rights. Shared responsibility for the environment (for example children taking responsibility for tidying up, arguably to maintain a high standard of provision) and for monitoring one another's social interactions (that is, protecting the rights of others) were examples that promoted participation in this context.

The Kindergarten teachers' perceptions of children's rights were framed by the context they worked in. A combination of teacher-initiated strategies, and the conditions the teachers and children both shared, facilitated participation rights. Even though the ratio of teacher to child was low (43 children, and three teachers), a jointly agreed to approach to the work resulted in a cultural climate in which children were accustomed to listening, and to being listened to (contributing). The effect was evident in several ways, most notably in the consistent, coherent social and cultural climate. Teachers' personal professional traits supported children, and deepened their participation at Kindergarten.

Throughout this chapter, data were used to illustrate participation rights. These data included examples of how protection rights (protecting children's rights to participate by nurturing a sense of belonging) and provision rights (for example, conditions of service; an architecturally designed, purpose-built facility) supported children's agency (a fundamental principle of participation rights) in the Kindergarten. The implementation of these types of rights facilitated meaningful participation in the Kindergarten. Chapter 6 discussed how the Crèche teachers' fore-grounded protection rights (protecting children, and protecting children's rights); the Playcentre case study focused on provision rights and adult responsibilities. While a category of rights may have been fore-grounded, this was en route to enhancing participation. Evidence of how the three categories intertwined was provided as a preface to the thesis.

Chapters 6, 7, and 8 have presented evidence of how children's rights were perceived and enacted in three different early childhood settings. Three categories of rights 
were used to explain these data. However, findings were not exclusively confined to a discrete category of rights. Chapter 6 focused on adult advocacy to protect children and to protect children's rights to participate, and to express a point of view. In order to achieve this, provision rights need to be considered and that chapter discussed the very real difficulties experienced by children and teachers in an environment ill suited to childcare for under-two-year-olds. Limited access to the outdoors is an example of this.

Chapter 7 explained how the Playcentre understood and implemented children's rights in terms of the resources provided, and in terms of the organisation's philosophy. Accordingly, play was regarded as foundational to children's learning and to childhood. Providing resources did not guarantee that children's rights to participate would be protected. Consequently, protecting children's ability to play freely and spontaneously was curtailed by adults' lack of confidence in managing the resources and in implementing children's participation rights equitably. Participation rights were not interpreted or implemented uniformly.

Chapter 8 explored children's participation rights and illustrated how these were well supported in the Kindergarten because teachers deliberately nurtured a culture in which children's rights to belong to, and participate in, the service were protected and provided for. Clearly, even though a category of rights might be fore-grounded, this category can only be understood if contextualised alongside other categories of rights.

In the final chapter, the theoretical themes of the thesis are aligned with the three strands of rights emerging from the case study settings to conclude the argument that perceptions of children's rights, and the context in which they are implemented, cannot be considered in isolation. 


\section{Chapter 9: Children's rights are interwoven, interrelated, and interdependent}

\subsection{Introduction}

This research began with the following questions about perceptions of children's rights as they participated in early childhood settings in New Zealand:

How do children, teachers, and adults in whānau/parent-led centres, perceive children's rights in early childhood settings?

How are children's rights enacted, or implemented, in early childhood settings?

Three different early childhood services were the focus of the investigation: the Creche for under-two-year-olds (described in Chapter 6); the parent-led Playcentre (Chapter 7) for mixed ages from birth to five-year-olds, and the sessional statefunded Kindergarten for three- and four-year-old children (Chapter 8). The initial focus of the research was on how participation in the proximal processes children experienced as members of communities of learners in early childhood settings supported their rights. However, it soon became clear that

a) the effect of the participants' (children's and adults') perceptions of children's rights were directly influenced by the organisational philosophy or auspice of the particular service; and

b) the philosophical and organisational auspice in turn influenced how children's rights were implemented and enacted.

This study interpreted participants' perceptions of children's rights using three well known categories of rights-provision rights, protection rights, and participation rights (Hammarberg, 1990; Lansdown, 1994; Stainton Rogers, 2004), and argued further that particular settings fore-grounded a certain category of rights, but that other categories of rights were also observable. Based on the evidence, a conclusion drawn was that the three categories of rights were interrelated (there was an observable dynamic between categories of rights), intertwined (categories of rights were not exclusive or discrete from one another), and interwoven (categories of rights supported one another). In other words, one category of rights cannot exist 
without the others. Therefore, to effectively support children's participation in early education requires that children's protection rights and provision rights are also implemented. Findings discussed in Chapters 6, 7, and 8 suggested that different types of services implemented rights differently, an idea first mooted in the preface to Chapter 6. In this chapter, the findings of this study are discussed alongside the theoretical ideas used throughout the thesis.

This study offers a New Zealand perspective on children's rights in early education. It is the first study to do this in New Zealand using sociocultural and ecological theories alongside UNCROC, concepts from the study of childhood, and childhood sociology. By merging ideas from these different theories and disciplines, this study has recorded perceptions of children's rights to be active agents in their early educational experiences. The research also provided qualitative evidence of the dialectic between participants' perceptions of children's rights and the particular early childhood settings in which rights were enacted or implemented. In other words, the type of setting influenced the ways in which children participated in their early education. This study argues that there is a coherence between the different theoretical ideas that can support a new rights-based pedagogy in early childhood education in New Zealand.

Sociocultural and ecological theories were used to explain how children learn and develop by participating in early childhood settings. In Chapter 4 it was argued that notions of participation provide common ground between theories of human development and sociological perspectives. The theoretical ideas are based on a premise that children learn and develop through participation in cultural processes. As a discipline, childhood studies is founded on a view of the child as an active participant with an opinion about his or her experiences. This discipline has emerged more strongly post-UNCROC. Childhood sociology explains how constructions of children are contextualised in time and place. Both childhood studies and childhood sociology recognise the child as entitled to participate in social and cultural processes, processes deemed essential to learning and development by sociocultural and ecological theories (Bronfenbrenner, 2005; Rogoff, 2003; Rogoff et al., 2007). Combining constructs from these theories and disciplines enabled a new configuration of theoretical ideas that provided the analytical framework used in this thesis. More specifically, the thesis contributes to the children's rights debate by 
exploring perceptions of children's rights and how these were enacted (if at all) in the three New Zealand early childhood education case study settings. The data also documented what influenced children's perceptions of rights and how they learnt about these. The evidence provided creates a strong argument for a conceptual justification for a rights-based pedagogy.

This study draws four key conclusions:

a) Children's rights do not exist in isolation but in the context of the early childhood setting.

b) Children's, teachers', and parents' perceptions of children's rights were influenced by the setting in which they participated.

c) The service type (in this study the Crèche, the Playcentre and the Kindergarten) influenced how children's rights were implemented or enacted within that setting.

d) Protection rights, provision rights, and participation rights are interwoven, interrelated, and interdependent.

The early childhood case study settings were distinctly different and this provided data which illustrated the complex dynamic between perceptions of children's rights and how these were implemented. The Crèche and the Kindergarten were teacherled services, and the Playcentre was a whānau/parent-led co-operative. Participants (including children in the Playcentre and the Kindergarten) in each case study appeared to fore-ground a particular category of rights, influenced by the context (for example, the age of the children, how long they spent in the setting). Further, environmental factors, such as the way the centres were managed, and the physical layout of these settings, had an impact on participants' perceptions of children's rights while they were in that setting. This chapter draws together key concepts from the different theories (refer to the summary in Chapter 4) to discuss the significance of the findings. The final sections discuss the potential of promoting a rights-based pedagogy and the implications for future research. The following sections review the main findings but synthesise these to make visible the dynamic between the data and the theoretical ideas and how this study might optimise existing perceptions of children's rights to support a new pedagogical approach. 


\subsection{Children's rights did not exist in isolation}

A major finding was that children's rights did not exist in isolation but in the context of the early childhood setting. This was significant because it established a dialectic between perceptions of children's rights and children's rights in reality. There were two aspects to this finding. First, children's, teachers', and parents' perceptions of rights were influenced by the early childhood service context; and second, this context influenced how rights were implemented. Perceptions of rights were interwoven with the implementation practices and processes observed in the particular settings. These appeared to be interrelated and, to some extent interdependent. For example, teachers believed that a strong sense of belonging in children supported children's right to participate at Kindergarten. In order to effect children's participation, teachers considered the realities of their particular context: 43 four- to five-year-old children enrolled for five three-hour sessions, five mornings a week. Their professional conditions of service allowed for non-child contact times that made it possible for them to meet together once a week during the day. These conditions, plus a perception that children had a right to participate, allowed them to develop teaching strategies designed to implement children's participation rights in the Kindergarten. There was a link between perception and context, and between the context and how the children's rights were enacted, or implemented. The Kindergarten teachers' strategies nurtured a sense of belonging by teaching children how to be a good friend.

In the Crèche, teachers sought strategies to establish a sense of belonging through self-proclaimed advocacy on behalf of the child to the parents. The ages of the children (all under two years old), and the hours of operation (8.00am to 6.00pm) focused teachers' actions on caregiving where protecting children's rights included strategies like using the telephone to communicate regularly with parents about their child, or to communicate expectations to parents that they would support teachers to support their child; for example, when settling a new child into the setting.

At the Playcentre, children's and parents' perceptions of children's rights indicated a strong commitment to Playcentre philosophy of child-initiated play. In this childcentred environment, the onus was on adults to provide resources that facilitated children's participation. Parents protected the Playcentre children's rights to 
participate in this environment. Figure 14 illustrates the relationship between perception, context, and implementation of children's rights.
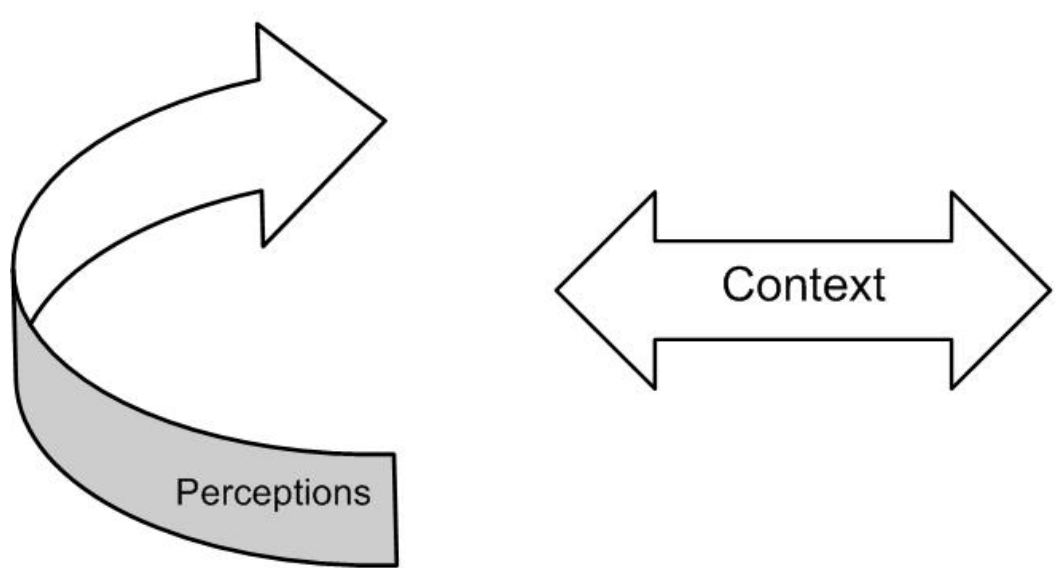

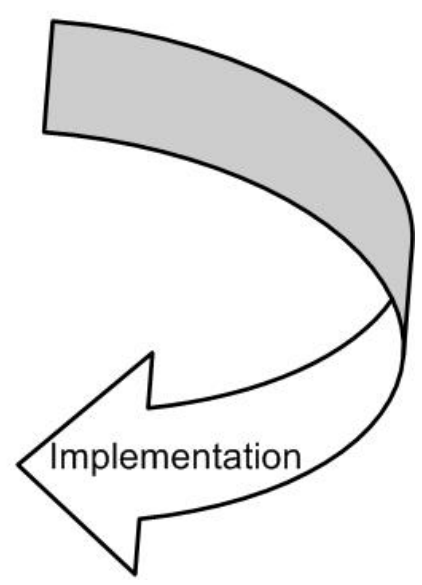

Figure 14: Relationships between perception, context, and implementation of children's rights

\subsection{Perceptions of rights were influenced by the context}

Participants' perceptions of children's rights were influenced by the contexts in which they were implemented. These perceptions are discussed below using the key themes of participation, protection, or wellbeing and the role of the adult as a guide to support children and provide an environment in which they can participate safely (see Chapter 4). Cultural processes, like the ways in which children were empowered to contribute, or inducted into the setting, were specific to the early childhood contexts.

\section{Participation}

Notions of participation are common to theories about rights (for example, Freeman, 2007; Lundy, 2007). They are also common to sociocultural and ecological theories (Bronfenbrenner, 2005d; Paavola et al., 2004; Rogoff, 2003; Rogoff et al., 1995, Rogoff et al., 1998; Rogoff et al., 2007; Vygotsky, 1978). Rogoff (2003) argued that children's learning and development is fostered through participation in social and cultural processes. Participation in social and cultural processes is also a principle of childhood studies and the sociology of childhood. Both these disciplines recognise children agency (Kehily, 2004; Pufall \& Unsworth, 2004; Woodhead, 2005). Several models of participation evaluate the extent to which children's participation rights are recognised (Hart, 1992, 1997; Lundy, 2007; Shier, 2001). They all acknowledge that the child's right to voice a viewpoint requires time, space, and a willingness to listen. 
In the Crèche, teachers were concerned to protect children's rights to participate in the programme, and they supported infants and toddlers to express a view (a participation right) by creating a protective space for them (Lundy, 2007). In Chapter 6, wellbeing and belonging, strands of Te Whāriki (Ministry of Education, 1996b), were interpreted by the teachers as rights to be protected because children's development and learning depended on meaningful participation in a community of learners (Rogoff et al., 1995). The Crèche teachers' emphasis on protecting children was interpreted as a way to protect their participation rights.

The data gathered as part of this study show that all participants believed that children had a right to be heard. This implied listening to children, which is an obvious participation right, but the conditions for listening to children differed between settings, and even within settings. For the teachers in the Crèche, listening to children involved taking a stance of advocating for children's rights to be both respected and protected. Protecting children's rights enabled children to participate and express their views verbally and non-verbally.

In the Kindergarten, actively listening to children was established as part of the culture of the place through teachers nurturing a sense of belonging and by embedding social rules for interacting as a good friend. The responsibility for respecting another's perspective was shared by adults and children because the ratios of child to adult were high (13:1). There were numerous examples of how children mediated play by calling on the common rules: "You need to share"; "You're not allowed to hit"; You need to say sorry." The data show how the Playcentre parents struggled, at times, to establish a shared understanding about the conditions needed for listening. As evidenced in Chapter 7, the Playcentre's overtly child-centred approach was not always managed fairly, and, consequently, some parents found it hard to guide children towards respect for the rights of others. An example of this was older children disrupting younger children's trolley play.

The data show that the Playcentre's philosophical commitment to free, spontaneous play led to parental perceptions of children's rights to participate being contingent on provisions in the environment. These provisions included traditional early childhood play experiences such as water play, painting, and dough, and early childhood education training for parents. Evidence suggested that the Playcentre training could 
have done more to create an awareness of how children need support to form a view point, express an opinion, and exercise a right to choose. The training experiences formed a strong community of practice (Wenger, 1998; Wenger et al., 2002). Participation in this community of practice was based on a shared understanding of the philosophy of Playcentre. A community of practice consists of novices and experts (Lave \& Wenger, 1991). The relative inexperience of some Playcentre (novice) parents was apparent in their interactions with children, notably a lack of confidence in dealing with conflict between the children. Guided participation from more experienced peers transformed perceptions of rights in the Playcentre context (Rogoff, 1990; Vygotsky, 1978), particularly regarding children's rights to express a view through play. There was a synergy between the community of learners and the community of practice because children and parents belonged in both community types.

The Kindergarten emphasised social responsibility towards one another (adults and children) as an essential ingredient to successful participation in their community. In the teachers' and children's words, "You have to be a good friend". Using the moral pull of a large group, led by teachers, participating at Kindergarten involved social considerations framed by 'the culture of the place'. Children's notions of citizenship (May, 2003), evinced through their sense of social responsibility towards the whole group, were well developed in this setting. The Kindergarten's community of practice (Wenger, 1998) supported the children's awareness of one another as they participated in social processes (Rogoff, 2003). These practices were based on respectful, reciprocal relationships (Ministry of Education, 1996b), and learning to participate in socially just ways (Article 29d, CRIN, 2005, p. 13). Relationships are critical to participation, and the notion of guided participation assumes relationships with adults and with peers (Rogoff, 1990). The Kindergarten's cultural milieu supported children and adults alike to engage in relationships which supported meaningful participation in socially mediated learning processes and practices such as mat times and sharing resources.

\section{The role of the adult}

Ecological and sociocultural theories position the adult as central to a child's learning and development (Bronfenbrenner, 2005d; Bronfenbrenner \& Morris, 1998; Rogoff, 2003). Recent research (see Bartel, 2005; Bodrova \& Leong, 2005; Hedges, 
2007; Rogoff, 2003; Rogoff et al., 2007) lends weight to the adults' pivotal role in communities of learning and inquiry. The findings of this thesis support previous research (Clark \& Moss, 2001; Einarsdottir, 2005; Lofdahl, 2007) which found that the role of the adult was a significant influence on how rights were experienced by children (across all three case studies). The data gathered as part of this study also revealed that adult participants' perceptions of children's participation rights included acknowledging their opinions as well as helping them to form and express their views. Data generated in the Crèche provided clear evidence of young children communicating but adults remained in control of the social and physical environment, which did not allow space for this and constrained children's participation rights to have their views taken into account. Adults creating space (Lundy, 2007) for viable contributions by children is a corollary expectation of participation. Certainly, research (see for example, Clark \& Moss, 2001; Flewitt, 2005; Hviid, 2004) demonstrated that very young children contribute sensible, sound advice, given the opportunity to participate. In this thesis, evidence of adults effectively consulting with children depended on the type of service, and the conditions in which adults' work influenced their relationships with children.

In all three cases studies, teachers and parents used a range of strategies to encourage children's contributions in their respective services. An emphasis on civilised interactions by being a good friend was encouraged by the Kindergarten teachers. For example, in Chapter 8 Paula worked alongside a child (Saul) with recognised special needs to include him, and value his contribution as competent and confident. The interplay between Paula and Saul in that instance illustrates a shift in the balance of power towards the child, and is an example of guided participation in which Paula (the teacher) offers her experience and knowledge to Saul to keep the interaction flowing.

United by a common belief in the Playcentre's philosophy, the Playcentre data showed that parents perceived that their role was to ensure children could play freely and uninterrupted by adult-imposed requirements. Even though parents were committed to providing 16 areas of play in every session, protecting time and space to support participation was not always straightforward. The role of the adult in the Playcentre was more conflicted by uncertain understandings of what exactly their role included. This was evident in Felicity's (a Playcentre parent, reported in 
Chapter 7) dilemma when helping children to negotiate turns on the trolley. As argued in Chapter 7, these minor conflicts, or tensions, however, are a normal part of cultural and social experiences, and are recognised in theory for their transformative effect (Rogoff, 2003; Wenger, 1998; Wenger et al., 2002). Conflicting values between home and centre, evidenced at the Playcentre during discussions and meetings about tidying up at the end of the day, led to shared understanding and tolerance amongst this particular community.

Adults in the Crèche referred to themselves as advocates for the children, a term associated with the children's rights movement and which reflected an awareness of children's rights generally. An emphasis on protecting children's rights to participate stimulated the Crèche teachers' resolve to advocate for the children. Very often this advocacy was concerned with children's health and wellbeing. Strategies used to advocate for children to parents included documenting children's experiences for parents and regular telephone calls during the day. Teachers also advocated for children to other children and facilitated their participation in activities and experiences. At times, teachers' interactions with children supported them to participate meaningfully with others. Teachers' advocacy in these situations interpreted children's perspectives and represented them to the wider group.

How parents and teachers were supported by their respective organisations varied between case studies, and consequently, this affected how children's rights were perceived and implemented. The conditions of service for the Kindergarten teachers provided time to meet together during the day in one non-contact (with children) session per week. At the Crèche, teachers met together monthly in the evening, although one hour-long non-contact session per week, during the day for individual teachers was a condition of employment. Parents in the Playcentre met as a team at the end of their weekly session. The ability to meet was a provision rights issue, particularly for the Crèche teachers where meeting outside of work hours, even when paid, was not ideal or conducive to their perceptions of good-quality practices. Evidence from the Crèche teachers suggested that demands and expectations to provide a service for parents came before children's rights to be consulted. Some of the Crèche teachers felt that if children's rights were to be taken seriously, discussions at a wider policy level were essential. Improving non-contact times might have financial implications for the service and, possibly, for parents' 
employment patterns. This argument adds strength to the notion that rights do not exist in isolation and suggests that implementing children's rights is part of a wider societal discussion about infants' and toddlers' participation in early education. The findings about the role of the adult also suggest that children's experiences in early education might be enhanced by a deeper awareness of UNCROC and theories about human development and learning.

\section{The physical environment}

A clear finding was the impact of the physical environment on the way centres operated. This was most noticeable in the Crèche where the data showed that the physical environment was inadequate. Although it met the official regulations, the environment of the Crèche, arguably, did not provide for the physical conditions needed to enact children's rights, in particular access to the outdoors. This illustrated a defect in how policy is implemented, and certainly curtailed teachers' and children's rights. Regulations could not control how that space was used at any one time. The Crèche children's access to physical spaces was extremely limited by a mix of management's and teachers' narrow interpretations of how the regulations for staff:child ratios should be implemented. At any one time during the day, large rooms were left empty because all the toddlers were required to move together as a group, even if individual children were busy playing. The tensions were evident in the concerns expressed by one of the teachers, Fiona, about challenging the current practices (see Chapter 6).

The most obvious challenge to rights to participate freely was the difficult access to the outdoors. As noted earlier, one of the Crèche supervisors, Harriet, even identified the difficult access as a breach of rights. The threats to participation rights in the Crèche's current physical conditions were extremely high, and potentially jeopardised the infants' and toddlers' learning and development because the conditions constrained physical exploration in a natural, outdoors environment. The infants' space was one large room full of equipment, adults, and infants (birth to 12 months). Opportunities to physically explore were very limited and the short, narrow corridor (with barrier gates across the open doorways) was used daily. Infants crawling to the toddlers' doorway, and peering through the barrier gate was a common sight, and interactions through the wooden bars were encouraged. Occasionally an infant or toddler was lifted over the gates to facilitate and extend an interaction. 
The practices in the Crèche community were imposed by adults, ostensibly to protect children, but, as argued in Chapter 6, actually to suit adults. This illustrated that not all learning in a community is positive; neither are all practices conducive to good practice. The detrimental impacts on children were noted by Fiona and Katrina, but not acted on for fear of upsetting the team. In this community of practice, conflict resolution was undeveloped and children's rights were not supported as well as they might have been. It could be argued that these conflicts could be resolved using the provisions in UNCROC to support changes to the management regime.

The Kindergarten data showed that in contrast to the above, when an environment is purpose-built, it can be managed to maximise options for children. This facility enhanced experiences of group care. The quality of the physical environment was of a higher standard than the regulations required, and the teachers recorded their pride in the gardens, sand pits, and inside areas. Data recorded a respect for children that was reflected by the way teachers cared for the environment and because of this attention to the aesthetics they believed these conditions for learning facilitated children's participation. The Playcentre building also met the regulatory requirements although it was not as well resourced as the Kindergarten. Both facilities had more outside space, and easier access to the outside than the Crèche, which was concerning for some teachers because some children spent over 40 hours a week at the Crèche without regular, daily access to the outdoors.

\section{Wellbeing and belonging}

Bronfenbrenner's (2005a) bioecological theory considers the synergy between the various environments and the attitudes of the participants in those environments. As detailed in all three findings chapters, adults' perceptions of children's rights tended to begin with a focus on children's wellbeing, and on developing a sense of belonging to the community of learners in the case study centres. Attending to children's wellbeing was articulated in terms of Te Whāriki (Ministry of Education, 1996b). The adult participants interpreted wellbeing as a child's right to adult protection to ensure their development. Data in Chapter 6 demonstrate that the younger the child, the greater emphasis there was on health and wellbeing. Teachers in the Crèche, fore-grounded children's protection rights and they constantly shared information about children's emotional and physical wellbeing. While not as pressing an issue in the other case studies, children's wellbeing was a foundation for participating in the centre. 
Closely related to wellbeing was the notion of belonging. The findings show teachers and parents developed a range of strategies to enhance children's sense of belonging based on a perception that belonging led to meaningful participation in the centre. This was interpreted as an ecological concept (Bronfenbrenner \& Morris, 1998). Fostering a sense of belonging engendered respect for the child, for the child's family and community, and for the community of learners the child belonged to as part of the early childhood service. Numerous strategies were used by teachers and parents to establish cultural processes to support children's sense of belonging to transform their participation (Bronfenbrenner, 2005a; Rogoff, 1998, 2003; Rogoff et al., 1995). These strategies encouraged children to participate based on trust that the adults understood them, and their rights.

\section{Respectful, reciprocal relationships}

There was a clear perception amongst all the participants, including children, that children were entitled to respect as individuals, and as part of the group. Once again, teachers used the language of Te Whäriki (Ministry of Education, 1996b) to reiterate the importance of respectful, reciprocal relationships. These values were perceived as underpinning relationships with children. The data from all three settings suggest that 'mutual respect' between adults and children enhanced children's participation in the centres, and built on their sense of belonging. The fact that teachers and parents from all three contexts mentioned 'respect' supports children's rights in several ways. Data from Chapters 6, 7, and 8 revealed different aspects to relationships with children and also illuminated how teachers and children in the different settings understood children's rights.

First, the desire for reciprocal relationships based on respect indicated adults' awareness of the power differences between adults and children (Power et al., 2001). The Crèche teachers were committed to advocating for the infants' and toddlers' rights to protect children's wellbeing and belonging, as well as protecting children's rights per se. At times these teachers felt constrained by a management regime that appeared to compromise their perceptions of children's participation rights. Power differentials between infants, toddlers, and adults were observed and articulated by teachers in this setting. 
Second, the Kindergarten data illustrated how adult-child relationships led to working partnerships. In partnerships, the respective groups, in this case adults and children, have to acknowledge one another's perspectives (Power et al., 2001; Qvarsell, 2005; Rogoff, 1996 et al.). While the roles and responsibilities of the partners may differ, for the relationship to work it is important that children are a) consulted and informed; and b) supported to form and express their views (Smith, 2002). In the Kindergarten, the teachers actively promoted friendship and kindness as a centre-wide strategy that teachers and children alike used to support respectfulness and belonging. Teachers also believed that the strategy enhanced children's rights to participate in the curriculum. Based on trusting relationships, the teachers felt more able to develop working partnerships with children. Observations illustrated how the Kindergarten programme "playing as a good friend" was developed in partnership with children.

Third, one of the most important rights is to respect the rights of others (Lansdown, 2005; New Zealand Human Rights Commission, 2004; UN Committee, 2005). Well-functioning relationships in group settings rely on shared values and commonly understood expectations (Bronfenbrenner, 2005; Rogoff et al., 1993). For example, in the Playcentre, respect for the individual child's view was centrally important; however, different opinions among parents were a source of benign tension. However, drawn together by a respect for the Playcentre's philosophy, and a common desire to support free and spontaneous learning through play, united the community. All three ideas mentioned above empowered children to participate in meaningful interactions with others in their environments, and were based on a respect for children's agency.

\subsection{Contextual differences influenced how rights are implemented or enacted}

As noted above, the data showed that different organisational contexts influenced how rights were enacted. The internal structures of the different settings determined how adults and teachers interacted with children via traditional activities and routines. The three categories of rights are explained in the context of the early childhood settings. 
At Playcentre (see Chapter 7), the adult role was to support and nurture the philosophy of non-interference in a child-centred environment that encouraged free play. Adults provided resources to support this. Provision rights came to the fore and the risks here were to participation rights, and to protection rights. The adults tended to be more responsive to children who proffered ideas for play and more assertive children tended to dominate. Different understandings amongst the parents about the degree to which they initiated play, or interfered with what they perceived were children's agendas, resulted in inconsistent expectations, and constituted a risk to participation rights for some children. Adults' perceptions of rights were constrained by the context where the philosophy of freeplay translated as noninterference in children's play, even when the play breached other children's rights. Rogoff et al. (1996) explain this as a child-centred approach where power is disproportionately distributed in favour of the child.

Different interpretations of what 'child-centred' meant were problematic in the Playcentre parents' community. Sociocultural explanations of the tensions and conflicts (Wenger, 1998) experienced in the community could have assisted parents and children to transform how they participated (Lave \& Wenger, 1991) in the Playcentre. Disagreements about routine events, and even turn-taking, constrained this community's ability to support all children's rights to participate equally. Uncertainty and a lack of confidence in some parents and children were examples of peripheral participation, but to successfully transform the contributions for some Playcentre parents would require more active participation in the community of learners, based on a more explicit shared understanding of how more experienced participants can encourage newer, less confident participants' engagement in everyday practices. The findings suggest that a rights-based pedagogy would strengthen participants' learning through play: Negotiating with one another based on children's rights engenders respect, and protects children's rights to participate in the Playcentre.

The Crèche was arguably the most complex social system (see Chapter 6). It was a service offered in a workplace and had developed its own sense of community, unrelated to its near neighbours. The teachers at the Crèche described their role as advocates for the child. There was an observable tension between the teachers' perceptions of children's rights and their perceptions of children's needs. This 
tension between rights and needs is reflected in the literature (Stainton Rogers, 2004; Walkerdine, 2004; Woodhead, 1997, 2005). This meant they advocated for protecting the child's rights to participate, as well as to protect the child. This study found that teacher advocacy was based on respect for children's rights to participate in the day-to-day life of the Crèche (Chapter 6). Alongside this advocacy role, a major preoccupation was with infants' health and wellbeing. The bottom line for the Crèche teachers was to provide a safe environment that allowed for participation, albeit predominantly adult directed and controlled.

The focus on protection rights in the Crèche affected children's participation rights, although implementing provision rights was also an issue as the centre was constrained by a tight budget and the physical layout of the building. Infants' and toddlers' participation in the daily activities, including the routines, was determined by adults who managed the routines by dealing with the group as a whole. A characteristic of this centre was the constantly changing staff as they arrived and left for breaks, for lunch, and for non-contact times. Rostered breaks were scheduled according to routines, and teachers were observed prioritising their breaks over and above what was happening for children. The tightly managed scheduling had to accommodate up to 12 or 13 staff (including part-timers and casual workers), as well as the children's schedules that, in turn, reflected their parents' schedules. The research revealed how this regime impacted on teaching strategies which focused on teachers' advocacy on behalf of one child to others, teachers' advocacy to management, and teachers' advocacy to parents. The regime was observed to impact directly on how children's rights were experienced in practice. Children and teachers were expected to conform to a rather rigid approach to managing a wide range of expectations, from policy compliance to parental requests.

Chapter 8 illustrated how the Kindergarten operated as a community of learners, sharing power between teachers and children (Rogoff et al., 1996). Curriculum foci were negotiable, but usually decided by teachers based on their pedagogical documentation. Children were aware of the pedagogical practices and were observed requesting teachers to photograph or record events for their portfolios. Routines were agreed to as a group, and children assumed responsibility during the tidy-up times. This developed a sense of responsibility and respect for others. For example, 
children tidying up the sand pit toys expressed concern for younger children, and children were observed directing others to their assigned tidying-up duties.

A central question this research investigated was how rights were enacted. For example, perceptions of rights suggested that children could act responsibly to contribute to the programme. Data revealed that teacher-led strategies, such as routine tidy-up times, were designed to engage children, and create an awareness of respect for others and the environment. The Kindergarten depended on a degree of self-discipline amongst the children, underpinned by the philosophy of being a good friend. Because of the high child to adult ratio (13:1), teachers achieved this by working with children as a group. End-of-session 'mat time' often emphasised appropriate messages about social participation and engagement.

This section describes how different early childhood contexts influenced the ways in which rights were observed and implemented in practice. These data emphasised the relevance of context to practice, a point made by Woodhead (1997). The data also suggested that teachers' perceptions of children's rights adjusted to contextual differences and teachers used a variety of teaching strategies, or philosophical beliefs, appropriate to the particular early childhood services.

\subsection{Protection rights, provision rights, and participation rights are interwoven, interrelated, and interdependent}

Table 8 below illustrates how rights were interpreted in the contexts of the case study centres. In the previous section, findings demonstrated how context appeared to influence the way rights were implemented by fore-grounding one type of right, but this emphasis did not preclude or prevent enactment of other types of rights. Chapters 6, 7, and 8 presented data which show that categories of rights were interwoven, interdependent, and interrelated (refer to Figure 4, p.36, Chapter 2). 
Table 8: Protection, provision, and participation rights are interwoven, interrelated and interdependent

\begin{tabular}{|l|l|l|}
\hline \multicolumn{1}{|c|}{ Free play at Playcentre } & \multicolumn{1}{|c|}{$\begin{array}{c}\text { Advocates for the child at } \\
\text { Crèche }\end{array}$} & \multicolumn{1}{c|}{$\begin{array}{c}\text { Being a good friend at } \\
\text { Kindergarten }\end{array}$} \\
\hline $\begin{array}{l}\text { Provision rights enhance } \\
\text { participation rights }\end{array}$ & $\begin{array}{l}\text { Protection rights enhance } \\
\text { participation rights }\end{array}$ & $\begin{array}{l}\text { Participation rights dependent on } \\
\text { protection and provision rights }\end{array}$ \\
\hline $\begin{array}{l}\text { Community of learners in a local } \\
\text { community }\end{array}$ & $\begin{array}{l}\text { Community of learners external to } \\
\text { the local community }\end{array}$ & $\begin{array}{l}\text { Community of learners alongside a } \\
\text { local community }\end{array}$ \\
\hline $\begin{array}{l}\text { Curriculum child-centred } \\
\text { One shared routine } \\
\text { Adults responsible for routines } \\
\text { Power with the child }\end{array}$ & $\begin{array}{l}\text { Curriculum child-focused } \\
\text { Dominated by rosters and routines } \\
\text { Power with the adults }\end{array}$ & $\begin{array}{l}\text { Curriculum based on children's } \\
\text { interests } \\
\text { Minimal routines, responsibilities } \\
\text { shared } \\
\text { Power shared with children }\end{array}$ \\
\hline $\begin{array}{l}\text { Open access to resources } \\
\text { Focus on individual child }\end{array}$ & $\begin{array}{l}\text { Limited access to resources } \\
\text { Group focus to suit adults }\end{array}$ & $\begin{array}{l}\text { Open access to resources } \\
\text { Group focus on social conditions } \\
\text { and cultural practices }\end{array}$ \\
\hline
\end{tabular}

Provision rights, protection rights, and participation rights were brought to the fore in particular settings, but co-existed alongside other types of rights. This thesis argues that each strand or type of right had unique characteristics, but these were limited if considered in isolation. Data suggested that, arguably, support for children's participation in their early education depended on protecting them, and their rights, and on providing resources to meet obligations to families and, ultimately, to society. The Playcentre context focused on providing certain conditions for learning (Vygotsky, 1978) based on a philosophy of learning through play (Somerset, 1976). Parents provided opportunities and experiences to encourage play in a child-centred community of learners. Connections between perceptions of children's rights to play freely, and in an uninterrupted way, obligated parents to provide resources that facilitated children's participation at Playcentre.

The Crèche teachers assumed the role of advocating for children to protect their health and wellbeing, and to protect their rights to participate in the programme. In this context, the age of the children influenced teachers' perceptions of rights. The context also impacted on how rights were implemented. The environment (which was very challenging) and the management regime exerted constraints on children and teachers, and affected participation rights. As well as the physical challenges the environment presented, access to the outdoor and to the indoor areas was dependent on teacher supply. If no teacher was present, there was no access for children. Data showed that the rationale for this was to protect children, as well as to comply with regulations. In the Kindergarten, there was open access to resources and a group focus on social competence. The well-appointed, purpose-built environment was 
observed to enhance participation in Kindergarten activities. Children were safe from harm (protected), and well provided for.

In the teacher-led settings (the Kindergarten and the Crèche) there was an observed awareness of how a community of learners acted to support the cultural processes of the services. In the Kindergarten this depended on teachers inducting children into the culture of being a good friend though strategies like brainstorming what that meant, and reading children numerous books about sharing and being kind; in the Crèche, the teachers emphasised belonging to the group via routine events. Acting as a group (community of learners) was observed to be essential to the smooth running of the programme, and disagreements amongst staff were muted in the interests of facilitating current practices. At times, teachers observed how their practices could undermine children's participation rights. In the Playcentre context, notions of community were not restricted to the setting. The Playcentre was an active and visible member of a wider community. However, the notion of a community of learners was not explored by the Playcentre parents and that meant individual children's rights were attended to more than group rights. Mild adult dissension and uncertainty about how to intervene, or how to support learning and development of the individual, at times curtailed other children's participation rights.

The four themes discussed so far were connected conceptually. Advocating for children's protection rights included their right to express themselves, arguably a participation right. Providing for children's play supported them to participate in a protected, adult-constructed environment. Articulating social and cultural expectations of community members also supported children's rights to participate in a well-resourced setting. In other words, categories of rights were useful for interpreting this research and, as such, illustrated how different contexts influenced how rights were both perceived and implemented. The evidence discussed thus far in this chapter supports the notion of the plait first introduced in Chapter 2 as a useful metaphor to explain how categories of rights were intertwined constructs in the study centres (Figure 15). 


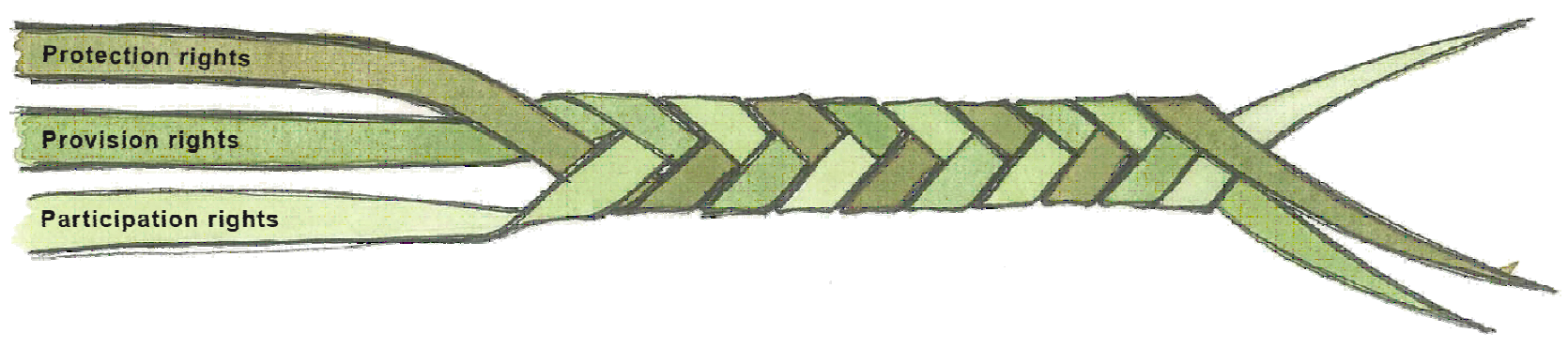

Figure 15: Protection rights, provision rights, and participation rights are interwoven, interrelated, and interdependent

The next section presents the notion of a rights-based pedagogy as a way to progress the implementation of children's rights in the New Zealand early childhood sector.

\subsection{Developing a rights-based pedagogy: Implications for future research}

This research suggests a new pedogogy as the way forward to move from descriptive accounts to more substantive, theoretically-based pedagogical practices. The four themes discussed in the previous sections established the following: Children's rights exist in the context of particular early childhood settings; these contexts were influenced by teachers' and parents' perceptions of children's rights; the service type also influenced how rights for children were implemented; and provision rights, protection rights, and participation rights were interwoven, interrelated, and interdependent in particular early childhood education settings.

The key questions driving this research aimed to investigate perceptions of children's rights, and to observe how these perceptions were enacted in the three early childhood settings. Important questions emerged from these lines of inquiry. For example, on whose terms do children participate? Whose choices are they selecting from? How can children influence these choices? To what extent are children involved in setting the structure of the day? Ultimately these questions are about power and how it is shared, and these are questions for future research.

Researchers (Hart, 1992, 1997; Lundy, 2007; Shier, 2001) have argued convincingly that merely seeking a viewpoint does not go far enough to promote children's rights. Notions of voice, listening, and hearing imply more than simply consulting with 
children. Dialogue acknowledges that "children and young people want and have a right to a share of the action. This means there needs to be a sharing of power" (Cairns, 2001, p. 359). Therein lies the complex nature of listening. While the 'seen and not heard' era has passed, there are numerous occasions when children are expected to learn by being seen and not heard. In this study, data revealed there was no disputing the child's right to be listened to and heard, but how children's contributions (or opinions) were recognised and authentically integrated into early childhood settings remained in question. On whose terms did children participate? An implication of the findings is that promoting an awareness of rights might provide a key to developing a rights-based pedagogy. The findings also indicate that while rights-based constructs were not widely used or discussed, participants were aware of children's rights and these constructs were underpinned by professional practices; for example, using Te Whāriki, (Ministry of Education, 1996b) and Learning Stories (Ministry of Education, 2005). This is an advantage of promoting a deeper understanding about children's rights.

Arguably, empowering children to realise their rights is challenging. Participation rights mean that children are "active [participants] in the formation of their own [early childhood education] experience" (Fisher, 2002, p. 129). How participation rights are understood influences the ways in which they are implemented. In this study some participants' perceptions of children's needs were, at times, interchanged with perceptions of children's rights. Further, exploration of the rights undertaken in this study encourages reflection on the implications of these terms. Does a child's need equate with a right? If so, who is accountable? Is a child's need the same as neediness, and does having needs mean having fewer rights? Alanen (2001) highlights how children's needs are used to excuse those in positions of responsibility from respecting children's rights.

Some researchers (for example, Dahlberg et al., 2000, 2007; Mayall, 2000a,) argue that situating play within childhood further marginalises children from adults; and diminishes their status as moral beings. Play and playfulness have long been associated with childhood innocence and freedom from responsibility, an argument which is often used against children having rights; because children play, their views do not need to be considered seriously. Childhood innocence and playfulness are relegated to the realm of domesticity and, therefore, children lack the political 
wherewithal to be rights holders (see for example, Federle, 1994; Holt, 1975; Mayall, 2000a). Children's vulnerability, inexperience, and incompetence are similarly cited as reasons for children to have only limited rights (see Freeman, 2007; Guggenheim, 2005). Early childhood settings rely on adults to establish safe, appropriate social environments. Participation is harder to achieve: Prout (2003, p. 21) wrote "unfortunately children's participation is a subject high in rhetoric but sometimes low in practical application." Mayall (2000, p. 257) noted "adult input rather than child agency are at the forefront of these visions". At a macro level, policy documents espouse the rhetoric of rights (Ministry of Education, 1996a, 1998, 2002; Ministry of Social Development, 2002) but at the micro level, enactment of policy intentions is not necessarily reflective of the rhetoric.

\section{Te Whāriki and UNCROC: Supporting children's rights}

All the adult participants believed children had rights, but these were not articulated with any reference to UNCROC. Rather, adult participants used the language of Te Whäriki (Ministry of Education, 1996b) to identify and describe their perceptions of children's rights (see Chapter 5, Section 5.9). The principles and strands of $T e$ Whäriki reflect the value of children's participation in society. Holistic in design, the curriculum framework integrates notions of empowerment, family, and community, and relationships with dispositional attributes associated with belonging, wellbeing, exploring, communicating, and contributing.

The aspiration of Te Whäriki (Ministry of Education, 1996b) is for children to contribute to a socially just society which is tolerant of diversity (Te One, 2003). Professional development resources, like the self-review guidelines for early childhood services and the early childhood assessment exemplars (Ministry of Education, 2005, 2006) introduced since Te Whäriki, highlight children's competence and capability, and support them as active partners in their own early educational experiences (Carr et al., 2003, Carr et al., 2004; Podmore et al., 2001). This aspiration closely aligns with Archard's (1993) perception that a) children have a right to know they have rights, and b) that these rights exist in the public realm. The early childhood centre is one of the first public educational institutions a child encounters. The onus is on teachers and parents in whānau-led services to educate children about their rights through practices appropriate to context (Woodhead, 1997). Therefore it is important that early childhood teachers and parents in whānau- 
led early childhood services recognise children as rights holders. This implies that adults must have, on some level, engaged with firstly, understanding children's rights, and secondly, how to implement or enact these rights. For example, an issue facing early childhood practitioners is how to respect the rights of an individual child together with the rights of all children in a group setting. Further research could shed some insights into how best to support the adults working with children to do this.

Te Whāriki's (Ministry of Education, 1996b) open-weave framework is conceptually consistent with the three categories of rights explored in this thesis. Kei tua o te Pae (Ministry of Education, 2005) provides numerous exemplars of 'the child's voice' in assessment. This resource extends the notion of assessment as part of curriculum (Ministry of Education, 1996b, 2005) and is evidence of respect for children's participation rights in their early educational experiences. Including children's perspectives on their learning supports children's participation rights. Evidence in this thesis (Chapter 6 and 7) suggests that more could be done to enhance respect for children's rights to voice their perspectives and hence suggests that conscientisation (Freire, 1993) is important.

Despite participants' relatively superficial knowledge of UNCROC, children's rights were considered extremely relevant to the principles of good practice, and were, more often than not, absorbed into the discourses of Te Whāriki (Ministry of Education, 1996b). In particular, the strands of wellbeing and belonging were commonly linked to children's rights, but other strands, such as communication, exploration, and contribution, were not mentioned in relation to children's rights, yet these strands are reflective of rights. However, just as "it has not been easy for educators to appreciate the complexity of Te Whäriki, or to take the more proactive teaching role envisaged by its sociocultural philosophy" (Anning, Cullen, \& Fleer, 2008 , p. 20), the adult participants in this study had not yet begun to appreciate the possibilities of UNCROC, let alone the complexities of children's rights discourses. Figure 16 depicts the categories of rights alongside the principles of Te Whāriki to illustrate how these are interwoven and interrelated, and how they might be used to affect pedagogical change. 


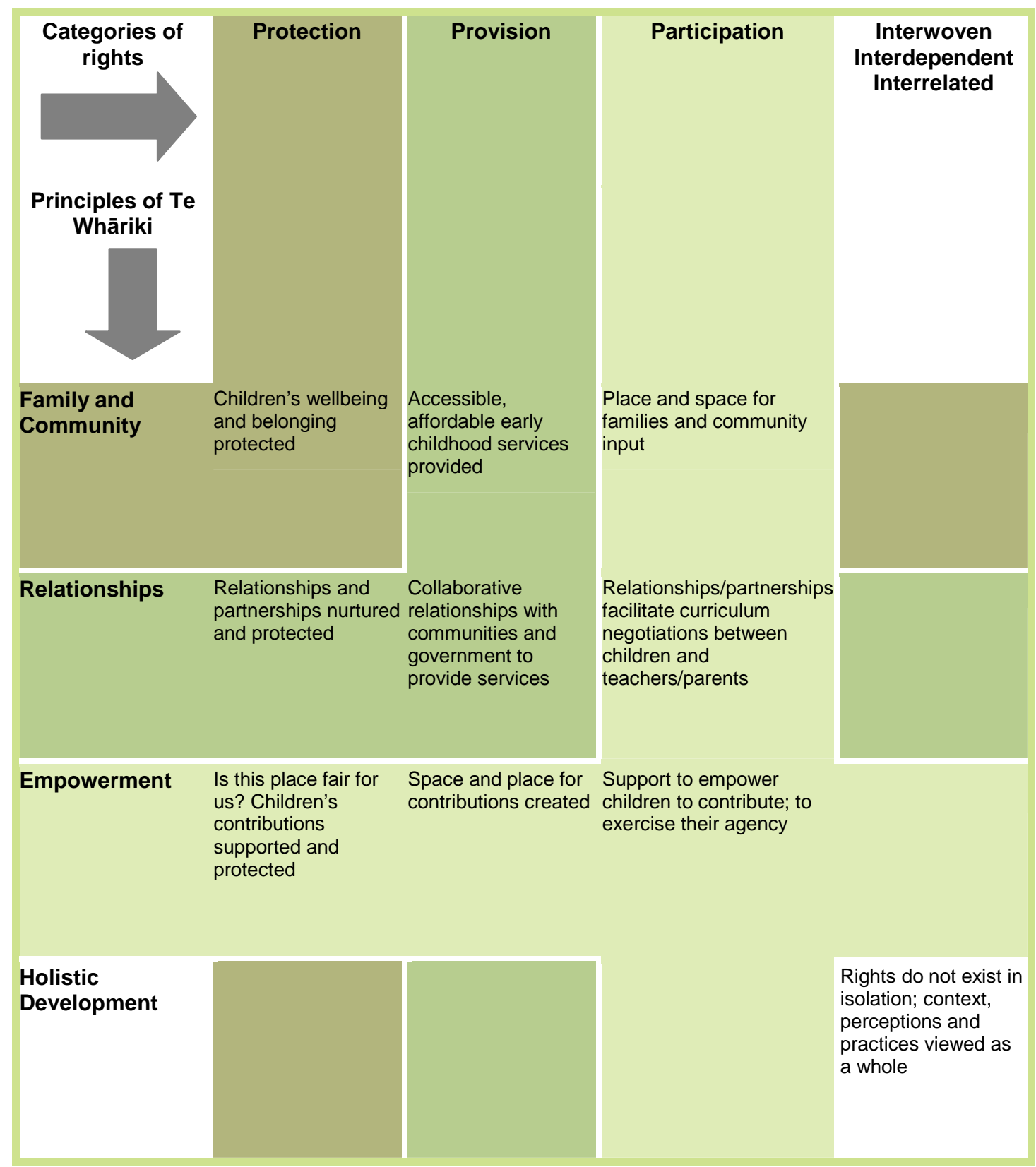

Figure 16: Categories of rights and the principles of Te Whāriki

In the case of children's rights, and associated theories, teachers' knowledge base and professional skills are relatively unknown. Teacher education and professional development providers could justify incorporating UNCROC into their programmes. This would be achievable because:

a) the principles and strands of Te Whäriki are easily identifiable as rights-based;

b) UNCROC, as a baseline for education, meets international obligations for compliance with the UN Committee; and

c) this study has identified how current early childhood theories interweave with key concepts from UNCROC and from sociological disciplines. 
The New Zealand Human Right Commission (2004) began this process, and cites Te Whāriki (Ministry of Education, 1996b) as an exemplar for building sustainable rights-based communities. The Human Rights in Education Initiative (2008) has continued the process with a specific focus on how to include human rights (and children's rights) in the school curriculum and in the early childhood curriculum. This initiative aims to develop a children's rights-based pedagogical approach for teachers and parents working in early education using a Web-based resource where exemplars and resources can be shared. A barrier to extending this has been a lack of understanding about the relevance of human rights as more than just a social studies subject. "Teaching children and teachers about human rights, and children's rights can change the cultural climate of a school community" (Simpson, 2009, personal communication). The challenge is now to examine more closely, and widely, how children's rights are understood in practice in early childhood, other educational sectors, and beyond, in society. The starting point should be a discussion on respecting the rights of others, which implies a role for adults to support children to form a point of view, and express this appropriately. Combining UNCROC, notably General Comment 7 (UN Committee, 2005) with Te Whäriki (Ministry of Education, 1996b) provides legitimate support for such discussion as pedagogically sound and theoretically viable. Professional development programmes in New Zealand could easily incorporate these ideas, and promote them as part of existing quality review systems.

Parents and teachers have a responsibility to ensure children's rights to development are protected and provided for, and that children are supported to participate in meaningful ways conducive to learning. States parties also have an obligation to ensure that parents and teachers can implement these rights (Article 18, CRIN, 2007, p. 7). While sociocultural theories do not specifically mention protection rights or provision rights, they do focus on conditions for learning (Rogoff, 2003, 2007; Vygotsky, 1978). If children are unprotected, or if conditions for learning are not adequately provided, children's ability to participate (develop) is at risk (Article 29, CRIN, p. 13; Verhellen, 2001). Therefore, conditions for learning have to support conditions for development. Children have a right to expect that their emerging competencies and capacities will be protected and provided for as they actively engage in their education. 
Implementing children's rights should improve conditions for children. There exists a raft of protective, quality control measures for the provision of early childhood services (Ministry of Education, 1996a, 1996b, 1998, 2002, 2005, 2006; Te One, 2004, 2005, 2006). These provisions promote and protect children's rights as well as encourage participation in early childhood services beyond enrolment. To effectively evaluate children's participation in early education requires teachers and parents in whānau-led services to do more than just listening and hearing. Based on respect for children's agency, participation means sharing the power, and inviting children to contribute, or co-construct (Jordan, 2004). Children also have a right to information (Alderson, 2000, 2002; Smith, 2007a). The extent to which this happened in the centres observed varied considerably - arguably because of the age of the children in the Crèche (under two); because of the large numbers of children in the Kindergarten (on average 41-43 children per session); and because of team supervision in the Playcentre (different parents for each session).

This study has shown that more could be done to investigate more specifically how, if at all, teachers and parents in whānau-led services uphold children's rights. More qualitative research about the effect of policies intended to enhance quality, provision, and participation is also needed to investigate young children's rights in a wider, cross-sectoral study. Such a study could lead to a better understanding about how children's rights and education intersect.

Many agencies have an interest in young children and support children's participation in matters that concern them. Theses about rights, childhood sociology, and theories of human development strengthen awareness of children's rights and children's experience of their rights. The adult participants in this research did not expressly teach children about their rights; however, teachers (in the Crèche and Kindergarten) and parents (in the Playcentre) believed they supported children, and by implication children's rights, by providing for free play, advocating on children's behalf, and supporting a culture of friendship. Research to deepen understanding of how theories and practices enhance children's rights would benefit children, policy makers, and teachers.

Teachers and adults working with young children need to examine more closely what participation rights mean for children and for those working with them in early 
education in New Zealand. Discussion about children's entitlements should be followed by further discussion and even debate about how rights are implemented and enacted. This thesis proposes that we move forward from a cosy perception of rights (Lundy, 2007), derived largely from discourses about Te Whāriki (Ministry of Education, 1996b), to seriously consider how to implement children's rights in early childhood education. 


\section{References}

Action for Children and Youth Aotearoa. (2003). Children and youth in Aotearoa 2003: The second non-governmental organisations' report from Aotearoa New Zealand to the United Nations Committee on the Rights of the Child. Wellington: Author.

Action for Children and Youth Aotearoa. (2008). ACYA submission to the Universal Periodic Review [Electronic Version]. Retrieved March 2, 2009, from www.acya.org.nz

Alanen, L. (2001). Explorations in generational analysis. In L. Alanen \& B. Mayall (Eds.), Conceptualizing child-adult relations (pp. 11-22). London: Routledge Falmer.

Alcock, S. A. (2005). Sociocultural interpretations of young children's playful and humorous communication. Unpublished $\mathrm{PhD}$ thesis, Massey University, Palmerston North.

Alderson, P. (2000). Children's rights: Exploring beliefs, principles and practices. London: Jessica Kingsley.

Alderson, P. (2002). Are younger children being sidelined in the child's rights movement? International Children's Rights Monitor, 15(3), 18-20.

Alderson, P. (2004). Ethics. In S. Fraser, S. Lewis, S. Ding, M. Kellet, \& C. Robinson (Eds.), Doing research with children and young people (pp. 97112). London: Sage.

Alderson, P., Hawthorne, J., \& Killen, M. (2005). The participation rights of premature babies. The International Journal of Children's Rights, 13(1), 3150 .

Alexander, G. (1995). Children's rights in their early years. From plaiting fog to knitting treacle. In B. Franklin (Ed.), The handbook of children's rights: Comparative policy and practice (pp. 131-146). London: Routledge.

Almog, S., \& Bendor, A. L. (2004). The UN Convention on the Rights of the Child meets the American Constitution: Towards a supreme law of the world. International Journal of Children's Rights, 11, 273-289.

Alston, P. (1994a). The best interests principle: Towards a reconciliation of culture of human rights. In P. Alston (Ed.), The best interests of the child: Reconciling culture and human rights (pp. 1-25). Oxford: UNICEF International Child Development Centre.

Alston, P. (Ed.). (1994b). The best interests of the child. Reconciling culture and human rights. Oxford: Clarendon Press.

Alston, P., Tobin, J., \& Darrow, M. (2005). Laying the foundations for children's rights: An independent study of some key legal and institutional aspects of the impact of the Convention on the Rights of the Child. Florence, Italy: UNICEF Innocenti Research Centre.

Altheide, D. L., \& Johnson, J. M. (1994). Criteria for assessing interpretive validity in qualitative research. In N. K. Denzin \& Y. S. Lincoln (Eds.), Handbook of qualitative research (pp. 485-499). Thousand Oaks, CA: Sage.

Amnesty International (NZ), Development Resource Centre, Human Rights Commission, Office of the Commissioner for Children, \& Peace Foundation. (2007). Building human rights communities in education: He whakatū tika tangata-a-iwi whānui. Wellington: Human Rights Commission. 
Anderson-Levitt, K. M. (2006). Ethnography. In J. L. Green, G. Camilli, \& P. B. Elmore (Eds.), Handbook of complementary methods in education research (pp. 279295). Mahwah, NJ: Lawrence Erlbaum.

Anning, A., Cullen, J., \& Fleer, M. (2008). Research contexts across cultures. In A. Anning, J. Cullen, \& M. Fleer (Eds.), Early childhood education: Society and culture (pp. 1-19). London: Sage.

Archard, D. (1993). Children: Rights and childhood. London: Routledge.

Aries, P. (1962). Centuries of childhood: A social history of family life. New York: Vintage.

Atkinson, P., \& Delamont, S. (2005). Analytic perspectives. In N. K. Denzin \& Y. S. Lincoln (Eds.), The Sage handbook of qualitative research (pp. 821-836). London: Sage.

Atkinson, P., \& Hammersley, M. (1998). Ethnography and participant observation. In N. K. Denzin \& Y. S. Lincoln (Eds.), Strategies of qualitative inquiry (pp. 110-136). Thousand Oaks, CA: Sage.

Aubrey, C., David, T., Godfrey, R., \& Thompson, L. (2000). Early childhood educational research: Issues in methodology and ethics. London: RoutledgeFalmer.

Babour, R. S., \& Schostak, J. (2005). Interviewing and focus groups. In B. Somekh \& C. Lewin (Eds.), Research methods in the social sciences (pp. 41-48). London: Sage.

Bartel, V. B. (2005). Learning communities: Beliefs embedded in content-based rituals. Early Childhood Education Journal, 33(3), 151-154.

Basit, T. N. (2003). Manual or electronic? The role of coding in qualitative data analysis. Educational Research, 45(2), 143-154.

Bein, E. S., Vlasova, T. A., Levina, R. E., Morozova, N. G., \& Shif, Z. I. (1993). Afterword (J. Knox \& C. B. Stevens, Trans.). In R. W. Reiber \& A. S. Carton (Eds.), The collected works of L. S. Vygotsky: Volume 2 The fundamentals of defectology (Abnormal psychology and learning disabilities) (pp. 302-314). New York: Plenum Press.

Belgrave, M., Blaiklock, A., Davenport, E., Hassell, I., Kiro, C., \& Low, W. (2002). When the invisible hand rocks the cradle: New Zealand children in a time of change (Vol. 93). Florence, Italy: Innocenti Research Centre.

Bentley, K. A. (2005). Can there be any universal children's rights? International Journal of Human Rights, 9(1), 107-123.

Benzie, D., Mavers, D., Somekh, B., \& Cisneros-Cohernour, E. J. (2005). Communities of practice. In B. Somekh \& C. Lewin (Eds.), Research methods in the social sciences (pp. 180-187). London: Sage.

Berg, B. L. (2007). Qualitative research methods for the social sciences $\left(6^{\text {th }}\right.$ ed.). Boston: Pearson Education.

Berger, P., \& Berger, B. (1991). Becoming a member of society - socialization. In F. C. Waksler (Ed.), Studying the social worlds of children: Sociological readings (pp. 3-11). London: Falmer Press.

Berk, L. E., \& Winsler, A. (1995). Scaffolding children's learning: Vygotsky and early childhood education (Vol. 7). Washington: NAEYC.

Bishop, R. (1996). Collaborative research stories: Whakawhanaungatanga. Palmerston North: Dunmore Press.

Bishop, R., \& Glynn, T. (1999). Culture counts: Changing power relations in education. Palmerston North: Dunmore Press.

Blaiklock, A. J. (1999, September). Seen and not heard? The place of children and young people in Aotearoa New Zealand. Paper presented at the Seventh Early Childhood Convention, Nelson. 
Bloch, M. N. (1992). Critical perspectives on the historical relationship between child development and early childhood education research. In S. Kessler \& B. B. Swadener (Eds.), Reconceptualizing the early childhood curriculum: Beginning the dialogue (pp. 3-20). New York: Teachers College, Columbia University.

Bloor, M., Frankland, J., Thomas, M., \& Robson, K. (2001). Focus groups in social research. London: Sage.

Bodrova, E., \& Leong, D. J. (2005). High quality preschool programs: What would Vygotsky say? Early Education and Development, 16(4), 435-443.

Borman, K. M., Clarke, C., Cotner, B., \& Lee, R. (2006). Cross-case analysis. In J. L. Green, G. Camilli, \& P. B. Elmore (Eds.), Handbook of complementary methods in education research (pp. 123-140). Mahwah, NJ: Lawrence Erlbaum.

Boston, J., Dalziel, P., \& St John, S. (Eds.). (1999). Redesigning the welfare state in New Zealand: Problems, policies, prospects. Auckland: Oxford University Press.

Brennan, M. A. (2005). "They just want to be with us." Young children learning to live the culture: A post-Vygotskian analysis of young children's enculturation into a childcare centre. Unpublished $\mathrm{PhD}$ thesis, Victoria University of Wellington, Wellington.

Bronfenbrenner, U. (1970). Two worlds of childhood: US and USSR. New York: Russel Sage Foundation.

Bronfenbrenner, U. (1979). The ecology of human development. Experiments by nature and design. Cambridge, MA: Harvard University Press.

Bronfenbrenner, U. (1995a). The bioecological model from a life course perspective: Reflections of a participant observer. In P. Moen, G. H. J. Elder, \& K. Lusher (Eds.), Examining lives in context: Perspectives on the ecology of human development (pp. 559-618). Washington, DC: American Psychological Association.

Bronfenbrenner, U. (1995b). Developmental ecology through space and time: A future perspective. In P. Moen, G. H. J. Elder, \& K. Lusher (Eds.), Examining lives in context: Perspectives on the ecology of human development (pp. 619647). Washington, DC: American Psychological Association.

Bronfenbrenner, U. (2005a). Ecological systems theory. In U. Bronfenbrenner (Ed.), Making human beings human: Bioecological perspectives on human development (pp. 106-173). Thousand Oaks, CA: Sage.

Bronfenbrenner, U. (2005b). Minority report of forum 15: 1970 White House Conference on Children. Report to the President: Child development recommendations. In U. Bronfenbrenner (Ed.), Making human beings human: Bioecological perspectives on human development (pp. 210-214). Thousand Oaks, CA: Sage.

Bronfenbrenner, U. (2005c). The social ecology of human development. In U. Bronfenbrenner (Ed.), Making human beings human. Bioecological perspectives on human development (pp. 113-123). Thousand Oaks, CA: Sage.

Bronfenbrenner, U. (Ed.). (2005d). Making human beings human: Bioecological perspectives on human development. Thousand Oaks, CA: Sage.

Bronfenbrenner, U., \& Morris, P. A. (1998). The ecology of developmental processes. In R. M. Lerner (Ed.), Theoretical models of human development ( $5^{\text {th }}$ ed., Vol. 1, pp. 993-1028). New York: John Wiley.

Brown, B. (2001). Combating discrimination: Persona dolls in action. Stoke on Trent, UK: Trentham Books. 
Cairns, L. (2001). Investing in children: Learning how to promote the rights of all children. Children and Society, 15, 347-360.

Callister, P., Podmore, V. N., Galtry, J., \& Sawicka, T. (1995). Striking a balance: Families, work, and early childhood education. Wellington: New Zealand Council for Educational Research.

Campbell, S., \& Smith, K. (2001). Equity observation and images of fairness in childhood. In S. Greishaber \& G. S. Cannella (Eds.), Embracing identities in early childhood education: Diversity and possibilities (pp. 89-102). New York: Teachers' College Press.

Canadian Child Care Federation. (2006, September). To speak, participate and decide: The child's right to be heard. Paper presented at the United Nations Day of General Discussion on the child's right to be heard. Geneva

Cannella, G. (2005). Reconceptualising the field (of early care and education). If 'western' child development is the problem, then what do we do? In N. Yelland (Ed.), Critical issues in early childhood education (pp. 17-39). Maidenhead: Oxford University Press.

Cannella, G. (Ed.). (1997). Deconstructing early childhood education: Social justice and revolution. New York: Peter Lang.

Carr, M. (2000). Seeking children's perspectives about their learning. In A. B. Smith, N. J. Taylor, \& M. M. Gollop (Eds.), Children's voices: Research, policy and practice (pp. 37-55). Auckland: Pearson Education.

Carr, M. (2001). Assessment in early childhood settings: Learning stories. London: Paul Chapman.

Carr, M. (2003, December). Changing the lens: Keynote address to the AARE/NZARE. Paper presented at the AARE/NZARE, Auckland.

Carr, M., Hatherly, A., Lee, W., \& Ramsey, K. (2003). Te Whāriki and assessment: A case study of teacher change. In J. Nuttall (Ed.), Weaving Te Whāriki: Aoteoroa New Zealand's early childhood curriculum document in theory and practice (pp. 187-214). Wellington: New Zealand Council for Educational Research.

Carr, M., Lee, W., \& Jones, C. (2004). Children's contributions to their own assessment: Assessment for learning exemplars. Wellington: Learning Media.

Carr, M., May, H., \& Podmore, V. N. (1998). Learning and teaching stories: New approaches to assessment and evaluation in relation to Te Whāriki. Wellington: Institute for Early Childhood Studies.

Carr, M., May, H., \& Podmore, V. N. (2002). Learning and teaching stories: Action research on evaluation in early childhood in Aotearoa-New Zealand. European Early Childhood Research Journal, 10(2), 115-125.

Casas, F., Saporiti, A., Gonzales, M., Figuer, C., Rostan, C., Sadurni, M., et al. (2006). Children's rights from the point of view of children, their parents and their teachers: A comparative study between Catalonia (Spain) and Il Molise (Italy). International Journal of Children's Rights, 14, 1-75.

Castle, C. (2000). For every child. London: Red Fox with UNICEF, Random House Children's Books.

Chaiklin, S., \& J. Lave. (Eds.) (1996). Understanding practice: perspectives on activity and context. Cambridge, UK: Cambridge University Press.

Child Poverty Action Group. (2003). Our children: The priority, for policy (No. 2). Auckland: Author.

Child Rights Information Network. (2007). Convention on the Rights of the Child [Electronic Version]. Children's Rights Information Network, 1-22. Retrieved June 25, 2007, from http://www.crin.org/docs/resources/treaties/uncrc.asp 
Christensen, P. (2004). Children's participation in ethnographic research: Issues of power and representation. Children and Society, 18, 165-176.

Christensen, P., \& James, A. (Eds.). (2000). Research with children: Perspectives and practices. London: Falmer Press.

Clark, A., \& Moss, P. (2001). Listening to young children: The Mosaic approach. London: National Children's Bureau and the Joseph Rowantree Foundation.

Coady, M. M. (1996). Reflection on children's rights. In K. Funder (Ed.), Citizen child: Australian law and children's rights (pp. 11-32). Victoria: Australian Institute of Family Studies.

Coffey, A., \& Atkinson, P. (1996). Making sense of qualitative data: Complementary research strategies. Thousand Oaks, CA: Sage.

Colley, H., James, D., \& Diment, K. (2007). Unbecoming teachers: Towards a more dynamic notion of professional participation. Journal of Education Policy, 22(2), 173-193.

Connolly, M., \& Doolan, M. (2007). Lives cut short: Child death by maltreatment. Wellington: Dunmore Publications for the Office of the Children's Commissioner.

Corsaro, W. A. (1997). The sociology of childhood. Thousand Oaks, CA: Pine Forge Press.

Corsaro, W. A. (1999). Preadolescent peer cultures. In M. Woodhead, D. Faulkner, \& K. Littleton (Eds.), Making sense of social development (pp. 27-50). London: Routledge/The Open University.

Corsaro, W. A. (2003). We're friends, right? Washington, DC: Joseph Henry Press.

Corsaro, W. A., \& Molinari, L. (2000). Entering and observing in children's worlds: A reflection on a longitudinal ethnography of early education in Italy. In P. Christensen \& A. James (Eds.), Research with children (pp. 179-200). London: Falmer Press.

Creswell, J. W. (1998). Qualitative inquiry and research design: Choosing among five traditions. Thousand Oaks, CA: Sage.

Cullen, J. (2003). The challenge of Te Whāriki. In J. Nuttall (Ed.), Weaving Te Whäriki: Aotearoa New Zealand's early childhood curriculum document in theory and practice (pp. 269-296). Wellington: New Zealand Council for Educational Research.

Cullen, J. (2004). Adults co-constructing professional knowledge. In A. Anning, J. Cullen, \& M. Fleer (Eds.), Early childhood education: Society and culture (pp. 69-79). London: Sage.

Cullen, J., Hedges, H., \& Bone, J. (2005). Planning, undertaking and disseminating research in early childhood settings: An ethical framework [Electronic Version]. Retrieved March 30, 2006, from <www.childforum.com/publication_details.asp ?REF_NO=1

Cunningham, H. (1995). Children and childhood in Western society since 1500. London: Harlow.

Dahlberg, G. (2000, September). Early childhood pedagogy in a changing world. Paper presented at the Policy, Practice and Politics, NZEI early childhood millennium conference, Wellington.

Dalhberg, G., \& Moss, P. (2005). Ethics and politics in early childhood education. London: RoutledgeFalmer.

Dahlberg, G., Moss, P., \& Pence, A. (2007). Beyond quality in early childhood education and care: Languages of evaluation ( $2^{\text {nd }}$ ed.). London: Routledge.

Dalli, C. (2002, March). Early childhood policy in New Zealand: Stories of sector collaborative action in the 1990s. Paper presented at the Country Seminar for Education International, Wellington. 
Dalli, C. (2006). Re-visioning love and care in early childhood: Constructing the future of our profession. New Zealand Journal of Infant and Toddler Education, 8(1), 5-11.

Dalli, C., \& Te One, S. (2002). Early childhood education in 2002: Pathways to the future. New Zealand Annual Review of Education, 12, 177-202.

Daniel, P., \& Ivatts, J. (1998). Children and social policy. Basingstoke: Macmillan.

Davidson, C., \& Tolich, M. (Eds.). (2003). Social science research in New Zealand: Many paths to understanding ( $2^{\text {nd }}$ ed.). Auckland: Pearson Education.

Davis, J. M. (1998). Understanding the meanings of children: A reflexive process. Children and Society, 12, 325-335.

De Visscher, S., \& Bouverne-De Bie, M. (2008). Children's presence in the neighbourhood: A social-pedagogical perspective. Children and Society, $22(6), 470-481$.

Delamont, S. (1992). Fieldwork in educational settings: Methods, pitfalls and perspectives. London: Falmer Press.

Densem, A., \& Chapman, B. (2000). Learning together: The playcentre way. Auckland: New Zealand Playcentre Federation.

Denzin, N. K. (2001). Strategies of multiple triangulation. In C. F. Conrad, H. J. G. Lattuca, \& L. R. Lattuca (Eds.), Qualitative research in higher education: Expanding perspectives ( $2^{\text {nd }}$ ed., pp. 317-327). Boston: Pearson Custom.

Denzin, N. K., \& Lincoln, Y. S. (1998). Entering the field of qualitative research. In N. K. Denzin \& Y. S. Lincoln (Eds.), Strategies of qualitative inquiry (pp. 134). Thousand Oaks, CA: Sage.

Denzin, N. K., \& Lincoln, Y. S. (2005). Introduction: The discipline and practice of qualitative research. In N. K. Denzin \& Y. S. Lincoln (Eds.), The Sage handbook of qualitative research $\left(3^{\text {rd }}\right.$ ed., pp. 1-32). Thousand Oaks, CA: Sage.

Department of Education. (1988). Education to be more: Report of the early childhood care and education working group. Wellington: Government Print.

Derman-Sparks \& the A.B.C. Task Force. (1989). Anti-bias curriculum: Tools for empowering young children. Washington, DC: National Association for the Education of Young Children.

Dixon, R., Widdowson, D., Meagher-Lundberg, P., Airini, \& McMurchy-Pilkington, C. (2007). Evaluation of promoting early childhood education (ECE) participation project [Electronic Version]. Retrieved March 20, 2009, from http://www.educationcounts.govt.nz/publications/ece/11760

Duncanson, M. (2006). Child deaths and serious injury as a result of assault in Sweden and New Zealand [Electronic Version], 4. Retrieved May 5, 2008, from http://www.occ.org.nz/childcomm/resources_links/reports_publications

Dunne, J. (2006). Childhood and citizenship: A conversation across modernity. European Early Childhood Education Research Journal, 14(1), 5-19.

Early Childhood Education Project. (1996). Future directions: Early childhood education in New Zealand. Wellington: NZEI Te Riu Roa.

Early Childhood Long Term Strategic Plan Working Group. (2001). Final report of the strategic plan working group to the Minister of Education. Wellington: Ministry of Education.

Easton, B. (1980). The economic needs and rights of children. Paper presented at the Social Policy and the Rights of the Child Symposium. In Proceedings of the third social policy symposium, Dunedin, 26-29 November, 1979.

Eder, D., \& Fingerson, L. (2003). Interviewing children and adolescents. In J. A. Holstein \& J. F. Gubrium (Eds.), Inside interviewing: New lenses, new concerns (pp. 33-53). Thousand Oaks, CA: Sage. 
Education Counts. (2008). Licensed services and licence-exempt groups 2007. Retrieved February 28, 2008, from http://www.educationcounts.govt.nz/statistics/ ece/ece_staff_return/licensed_services_and_licence-exempt_groups/17812

Eekelaar, J. (1992). The emergence of children's rights. In H. D. Krause (Ed.), Child law: Parent, child and state (pp. 37-58). Aldershot: Dartmouth.

Einarsdottir, J. (2005). We can decide what to play! Children's perceptions of quality in an Icelandic playschool. Early Education and Development, 16(4), 469-488.

Elam, P. (2005). To teach as Magda taught or mutual respect and trust: The role of the mentor in RIE. In S. Petrie \& S. Owen (Eds.), Authentic relationships in group care for infants and toddlers: Resources for infant educarers (RIE): Principles into practice (pp. 113-126). Philadelphia: Jessica Kingsley.

Else, A., \& Bishop, B. (2003). Occupational patterns of employment: New Zealand women: An analysis of the 2001 census data. A report prepared for the Ministry of Women's Affairs. Wellington: Ministry of Women's Affairs.

Erikson, M. F. (2001). Status and prospects: Concluding perspectives. In S. N. Hart, C. P. Cohen, M. F. Erikson, \& M. Flekkoy (Eds.), Children's rights in education (pp. 216-229). London: Jessica Kingsley.

Farson, R. (1974). Birthrights. London: Collier Macmillan.

Fattore, T., Mason, J., with Sidoti, C. (2005). Working seriously towards new partnerships. In J. Mason \& T. Fattore (Eds.), Children taken seriously: In theory, policy and practice (Vol. 12, pp. 15-27). London: Jessica Kingsley.

Federle, K. H. (1994). Rights flow downhill. The International Journal of Children's Rights, 2, 343-368.

Fennimore, B. (1989). Childhood advocacy for early childhood educators. New York: Teachers' College Press.

Fisher, J. (2002). Starting from the child? Teaching and learning from 3-8 (2 $2^{\text {nd }}$ ed.). Buckingham: Open University Press.

Fleer, M. (2003). Early childhood education as an evolving 'community of practice' or as lived 'social reproduction': Researching the 'taken-for-granted'. Contemporary Issues in Early Childhood, 4(1), 220-235.

Fleer, M., \& Richardson, C. (2004). Moving from a constructivist-developmental framework for planning to a sociocultural approach: Foregrounding the tension between individual and community. Journal of Australian Research in Early Childhood Education, 11(2), 70-87.

Fleer, M., \& Robbins, J. (2004). "Yeah that's what they teach you at uni, it's just rubbish": The participatory appropriation of new cultural tools as early childhood student teachers move from a developmental to a sociocultural framework for observing and planning. Journal of Australian Research in Early Childhood Education, 11(1), 47-62.

Flewitt, R. (2005). Is every child's voice heard? Researching different ways 3-yearold children communicate and make meaning at home and in a pre-school playgroup. Early Years, 25(3), 207-222.

Franklin, B. (1986). The rights of children. Oxford: Blackwell.

Franklin, B. (1995). The case for children's rights: A progress report. In B. Franklin (Ed.), The handbook of children's rights: Comparative policy and practice (pp. 3-22). London: Routledge.

Freeman, C., Henderson, P., \& Kettle, J. (1999). Planning with children for better communities. Bristol: The Policy Press.

Freeman, M. (1992). The limits of children's rights. In M. Freeman \& P. Veerman (Eds.), The ideologies of children's rights. International studies in human rights (Vol. 23, pp. 29-46). Dordrecht: Martinus Nijhoff. 
Freeman, M. (1998). The sociology of childhood and children's rights. International Journal of Children's Rights, 6, 433-444.

Freeman, M. (2002). Human rights. Oxford: Polity Press.

Freeman, M. (2007). Why it remains important to take children's rights seriously. International Journal of Children's Rights, 15, 5-23.

Freire, P. (1993). Pedagogy of the oppressed (20th Anniversary ed.). New York: Continuum.

Froese, N. (2008). Early effects of 20 hours ECE [Electronic Version]. Retrieved March 20, 2009, from http://www.educationcounts.govt.nz/publications/ece/30449/30476

Funder, K. (1996). Children's rights: Setting the scene. In K. Funder (Ed.), Citizen child: Australian law and children's rights (pp. 1-10). Victoria: Australian Institute of Family Studies.

Gammage, P. (2006). Early childhood education and care: Politics, policies and possibilities. Early Years, 26(3), 235-248.

Gavin, M. (1980). Children are persons: The problem or the solution. Paper presented at the Social Policy and the Rights of the Child Symposium. In Proceedings of the third social policy symposium, Dunedin, 26-29 November, 1979.

Geddis, D. (1980). Parental autonomy and the rights of the child. Paper presented at the Social Policy and the Rights of the Child Symposium. Proceedings of the third social policy symposium. Dunedin, 26 - 29 November 1979.

Geertz, C. (1973). The interpretation of cultures. New York: Basic Books.

Geertz, C. (1979). From the native's point of view. In P. Rabinow \& W. Sullivan (Eds.), Interpretive social science: A reader (pp. 225-241). California: University of California Press.

Gerber, M. (2002). Dear parent: Caring for infants with respect. In J. Weaver (Ed.), Resources for infant educarers (RIE). Los Angeles: Resources for Infant Educators.

Gerber, R. (2001). Developing a sense of community and place in different cultural settings and environments. In M. Robertson \& R. Gerber (Eds.), Children's ways of knowing: Learning through experience (pp. 62-78). Melbourne: ACER Press.

Gillham, B. (2000). Case study research methods. London: Continuum.

Glesne, C. (2006). Becoming qualitative researchers: An introduction ( $\left.{ }^{\text {rd }} \mathrm{ed}.\right)$. Boston: Allyn \& Bacon.

Goldson, B. (1997). 'Childhood': An introduction to historical and theoretical analyses. In P. Scraton (Ed.), 'Childhood' in 'crisis' (pp. 1-26). London: UCL Press.

Greig, A., \& Taylor, J. (1999). Doing research with children. London: Sage.

Griffith, R. (1996). New powers for old: Transforming power relationships. In M. John (Ed.), Children in our charge: The child's right to resources (pp. 201222). London: Jessica Kingsley.

Gubrium, J. F., \& Holstein, J. A. (2003). Analyzing interpretive practice. In N. Denziin \& Y. Lincoln (Eds.), Strategies of qualitative inquiry $\left(2^{\text {nd }}\right.$ ed., pp. 214-248): Thousand Oaks, CA: Sage.

Guggenheim, M. (2005). What's wrong with children's rights. Cambridge, MA: Harvard University Press.

Guy, L. (2005). The concept of children's rights: Still a slogan in search of definition. Early Childhood Practice, 7(2), 58-65.

Haar, K. (2004). A fight to the death? The needs, rights and welfare of the child in need of life-saving medical treatment. In C. Breen (Ed.), Children's needs, 
rights and welfare: Developing strategies for the 'whole child' in the 21st century (pp. 15-40). Southbank, Victoria: Thomson Dunmore Press.

Hammarberg, T. (1990). The UN Convention on the Rights of the Child - and how to make it work. Human Rights Quarterly, 12(1), 97-105.

Hart, R. A. (1992). Children's participation: From tokenism to citizenship (No. 4). Florence: UNICEF, International Child Development Centre.

Hart, R. A. (1997). Children's participation: The theory and practice of involving young citizens in community development and environmental care. London: UNICEF.

Haste, H. (1987). Growing into rules. In J. Bruner \& H. Haste (Eds.), Making sense. The child's construction of the world (pp. 163-195). London: Routledge.

Hedges, H. (2002). Beliefs and principles in practice: Ethical research with child participants. New Zealand Research in Early Childhood Education, 5, 31-47.

Hedges, H. (2007). Funds of knowledge in early childhood communities of inquiry. Unpublished PhD thesis, Massey University, Palmerston North.

Holloway, S., \& Valentine, G. (2000a). Children's geographies and the new social studies of children. In S. Holloway \& G. Valentine (Eds.), Children's geographies: Playing, living, learning (Vol. 8, pp. 1-26). London: Routlege.

Holloway, S., \& Valentine, G. (Eds.). (2000b). Children's geographies: Playing, living, learning (Vol. 8). London: Routledge.

Holstein, J. A., \& Gubrium, J. F. (2003). Inside interviewing: New lenses, new concerns. In J. A. Holstein \& J. F. Gubrium (Eds.), Inside interviewing: New lenses, new concerns (pp. 3-30). Thousand Oaks, CA: Sage.

Holt, J. C. (1975). Escape from childhood: The needs and rights of children. Harmondsworth: Penguin.

Huberman, A. M., \& Miles, M. B. (Eds.). (2002). The qualitative researcher's companion. Thousand Oaks, CA: Sage.

Hultqvist, K. (2001). Bringing the gods and the angels back? A modern pedagogical saga about excesses in moderation. In K. Hultqvist \& G. Dahlberg (Eds.), Governing the child in the new millennium (pp. 143-171). New York: RoutledgeFalmer.

Hultqvist, K., \& Dahlberg, G. (Eds.). (2001). Governing the child in the new millennium. London: RoutledgeFalmer.

Human Rights Commission. (1959). Declaration on the rights of the child [Electronic Version]. Retrieved February 14, 2008, from http://www.unhchr.ch/html/menu3/b/25.htm

Human Rights in Education. (2008). Rights, respect, responsibilities. A school resource kit for developing respect for self, others and human rights. Wellington NZ: Author.

Hviid, P. (2004, September). Children's participation in research on children's development. Paper presented at the European Early Childhood Education Research Association, Malta.

Irwin, K. (1990). The politics of kōhanga reo. In S. Middleton, J. Codd, \& A. Jones (Eds.), New Zealand education policy today: Critical perpsectives. Wellington: Allen \& Unwin.

James, A. (2004). Understanding childhood from an interdisciplinary perspective: Problems and potentials. In P. B. Pufall \& R. P. Unsworth (Eds.), Rethinking childhood (pp. 25-37). New Brunswick: Rutgers University Press.

James, A., Jenks, C., \& Prout, A. (1998). Theorizing childhood. New York: Teachers College Press.

James, A., \& Prout, A. (1997). Constructing and reconstructing childhood. London: RoutledgeFalmer. 
Jenks, C. (1996). Childhood. London: Routledge.

John, M. (1996). Children in our charge: A child's right to resources. London: Jessica Kingsley.

John, M. (2003). Children's rights and power: Charging up for a new century. London: Jessica Kingsley.

Jordan, B. (2004). Scaffolding learning and co-constructing understanding. In A. Anning, J. Cullen, \& M. Fleer (Eds.), Early childhood education: Society and culture (pp. 31-42). London: Sage.

Kehily, M. J. (Ed.). (2004). An introduction to childhood studies. Maidenhead: Open University Press.

Kessler, S., \& Swadener, B. B. (Eds.). (1992). Reconceptualizing the early childhood curriculum: Beginning the dialogue. New York: Teachers College, Columbia University.

Key, J. (2008, August). A better today. A better tomorrow. What's it going to take? Address to Every Child Counts Conference. Wellington.

Kincheloe, J. L., \& Berry, K. S. (2004). Rigour and complexity in educational research: Conceptualizing the bricolage. Maidenhead, Berkshire: Open University Press.

Kirby, P., \& Gibbs, S. (2006). Facilitating participation: Adults' caring support roles within child-to-child projects in schools and after-school settings. Children and Society, 20, 209-222.

Knox, J., \& Stevens, C. B. (1993). Vygotsky and Soviet Russian defectology: An introduction. In R. W. Reiber \& A. S. Carton (Eds.), The collected works of L. S. Vygotsky: Volume 2 The fundamentals of defectology (Abnormal psychology and learning disabilities) (pp. 1-25). New York: Plenum Press.

Kohl, H. (1967). 36 children. New York: New American Library.

Kozol, J. (1967). Death at an early age: The destruction of the hearts and minds of Negro children in the Boston public schools. Boston: Houghton-Mifflin.

Kozulin, A., Gindis, B., Ageyev, V. S., \&. Miller S. M. (Eds.). (2003). Vygotsky's educational theory in cultural context. Cambridge: Cambridge University Press.

Kvale, S. (1996). InterViews: An introduction to qualitative research interviewing. California: Sage.

Lansdown, G. (1994). Children's rights. In B. Mayall (Ed.), Children's childhoods: Observed and experienced (pp. 33-44). London: Falmer Press.

Lansdown, G. (2005). Can you hear me? The rights of young children to participate in decisions affecting them: Working Paper 36. The Hague, The Netherlands: Bernard van Leer Foundation.

Lave, J., \& Wenger, E. (1991). Situated learning: Legitimate peripheral participation. Cambridge, UK: Cambridge University Press.

Lave, J., \& Wenger, E. (1996). Person, practice and the social world. In H. Daniels (Ed.), An introduction to Vygotsky (pp. 143-150). London: Routledge.

Lerner, R. M. (2005). Foreword. In U. Bronfenbrenner (Ed.), Making human beings human: Bioecological perspectives on human development (pp. ix-xxvi). Thousand Oaks, CA: Sage.

Lichtman, M. (2006). Qualitative research in education: A user's guide. Thousand Oaks, CA: Sage.

Lindahl, M. (2005). Children's right to democratic upbringings. International Journal of Early Childhood, 37(3), 33-47.

Lofdahl, A., \& Hagglund, S. (2007). Spaces for participation in pre-school: Arenas for establishing power orders? Children and Society, 21, 328-338. 
Ludbrook, R. (2000). Victims of tokenism and hypocrisy: New Zealand's failure to implement the United Nations Convention on the Rights of the Child. In A. B. Smith, M. M. Gollop, K. Marshall, \& K. Nairn (Eds.), Advocating for children: International perspectives on children's rights (pp. 109-125). Dunedin: University of Otago Press.

Lundy, L. (2007). Voice is not enough: Conceptualising Article 12 of the United Nations Convention on the Rights of the Child. British Educational Research Journal, 33(6), 927-942.

Macfarlane, A. H. (2004). Kia hiwa ra: Listen to culture: Māori students' plea to educators. Wellington: New Zealand Council for Educational Research.

MacNaughton, G. (2003). Eclipsing voice in research with young children. Australian Journal of Early Childhood Education, 28(1), 36-42.

Mason, J. (2005). Child protection policy and the construction of childhood. In J. Mason \& T. Fattore (Eds.), Children taken seriously in theory policy and practice (pp. 91-97). London: Jessica Kingsley.

Matthews, H. (2003). Children and regeneration: Setting an agenda for community participation and integration. Children and Society, 17, 264-276.

Matthews, S. H. (2007). A window on the 'new' sociology of childhood. Sociology Compass, 1(1), 322-334.

May, H. (1999). The price of partnership: The 'before five' decade. In M. Thrupp \& M. Payne (Eds.), A decade of reform in New Zealand: Where to now? New Zealand Journal of Educational Studies, 34, 18-27.

May, H. (2001). Politics in the playground: The world of early childhood in post war New Zealand. Wellington: Bridget Williams Books.

May, H. (2003). Towards citizenry rights in the early childhood sector 1930s-2000s. Keynote address. Paper presented at the Quality Public Education Campaign (QPEC), Palmerston North.

May, H. (2004, September). Towards citizenry rights in the early childhood sector 1930s-2000s. Paper presented at the European Early Childhood Education Research Association Conference, Malta.

May, H. (2005). A right as a citizen to a free [early childhood] education 1930s2000s. Childrenz issues, Journal of the Children's Issues Centre, 9(2), 20-24.

May, H., \& Podmore, V. N. (1998, September). Developing a framework for self evaluation of early childhood programmes. Paper presented at the 8th European Conference on Quality in Early Childhood Settings, Santiago de Compostela, Spain.

Mayall, B. (2000a). The sociology of childhood: Children's autonomy and participation rights. In A. B. Smith, M. M. Gollop, K. Marshall, \& K. Nairn (Eds.), Advocating for children: International perspectives on children's rights (pp. 126-140). Dunedin: University of Otago.

Mayall, B. (2000b). The sociology of childhood in relation to children's rights. The International Journal of Children's Rights, 8, 243-259.

Mayall, B. (2003). Sociologies of childhood and educational thinking: Professorial lecture. London: Institute of Education, University of London.

Mayall, B. (Ed.). (1994). Children's childhoods: Observed and experienced. London: Falmer Press.

McDonald, D. J. (1978). Children and young persons in New Zealand Society. Wellington: Metheun.

McDonald, D. J. (1980). The paradox of inequality: A review of child welfare policies in New Zealand. Paper presented at the Social Policy and the Rights of the Child. Proceedings of the third social policy symposium, Dunedin, 2629 November, 1979. 
Meade, A. (1999, June). Not only child-centred, it must be children-centred. Paper presented at the NIPPA Millennium AGM/Conference, Belfast.

Meade, A. (2000). The early childhood landscapes in New Zealand: 'Before five'. In J. Hayden (Ed.), Landscapes in early education: Cross-national perspectives on empowerment: A guide for the new millennium (pp. 83-94). New York: Peter Lang.

Meade, A. (Ed.). (2005). Catching the waves: Innovation in early childhood education. Wellington: NZCER Press.

Meade, A. (Ed.). (2006). Riding the waves. Innovation in early education. Wellington: NZCER Press.

Meade, A. (Ed.). (2007). Cresting the waves: Innovation in early education. Wellington: NZCER Press.

Meade, A., \& Cubey, P. (1995). Competent children and their teachers: Learning about trajectories and other schemas: A report from the action research component of the Competent Children Longitudinal Research Project. Wellington: New Zealand Council for Educational Research and Faculty of Education, Victoria University, Wellington.

Meade, A., \& Podmore, V. N. (2002). Early childhood education policy coordination under the auspices of the Department/Ministry of Education. Paris: UNESCO.

Melton, G. B., \& Limber, S. P. (1992). What children's rights mean to children: Children's own views. In M. Freeman \& P. Veerman (Eds.), The ideologies of children's rights: International studies in human rights (Vol. 23, pp. 167187). Dordrecht: Martinus Nijoff.

Melville Jones, H. E. (2000, January). The rights of children: A suggested approach for early childhood care and education in Australia. Paper presented at the Australian Association for Research in Education Conference, Sydney.

Merriam, S. (2002). Assessing and evaluating qualitative research. In S. Merriam \& Associates (Eds.), Qualitative research in practice: Examples for discussion and analysis (pp. 18-39). San Francisco: Jossey-Bass.

Millar, J. L. (1992). Teachers' autobiography and curriculum: Critical feminist perspectives. In S. Kessler \& B. B. Swadener (Eds.), Reconceptualizing the early childhood curriculum: Beginning the dialogue (pp. 103-122). New York: Teachers' College Press.

Ministry of Education. (1993). Te Whāriki: He whāriki matauranga mo ngā mokopuna of Aotearoa: Draft guidelines for developmentally appropriate programmes in early childhood services. Wellington: Learning Media.

Ministry of Education. (1996a, 3 October). Revised statement of desirable objectives and practices (DOPs) for chartered early childhood services in New Zealand. Wellington: The New Zealand Gazette.

Ministry of Education. (1996b). Te Whāriki. He whāriki matauranga mo ngā mokopuna o Aotearoa: Early childhood curriculum. Wellington: Learning Media.

Ministry of Education. (1998). Quality in action: Te mahi whai hua: Implementing the revised statement of desirable objectives and practices in New Zealand early childhood services. Wellington: Learning Media.

Ministry of Education. (2002). Pathways to the future: Nga huarahi arataki: A 10 year strategic plan for early childhood education. Wellington: Ministry of Education.

Ministry of Education. (2005). Kei tua o te pae/Assessment for learning: Early childhood exemplars. Wellington: Learning Media. 
Ministry of Education. (2006). Ngā arohaehae whai hua: Self-review guidelines for early childhood education. Wellington: Learning Media.

Ministry of Education. (2007a). Licensed services and licence-exempt groups 2007 [Electronic Version], 1-11. Retrieved May, 5, 2008, from http://www.educationcounts.govt.nz/statistics/ece/ece_staff_return/licensed_ services_and_licence-exempt_groups/17812

Ministry of Education. (2007b). The state of education 2007 [Electronic Version].

Retrieved 5 May, 2008 from http://www.educationcounts.govt.nz/_data/assets/ pdf_file/0020/17327/882273_MoE_State_of_Education_v7_p1.pdf

Ministry of Social Development, \& Ministry of Education. (2004). ECE centre based parent support: Overview paper. Wellington: Ministry of Social Development.

Ministry of Social Development. (2002). New Zealand's agenda for children: Making life better for children. Wellington: Author.

Ministry of Social Development. (2006). Early years service hubs. Wellington, New Zealand: Ministry of Social Development.

Mitchell, H., \& Wild, M. (2004). Placing the child in childhood: A thematic review. British Educational Research Journal, 30(5), 731-739.

Mitchell, L. (1996). Crossroads: Early childhood education in the mid 1990s. New Zealand Annual Review of Education, 5, 75-92.

Mitchell, L. (2002). Currents of change: Early childhood education in 2001. New Zealand Annual Review of Education, 11, 123-142.

Mitchell, L. (2003, September). Views of children and investment in early childhood education: New Zealand experiences. Paper presented at the European Early Childhood Education Research Association Conference, "Possible Childhoods: Relationships and Choices", Glasgow, Scotland.

Mitchell, L. (2007). A new debate about children and childhood: Could it make a difference to early childhood pedagogy and policy. Unpublished $\mathrm{PhD}$ thesis, Victoria University of Wellington, Wellington.

Mitchell, L., \& Hodgen, E. (2008). Locality-based evaluation of Pathways to the Future - Ngā Huarahi Arataki: Stage 1 Report [Electronic Version]. Retrieved March 20, 2009, from http://www.educationcounts.govt.nz/publications/ece/28939/28940.

Morris, B. (1994). Understanding children: Whakamōhiotanga i ngā tamariki: Learning about children from birth to teens $\left(2^{\text {nd }}\right.$ ed.). Auckland: New Zealand Playcentre Federation.

Morss, J. R. (2002). The several social constructions of James, Jenks, and Prout: A contribution to the sociological theorization of childhood. The International Journal of Children's Rights, 10, 39-54.

Moss, P. (2006). Listening to young children: Beyond rights to ethics. In Let's talk about listening to children. Towards a shared understanding for early years education in Scotland (Vol. 2). Scotland: Learning and Teaching Scotland.

Moss, P., \& Petrie, P. (2002). From children's services to children's spaces. London: RoutledgeFalmer.

Murrow, K. (1995). Early childhood workers' opinions on the draft document 'Te Whāriki'. Wellington: Ministry of Education.

Mutch, C. (2005). Doing educational research: A practitioner's guide to getting started. Wellington: NZCER Press.

Neill, A. S. (1968). Summerhill. Hammondsworth, UK: Penguin.

New Zealand Association for Research in Education. (1999, March). New Zealand Association for Research in Education - Ethical Guidelines. NZARE Membership Directory. 
New Zealand Government. (2008). Third and fourth periodic report for the United Nations Committee [Electronic Version]. Retrieved March 20, 2009, from http://www.myd.govt.nz/Publications/Rights/thirdandfourthperiodicreportfort he.aspx

New Zealand Human Rights Commission. (2004, September). Human rights in New Zealand today/Ngā tika tangata o te motu. Wellington: Human Rights Commission, Te Kahui Tika Tangata.

Noonan, R. (2001, October). Early childhood education - a child's right? Paper presented at the Early Education for a Democratic Society, Wellington. Wellington: New Zealand Council for Educational Research.

Noonan, R. (2003, October). Early childhood education from optional extra to essential, from privilege to right. Paper presented at the AEU National Early Childhood Education Forum, Melbourne.

Nutbrown, C. (1996a). Questions for respectful educators. In C. Nutbrown (Ed.), Respectful educators - capable children: Children's rights in early education (pp. 99-108). London: Paul Chapman.

Nutbrown, C. (1996b). Wide eyes and open minds. In C. Nutbrown (Ed.), Respectful educators - capable learners: Children's rights in early education (pp. 4455). London: Paul Chapman.

Nuttall, J. (2004). Why don't you ask someone who cares? Teacher identity, intersubjectivity and curriculum negotiation in a New Zealand childcare centre. Unpublished $\mathrm{PhD}$ thesis, Victoria University of Wellington, Wellington.

Nuttall, J. (Ed.). (2003). Weaving Te Whāriki: Aoteoroa New Zealand's early childhood curriculum document in theory and practice. Wellington: New Zealand Council for Educational Research.

Oldman, D. (1994). Adult-child relations as class relations. In J. Qvortrop, M. Bardy, G. Sgritta, \& H. Wintersberger (Eds.), Childhood matters: Social theory, practice and politics (pp. 43-58). Aldershot, UK: Avebury.

Paavola, S., Lipponen, L., \& Hakkarainen, K. (2004). Models of knowledge communities and three metaphors of learning. Review of Educational Research, 74(4), 557-576.

Palinscar, A. S. (1998). Social constructivist perspectives on teaching. Annual Review of Psychology, 49, 345-375.

Penuel, W. R., \& Wertsch, J. V. (1995). Vygotsky and identity formation: A sociocultural approach. Educational Psychologist, 30(2), 83-92.

Phadraig, M. N. G. (1994). Day care - adult interests versus children's needs? A question of compatibility. In J. Qvortrop, M. Bardy, G. Sgritta, \& H. Wintersberger (Eds.), Childhood matters: Social theory, practice and politics (pp. 77-100). Vienna: Avebury.

Podmore, V. N. (1992). Meeting their needs: A national-level collaborative study of playcentre children aged two and a half years. Wellington: New Zealand Council for Educational Research and New Zealand Playcentre Federation.

Podmore, V. N. (2004a). Collectivism, communities, and constellations: Some reflections on early childhood innovations 2003. In I. Livingston (Ed.), New Zealand Annual Review of Education, 13, 189-204.

Podmore, V. N. (2004b). Questioning evaluation quality in early childhood. In A. Anning, J. Cullen, \& M. Fleer (Eds.), Early childhood education: Society and culture (pp. 149-158). London: Sage.

Podmore, V. N., May, H., \& Carr, M. (2001). “The child's questions”: Programme evaluation with Te Whäriki using "teaching stories". Wellington: Institute for Early Childhood Studies, Victoria University of Wellington. 
Podmore, V. N., Meade, A., \& Kerslake Hendricks, A. (2000). Aspects of quality in early education. Wellington: New Zealand Council for Educational Research.

Podmore, V. N., \& Te One, S. (2008). Nurturing a culture of care for infants and firsttime parents: The SPACE programme at Te Marua/Mangaroa Playcentre early childhood centre of innovation (Round 2). Final research report for the Ministry of Education. Wellington: Ministry of Education.

Pollard, A. (1993). Learning in primary school. In H. Daniels (Ed.), Charting the agenda: Educational activity after Vygotsky (pp. 171-189). London: Routledge.

Powell, M. A., \& Smith, A. B. (2006). Ethical guidelines for research with children: A review of current research ethics documents in New Zealand [Electronic Version]. Kotuitui: New Zealand Journal of Social Sciences Online, 1, 125138. Retrieved July 15, 2008, from http://www.rsnz.org.helicon.vuw.ac.nz /publish/kotuitui/2006/09.php

Power, F., Power, A. R., Bredemeir, B. L., \& Sheilds, D. L. (2001). Democratic education and children's rights. In R. A. Hart, C. P. Cohen, M. F. Erikson, \& M. Flekkoy (Eds.), Children's rights in education (pp. 98-118). London: Jessica Kingsley.

Prasad, P. (2005). Crafting qualitative research: Working in the postpostivist traditions. New York: M.E. Sharpe.

Prout, A. (2003). Participation, policy and the changing conditions of childhood. In A. Prout \& C. Hallett (Eds.), Hearing the voices of children: Social policy for a new century (pp. 11-25). London: RoutledgeFalmer.

Prout, A., \& Hallett, C. (Eds.). (2003). Hearing the voices of children: Social policy for a new century. London: RoutledgeFalmer.

Prout, A., \& James, A. (1990). A new paradigm for the sociology of childhood. In A. James \& A. Prout (Eds.), Constructing and reconstructing childhood: Contemporary issues in the sociological study of childhood (pp. 7-34). Basingstoke: Falmer Press.

Pufall, P. B., \& Unsworth, R. P. (2004). The imperative and process for rethinking childhood. In P. B. Pufall \& R. P. Unsworth (Eds.), Rethinking childhood. (pp. 1-21). New Brunswick: Rutgers University Press.

Pugh, G., \& Rouse Sellack, D. (1996). Listening to and communicating with young children. In R. Davie, G. Upton, \& V. Varma (Eds.), The voice of the child: A handbook for professionals (pp. 120-136). London: Falmer Press.

Punch, K. F. (1998). Introduction to social research: Quantitative and qualitative approaches. London: Sage.

Qvarsell, B. (2005). Early childhood culture and education for children's rights. International Journal of Early Childhood, 37(3), 99-108.

Qvortrop, J. (1999). A voice for children in statistical and social accounting: A plea for children's rights to be heard. In A. James \& A. Prout (Eds.), Constructing and reconstructing childhood (pp. 85-106). London: Falmer Press.

Reiber, R. W., \& Carton, A. S. (Eds.). (1993). The collected works of L. S. Vygotsky: Volume 2 The fundamentals of defectology (Abnormal psychology and learning disabilities). New York: Plenum Press.

Reid, M. (2006). From innocents to agents: Children and children's rights in New Zealand. Auckland: Maxim Institute.

Rinaldi, C. (2006). In dialogue with Reggio Emilia: Listening, researching and learning. London: Routledge.

Ritchie, J., \& Ritchie, J. (1997). The next generation: Child rearing in New Zealand. Auckland: Penguin. 
Roberts, H. (2003). Children's participation in policy matters. In A. Prout \& C. Hallett (Eds.), Hearing the voices of children (pp. 26-37). London: RoutledgeFalmer.

Rogoff, B. (1990). Apprenticeship in thinking: Cognitive development in social context. Oxford: Oxford University Press.

Rogoff, B. (1995). Observing sociocultural activity on three planes: Participatory appropriation, guided participation, and apprenticeship. In J. V. Wertsch, P. Del Rio, \& A. Alvarez (Eds.), Sociocultural studies of the mind (pp. 139164). New York: Cambridge University Press.

Rogoff, B. (1998). Cognition as a collaborative process. In D. Kuhn \& S. D. Siegler (Eds.), Handbook of child psychology, Vol. 2: Cognition, perception, and language. $\left(5^{\text {th }}\right.$ ed., pp. 679-744). New York: Wiley.

Rogoff, B. (2003). The cultural nature of human development. Oxford: Oxford University Press.

Rogoff, B., Baker-Sennett, J., Lacasa, P., \& Goldsmith, D. (1995). Development through participation in sociocultural activity. In J. J. Goodnow, P. J. Miller, \& F. Kessel (Eds.), Cultural practices as contexts for development (pp. 4565). San Francisco: Jossey-Bass.

Rogoff, B., Matusov, E., \& White, C. (1996). Models of teaching and learning: Participation in a community of learners. In D. Olsen \& N. Torrance (Eds.), The handbook of education and human development (pp. 388-414). Cambridge, MA: Blackwell.

Rogoff, B., Mistry, J., Göncu, A., \& Mosier, C. (1993). Guided participation in cultural activity by toddlers and caregivers. Society for Research in Child Development, 58(8).

Rogoff, B., Moore, L., Najafi, B., Dexter, A., Corea-Chávas, M., \& Solís, J. (2007). Children's development of cultural repertoires through participation in everyday routines and practices. In J. E. Crusec \& P. D. Hastings (Eds.), Handbook of socialization (pp. 490-515). NY: Guildford.

Rubin, H. J., \& Rubin, I. S. (Eds.). (2005). Qualitative interviewing: The art of hearing data $\left(2^{\text {nd }}\right.$ ed.). Thousand Oaks, CA: Sage.

Sanchez-Jankowski, M. (2002). Representation, responsibility and reliability in participant-observation. In T. May (Ed.), Qualitative research in action (pp. 144-160). London: Sage.

Schwandt, T. (2000). Three epistemological stances for qualitative inquiry: Interpretivism, hermeneutics, and social constructionism. In N. K. Denziin \& Y. S. Lincoln (Eds.), The Sage handbook of qualitative research $\left(2^{\text {nd }}\right.$ ed., pp. 189-213). Thousand Oaks, CA: Sage.

Schweinhart, L. J., \& Weikart, D. P. (1997). Lasting differences: The High/Scope preschool curriculum comparison study through age 23 (Vol. 12). Ypsilanti, MI: High/Scope Press.

Scraton, P. (1997). Whose 'childhood'? What 'crisis'? In P. Scraton (Ed.), Childhood in crisis (pp. 163-186). London: UCL Press.

Sheridan, S., \& Pramling Samuelsson, I. (2001). Children's conceptions of participation and influence in pre-school: A perspective on pedagogical quality. Contemporary Issues in Early Childhood, 2(2), 169-194.

Shier, H. (2001). Pathways to participation: Openings, opportunities and obligations: A new model for enhancing children's participation in decision-making, in line with Article 12.1 of the United Nations Convention on the Rights of the Child. Children and Society, 15, 107-117.

Silverman, D. (1993). Interpreting qualitative data. London: Sage. 
Silverman, D. (Ed.). (1997). Qualitative research theory, method and practice. London: Sage.

Simon, T. W. (2000). United Nations Convention on the wrongs to the child. The International Journal of Children's Rights, 8, 1-13.

Sinclair, R. (2004). Participation in practice: Making it meaningful, effective and sustainable. Children and Society, 18, 106-118.

Siraj-Blatchford, I. (2004). Quality teaching in the early years. In A. Anning, J. Cullen, \& M. Fleer (Eds.), Early childhood education (pp. 137-148). London: Sage.

Smith, A. B. (1980). Children's ideas about children's rights. Paper presented at the Social Policy and the Rights of the Child. Proceedings of the Third Social Policy Symposium, Dunedin, 26-29 November, 1979.

Smith, A. B. (1993). Early childhood educare: Seeking a theoretical framework in Vygotsky's work. International Journal of Early Years Education, 1, 47-61.

Smith, A. B. (1998). Understanding children's development: A New Zealand perspective ( $4^{\text {th }}$ ed.). Wellington: Bridget Williams.

Smith, A. B. (2000). Children's rights and early childhood education: The rights of babies and young children. In A. B. Smith, M. M. Gollop, K. Marshall, \& K. Nairn (Eds.), Advocating for children: International perspectives on children's rights (pp. 1-17). Dunedin: University of Otago Press.

Smith, A. B. (2002). Interpreting and supporting participation rights: Contributions from sociocultural theory. The International Journal of Children's Rights, 10, 73-88.

Smith, A. B. (2003). Children's rights: What are the implications for early childhood education and family day care? Dunedin: Children's Issues Centre, University of Otago Press.

Smith, A. B. (2007a). Children's rights and early childhood education: Links to theory and advocacy. Australian Journal of Early Childhood, 32(3), 1-8.

Smith, A. B. (2007b). Children and young people's participation rights in education. International Journal of Children's Rights, 15, 147-164.

Smith, A. B. (Ed.). (1996). The quality of childcare centres for infants in New Zealand. Palmerston North: The New Zealand Association for Research in Education/Department of Policy Studies, Massey University.

Smith, A. B., Taylor, N. J., \& Gollop, M. M. (Eds.). (2000). Children's voices: Research, policy and practice. Auckland: Pearson Education.

Smith, R. (2000). Order and disorder: The contradictions of childhood. Children and Society, 14, 3-10.

Snook, I. (1981). Ethics of educational research. Delta, 29, November, 9-15.

Snook, I. (2003). The ethics and politics of social research. In C. Davidson \& M. Tolich (Eds.), Social science research in New Zealand: Many paths to understanding ( $2^{\text {nd }}$ ed., pp. 69-87). Auckland: Pearson Education.

Somekh, B., \& Lewin, C. (Eds.). (2005). Research methods in the social sciences. London: Sage.

Somerset, G. (1976). Vital play in early childhood. Auckland: New Zealand Playcentre Federation.

Somerset, G. (1986). Work and play in the pre-school years ( $3^{\text {rd }}$ ed.). Auckland: New Zealand Playcentre Federation.

St John, S., \& Wynd, D. (Eds.). (2008). Left behind: How social and income inequalities damage New Zealand children. Auckland: Child Poverty Action Group. 
Stainton Rogers, W. (2004). Promoting better childhoods: Constructions of child concern. In M. J. Kehily (Ed.), An introduction to childhood studies (pp. 125144). Maidenhead: Open University Press.

Stake, R. E. (2005). Qualitative case studies. In N. K. Denzin \& Y. S. Lincoln (Eds.), The Sage handbook of qualitative research ( $3^{\text {rd }}$ ed., pp. 443-466). Thousand Oaks. CA: Sage.

Strauss, A., \& Corbin, J. (1994). Grounded theory methodology: An overview. In N. K. Denzin \& Y. S. Lincoln (Eds.), The handbook of qualitative research (pp. 273-285). California: Sage.

Stuart, D., Aitken, H., Gould, K., \& Meade, A. (2008). Evaluation of the implementation of Kei Tua o te Pae Assessment for Learning: Early childhood exemplars: Impact evaluation of the Kei Tua o te Pae 2006 professional development [Electronic Version]. Retrieved March 20, 2008, from http://www.educationcounts.govt.nz/publications/ece/26255/26256

Tapp, P., \& Henaghan, M. (2000). Family law: Concepts of childhood and children's voices: The implications of Article 12 of the United Nations Convention on the Rights of the Child. In A. B. Smith, N. J. Taylor, \& M. M. Gollop (Eds.), Children's voices: Research, policy and practice. Auckland: Pearson Education.

Taylor, N. J., Smith, A. B., \& Nairn, K. (2001). Rights important to young people: Secondary student and staff perspectives. The International Journal of Children's Rights, 9, 137-156.

Te One, S. (2003). Te Whāriki: Contemporary issues of influence. In J. Nuttall (Ed.), Weaving Te Whäriki: Aotearoa New Zealand's early childhood curriculum document in theory and in practice (pp. 17-49). Wellington: New Zealand Council for Educational Research.

Te One, S. (2004). Children's rights and early childhood policy: Impacts and influences. New Zealand Annual Review of Education, 14, 171-193.

Te One, S. (2005). Children's rights and early childhood policy: A New Zealand Story. European Early Childhood Research Journal, 13(2), 25-39.

Te One, S. (2006). Setting the context for children's rights in early childhood. Childrenz issues, Journal of the Children's Issues Centre, 10(1), 18-22.

Te One, S. (2007). Participatory-research methods with young children: Experiences from the field. Early Childhood Folio, 11, 21-25.

Tedlock, B. (2005). The observation of participation and the emergence of public ethnography. In N. K. Denzin \& Y. S. Lincoln (Eds.), The Sage handbook of qualitative research (455-486). Thousand Oaks, CA: Sage.

The New Era in Home and School. (1943, March). A children's charter: Memorandum. The New Era in Home and School, 24, 37-42.

Thomas, N. (2007). Towards a theory of children's participation. International Journal of Children's Rights, 15, 199-218.

Thomas, N., \& O'Kane, C. (1998). The ethics of participatory research with children. Children and Society, 12, 336-348.

Titchen, A., \& Hobson, D. (2005). Phenomenology. In B. Somekh \& C. Lewin (Eds.), Research methods in the social sciences (pp. 121-129). London: Sage.

Toma, J. D. (2006). Approaching rigor in applied qualitative research. In C. F. Conrad \& R. C. Sertin (Eds.), The Sage handbook for research in education (pp. 405-423). Thousand Oaks, CA: Sage.

Tomanovic, S. (2003). Negotiating children's participation and autonomy within families. International Journal of Children's Rights, 11, 51-71.

UNICEF. (2005). Child poverty in rich countries 2005. Florence, Italy: Innocenti Research Centre. 
UNICEF. (2006). 1946-2006 Sixty years for children. Florence, Italy: Author

UNICEF. (2008). The child care transition: A league table of early childhood education and care in economically advanced countries. Florence, Italy: Innocenti Research Centre.

United Nations Committee on the Rights of the Child. (1995). Initial reports of States parties due in 1995: New Zealand. 12/10/95. CRC/C/28/Add.3. (State Party Report) [Electronic Version] Retrieved November 12005 from http://www.unhchr.ch/tbs/doc.nsf/\%28Symbol\%29/7a56fc7de1a7023fc12563 e70033a9e4? Opendocument

United Nations Committee on the Rights of the Child (Thirty-fourth session). (2000). Consideration of reports submitted by States Parties under Article 44 of the Convention: Concluding observations: New Zealand [Electronic Version], 111. Retrieved March 15, 2009, from http://www.unhchr.ch/tbs/doc.nsf/898586b1dc7b4043c1256a450044f331/73f 172e77b12c842c1256df20033829f/\$FILE/G0344655.pdf

United Nations Committee on the Rights of the Child: New Zealand. (2003, October). Concluding observations on the committee on the rights of the child: New Zealand. CRC/C/15/Add 216. Retrieved August 10, 2004, http://www.unhcr.org/cgibin/texis/vtx/refworld/rwmain?page=search\&amp; docid=3f2592932\&amp;sk ip $=0 \&$ amp;query $=\mathrm{UN} \% 20$ committee $\% 202003 \% 20 \mathrm{NZ}$

United Nations Committee on the Rights of the Child. (2005). General comment No. 7, Implementing child's rights in early education [Electronic Version]. Retrieved November 1, 2005 from http://www2.ohchr.org/english/bodies/crc/docs/AdvanceVersions/GeneralCo mment7Rev1.pdf

Valsiner, J. (1997). Bounded indeterminacy in discourse processes. In C. Coll \& D. Edwards (Eds.), Teaching, learning and classroom discourse (pp. 23-32). Madrid: Fundacion Ingancia y Aprendizaje.

Veerman, P., \& Levine, H. (2000). Implementing children's rights on a local level: Narrowing the gap between Geneva and the grassroots. The International Journal of Children's Rights, 8, 373-384.

Verhellen, E. (2001). Facilitating children's rights in education. Expectations and demands on teachers and parents. In S. N. Hart, C. P. Cohen, M. F. Erikson, \& M. Flekkoy (Eds.), Children's rights in education (pp. 179-190). London: Jessica Kingsley.

Vygotsky, L. S. (1978). Mind in society: The development of higher psychological processes. Cambridge, MA: Harvard University Press.

Vygotsky, L. S. (1993a). The collective as a factor in the development of the abnormal child (J. Knox \& C. B. Stevens, Trans.). In R. W. Reiber (Ed.), The collected works of L. S. Vygotsky: Volume 2 The fundamentals of defectology (Abnormal psychology and learning disabilities) (pp. 191-208). New York: Plenum Press.

Vygotsky, L. S. (1993b). The diagnostics of development and the pedological clinic for difficult children. In R. W. Reiber \& A. S. Carton (Eds.), The collected works of L. S. Vygotsky: Volume 2 The fundamentals of defectology (Abnormal psychology and learning disabilities) (pp. 241-291). New York: Plenum Press.

Waksler, F. C. (Ed.). (1991). Studying the social worlds of children: Sociological readings. London: Falmer Press. 
Walkerdine, V. (2004). Developmental psychology and the study of childhood. In M. J. Kelhily (Ed.), An introduction to childhood studies (pp. 96-107). Maidenhead: Open University Press.

Wenger, E. (1998). Communities of practice: Learning, meaning and identity. Cambridge: Cambridge University Press.

Wenger, E., McDermott, R., \& Snyder, W. M. (2002). Cultivating communities of practice: A guide to managing knowledge. Boston, MA: Harvard Business School Press.

Wertsch, J. V. (1985). Vygotsky and the social formation of mind. Cambridge, MA: Harvard University Press.

Wolcott, H. (1994). Transforming qualitative data. California: Sage.

Wolcott, H. (2001). Description, analysis, and interpretation in qualitative inquiry. In C. F. Conrad, J. G. Haworth, \& L. R. Lattuca (Eds.), Qualitative research in higher education: Expanding perspectives ( $2^{\text {nd }}$ ed., pp. 573-598). Boston, MA: Pearson Custom.

Woodhead, M. (1997). Psychology and the cultural construction of children's needs. In A. James \& A. Prout (Eds.), Constructing and reconstructing childhood: Contemporary issues in the sociological study of childhood (pp. 63-84). London: Falmer Press.

Woodhead, M. (2004). Foreword. In M. J. Kehily (Ed.). An introduction to childhood studies (pp. X-xi). Maidenhead: Open University Press.

Woodhead, M. (2005). Early childhood development: A question of rights. International Journal of Early Childhood, 37(3), 79-98.

Woodhead, M., \& Faulkner, D. (2000). Subjects, objects or participants? Dilemmas of psychological research with children. In P. Christensen \& A. James (Eds.), Research with children: Perspectives and practices (pp. 9-35). London: Falmer Press.

Woodhouse, R. B. (2004). Re-visioning rights for children. In P. B. Pufall \& R. P. Unsworth (Eds.), Rethinking childhood (pp. 229-243). New Brunswick: Rutgers University Press.

Wyness, M. (2006). Childhood and society: An introduction to the sociology of childhood. Hampshire: Palgrave Macmillan.

Yelland, N. (2005). Critical issues in early childhood education. Maidenhead: Oxford University Press.

Yin, R. (2006). Case study methods. In J. L. Green, G. Camilli, \& P. B. Elmore (Eds.), Handbook of complementary methods in education research (pp. 111122). London: Lawrence Erlbaum.

Youniss, J. (1999). Children's friendship and peer culture. In M. Woodhead, D. Faulkner, \& K. Littleton (Eds.), Making sense of social development (pp. 1326). London: Routledge in association with The Open University. 


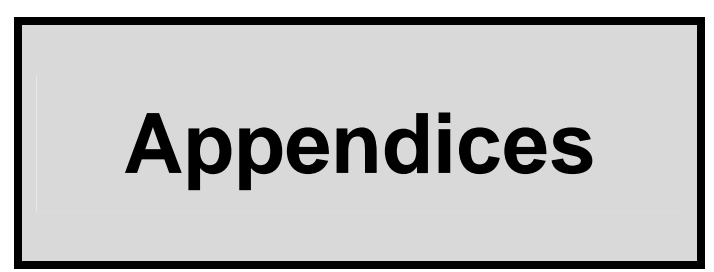




\section{Appendix A: Information sheet for participants}

\section{Letterhead}

Kia Ora and Greetings

My name is Sarah Te One and I am a doctoral student with the Institute of Early Childhood Studies at Victoria University of Wellington.

\section{INVITATION TO BE A PARTICIPANT IN A PHD PROJECT ABOUT CHILDREN'S RIGHTS}

\section{In whose best interests? Perceptions of children's rights in early childhood settings}

For some time now there has been a growing interest in the children's rights movement. Under its obligations to the United Nations Convention on the Rights of the Child, the government is now required to consider the impact of its policies on children, directly and indirectly. This includes the effects of policy in the early childhood education sector, which has focused largely on children's rights to early childhood education as well as the quality of the experience. However, there is hardly any research investigating what those directly involved in the sector think about rights for very young children. This thesis will gather data from three different early childhood services: a kindergarten, a whānau/parent led service and a childcare centre.

The supervisors for the study are Professor Helen May and Dr Val Podmore. The School of Education's Human Ethics Committee has approved this study.

As part of my study investigating perceptions of children's rights in early childhood settings, I would like to invite your centre to be part of this project.

What does this involve?

1. Observing the centre in action

As one of the centres in the project it means that I would spend time observing children and parents or teachers in your centre, taking notes, photos and some video footage. It will also allow me to have access to relevant centre documentation, such as the charter and some policies. Of particular interest will be the programme planning, evaluation and assessment documentation.

2. Interviewing the participants - team leaders, teachers and children

I will also interview team leaders, teachers as well as some children about their understandings of rights for children. For the adults, this would involve two individual interviews of (approximately one hour per interview) and two group interviews of approximately one hour each. The group interviews will be the team leaders or the teachers in your centre only. For the children, the interviews will be more like conversations in small groups based around a meaningful activity during the session time. How this might happen will be discussed in full consultation with those involved, but it is important that the 'interview' be a part of the everyday events. 
If you agree to participate in this study, please complete the attached consent form and return it to me in the enclosed stamped, addressed envelope. Should you have any questions please feel free to contact my supervisors or me.

Sarah Te One sarah.teone@vuw.ac.nz 044635716

Helen May Helen.may@vuw.ac.nz 044635166

Val Podmore val.podmore@vuw.ac.nz 044635166

Thank you for considering this invitation and I look forward to hearing from you

Sarah Te One

(Researcher) 


\section{Appendix B: Consent forms for parents and teachers}

\section{Consent Form: Parents}

I am willing to take part in this research project and I am aware that my responses will be used to help understand perceptions of children's rights in early childhood settings. I am also willing to allow my child to take part in this research and I am aware that his or her responses will be used to help understanding perceptions of children's rights in early childhood settings. The findings will be confidential and discussed only with the supervisors of the project: Professor Helen May and Dr. Val Podmore. Once completed, the thesis will be lodged in the University Library.

I understand and agree to the following: Please tick if you agree.

That any identifying features of the centre will be disguised;

That I will remain anonymous;

That my child will remain anonymous;

That all the interviews will be audio-taped and transcribed and the transcripts will be returned to me for verification, amendment or deletion if necessary. This includes interviews with my child;

That all video clips and photographs that include me, or my child will be returned to me for verification, amendment or deletion if necessary;

That the results of the research, video clips and or photographs may be used in the final report, publications or in conference presentations;

Participation in this research is entirely voluntary and that I am free to withdraw, or to withdraw my child, at anytime without question before the data is analysed;

That any information I provide will be stored in a secure way, and only used as agreed to in this consent form. Should the data be used in any other way, new consent will be obtained.

Name:

Date:

Child's name:

Adult signature:

Child's signature:

Phone:

Postal address:

Email address:

Would you like a copy of the summary made available to you? Please tick 


\section{Consent Form: Teacher/whānau member}

I am willing to take part in this research project and I am aware that my responses will be used to help understand perceptions of children's rights in early childhood settings. The findings will be confidential and discussed only with the supervisors of the project: Professor Helen May and Dr. Val Podmore. Once completed, the thesis will be lodged in the University Library.

I understand and agree to the following: Please tick if you agree.

That any identifying features of the centre will be disguised;

That I will remain anonymous;

That all the interviews will be audio-taped and transcribed and the transcripts will be returned to me for verification, amendment or deletion if necessary;

That all video clips and photographs that include me, will be returned to me for verification, amendment or deletion if necessary;

That the results of the research, video clips and or photographs may be used in the final report, publications or in conference presentations;

Participation in this research is entirely voluntary and that I am free to withdraw, or to withdraw my child, at anytime without question before the data is analysed;

That any information I provide will be stored in a secure way, and only used as agreed to in this consent form. Should the data be used in any other way, new consent will be obtained.

Name:

Date:

Signature:

Phone:

Postal address:

Email address:

Would you like a copy of the summary made available to you? Please tick 


\section{Appendix C: Information letter and assent form for children}

Hi!

My name is Sarah and I want to talk to you about children's rights. If you don't know what that means, that's OK because we can talk about it. Maybe we could read some stories, or do some drawings or play outside.

Would you let me tape our conversations and take some photos? I will show you everything I do, and I will talk to your family about it all too. I want to write down some of your ideas for other people to read and think about, but they won't know who you are because you will need to choose a pretend name.

If you and your friends want to do this, you can post the special form in my posting box at your centre, and if you don't want to, that's OK too.

See you soon

Sarah

My name is

My birthday is

My mother or father or caregiver's name is

My address and phone number or contact details are

I would be happy to talk to you (Please tick the boxes)

I don't mind if you tape our conversations or take some photos

or videos, but you will show me what you've done
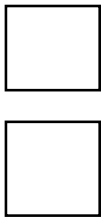

If I change my mind about what we're doing, you will respect my decision

I can ask lots of questions if I want to

I want my research name to be

Please post this into my posting box in the office

Thank you

Sarah 


\section{Appendix D: Focus group interview guide}

1. Tell me about your philosophy and how that contributes to your image of the child?

2. How do teachers and adults perceive children's rights generally?

3. How do children perceive children's rights generally?

4. How do you perceive children's rights in this setting?

5. What influences teachers' and adults' personal beliefs and ideas about children's rights?

6. What influences teachers' and adults professional beliefs and ideas about children's rights?

7. What rights do you think children have in early childhood?

8. What rights do they have in this centre?

9. How are these rights enacted in this centre?

10. What influences children's understandings and experiences of their rights?

11. How do children learn about rights in this centre?

12. Where would I see children exercising their rights in this centre?

13. What should I look for? What rights would I see? 


\section{Appendix E: Individual interview guide: Parents and teachers}

Part A: Personal beliefs and influences about rights for children generally

1. How do you think your family felt about children as having rights?

2. Did you think about children's rights as a child or young person?

3. Tell me about your image of children before you became a teacher or involved as an educator in this setting.

4. What rights do you think children have?

5. What rights should they have?

6. Why do you think this?

7. What for you are the key influences and issues about children's rights?

8. Why?

Part B: Professional beliefs and influences about rights for children in early childhood settings

1. When you became a teacher or involved in this early childhood setting, did you have any ideas about children's rights in early childhood settings?

2. What did you learn about children's rights at any time during your training?

3. Tell me about your image of children since becoming a teacher or involved as an educator in this setting.

4. How do you think teachers/educators perceive children's rights generally?

5. How do you think children perceive children's rights generally?

6. What rights do you think children have in this centre? How do they know?

7. What rights should they have? How do you let them know?

8. Are there any resources, policies or experiences that you think support children to

a. exercise their rights

b. understand their rights

9. Are there any resources, policies or experiences that you think deny children rights?

10. What are the key issues for you regarding children's rights in early childhood?

11. What are the key influences for you regarding children's rights in early childhood?

12. Where do you see children exercising their rights?

13. What do you see as your role with children regarding their rights?

a. How are you supported? (e.g. staff, families, children, the environment, resources)

b. What barriers are there? 


\section{Appendix F: Transcriber confidentiality agreement and transcript letter to participants}

I , (name) understand that all audio tapes supplied for

transcription are confidential to the researcher. All tapes supplied will be returned to the researcher with the transcripts.

(Name)

(Signed)

(Date)

\section{Letterhead}

Sarah Te One

Ph: 044635716 or 044635166

Email: sarah.teone@vuw.ac.nz

RE: In whose best interests? Perceptions of children's rights in early childhood settings

Enclosed is a transcript of your interview with me earlier this year. Now is your opportunity to review the text and get back to me as soon as possible with any changes you would like to see.

Please feel free to contact me about this transcript or any questions or comments about the research that you may have.

Once the transcript has been returned, I will begin the process of formally analysing the data.

I would like to thank you for contributing to this phase of the research and to express my gratitude to you for participating in the process so far. I have learnt a great deal about research, about children's rights and about the early childhood sector in general. I appreciated the time and thought you put in to answering my questions, especially because you were so busy with your own work and lives.

Sincerely

Sarah Te One

Encl; 
Appendix G: Researcher's check list for data processing

\begin{tabular}{|l||l||l|}
\hline Case study & $\begin{array}{l}\text { Transcript approved. } \\
\text { (Interviews and focus } \\
\text { groups) }\end{array}$ & NVIVO \\
\hline \begin{tabular}{l|l|} 
Focus group \\
interviews \\
Total: 5
\end{tabular} & & \\
\hline $\begin{array}{l}\text { Individual interviews } \\
\text { Total: } 21\end{array}$ & & \\
\hline $\begin{array}{l}\text { Field notes } \\
\text { Total: } 45 \text { days }\end{array}$ & \\
\hline
\end{tabular}




\section{Appendix H: Early NVIVO codes}

Advocacy

Agency

Awareness of rights

Barriers to rights

Belonging

Consultation

Contribution

Cultural context

Empowerment

Environment

Exploration

Fairness
Listening

Image of the child

Participation

Protection

Provision

Quality

Relationships

Respect

Role of adult

Routines, rules

Wellbeing 


\section{Appendix I: Example of an NVIVO coding report}

NB Technical reasons prevented the original NVIVO reports being inserted.

I arrived at the beginning of the session - at the time when the parents were arriving with their children. Many of them have consented to participating in the study, which is great and the focus interview last night went really well. The new teacher is not starting until after Easter and we discussed this too. It is likely that she will participate in the next focus group interview, but it is hard to know at this stage.

Coding: Participation and access

Sharon mentioned this morning how drab my box looked with its swirls and twirls in red. I took it to the collage table and showed a small group of girls the box and asked if they would like to decorate it. Lucy was nearby and looked with interest and then painted a streak across it. The others said No it;s for sticking - she went off and the children left began to choose the pictures for the box. Lots of flowers.

Coding: Contribution

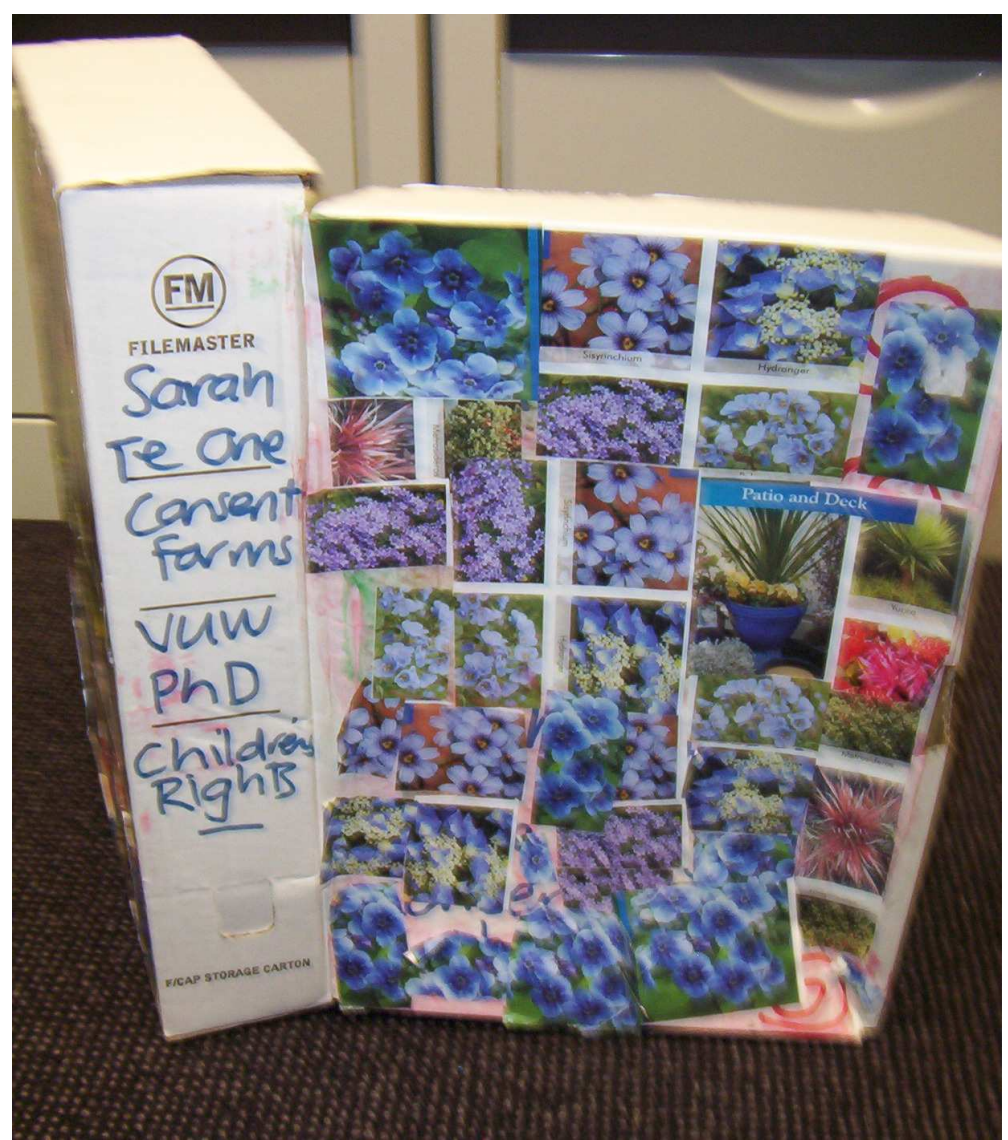

Nearby the ESW visiting teacher has come to observe Jimmy. Paula is sitting next to him - they are trying to encourage and support him with following through 
with things and meeting with success too. Paula has introduced the idea of leaf rubbing and shows him how to do this. That's right, hold the paper over the top and then use your thumb and your other fingers on this hand to rub over the leaf. Well done - keep your fingers there and push down. Can you see the rubbing? See it appearing? [Can you] see the shape of the leaf? And the veins? Those are the veins.

Coding: Relationships, participation and access

There are many visitors this morning. Another ESW teacher has visited with a pink suitcase on wheels full of special games for some of the children. She is working in the office with two children. Karla is the early intervention teacher and she and Paula discuss the progress and programme for Jimmy - how can we meet with the family next? There is an issue to discuss and it may be difficult. They strategise about how to sensitively introduce the topic to the parents.

Coding: Relationships, participation

The speech and language therapist needs to see Paula and quickly they chat about the progress of the children under her care. Then she goes into the office and takes her pink wheely bag off with her - I comment on what agood idea that is. Yes she tells me, it has changed my life and the children love the pink bag - they think it is like a giant lolly.

Coding: Relationships, participation, playfulness

James, the community constable has arrived as has Karla's husband, also a police officer. James is quickly included in the collage table and he ends up with a paper thing behind his ear - a flower. Paula comes to me and comments that one of the children is terrified of the police and now won't even let her mother drive past the station. She thinks they lock children up in jail and leave them there. It's become a real problem said Paula and so we've been talking about it and we thought we could do a visit and meet some of the police but Ava won't go near the place and so we invited James in. We explained that he is a Dad and now look. We can see Ava and James talking near the clay table deck. She's been really hanging back on the edges said Paula - this will really help her.

Coding: Education, participation, relationships

\section{Memo}

Building a community of learners to make things happen - collaborative work inside, directly with the children and then at the teacher level and then with the school, with the ESW and then ... The list goes on and on in a series of intersecting communities working for the child - connections to 
the ideas of Bronfenbrenner and Rogoff. Communities of learners moving into different levels of thinking about child-positives and negatives from a child's rights perspective. The positive is engagement (to promote participation) at the Kindergarten level between teacher/child/children. The negative is the discussion without the child but which will directly affect his or her wellbeing in the kindergarten.

Level of consultation variable - importance of friendship noted (relationships) but done on the run so slightly bewildering for the child.

Role of the adult - responsibility for awareness of rights - social responsibility an issue. Adult-organised systems, but with child participation and consultation about how to manage the environments social, physical and emotional.

Sharon comes in with Rachel. Hey Wendy, could you please be a friend for Rachel for today and for tomorrow. Rachel - this is Wendy- she will be your friend. Ok Wendy? OK Rachel? You can play with the wooden rods? She moves off quite quickly. The parent helper, whose son is turning 5 this week and it is his last day today, joins them and builds a complicated fan like structure (she is an industrial designer) - the children think it's terrific and she says - do you think it will stay there all session. Wendy and Rachel nod doubtfully.

Coding: Consulted, belonging,

friendship, wellbeing

\section{Memo}

Parents working alongside others, busy, community based feel, inclusive. Part of the cultural context of the place - once again the emphasis on friendship as a route to participation, but based on belonging too.

Kaleb comes in and is looking tearful - What's up I ask - can I help? He leans against me and plays with Mousey mouse the name he gave to my rainbow mouse. Well, he sighs, it's not a trolley day today. Oh I say, well is there something else you might like to do? There are two of his friends near by - hey says one - we could play in the sand pit. Yay they yell and rush out. So easily solved.

Coding: Cultural context, emotional rights, feelings

Emma R and Emma $\mathrm{W}$ are playing behind me on the block mat. Emma $\mathrm{W}$ is looking really cross and is not letting Emma $\mathrm{R}$ build her swimming pool structure - I need more room says Emma R Can I try it here? Emma W moves backwards crowding her even further to the edges of the mat.

Coding: Environment 
Amber, the student and I are watching with interest. Emma R looks up at us appealingly - what can be done is the non-verbal message. She asks her friend where she can play - seeking permission from her to use more of the mat - Amber supports her here and suggests that they divide the mat into sections - Maybe you could play in this part and you could have that part? Nope - not a good solution. I need more room says Emma W moving her body widely into the spaces and taking the other Emma's blocks out of the beginning of her swimming pool pattern.

Coding: Fairness, restrictions on rights, participation

Didn't you make an amazing swimming pool together the other day Amber asks, remembering the event in more detail and recognising that both Emmas were involved in its construction. She asks Emma $\mathrm{R}$ if she was trying to replicate the amazing buildings from the other day. She nods and said yes. Then Amber starts asking about the research. By the time we look again - about a minute if that both girls were playing together with the Duplo animals and had begun the complex negotiation about how to get into the pool - "It needs a gap here like this. No, it means that the animals just jump in like this." Peaceful resolution with no problems and no adults.

Coding: Contributions and belonging

Coding: Role of the adult, participation,

environment

\section{Memo}

Enough resources for all the children, and enough room to allow for participation. What helped resolve the argument? Acknowledging the previous block building prompted collaboration.

Sophie comes in with a sore head. I banged my head on the rainbow and it's really sore. She makes her way to the kitchen and is followed by Becca. They take an icepack from the freezer and sit together while Sophie holds the pack to her forehead. 


\section{Memo}

Very confident about their rights in the environment. Belonging and participation seem linked here and a shared concern for wellbeing. Contribution role - taking responsibility for care for Sophie

Jimmy and some of the other boys come rushing into the block area. Remember it's construct, not destruct won't you - Look Jimmy, look at the careful building you need to be careful of other people's work too. Construct, not destruct.

Coding: Role of the adult, environment, awareness of rights

\section{Memo}

Paula reinforcing the rules for the social and physical environment. All add to creating an awareness of the rights of others.

The bell rings and the children start the tidying-up routine - they are divided into groups and are responsible for an area each. The teachers have organised the groups and the areas with children that they might not usually play with in places they might not usually play.

Coding: Role of the adult, awareness of rights, participation, contribution

\section{Memo}

Contribution via responsibility for the environment - broadening an awareness of rights in the Kindergarten. 


\title{
Appendix J: United Nations Convention on the Rights of the Child (CRIN, 2009)
}

\section{Convention on the Rights of the Child}

\author{
Adopted and opened for signature, ratification and accession \\ by General Assembly resolution 44/25 of 20 November 1989 \\ entry into force 2 September 1990, in accordance with article 49 \\ Links | status of ratifications | declarations and reservations | monitoring body \\ Language versions | Arabic | Chinese | French | Russian | Spanish \\ Optional protocols |armed conflicts | sale of children, child prostitution and child pornography
}

\section{Articles: Part 1: Substantive Provisions}

$1-2-3-4-5-6-7-8-9-10-11-12-13-14-15$

$16-17-18-19-20-21-22-23-24-25-26-27-28-29-30$

$31-32-33-34-35-36-37-38-39-40-41$

\section{Part 2: Implementation and monitoring}

$$
42-43-44-45
$$

Part 3: Final Clauses

$46-47-48-49-50-51-52-53-54$

Text

Preamble

The States Parties to the present Convention,

Considering that, in accordance with the principles proclaimed in the Charter of the United Nations, recognition of the inherent
Unofficial Summary

Preamble

The preamble recalls the basic principles of the United Nations and specific provisions of certain relevant human rights 
dignity and of the equal and inalienable rights of all members of the human family is the foundation of freedom, justice and peace in the world,

Bearing in mind that the peoples of the United Nations have, in the Charter, reaffirmed their faith in fundamental human rights and in the dignity and worth of the human person, and have determined to promote social progress and better standards of life in larger freedom,

Recognizing that the United Nations has, in the Universal Declaration of Human Rights and in the International Covenants on Human Rights, proclaimed and agreed that everyone is entitled to all the rights and freedoms set forth therein, without distinction of any kind, such as race, colour, sex, language, religion, political or other opinion, national or social origin, property, birth or other status,

Recalling that, in the Universal Declaration of Human Rights, the United Nations has proclaimed that childhood is entitled to special care and assistance,

Convinced that the family, as the fundamental group of society and the natural environment for the growth and well-being of all its members and particularly children, should be afforded the necessary protection and assistance so that it can fully assume its responsibilities within the community,

Recognizing that the child, for the full and harmonious development of his or her personality, should grow up in a family environment, in an atmosphere of happiness, love and understanding,

Considering that the child should be fully prepared to live an individual life in society, and brought up in the spirit of the ideals proclaimed in the Charter of the United Nations, and in particular in the spirit of peace, dignity, tolerance, freedom, equality and solidarity,

Bearing in mind that the need to extend particular care to the child has been stated in the Geneva Declaration of the Rights of the Child of 1924 and in the Declaration of the Rights of the Child adopted by the United Nations on 20 November 1959 and recognized in the Universal Declaration of Human Rights, in the International Covenant on Civil and Political Rights (in particular in articles 23 and 24), in the International Covenant on Economic, Social and Cultural Rights (in particular in article ten) and in the statutes and relevant instruments of specialized agencies and international organizations concerned with the welfare of children,

Bearing in mind that, as indicated in the Declaration of the Rights of the Child, "the child, by reason of his physical and mental immaturity, needs special safeguards and care, including appropriate legal protection, before as well as after birth,"

Recalling the provisions of the Declaration on Social and Legal treaties and proclamations. It reaffirms the fact that children, because of their vulnerability, need special care and protection, and it places special emphasis on the primary caring and protective responsibility of the family. It also reaffirms the need for legal and other protection of the child before and after birth, the importance of respect for the cultural values of the child's community, and the vital role of international cooperation in securing children's rights. 
Principles relating to the Protection and Welfare of Children, with Special Reference to Foster Placement and Adoption Nationally and Internationally; the United Nations Standard Minimum Rules for the Administration of Juvenile Justice ("The Beijing Rules"); and the Declaration on the Protection of Women and Children in Emergency and Armed Conflict,

Recognizing that, in all countries in the world, there are children living in exceptionally difficult conditions, and that such children need special consideration,

Taking due account of the importance of the traditions and cultural values of each people for the protection and harmonious development of the child,

Recognizing the importance of international cooperation for improving the living conditions of children in every country, in particular in the developing countries,

Have agreed as follows:

\section{PART I: Substantive Provisions}

\section{Article 1}

For the purposes of the present Convention, a child means every human being below the age of 18 years unless, under the law applicable to the child, majority is attained earlier.

\section{Article 2}

1. States Parties shall respect and ensure the rights set forth in the present Convention to each child within their jurisdiction without discrimination of any kind, irrespective of the child's or his or her parent's or legal guardian's race, colour, sex, language, religion, political or other opinion, national, ethnic or social origin, property, disability, birth or other status.

2. States Parties shall take all appropriate measures to ensure that the child is protected against all forms of discrimination or punishment on the basis of the status, activities, expressed opinions, or beliefs of the child's parents, legal guardians, or family members.

\section{Definition of a child}

A child is recognized as a person under 18 , unless national laws recognize the age of majority earlier.

\section{Non-discrimination}

All rights apply to all children without exception. It is the State's obligation to protect children from any form of discrimination and to take positive action to promote their rights. 
1. In all actions concerning children, whether undertaken by public or private social welfare institutions, courts of law, administrative authorities or legislative bodies, the best interests of the child shall be a primary consideration.

2. States Parties undertake to ensure the child such protection and care as is necessary for his or her well-being, taking into account the rights and duties of his or her parents, legal guardians, or other individuals legally responsible for him or her, and, to this end, shall take all appropriate legislative and administrative measures.

3. States Parties shall ensure that the institutions, services and facilities responsible for the care or protection of children shall conform with the standards established by competent authorities, particularly in the areas of safety, health, in the number and suitability of their staff, as well as competent supervision.

\section{Article 4}

States Parties shall undertake all appropriate legislative, administrative, and other measures for the implementation of the rights recognized in the present Convention. With regard to economic, social and cultural rights, States Parties shall undertake such measures to the maximum extent of their available resources and, where needed, within the framework of international cooperation.

\section{Article 5}

States Parties shall respect the responsibilities, rights and duties of parents or, where applicable, the members of the extended family or community as provided for by local custom, legal guardians or other persons legally responsible for the child, to provide, in a manner consistent with the evolving capacities of the child, appropriate direction and guidance in the exercise by the child of the rights recognized in the present Convention.
All actions concerning the child shall take full account of his or her best interests. The State shall provide the child with adequate care when parents, or others charged with that responsibility, fail to do so.

Implementation of rights

The State must do all it can to implement the rights contained in the Convention.

Parental guidance and the child's evolving capacities

The State must respect the rights and responsibilities of parents and the extended family to provide guidance for the child which is appropriate to her or his evolving capacities. 
1. States Parties recognize that every child has the inherent right to life.

2. States Parties shall ensure to the maximum extent possible the survival and development of the child.

\section{Article 7}

1. The child shall be registered immediately after birth and shall have the right from birth to a name, the right to acquire a nationality and, as far as possible, the right to know and be cared for by his or her parents.

2. States Parties shall ensure the implementation of these rights in accordance with their national law and their obligations under the relevant international instruments in this field, in particular where the child would otherwise be stateless.

\section{Article 8}

1. States Parties undertake to respect the right of the child to preserve his or her identity, including nationality, name and family relations as recognized by law without unlawful interference.

2. Where a child is illegally deprived of some or all of the elements of his or her identity, States Parties shall provide appropriate assistance and protection, with a view to speedily re-establishing his or her identity
Every child has the inherent right to life, and the State has an obligation to ensure the child's survival and development.

\section{Name and nationality}

The child has the right to a name at birth. The child also has the right to acquire a nationality and, as far as possible, to know his or her parents and be cared for by them.

\section{Preservation of identity}

The State has an obligation to protect, and if necessary, re- establish basic aspects of the child's identity. This includes name, nationality and family ties. 
1. States Parties shall ensure that a child shall not be separated from his or her parents against their will, except when competent authorities subject to judicial review determine, in accordance with applicable law and procedures, that such separation is necessary for the best interests of the child. Such determination may be necessary in a particular case such as one involving abuse or neglect of the child by the parents, or one where the parents are living separately and a decision must be made as to the child's place of residence.

2. In any proceedings pursuant to paragraph 1 of the present article, all interested parties shall be given an opportunity to participate in the proceedings and make their views known.

3. States Parties shall respect the right of the child who is separated from one or both parents to maintain personal relations and direct contact with both parents on a regular basis, except if it is contrary to the child's best interests.

4. Where such separation results from any action initiated by a State Party, such as the detention, imprisonment, exile, deportation or death (including death arising from any cause while the person is in the custody of the State) of one or both parents or of the child, that State Party shall, upon request, provide the parents, the child or, if appropriate, another member of the family with the essential information concerning the whereabouts of the absent member(s) of the family unless the provision of the information would be detrimental to the well-being of the child. States Parties shall further ensure that the submission of such a request shall of itself entail no adverse consequences for the person(s) concerned.
The child has a right to live with his or her parents unless this is deemed to be incompatible with the child's best interests. The child also has the right to maintain contact with both parents if separated from one or both. 
1. In accordance with the obligation of States Parties under article 9, paragraph 1, applications by a child or his or her parents to enter or leave a State Party for the purpose of family reunification shall be dealt with by States Parties in a positive, humane and expeditious manner. States Parties shall further ensure that the submission of such a request shall entail no adverse consequences for the applicants and for the members of their family.

2. A child whose parents reside in different States shall have the right to maintain on a regular basis, save in exceptional circumstances personal relations and direct contacts with both parents. Towards that end and in accordance with the obligation of States Parties under article 9, paragraph 1, States Parties shall respect the right of the child and his or her parents to leave any country, including their own, and to enter their own country. The right to leave any country shall be subject only to such restrictions as are prescribed by law and which are necessary to protect the national security, public order (ordre public), public health or morals or the rights and freedoms of others and are consistent with the other rights recognized in the present Convention

\section{Article 11}

1. States Parties shall take measures to combat the illicit transfer and non-return of children abroad.

2. To this end, States Parties shall promote the conclusion of bilateral or multilateral agreements or accession to existing agreements.

\section{Article 12}

1. States Parties shall assure to the child who is capable of forming his or her own views the right to express those views freely in all matters affecting the child, the views of the child being given due weight in accordance with the age and maturity of the child.

2. For this purpose, the child shall in particular be provided the opportunity to be heard in any judicial and administrative proceedings affecting the child, either directly, or through a representative or an appropriate body, in a manner consistent with the procedural rules of national law
Children and their parents have the right to leave any country and to enter their own for purposes of reunion or the maintenance of the child-parent relationship.

\section{Illicit transfer and non- return}

The State has an obligation to prevent and remedy the kidnapping or retention of children abroad by a parent or third party.

\section{The child's opinion}

The child has the right to express his or her opinion freely and to have that opinion taken into account in any matter or procedure affecting the child. 
1. The child shall have the right to freedom of expression; this right shall include freedom to seek, receive and impart information and ideas of all kinds, regardless of frontiers, either orally, in writing or in print, in the form of art, or through any other media of the child's choice.

2. The exercise of this right may be subject to certain restrictions, but these shall only be such as are provided by law and are necessary:

(a) For respect of the rights or reputations of others; or

(b) For the protection of national security or of public order (ordre public), or of public health or morals.

\section{Article 14}

1. States Parties shall respect the right of the child to freedom of thought, conscience and religion.

2. States Parties shall respect the rights and duties of the parents and, when applicable, legal guardians, to provide direction to the child in the exercise of his or her right in a manner consistent with the evolving capacities of the child.

3. Freedom to manifest one's religion or beliefs may be subject only to such limitations as are prescribed by law and are necessary to protect public safety, order, health or morals, or the fundamental rights and freedoms of others.

\section{Article 15}

1. States Parties recognize the rights of the child to freedom of association and to freedom of peaceful assembly.

2. No restrictions may be placed on the exercise of these rights other than those imposed in conformity with the law and which are necessary in a democratic society in the interests of national security or public safety, public order (ordre public), the protection of public health or morals or the protection of the rights and freedoms of others.
The child has the right to express his or her views, obtain information, make ideas or information known, regardless of frontiers.

\section{Freedom of thought, conscience and religion}

The State shall respect the child's right to freedom of thought, conscience and religion, subject to appropriate parental guidance.

\section{Freedom of association}

Children have a right to meet with others, and to join or form associations. 
1. No child shall be subjected to arbitrary or unlawful interference with his or her privacy, family, home or correspondence, nor to unlawful attacks on his or her honour and reputation.

2. The child has the right to the protection of the law against such interference or attacks.

\section{Article 17}

States Parties recognize the important function performed by the mass media and shall ensure that the child has access to information and material from a diversity of national and international sources, especially those aimed at the promotion of his or her social, spiritual and moral well-being and physical and mental health. To this end, States Parties shall:

(a) Encourage the mass media to disseminate information and material of social and cultural benefit to the child and in accordance with the spirit of article 29;

(b) Encourage international cooperation in the production, exchange and dissemination of such information and material from a diversity of cultural, national and international sources;

(c) Encourage the production and dissemination of children's books;

(d) Encourage the mass media to have particular regard to the linguistic needs of the child who belongs to a minority group or who is indigenous;

(e) Encourage the development of appropriate guidelines for the protection of the child from information and material injurious to his or her well-being, bearing in mind the provisions of articles 13 and 18
Children have the right to protection from interference with privacy, family, home and correspondence, and from libel or slander.

\section{Access to appropriate information}

The State shall ensure the accessibility to children of information and material from a diversity of sources, and it shall encourage the mass media to disseminate information which is of social and cultural benefit to the child, and take steps to protect him or her from harmful materials. 
1. States Parties shall use their best efforts to ensure recognition of the principle that both parents have common responsibilities for the upbringing and development of the child. Parents or, as the case may be, legal guardians, have the primary responsibility for the upbringing and development of the child. The best interests of the child will be their basic concern.

2. For the purpose of guaranteeing and promoting the rights set forth in the present Convention, States Parties shall render appropriate assistance to parents and legal guardians in the performance of their child-rearing responsibilities and shall ensure the development of institutions, facilities and services for the care of children.

3. States Parties shall take all appropriate measures to ensure that children of working parents have the right to benefit from child-care services and facilities for which they are eligible.

\section{Article 19}

1. States Parties shall take all appropriate legislative, administrative, social and educational measures to protect the child from all forms of physical or mental violence, injury or abuse, neglect or negligent treatment, maltreatment or exploitation, including sexual abuse, while in the care of parent(s), legal guardian(s) or any other person who has the care of the child.

2. Such protective measures should, as appropriate, include effective procedures for the establishment of social programmes to provide necessary support for the child and for those who have the care of the child, as well as for other forms of prevention and for identification, reporting, referral, investigation, treatment and follow-up of instances of child maltreatment described heretofore, and, as appropriate, for judicial involvement.
Parents have joint primary responsibility for raising the child, and the State shall support them in this. The State shall provide appropriate assistance to parents in child-raising.

\section{Protection from abuse and neglect}

The State shall protect the child from all forms of maltreatment by parents or others responsible for the care of the child and establish appropriate social programmes for the prevention of abuse and the treatment of victims. 
Article 20

1. A child temporarily or permanently deprived of his or her family environment, or in whose own best interests cannot be allowed to remain in that environment, shall be entitled to special protection and assistance provided by the State.

2. States Parties shall in accordance with their national laws ensure alternative care for such a child.

3. Such care could include, inter alia, foster placement, Kafala of Islamic law, adoption, or if necessary placement in suitable institutions for the care of children. When considering solutions, due regard shall be paid to the desirability of continuity in a child's upbringing and to the child's ethnic, religious, cultural and linguistic background.

\section{Article 21}

States Parties that recognize and/or permit the system of adoption shall ensure that the best interests of the child shall be the paramount consideration and they shall:

(a) Ensure that the adoption of a child is authorized only by competent authorities who determine, in accordance with applicable law and procedures and on the basis of all pertinent and reliable information, that the adoption is permissible in view of the child's status concerning parents, relatives and legal guardians and that, if required, the persons concerned have given their informed consent to the adoption on the basis of such counselling as may be necessary;

(b) Recognize that inter-country adoption may be considered as an alternative means of child's care, if the child cannot be placed in a foster or an adoptive family or cannot in any suitable manner be cared for in the child's country of origin;

(c) Ensure that the child concerned by intercountry adoption enjoys safeguards and standards equivalent to those existing in the case of national adoption;

(d) Take all appropriate measures to ensure that, in intercountry adoption, the placement does not result in improper financial gain for those involved in it;

(e) Promote, where appropriate, the objectives of the present article by concluding bilateral or multilateral arrangements or agreements, and endeavour, within this framework, to ensure that the placement of the child in another country is carried out by competent authorities or organs.

\section{Protection of a child without family}

The State is obliged to provide special protection for a child deprived of the family environment and to ensure that appropriate alternative family care or institutional placement is available in such cases. Efforts to meet this obligation shall pay due regard to the child's cultural background.

\section{Adoption}

In countries where adoption is recognized and/or allowed, it shall only be carried out in the best interests of the child, and then only with the authorization of competent authorities, and safeguards for the child. 


\section{Refugee children}

1. States Parties shall take appropriate measures to ensure that a child who is seeking refugee status or who is considered a refugee in accordance with applicable international or domestic law and procedures shall, whether unaccompanied or accompanied by his or her parents or by any other person, receive appropriate protection and humanitarian assistance in the enjoyment of applicable rights set forth in the present Convention and in other international human rights or humanitarian instruments to which the said States are Parties.

2. For this purpose, States Parties shall provide, as they consider appropriate, cooperation in any efforts by the United Nations and other competent intergovernmental organizations or nongovernmental organizations co-operating with the United Nations to protect and assist such a child and to trace the parents or other members of the family of any refugee child in order to obtain information necessary for reunification with his or her family. In cases where no parents or other members of the family can be found, the child shall be accorded the same protection as any other child permanently or temporarily deprived of his or her family environment for any reason, as set forth in the present Convention.
Special protection shall be granted to a refugee child or to a child seeking refugee status. It is the State's obligation to co- operate with competent organizations which provide such protection and assistance. 
1. States Parties recognize that a mentally or physically disabled child should enjoy a full and decent life, in conditions which ensure dignity, promote self-reliance, and facilitate the child's active participation in the community.

2. States Parties recognize the right of the disabled child to special care and shall encourage and ensure the extension, subject to available resources, to the eligible child and those responsible for his or her care, of assistance for which application is made and which is appropriate to the child's condition and to the circumstances of the parents or others caring for the child.

3. Recognizing the special needs of a disabled child, assistance extended in accordance with paragraph 2 of the present article shall be provided free of charge, whenever possible, taking into account the financial resources of the parents or others caring for the child, and shall be designed to ensure that the disabled child has effective access to and receives education, training, health care services, rehabilitation services, preparation for employment and recreation opportunities in a manner conducive to the child's achieving the fullest possible social integration and individual development, including his or her cultural and spiritual development.

4. States Parties shall promote, in the spirit of international cooperation, the exchange of appropriate information in the field of preventive health care and of medical, psychological and functional treatment of disabled children, including dissemination of and access to information concerning methods of rehabilitation, education and vocational services, with the aim of enabling States Parties to improve their capabilities and skills and to widen their experience in these areas. In this regard, particular account shall be taken of the needs of developing countries.
A disabled child has the right to special care, education and training to help him or her enjoy a full and decent life in dignity and achieve the greatest degree of self-reliance and social integration possible. 
1. States Parties recognize the right of the child to the enjoyment of the highest attainable standard of health and to facilities for the treatment of illness and rehabilitation of health. States Parties shall strive to ensure that no child is deprived of his or her right of access to such health care services.

2. States Parties shall pursue full implementation of this right and, in particular, shall take appropriate measures: (a) To diminish infant and child mortality;

(b) To ensure the provision of necessary medical assistance and health care to all children with emphasis on the development of primary health care;

(c) To combat disease and malnutrition including within the framework of primary health care, through inter alia the application of readily available technology and through the provision of adequate nutritious foods and clean drinking water, taking into consideration the dangers and risks of environmental pollution;

(d) To ensure appropriate pre-natal and post-natal health care for mothers;

(e) To ensure that all segments of society, in particular parents and children, are informed, have access to education and are supported in the use of basic knowledge of child health and nutrition, the advantages of breast-feeding, hygiene and environmental sanitation and the prevention of accidents;

(f) To develop preventive health care, guidance for parents and family planning education and services.

3. States Parties shall take all effective and appropriate measures with a view to abolishing traditional practises prejudicial to the health of children.

4. States Parties undertake to promote and encourage international cooperation with a view to achieving progressively the full realization of the right recognized in the present article. In this regard, particular account shall be taken of the needs of developing countries.

\section{Article 25}

States Parties recognize the right of a child who has been placed by the competent authorities for the purposes of care, protection or treatment of his or her physical or mental health, to a periodic review of the treatment provided to the child and all other circumstances relevant to his or her placement.
The child has a right to the highest standard of health and medical care attainable. States shall place special emphasis on the provision of primary and preventive health care, public health education and the reduction of infant mortality. They shall encourage international cooperation in this regard and strive to see that no child is deprived of access to effective health services.

\section{Periodic review of placement}

A child who is placed by the State for reasons of care, protection or treatment is entitled to have that placement evaluated regularly. 
Article 26

1. States Parties shall recognize for every child the right to benefit from social security, including social insurance, and shall take the necessary measures to achieve the full realization of this right in accordance with their national law.

2. The benefits should, where appropriate, be granted, taking into account the resources and the circumstances of the child and persons having responsibility for the maintenance of the child, as well as any other consideration relevant to an application for benefits made by or on behalf of the child.

Back to top

Article 27

1. States Parties recognize the right of every child to a standard of living adequate for the child's physical, mental, spiritual, moral and social development.

2. The parent(s) or others responsible for the child have the primary responsibility to secure, within their abilities and financial capacities, the conditions of living necessary for the child's development.

3. States Parties, in accordance with national conditions and within their means, shall take appropriate measures to assist parents and others responsible for the child to implement this right and shall in case of need provide material assistance and support programmes, particularly with regard to nutrition, clothing and housing.

4. States Parties shall take all appropriate measures to secure the recovery of maintenance for the child from the parents or other persons having financial responsibility for the child, both within the State Party and from abroad. In particular, where the person having financial responsibility for the child lives in a State different from that of the child, States Parties shall promote the accession to international agreements or the conclusion of such agreements, as well as the making of other appropriate arrangements.

\section{Social security}

The child has the right to benefit from social security including social insurance.

\section{Standard of living}

Every child has the right to a standard of living adequate for his or her physical, mental, spiritual, moral and social development. Parents have the primary responsibility to ensure that the child has an adequate standard of living. The State's duty is to ensure that this responsibility can be fulfilled, and is. State responsibility can include material assistance to parents and their children. 
1. States Parties recognize the right of the child to education, and with a view to achieving this right progressively and on the basis of equal opportunity, they shall, in particular:

(a) Make primary education compulsory and available free to all;

(b) Encourage the development of different forms of secondary education, including general and vocational education, make them available and accessible to every child, and take appropriate measures such as the introduction of free education and offering financial assistance in case of need;

(c) Make higher education accessible to all on the basis of capacity by every appropriate means;

(d) Make educational and vocational information and guidance available and accessible to all children;

(e) Take measures to encourage regular attendance at schools and the reduction of drop-out rates.

2. States Parties shall take all appropriate measures to ensure that school discipline is administered in a manner consistent with the child's human dignity and in conformity with the present Convention.

3. States Parties shall promote and encourage international cooperation in matters relating to education, in particular with a view to contributing to the elimination of ignorance and illiteracy throughout the world and facilitating access to scientific and technical knowledge and modern teaching methods. In this regard, particular account shall be taken of the needs of developing countries.
The child has a right to education, and the State's duty is to ensure that primary education is free and compulsory, to encourage different forms of secondary education accessible to every child and to make higher education available to all on the basis of capacity. School discipline shall be consistent with the child's rights and dignity. The State shall engage in international cooperation to implement this right. 
1. States Parties agree that the education of the child shall be directed to:

(a) The development of the child's personality, talents and mental and physical abilities to their fullest potential;

(b) The development of respect for human rights and fundamental freedoms, and for the principles enshrined in the Charter of the United Nations;

(c) The development of respect for the child's parents, his or her own cultural identity, language and values, for the national values of the country in which the child is living, the country from which he or she may originate, and for civilizations different from his or her own;

(d) The preparation of the child for responsible life in a free society, in the spirit of understanding, peace, tolerance, equality of sexes, and friendship among all peoples, ethnic, national and religious groups and persons of indigenous origin;

(e) The development of respect for the natural environment.

2. No part of the present article or article 28 shall be construed so as to interfere with the liberty of individuals and bodies to establish and direct educational institutions, subject always to the observance of the principles set forth in paragraph 1 of the present article and to the requirements that the education given in such institutions shall conform to such minimum standards as may be laid down by the State.

\section{Article 30}

In those States in which ethnic, religious or linguistic minorities or persons of indigenous origin exist, a child belonging to such a minority or who is indigenous shall not be denied the right, in community with other members of his or her group, to enjoy his or her own culture, to profess and practise his or her own religion, or to use his or her own language.
Education shall aim at developing the child's personality, talents and mental and physical abilities to the fullest extent. Education shall prepare the child for an active adult life in a free society and foster respect for the child's parents, his or her own cultural identity, language and values, and for the cultural background and values of others.

\section{Children of minorities or} indigenous populations

Children of minority communities and indigenous populations have the right to enjoy their own culture and to practise their own religion and language. 
Article 31

1. States Parties recognize the right of the child to rest and leisure, to engage in play and recreational activities appropriate to the age of the child and to participate freely in cultural life and the arts.

2. States Parties shall respect and promote the right of the child to participate fully in cultural and artistic life and shall encourage the provision of appropriate and equal opportunities for cultural, artistic, recreational and leisure activity.

Article 32

1. States Parties recognize the right of the child to be protected from economic exploitation and from performing any work that is likely to be hazardous or to interfere with the child's education, or to be harmful to the child's health or physical, mental, spiritual, moral or social development.

2. States Parties shall take legislative, administrative, social and educational measures to ensure the implementation of the present article. To this end, and having regard to the relevant provisions of other international instruments, States Parties shall in particular:

(a) Provide for a minimum age or minimum ages for admissions to employment;

(b) Provide for appropriate regulation of the hours and conditions of employment;

(c) Provide for appropriate penalties or other sanctions to ensure the effective enforcement of the present article.

Article 33

States Parties shall take all appropriate measures, including legislative, administrative, social and educational measures, to protect children from the illicit use of narcotic drugs and psychotropic substances as defined in the relevant international treaties, and to prevent the use of children in the illicit production and trafficking of such substances.

\section{Leisure, recreation and} cultural activities

The child has the right to leisure, play and participation in cultural and artistic activities.

\section{Child labour}

The child has the right to be protected from work that threatens his or her health, education or development. The State shall set minimum ages for employment and regulate working conditions.

\section{Drug abuse}

Children have the right to protection from the use of narcotic and psychotropic drugs, and from being involved in their production or distribution. 
States Parties undertake to protect the child from all forms of sexual exploitation and sexual abuse. For these purposes, States Parties shall in particular take all appropriate national, bilateral and multilateral measures to prevent: >

(a) The inducement or coercion of a child to engage in any unlawful sexual activity;

(b) The exploitative use of children in prostitution or other unlawful sexual practises;

(c) The exploitative use of children in pornographic performances and materials.

Back to top

\section{Article 35}

States Parties shall take all appropriate national, bilateral and multilateral measures to prevent the abduction of, the sale of or traffic in children for any purpose or in any form.

Back to top

\section{Article 36}

States Parties shall protect the child against all other forms of exploitation prejudicial to any aspects of the child's welfare.
The State shall protect children from sexual exploitation and abuse, including prostitution and involvement in pornography.

\section{Sale, trafficking and abduction}

It is the State's obligation to make every effort to prevent the sale, trafficking and abduction of children.

\section{Other forms of exploitation}

The child has the right to protection from all forms of exploitation prejudicial to any aspects of the child's welfare not covered in articles 32, 33, 34 and 35. 
Article 37

States Parties shall ensure that:

(a) No child shall be subjected to torture or other cruel, inhuman or degrading treatment or punishment. Neither capital punishment nor life imprisonment without possibility of release shall be imposed for offences committed by persons below 18 years of age;

(b) No child shall be deprived of his or her liberty unlawfully or arbitrarily. The arrest, detention or imprisonment of a child shall be in conformity with the law and shall be used only as a measure of last resort and for the shortest appropriate period of time;

(c) Every child deprived of liberty shall be treated with humanity and respect for the inherent dignity of the human person, and in a manner which takes into account the needs of persons of his or her age. In particular every child deprived of liberty shall be separated from adults unless it is considered in the child's best interest not to do so and shall have the right to maintain contact with his or her family through correspondence and visits, save in exceptional circumstances;

(d) Every child deprived of his or her liberty shall have the right to prompt access to legal and other appropriate assistance, as well as the right to challenge the legality of the deprivation of his or her liberty before a court or other competent, independent and impartial authority, and to a prompt decision on any such action.

Article 38

1. States Parties undertake to respect and to ensure respect for rules of international humanitarian law applicable to them in armed conflicts which are relevant to the child.

2. States Parties shall take all feasible measures to ensure that persons who have not attained the age of 15 years do not take a direct part in hostilities.

3. States Parties shall refrain from recruiting any person who has not attained the age of 15 years into their armed forces. In recruiting among those persons who have attained the age of 15 years but who have not attained the age of 18 years, States Parties shall endeavour to give priority to those who are oldest.

4. In accordance with their obligations under international humanitarian law to protect the civilian population in armed conflicts, States Parties shall take all feasible measures to ensure protection and care of children who are affected by an armed conflict.

\section{Torture and deprivation of} liberty

No child shall be subjected to torture, cruel treatment or punishment, unlawful arrest or deprivation of liberty. Both capital punishment and life imprisonment without the possibility of release are prohibited for offences committed by persons below 18 years. Any child deprived of liberty shall be separated from adults unless it is considered in the child's best interests not to do so. A child who is detained shall have legal and other assistance as well as contact with the family.

\section{Armed conflicts}

States Parties shall take all feasible measures to ensure that children under 15 years of age have no direct part in hostilities. No child below 15 shall be recruited into the armed forces. States shall also ensure the protection and care of children who are affected by armed conflict as described in relevant international law. 
States Parties shall take all appropriate measures to promote physical and psychological recovery and social reintegration of a child victim of: any form of neglect, exploitation, or abuse; torture or any other form of cruel, inhuman or degrading treatment or punishment; or armed conflicts. Such recovery and reintegration shall take place in an environment which fosters the health, selfrespect and dignity of the child.

\section{Back to top}

\section{Article 40}

1. States Parties recognize the right of every child alleged as, accused of, or recognized as having infringed the penal law to be treated in a manner consistent with the promotion of the child's sense of dignity and worth, which reinforces the child's respect for the human rights and fundamental freedoms of others and which takes into account the child's age and the desirability of promoting the child's reintegration and the child's assuming a constructive role in society.

2. To this end, and having regard to the relevant provisions of international instruments, States Parties shall, in particular, ensure that:

(a) No child shall be alleged as, be accused of, or recognized as having infringed the penal law by reason of acts or omissions that were not prohibited by national or international law at the time they were committed;

(b) Every child alleged as or accused of having infringed the penal law has at least the following guarantees:

(i) To be presumed innocent until proven guilty according to law;

(ii) To be informed promptly and directly of the charges against him or her, and, if appropriate, through his or her parents or legal guardians, and to have legal or other appropriate assistance in the preparation and presentation of his or her defence;

(iii) To have the matter determined without delay by a competent, independent and impartial authority or judicial body in a fair hearing according to law, in the presence of legal or other appropriate assistance and, unless it is considered not to be in the best interest of the child, in particular, taking into account his or her age or situation, his or her parents or legal guardians;

(iv) Not to be compelled to give testimony or to confess guilt; to examine or have examined adverse witnesses and to obtain the participation and examination of witnesses on his or her behalf under
The State has an obligation to ensure that child victims of armed conflicts, torture, neglect, maltreatment or exploitation receive appropriate treatment for their recovery and social reintegration.

\section{Administration of juvenile justice}

A child in conflict with the law has the right to treatment which promotes the child's sense of dignity and worth, takes the child's age into account and aims at his or her reintegration into society. The child is entitled to basic guarantees as well as legal or other assistance for his or her defence. Judicial proceedings and institutional placements shall be avoided wherever possible. 
conditions of equality;

(v) If considered to have infringed the penal law, to have this decision and any measures imposed in consequence thereof reviewed by a higher competent, independent and impartial authority or judicial body according to law;

(vi) To have the free assistance of an interpreter if the child cannot understand or speak the language used;

(vii) To have his or her privacy fully respected at all stages of the proceedings.

3. States Parties shall seek to promote the establishment of laws, procedures, authorities and institutions specifically applicable to children alleged as, accused of, or recognized as having infringed the penal law, and, in particular:

(a) the establishment of a minimum age below which children shall be presumed not to have the capacity to infringe the penal law;

(b) whenever appropriate and desirable, measures for dealing with such children without resorting to judicial proceedings, providing that human rights and legal safeguards are fully respected.

4. A variety of dispositions, such as care, guidance and supervision orders; counselling; probation; foster care; education and vocational training programmes and other alternatives to institutional care shall be available to ensure that children are dealt with in a manner appropriate to their well-being and proportionate both to their circumstances and the offence.

Back to top

\section{Article 41}

Nothing in the present Convention shall affect any provisions which are more conducive to the realization of the rights of the child and which may be contained in:

(a) The law of a State Party; or

(b) International law in force for that State.

\section{Respect for higher standards}

Wherever standards set in applicable national and international law relevant to the rights of the child that are higher than those in this Convention, the higher standard shall always apply.

(go to top of document) 


\section{PART II: Implementation and Monitoring}

Article 42

States Parties undertake to make the principles and provisions of the Convention widely known, by appropriate and active means, to adults and children alike.

\section{Article 43}

1. For the purpose of examining the progress made by States Parties in achieving the realization of the obligations undertaken in the present Convention, there shall be established a Committee on the Rights of the Child, which shall carry out the functions hereinafter provided.

2. The Committee shall consist of 10 experts of high moral standing and recognized competence in the field covered by this Convention. The members of the Committee shall be elected by States Parties from among their nationals and shall serve in their personal capacity, consideration being given to equitable geographical distribution, as well as to the principal legal systems.

3. The members of the Committee shall be elected by secret ballot from a list of persons nominated by States Parties. Each State Party may nominate one person from among its own nationals.

4. The initial election to the Committee shall be held no later than six months after the date of the entry into force of the present Convention and thereafter every second year. At least four months before the date of each election, the Secretary-General of the United Nations shall address a letter to States Parties inviting them to submit their nominations within two months. The Secretary-General shall subsequently prepare a list in alphabetical order of all persons thus nominated, indicating States Parties which have nominated them, and shall submit it to the States Parties to the present Convention.

5. The elections shall be held at meetings of States Parties convened by the Secretary-General at United Nations Headquarters. At those meetings, for which two thirds of States Parties shall constitute a quorum, the persons elected to the Committee shall be those who obtain the largest number of votes and an absolute majority of the votes of the representatives of States Parties present and voting.

6. The members of the Committee shall be elected for a term of four years. They shall be eligible for re-election if renominated. The term of five of the members elected at the first election shall expire at the end of two years; immediately after the first election, the names of these five members shall be chosen by lot by the Chairman of the meeting.

7. If a member of the Committee dies or resigns or declares that for any other cause he or she can no longer perform the duties of the
Implementation and entry into force

The provisions of articles 42-54 notably foresee:

(i) the State's obligation to make the rights contained in this Convention widely known to both adults and children.

(ii) the setting up of a Committee on the Rights of the Child composed of 10 experts, which will consider reports that States Parties to the Convention are to submit two years after ratification and every five years thereafter. The Convention enters into force - and the Committee would therefore be set up once 20 countries have ratified it.

(iii) States Parties are to make their reports widely available to the general public.

(iv) The Committee may propose that special studies be undertaken on specific issues relating to the rights of the child, and may make its evaluations known to each State Party concerned as well as to the UN General Assembly.

(v) In order to "foster the effective implementation of the Convention and to encourage international 
Committee, the State Party which nominated the member shall appoint another expert from among its nationals to serve for the remainder of the term, subject to the approval of the Committee.

8. The Committee shall establish its own rules of procedure.

9. The Committee shall elect its officers for a period of two years.

10. The meetings of the Committee shall normally be held at United Nations Headquarters or at any other convenient place as determined by the Committee. The Committee shall normally meet annually. The duration of the meetings of the Committee shall be determined, and reviewed, if necessary, by a meeting of the States Parties to the present Convention, subject to the approval of the General Assembly.

11. The Secretary-General of the United Nations shall provide the necessary staff and facilities for the effective performance of the functions of the Committee under the present Convention.

12. With the approval of the General Assembly, the members of the Committee established under the present Convention shall receive emoluments from the United Nations resources on such terms and conditions as the Assembly may decide.

Back to top

\section{Article 44}

1. States Parties undertake to submit to the Committee, through the Secretary-General of the United Nations, reports on the measures they have adopted which give effect to the rights recognized herein and on the progress made on the enjoyment of those rights:

(a) Within two years of the entry into force of the Convention for the State Party concerned,

(b) Thereafter every five years.

2. Reports made under the present article shall indicate factors and difficulties, if any, affecting the degree of fulfilment of the obligations under the present Convention. Reports shall also contain sufficient information to provide the Committee with a comprehensive understanding of the implementation of the Convention in the country concerned.

3. A State Party which has submitted a comprehensive initial report to the Committee need not in its subsequent reports submitted in accordance with paragraph 1(b) of the present article repeat basic information previously provided.

4. The Committee may request from States Parties further information relevant to the implementation of the Convention. co- operation," the specialized agencies of the UN - such as the International Labour Organisation (ILO), World Health Organization (WHO) and United Nations Educational, Scientific and Cultural Organization (UNESCO) - and UNICEF would be able to attend the meetings of the Committee. Together with any other body recognized as 'competent', including non-governmental organizations (NGOs) in consultative status with the UN and UN organs such as the United Nations High Commissioner for Refugees (UNHCR), they can submit pertinent information to the Committee and be asked to advise on the optimal implementation of the Convention. 
5. The Committee shall submit to the General Assembly, through the Economic and Social Council, every two years, reports on its activities.

6. States Parties shall make their reports widely available to the public in their own countries.

\section{Article 45}

In order to foster the effective implementation of the Convention and to encourage international cooperation in the field covered by the Convention:

(a) The specialized agencies, the United Nations Children's Fund and other United Nations organs shall be entitled to be represented at the consideration of the implementation of such provisions of the present Convention as fall within the scope of their mandate. The Committee may invite the specialized agencies, the United Nations Children's Fund and other competent bodies as it may consider appropriate to provide expert advice on the implementation of the Convention in areas falling within the scope of their respective mandates. The Committee may invite the specialized agencies, the United Nations Children's Fund and other United Nations organs to submit reports on the implementation of the Convention in areas falling within the scope of their activities;

(b) The Committee shall transmit, as it may consider appropriate, to the specialized agencies, the United Nations Children's Fund and other competent bodies, any reports from States Parties that contain a request, or indicate a need, for technical advice or assistance, along with the Committee's observations and suggestions, if any, on these requests or indications;

(c) The Committee may recommend to the General Assembly to request the Secretary-General to undertake on its behalf studies on specific issues relating to the rights of the child;

(d) The Committee may make suggestions and general recommendations based on information received pursuant to articles 44 and 45 of the present Convention. Such suggestions and general recommendations shall be transmitted to any State Party concerned and reported to the General Assembly, together with comments, if any, from States Parties.

Back to top

\section{PART III: Final Clauses}

\section{Article 46}

The present Convention shall be open for signature by all States. 


\section{Article 47}

The present Convention is subject to ratification. Instruments of ratification shall be deposited with the Secretary-General of the United Nations.

\section{Article 48}

The present Convention shall remain open for accession by any State. The instruments of accession shall be deposited with the Secretary-General of the United Nations.

\section{Article 49}

1. The present Convention shall enter into force on the thirtieth day following the date of deposit with the Secretary-General of the United Nations of the twentieth instrument of ratification or accession.

2. For each State ratifying or acceding to the Convention after the deposit of the twentieth instrument of ratification or accession, the Convention shall enter into force on the thirtieth day after the deposit by such State of its instrument of ratification or accession.

\section{Article 50}

1. Any State Party may propose an amendment and file it with the Secretary-General of the United Nations. The Secretary-General shall thereupon communicate the proposed amendment to States Parties, with a request that they indicate whether they favour a conference of States Parties for the purpose of considering and voting upon the proposals. In the event that, within four months from the date of such communication, at least one third of the States Parties favour such a conference, the Secretary-General shall convene the conference under the auspices of the United Nations. Any amendment adopted by a majority of States Parties present and voting at the conference shall be submitted to the General Assembly for approval.

2. An amendment adopted in accordance with paragraph 1 of the present article shall enter into force when it has been approved by the General Assembly of the United Nations and accepted by a two-thirds majority of States Parties.

3. When an amendment enters into force, it shall be binding on those States Parties which have accepted it, other States Parties still being bound by the provisions of the present Convention and any earlier amendments which they have accepted.

\section{Article 51}

1. The Secretary-General of the United Nations shall receive and circulate to all States the text of reservations made by States at the time of ratification or accession.

2. A reservation incompatible with the object and purpose of the present Convention shall not be permitted.

3. Reservations may be withdrawn at any time by notification to that effect addressed to the Secretary-General of the United Nations, who shall then inform all States. Such notification shall take effect on the date on which it is received by the Secretary-General. 


\section{Article 52}

A State Party may denounce the present Convention by written notification to the SecretaryGeneral of the United Nations. Denunciation becomes effective one year after the date of receipt of the notification by the Secretary-General.

\section{Article 53}

The Secretary-General of the United Nations is designated as the depositary of the present Convention.

\section{Article 54}

The original of the present Convention, of which the Arabic, Chinese, English, French, Russian and Spanish texts are equally authentic, shall be deposited with the Secretary-General of the United Nations.

In witness thereof the undersigned plenipotentiaries, being duly authorized thereto by their respective Governments, have signed the present Convention. 